\title{
Vasopressin in the brain and plasma of the aging rat : a radioimmunoassay study
}

Citation for published version (APA):

Terwel, D. (1992). Vasopressin in the brain and plasma of the aging rat : a radioimmunoassay study. [Doctoral Thesis, Maastricht University]. Datawyse / Universitaire Pers Maastricht. https://doi.org/10.26481/dis.19921105dt

Document status and date:

Published: 01/01/1992

DOI:

10.26481/dis. $19921105 \mathrm{dt}$

Document Version:

Publisher's PDF, also known as Version of record

\section{Please check the document version of this publication:}

- A submitted manuscript is the version of the article upon submission and before peer-review. There can be important differences between the submitted version and the official published version of record.

People interested in the research are advised to contact the author for the final version of the publication, or visit the DOI to the publisher's website.

- The final author version and the galley proof are versions of the publication after peer review.

- The final published version features the final layout of the paper including the volume, issue and page numbers.

Link to publication

\footnotetext{
General rights rights.

- You may freely distribute the URL identifying the publication in the public portal. please follow below link for the End User Agreement:

www.umlib.nl/taverne-license

Take down policy

If you believe that this document breaches copyright please contact us at:

repository@maastrichtuniversity.nl

providing details and we will investigate your claim.
}

Copyright and moral rights for the publications made accessible in the public portal are retained by the authors and/or other copyright owners and it is a condition of accessing publications that users recognise and abide by the legal requirements associated with these

- Users may download and print one copy of any publication from the public portal for the purpose of private study or research.

- You may not further distribute the material or use it for any profit-making activity or commercial gain

If the publication is distributed under the terms of Article $25 \mathrm{fa}$ of the Dutch Copyright Act, indicated by the "Taverne" license above, 
VASOPRESSIN IN THE BRAIN AND PLASMA OF THE AGING RAT 


\title{
VASOPRESSIN IN THE BRAIN AND PLASMA OF THE AGING RAT
}

\section{A RADIOIMMUNOASSAY STUDY}

\section{PROEFSCHRIFT}

\author{
ter verkrijging van de graad van doctor \\ aan de Rijksuniversiteit Limburg te Maastricht, \\ op gezag van de Rector Magnificus, Prof. Mr. M.J. Cohen, \\ volgens het besluit van het College van Dekanen, \\ in het openbaar te verdedigen op \\ donderdag, 5 november 1992 om 16.00 uur
}

door

\section{DIRK TERWEL}

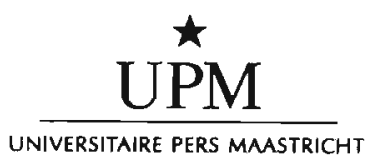


PROMOTOR:

Prof. Dr. J. Jolles

BEOORDELINGSCOMMISSIE:

Prof. Dr. A.C. Nieuwenhuijzen Kruseman (voorzitter)

Dr. M.H. de Baets

Prof. Dr. J.F.M. Smits

Prof. Dr. D.F. Swaab (Nederlands Instituut voor Hersenonderzoek)

Prof. Dr. Tj.B. van Wimersma Greidanus (Rijksuniversiteit van Utrecht)

CIP-DATA KONINKLIJKE BIBLIOTHEEK, DEN HAAG

Terwel, Dirk

Vasopressin in the brain and plasma of the aging rat : a radioimmunoassay study / Dirk Terwel. - Maastricht :

Universitaire Pers Maastricht. - III.

Thesis Maastricht. - With ref. - With summary in Dutch.

ISBN 90-5278-044-7

NUGI 743

Subject headings: vasopressin / ageing / radioimmunoassay.

Omslag: R. Leliveld

Druk: Datawyse Maastricht / Krips Repro Meppel

The studies described in this thesis were carried out at the department of Neuropsychology \& Psychobiology within the research programme 'Aging of Brain and Behavior' of the University of Limburg, Maastricht, The Netherlands. 
Aan Wieke

'L'impression de la certitude est un certain tesmoignage de folie et d'incertitude extreme....'

Michael Eyquem de Montaigne (1533-1592) 


\section{CONTENTS}

\section{PART ONE}

\section{METHODOLOGICAL SECTION}

2. Radioimmunoassay of vasopressin in rat brain and plasma.

D. Terwel, J.A. ten Haaf, M. Markerink, B.J.M. van de Heijning and

Tj.B van Wimersma Greidanus

Parts of this chapter will be published in J Control Rel 1992.

\section{PART TWO}

\section{PLASMA VASOPRESSIN AND OSMOLALITY IN AGING}

3. Changes in plasma vasopressin concentration and plasma osmolality in relation to age and time of day in the male Wistar rat

D. Terwel, J.A. ten Haaf, M. Markerink and J. Jolles Acta Endocrinol 1992;125:357-62.

4. Osmoreceptor sensitivity is reduced in old male Lewis rats

D. Terwel and J. Jolles

Submitted

5. The influence of age on plasma sodium and osmolality in healthy individuals after an overnight fast

N. Bohnen, D. Terwel, G. Wijnen

\section{PART THREE}

\section{BRAIN VASOPRESSIN IN AGING}

6. Age-related changes in concentrations of vasopressin in the central nervous system and plasma of the maleWistar rat

D. Terwel, M. Markerink and J. Jolles

Mech Ageing Dev 1992 (in press).

7. Effects of aging and castration on vasopressin concentrations in the brain of male Brown-Norway rats. 
8. Alterations in vasopressinergic systems in the rat brain in relation to age, strain and season

D. Terwel, M. Markerink and J. Jolles

Submitted

\section{PART FOUR}

\section{BRAIN VASOPRESSIN-CONVERTING ENZYMES IN AGING AND ALZHEIMER'S DISEASE}

9. Vasopressin-converting enzymes in relation to aging in the rat brain

D. Terwel, M.H.F. Rudolph and M. Markerink

10. Peptidases are affected differently in brains from patients with Alzheimer's disease

D. Terwel, M. Markerink and J. Jolles Dementia 1992;3:108-13.

11. GENERAL DISCUSSION

SUMMARY

SAMENVATTING

LIST OF PUBLICATIONS 155

DANKWOORD. 


\section{GENERAL INTRODUCTION}

\section{1}

\section{Introduction}

It was not until recently that the study of biological aging has developed into a serious science (Hayflick 1985). Why this did not happen sooner is surprising when it is appreciated that aging affects all multicellular organisms including man. One of the reasons for this postponement may have been that aging is considered inevitable. Another possible reason is that the study of aging was regarded as a pseudoscience (Hayflick 1985) because of claims of life extension and rejuvenation. Still other reasons have to do with the fact that aging research lacks a clearly defined subject of investigation (Kirkwood 1985), and that it is only recently that biological science has become advanced enough to deal with questions related to aging. In a way, the field has forced itself upon the community as a result of the increased life span and its ensuing problems (Brody and Brock 1985). The problems posed by an increased life span have also changed the goals of aging research. Instead of addressing questions related to the causes of aging, questions related to improving the quality of life have become equally important (see Vijg 1990).

It has been recognized that aging involves the whole body, and that one of the main characteristics of aging is a loss of integration between the constituent parts of the body (Finch and Landfield 1985, Meites et al. 1987, Meites 1988). Therefore changes in the actions of integretory principles are thought to be important in aging. The main aim of the present series of studies is to establish whether systems that use VP for the integration of body functions are affected with age. This introductory chapter will give a brief account of aging theories, vasopressinergic systems, and their putative role in aging as relevant to our studies. The reader is referred to others for a more extensive introduction into the peripheral and central actions of VP (Cowley and Liard 1987, Gash et al. 1987, Hedge and Hufman 1987, Hoffman 1987, Jolles 1987, Valtin 1987), neuroanatomical distribution (Buijs 1987) and changes in vasopressinergic systems with aging (Aravich and Sladek 1987, Miller 1985, Swaab et al. 1987).

Theories of aging: why and how?

So far, researchers have come up with various aging theories. Theories of aging can be subdivided into three main groups: organ theories, physiological theories and genomebased theories (Hayflick 1985). Organ theories hold that aging evolves from decreases in organ function (Meites et al. 1987, Walford 1969), whereas physiological theories state that aging is caused by the consequences of some basic molecular process, such as free radical formation (Harman 1981), molecular cross-linkage (Bjorksten 1968) or waste-product accumulation (Strehler 1977). With respect to the genetic basis of aging, two main theories have been formulated. Williams (1957) formulated the theory that aging is attributable to pleiotropic genes that have beneficial effects early 
in life, but become harmful later in life (Late-acting Deleterious Genes). According to Kirkwood (1981), aging is the consequence of the principle that the maximum fitness of a species does not allow it to allocate the amount of energy for maintenance and repair that is necessary for indefinite survival (Disposable Soma Theory). The genetic theories of aging explain why organisms age from a evolutionary perspective, but not how organisms age. Therefore, they have not replaced other theories, but instead have provided a framework for other theories.

The difficulty with aging theories in general is that they are not mutually exclusive and do not discriminate between cause and effect. It is also difficult to translate changes at the molecular level into changes at the level of the organism. The ultimate aging theory should disclose the fundamental aging processes and, at least in theory, provide means of extending the life span (Hayflick 1985). For the time being it may be best to look for cause and effect in the specific theory one adheres to. This pragmatic approach may not immediately lead to the causes of aging, but may well provide insights into age-associated pathologies. In this thesis the neuroendocrine theory of aging is adhered to. Everitt and Meites (1989) described this theory as follows: 'a general decline in organ functions associated with a decreased ability to maintain homeostasis'. Most body functions are governed by the nervous and hormonal systems. Changes in these systems underlie age-related dysfunctions and diseases. For instance, reproductive function declines with age because of reduced gonadal and hypothalamic functions (Harman and Talbert 1985); reduced estradiol levels in postmenopausal women increases the risk of osteoporosis (Duursma and Raymakers 1990); dopaminergic deficiency causes Parkinson's disease in the elderly (Hornykiewicz 1973); and cholinergic defiency may contribute to the dementia observed in Alzheimer's disease (Fibiger 1991, Perry et al. 1978). Changes in neurotransmitter systems in the central nervous system may also underlie normal motor disturbances and the cognitive decline observed with age (Ochs et al. 1985, Rogers and Bloom 1985). The neuroendocrine hypothesis has been criticized because it lacks universal applicability, since not all organisms that age have complex neuroendocrine systems. Although neuroendocrine dysfunction may be rooted in some fundamental changes with age, it probably contributes to the aging process of many multicellular organisms (Meites et al. 1987). Some investigators have suggested that neuroendocrine changes with age are programmed (Meites et al. 1987, von Weizsäcker 1980, Woolhouse 1967). However, neuroendocrine changes may also be a by-product of aging, but nonetheless contribute to the aging process (Kirkwood 1985, Meites et al. 1987).

To investigate which neuroendocrine factors are involved in aging the following questions should be addressed. First, which processes are impaired with aging? Second, what factors control these processes? Third, are there age-related changes in the synthesis or turnover of these factors? Fourth, can the impairment be restored by suppletion of the factor or another intervention that restores synthesis or turnover? VP is an important candidate as a factor in neuroendocrine aging, because it is involved in many processes that change with age, such as the regulation of water homeostasis (Aravich and Sladek 1987, Miller 1985), cardiovascular regulation (Hajduczok et al. 
1991), learning and memory (Ingram 1985), temperature regulation (Refineti et al. 1990) and circadian rhythms (Van Gool and Mirmiran 1986), and changes in vasopressinergic systems have been found with age (see below for a detailed discussion). The question whether VP suppletion can counteract age-related impairments has only been dealt with in a few studies as yet, but results are promising (Cooper et al 1980, Nyakas et al. 1986).

\section{Vasopressinergic systems in the rat brain}

VP is referred to as antidiuretic hormone and vasopressin, because of its antidiuretic action on the kidney (Verney 1947) and pressor action on the vasculature (Oliver and Schäfer 1895). It is one of the classical neuroendocrine hormones synthesized in the brain and released into the circulation (Scharrer and Scharrer 1954); however, over the past decades it has been demonstrated that this peptide also has important functions within the brain (De Wied et al. 1988).

VP-containing neurons belong to the class of peptidergic neurons (Brownstein et al. 1980, North 1987, Richter 1987). Unlike neurons that produce classical neurotransmitters, the secretory product in peptidergic neurons is synthesized in the cell body as a part of a larger precursor protein (Gainer et al. 1977, Sachs et al. 1969) by a ribosomal mechanism on rough endoplasmatic reticulum (Land et al. 1982) and packaged into secretory granules by the Golgi apparatus (North et al. 1983, Swann et al. 1982). Inside the secretory granules the active peptide product is liberated from the precursor protein by proteolytic cleavage (North 1987 and references cited therein). Secretory granules are transported along the neuron extensions by fast axoplasmatic flow (Gainer et al. 1977) and released into the circulation or synaptic cleft following neuron excitation and $\mathrm{Ca}^{2}+$ influx (Nordmann 1983). After release, peptides bind to receptors on neuronal dendrites or body cells and alter cellular functions (Berridge et al. 1985). In this way peptides are involved in the adaptation of an organism to internal and external changes.

\subsection{Vasopressinergic pathways in the brain}

The first brain nuclei in which VP was demonstrated with the use of classical staining techniques were the paraventricular and supraoptic nuclei (Bargmann 1949). These nuclei send extensions to the neurohypohysis, where VP is released into the circulation in response to osmotic or pressure stimuli (Robinson and Verbalis 1987). Barry et al. already observed in 1954 that there were vasopressinergic projections to other parts of the brain. However, this observation was disregarded as at that time it was hardly accepted that a peripheral hormone was synthesized in the brain. It was not until the formulation of the concept that peptides act in the brain (De Wied 1969) that interest was aroused in the presence of peptides in the central nervous system. It was this interest that led to the discovery of elaborate vasopressinergic systems in the brain 
(Buijs et al. 1978, De Vries et al. 1985, Sofroniew 1985a,b). In addition to magnocellular neurons that project to the hypophysis, the paraventricular nuclei contain VP-containing parvocellular neurons that project to the median eminence (Swanson and Sawchenko 1980), brain stem and spinal cord (Buijs et al. 1978, Sawchenko and Swanson 1982, Sofroniew and Schrell 1981). Other VP-synthesizing parvocellular neurons are found in the suprachiasmatic nucleus (Swaab et al. 1975, Vandesande et al. 1975), the bed nucleus of the stria terminalis, the medial amygdala and the locus coeruleus (Caffé and Van Leeuwen 1983, Van Leeuwen and Caffé 1983). VP-containing cell bodies in the bed nucleus of the stria terminalis project to the lateral septum, diagonal band of Broca, lateral habenula, central gray, raphe nucleus and locus coeruleus (De Vries and Buijs 1983, De Vries et al. 1985). The suprachiasmatic nucleus sends vasopressinergic fibers to the periventricular thalamic and hypothalamic nuclei and to the dorsal hypothalamic nucleus (Hoorneman and Buijs 1982). The medial amygdala projects to both the ventral hippocampus and the lateral septum (Caffé et al. 1987). It has been shown that VP disappears from the bed nucleus, the medial amygdala, and their projections after castration (De Vries et al 1985). This demonstrated that the synthesis of VP in these nuclei depends on testosterone. In contrast, VP synthesis is increased in the parvocellular part of the paraventricular nucleus after adrenalectomy (Davis et al. 1986). In other words, glucocorticoids appear to suppress VP synthesis in this subdivision of the paraventricular nucleus.

\subsection{VP receptors}

After its release into the blood VP binds to receptors on kidney tubular cells (Bockaert et al. 1973), smooth muscle cells (Penit et al. 1983), or hepatocytes (Keppens and DeWulf 1979). VP receptors on kidney tubular cells are coupled to adenylate cyclase (Butlen et al. 1978), whereas VP receptors on other cell types are coupled to phospholipase $C$ (Michell et al. 1979). These receptor types have been designated V1 and V2 receptors, respectively. Occupation of V2 receptors triggers a series of intracellular events that increase the permeability of tubular cells to water, thereby causing antidiuresis (Harmanci et al. 1978, 1980). Stimulation of V1 receptors increases intracellular $\mathrm{Ca}^{2}+$ resulting in smooth muscle cell contraction (Berridge and Irvine 1984) or glycogenolysis in hepatocytes (Hems and Whitton 1980). Two types of VP receptors were initially distinguished in the brain: a high-affinity receptor site that binds both VP and oxytocin (type 1), and a binding site that shows high affinity for VP, but not for oxytocin (type 2) (Audigier and Barberis 1985, Barberis 1983). Type 2 binding sites are predominately found in structures of the limbic system, two hypothalamic nuclei (suprachiasmatic and dorsal tuber), and in the area of the nucleus of the solitary tract; Type 1 binding sites are present in the olfactory tubercle, the ventromedial hypothalamic nucleus, the central amygdaloid nucleus and the ventral hippocampus (Tribollet et al. 1988). The pharmacological profile of the type 1 receptor is unique to the brain, that of the type 2 receptor is consistent with that of V1 
Table 1. Processses in which VP plays a role or a putative role and brain structures involved.

\begin{tabular}{ll} 
Structure(s) & Process \\
\hline SCNa & $\begin{array}{l}\text { circadian rhythms (corticosterone secretion, } \\
\text { sleep pattem) }\end{array}$ \\
BNST, MA & $\begin{array}{l}\text { central cardiovascular regulation } \\
\text { behavior (sexual, agressive, cognitive, excessive } \\
\text { grooming) } \\
\text { antipyresis }\end{array}$ \\
PVN (parvocellular part) & $\begin{array}{l}\text { central cardiovascular regulation } \\
\text { secretion of ACTH }\end{array}$ \\
PVN (magnocellular part), SON & $\begin{array}{l}\text { maintenance of waterhomeostasis } \\
\text { glycogenolysis } \\
\text { blood vessel contraction }\end{array}$ \\
unknown & excessive grooming, food intake \\
\hline
\end{tabular}

-SCN = suprachiasmatic nucleus, BNST = bed nucleus of the stria terminalis, $\mathrm{MA}=$ medial amygdala, $\mathrm{PVN}=$ paraventricular nucleus, $\mathrm{SON}=$ supraoptic nucleus.

receptors. VP receptors in the nervous system appear to be coupled to phospholipase C (Bone et al. 1984, Horn and Lightman 1988, Moratalla et al. 1988, Shewey and Dorsa 1988). VP binding sites have also been found in the anterior lobe of the pituitary gland (Van Leeuwen and Wolters 1983). This receptor has a different ligand selectivity than the other receptor types and has been designated the $\mathrm{V} 1 \mathrm{~b}$ receptor (Jard et al. 1986). Yet another VP binding site has been found on the cell bodies and axonal extensions of magnocellular neurons of the paraventricular and supraoptic nuclei, and is distinct from others in that it associates with VP anti-idiotype antibody (Knigge et al. 1987).

\section{Functions of VP: from hormone to neuropeptide}

VP is a very versitile peptide, having manifold functions in the body. Table 1 lists processes in which VP plays a role and brain nuclei involved, which will be discussed below. 


\subsection{Peripheral actions}

In the general circulation VP acts as a hormone, as was mentioned above. The release of VP into the blood is regulated by osmolality (Dunn et al. 1973), blood pressure (Verbalis and Robinson 1984), and blood volume (Dunn et al. 1973). Blood pressure changes are a much weaker stimulus than osmolality changes, but relatively small changes in blood pressure markedly alter the sensitivity of VP release to changes in osmolality (Robertson and Athar 1976). The most important hormonal action of VP is to increase water permeability of the late distal tubules and collecting ducts of the kidney (Grantham and Burg 1966, Ullrich et al. 1964). In addition, three ancillary actions of VP that aid in the concentration of urine have been described, namely its action on the permeability of inner medullary collecting ducts to urea (Morgan and Berkiner 1968), on the reabsorption of sodium chloride by medullary thick ascending limbs of Henle (Hall and Varney 1980, Sasaki and Imai 1980) and on the filtration rate of juxtamedullary nephrons (Trinh-Tran-Tan et al. 1981). The pressor action of VP exerted at arterioles does not appear to be important under normal physiological conditions (Cowley and Liard 1987), nor does its glycogenolytic action in the liver (Hems and Whitton 1980).

\subsection{Central actions}

VP not only acts in peripheral target tissues, but also in the brain. The peptide has been implicated in learning and memory processes (De Wied 1983), regulation of sexual behavior (Södersten et al. 1983), excessive grooming (Van Wimersma Greidanus 1990), regulation of circadian (Reppert et al. 1987) and seasonal (Buijs et al. 1986) rhythms, food intake (Murphy and Wideman 1991, Wideman and Murphy 1991), central cardiovascular regulation (Cowley and Liard 1987) and temperature regulation (Kasting 1989). Furthermore, VP acts on the hypothalamoneurohypophyseal-adrenal axis, although it is not the long looked for corticotropinreleasing factor. Instead, it potentiates the effect of corticotropin-releasing factor (Gillies et al. 1982). Below the roles of VP in some central processes will be discussed in more detail.

Much attention has been paid to the so-called learning and memory effects of VP. The first indication that VP influences brain processes was obtained by De Wied (1965). It was observed that posterior lobectomized rats performed less well than control rats in an active avoidance task. Passive avoidance performance was restored by subcutaneous administration of a hypophyseal extract (Pitressin). Later experiments showed that Pitressin and synthetic VP also inhibited the extinction of avoidance and passive avoidance behavior in intact rats (De Wied 1971, Ader and De Wied 1972, De Wied and Bohus 1966). In other studies VP was also found to enhance the acquisition of a conditioned avoidance response (Bohus et al. 1973, Lande et al. 1971). These results were regarded as a facilitatory action of VP on learning and memory. 
After the initial enthusiasm about the 'memory enhancing' effects of VP, skepticism set in. Both the nature and the site of action of VP were scrutinized. There is controversy about whether VP acts centrally or peripherally to affect avoidance behavior. Le Moal et al. (1981) proposed that the peripheral effects of VP may be responsible for its action, since a VP antagonist (dPTyr(Me)VP) that prevented an early pressor response elicited by subcutaneous administration of VP also prevented the behavioral response. However, the pressor response and the behavioral response need not be related. This possibility is strengthened by the observation that the antagonist used easily gains access to the brain, where it may have blocked the behavioral response. There is also a relatively large body of evidence that supports a central site of action for VP, some of the most pertinent findings of which will be mentioned. For instance, it has been shown that VP administered intracerebroventricularly can maintain a passive avoidance response at a much lower dose than when administered peripherally (De Wied 1976, Koob et al. 1981). Several studies using lesioning and local administration of the peptide have revealed sites of action in the brain (for review see Van Wimersma Greidanus et al. 1983). VP appears to influence avoidance behavior at midbrain limbic structures. Data available allow one to postulate that VP affects retrieval processes in the amygdala and dentate gyrus of the hippocampal complex. The data suggest that storage processes are affected in the dorsal septum, dorsal raphe and dentate gyrus of the hippocampus. Evidence for a role of endogenous VP stems from studies using intracerebroventricular (icv) or local administration of anti-VP antiserum. Central injection of a 1:10 dilution of anti-VP antiserum induces a deficit in avoidance behavior (Bohus et al. 1978, Van Wimersma Greidanus et al. 1975a,b). Administration of a 1:50 dilution in brain sites as hippocampus or septum results in attenuation of passive avoidance responding (Van Wimersma Greidanus and Veldhuis 1985), while at this dilution antiserum is ineffective upon icv administration. Besides its site of action, the mechanism of action of VP has also been a subject of debate. Sahgal and Wright (1983) suggested that VP affects alertness or arousal and not memory per se, since they found that substances known to affect arousal (i.e. amphetamine and chlordiazepoxide) had effects that were similar to those of VP on passive avoidance retention. However, it remains to be demonstrated whether amphetamine mimics the action of VP in other behavioral paradigms.

Another criticism of the effects of VP on learning and memory is that the initial positive effects of VP were obtained in aversively motivated tasks, whereas positively motivated tasks probably represent a more 'natural' situation. However, VP also appears to elicit effects in appetitively motivated tasks, although results have been less straightforward than on aversively motivated tasks. A number of studies reported delayed extinction of a learned response (Alescio et al. 1987, Bohus 1977, Dantzer et al 1987, Hostetter et al. 1977, Messing and Sparber 1983), but delayed extinction has not been observed in other studies using positive reinforcement (Alexinsky and Alliot 1987, Beckwith et al. 1987, Couk and Beckwith 1982). Positive findings have also been obtained for learning in appetitively rewarded tasks, but disruptive effects of peptide treatment have also been reported. For instance, enhanced aquisition by lysine 
VP or VP analogs has been observed in brightness discrimination tasks (Couk and Beckwith 1982, Sara et al. 1982) and food-reinforced autoshaped lever-touching response (Messing and Sparber 1983). In contrast, VP disrupts reversal learning of brightness discrimination (Couk and Beckwith 1982, Sara et al. 1982). The seemingly inconsistent results may be related to the inability to forget a learned response under the influence of VP, to the time of administration of the peptide, to the adversive or sedative properties of the peptide, or because the tasks may have been too difficult. For example, Sara et al. (1982) found that rats were impaired in reversal learning when the drug was given prior to initial learning and reversal training. From this it was concluded that VP facilitated both learning and the tendency to 'perseverate'. This interpretation is further strengthened by the observation that a VP analog facilitated reversal learning only when given prior to reversal learning (Couk and Beckwith 1982). Alliot and Alexinsky (1982) did not find an effect of lysine VP on acquisition of a light-dark discrimination task, but the dose given may have sedated the animals. VP injections have also been shown to impair working memory in a delayed matching to sample task in rats (Alexinsky and Alliot 1987), but the aversive properties of the peptide may have interfered with the approach tendencies demanded by the matching rule in this particular task.

A great deal of research has been done in recent years on the effects of VP on social memory in rats. In this task an adult rat has to learn the scent of a conspecific juvenile. Subcutaneous or central administration of the peptide improves social memory in male and female rats. With the use of VP antagonists it could be demonstrated that social memory is VP-dependent in male rats (Dantzer et al. 1988, Bluthé et al. 1990), but independent of VP in female rats (Bluthé and Dantzer 1990). It was concluded, therefore, that social memory is affected by VP in a specific way in male rats and in a nonspecific way in female rats. Whether such a sexual dichotomy with respect to the effects of VP on social memory also applies to other forms of memory and other central processes is an interesting question for future research.

When the data on the behavioral effects of VP are taken together, it can be concluded that VP acts centrally on performance of rats in paradigms designed to measure learning and memory. Whether, additionally, behavior is affected by VP through a peripheral mechanism cannot be excluded. In fact systemic administration has other effects than eliciting a pressor response that might effect learning and memory. Systemic administration of VP increases glucose concentration in a biphasic manner and increases corticosterone secretion long lasting (Buwalda et al. 1991). The observation that glucose injections immediately after passive avoidance training are known to improve retention in a dose-dependent manner (Gold 1986) may be pertinent to a peripheral effect of VP. Whether the increased corticosterone secretion is instrumental in the action of VP on passive avoidance is less likely, since effects of corticosterone opposite to that of VP on inhibitory avoidance have been found (Bohus 1982).

Besides processes related to leaming and memory, evidence has been obtained for a role of VP in a number of other brain actions. Vasopressinergic projections from the paraventricular nucleus to the brain stem and spinal cord are compatible with a role in 
cardiovascular regulation (Sladek and Sladek 1983). Blood pressure increases after icv administration (Pittman et al. 1982, Unger et al. 1984) or local injection of VP into the nucleus of the solitary tract (Matsuguchi et al. 1982), effects which were found to be mediated by increased sympathetic outflow (Unger et al. 1984). Pittman and Franklin (1985) found that a vasopressor antagonist suppressed the pressor response evoked by stimulation of the paraventricular nucleus following local administration of the antagonist into the nucleus of the solitary tract. However, there is evidence of other central VP influences in forebrain that attenuate pressor responses (Bohus et al. 1989). It has also been demonstrated that central administration of VP increases baroreceptor sensitivity in rats (Brattstrom et al. 1990, Unger et al. 1986).

Since VP concentrations in various brain areas depend on steroid hormones, a role of VP in reproductive and aggressive behaviors immediately comes to mind. Södersten et al. (1983) observed that VP injected into the cerebral ventricles inhibits lordosis behavior in female rats, while an antagonist enhances lordosis behavior. The vasopressinergic input to the lateral septum may be crucial to the inhibition of lordosis, since horizontal cuts ventrolateral to the septum increase lordosis behavior in female rats (Yamanouchi and Arai 1987). A role for VP in aggressive behavior stems from observations in hamsters. In hamsters, a local injection of a selective VP antagonist into the anterior hypothalamus suppresses scent marking and aggression, and reverses dominant-subordinate behavior relationships (Ferris and Potegal 1988, Ferris et al. 1986, 1988).

A large body of evidence suggests that VP is a naturally occurring fever suppressant (Kasting 1989). The site of action of VP to produce antipyresis appears to be the ventral septal area, since VP is only active when perfused in this site (Cooper et al. 1979). Receptor antagonists block the antipyretic action of endogenous VP (Cooper et al. 1987). Interestingly, the VP antagonist also blocks the effect of the fever suppressant indomethacin administered parenterally (Kasting 1989).

VP is secreted in a circadian fashion into the cerebrospinal fluid at terminals of neurons in the suprachiasmatic nuclei (Reppert et al. 1987), suggesting a role of VP in regulation of circadian rhythms. The expression of fairly normal rhythms in rats with hereditary diabetus insipidus (e.g., circadian rhythms of sleeping and waking, locomotion, drinking, $\mathrm{ACTH}$ and pineal $\mathrm{N}$-acetyltransferase activities) made the role of VP in the modulation of circadian rhythms enigmatic, although Brattleboro rats of some colonies show disruptions of sleep waking pattems (Danguir 1983). Results of a recent study imply that VP-containing neurons of the suprachiasmatic nuclei influence the daily corticosterone rhythm (Kalsbeek et al. 1992). Furthermore, it has become clear that the vasopressinergic system of the suprachiasmatic nuclei may play a role in the transmission of seasonally changing environmental information to the pineal gland (Buijs et al. 1986).

\subsection{Relationships between vasopressinergic functions}

While some actions of VP may be related, others may be not. This inter-relatedness of 
functions is clearly suggested by several findings. Firstly, a number of vasopressinergic subnuclei of the paraventricular nuclei lie in close proximity to each other. These subnuclei are major integrative centers for the control of many homeostatic functions of the body and act in a concerted fashion during disturbances in fluid balance (Swanson and Sawchenko 1983, Watts 1992). Other stressful stimuli bring about different responses of the paraventricular subnuclei. The functional relationship of the paraventricular subnuclei is also indicated by the fact that parvocellular and magnocellular nuclei are interconnected (Piekut and Joseph 1985). The paraventricular nucleus is involved in antidiuresis (Valtin 1987), cardiovascular regulation (Cowley and Liard 1987), and regulation of the release of adrenocorticotropic hormone (ACTH) (Roth et al. 1983). Both the cardiovascular action and the antidiuretic action of VP seem to cooperate to maintain a constant milieu intérieur. The role of VP in the stress response may have evolved in relation to the stress associated with dehydration. Secondly, different central actions of VP at least partly involve the same brain circuits and may be related to or resemble the effects on memory. For example, one central action of VP which may have certain aspects in common with memory consolidation is the ability to maintain tolerance to drugs, in that both represent adaptation to changed external stimuli (Hoffman 1987). In rats, androgen-dependent vasopressinergic neurons appear to be involved in diverse processes such as social recognition, the relative bradycardiac response as a result of fear of pain, and antipyresis (Bluthé et al. 1990, Bohus et al. 1990, Pittman et al. 1988). It has been suggested that the relationship between the different central actions of VP may be understood in terms of strategies for coping with stress (Bohus et al. 1990). Individual animals differ in their behavioral and physiological responses to stress. Coping with stress as viewed in the classical fight-flight pattern is only one of two possible ways. This pattern is adopted by aggressive animals and is characterized by high sympathetic activity and hormonal reactivity, as reflected in high plasma levels of prolactin, norepinephrine, epinephrine and testosterone. In addition to the active pattern of stress coping a passive pattern has been advocated by Henry and Stephens (1977), which is ruled by vagal activity and low hormonal reactivity. VP has been considered to be a neuroendocrine factor that serves a passive coping strategy for both central and peripheral mechanisms (Bohus et al. 1990). There are indications, however, to suggest that VP may also have important actions in active coping animals as well. It has been observed that vasopressinergic innervation of the brain is more intense in genetically selected active coping mice, which is consistent with the higher plasma testosterone levels in these animals. Furthermore, as mentioned above, female and castrated rats, which have low VP concentrations in steroid-dependent brain regions, do not depend on VP for social recognition (Bluthé and Dantzer 1990, Bluthé et al. 1990). The fact that a role for VP in active coping animals has not been recognized may be the result of the pharmacological nature of the experiments performed. The use of VP antagonists may reveal a role for VP in active coping animals. VP may prevent the exaggerated responses of active coping in these animals.

In conclusion, the different vasopressinergic systems in the brain operate separately, but there are important inter-relations that serve coordinated actions. For example, VP 
is involved in antidiuresis during water deprivation, while water deprivation activates stress and autonomic responses that are modulated by VP. The testosterone-dependent vasopressinergic system may determine behavioral strategies, including stress responses, in relation to social status.

\section{$5 \quad$ Vasopressinergic systems in aging}

In order to understand better the possible causes or consequences of changes in vasopressinergic systems with age, these changes will be dealt with in conjunction with age-related changes in processes in which VP is involved. A great deal of the research into vasopressinergic systems with age has involved the hypothalamoneurohypophyseal system in relation to changes in waterhomeostasis. Les research has been devoted to extrahypothalamic vasopressinergic systems. The functional

Table 2. Changes in parameters related to water homeostasis in aged rats relative to adult rats. Direction of change is indicated by arrows. $\downarrow$ : reduction, $\uparrow$ : increase, $\leftrightarrow$ : no change.

Strain

Sprague-

Dawley Fischer 344 Long-Evans Wistar Brown-Norway

VP concentration

plasma

$\downarrow$ (a)

$\downarrow$ (b)

$\uparrow(c)$

$\uparrow(d)$

$\leftrightarrow(e)$

hypothalamus

$\downarrow(\mathbf{a})$

$\downarrow(\mathrm{b}), \leftrightarrow(\mathrm{f}, \mathrm{g}) \quad \downarrow(\mathrm{c}, \mathrm{h})$

pituitary gland

$\leftrightarrow(a)$

$\leftrightarrow(\mathrm{b}), \downarrow(\mathrm{c})$

$\downarrow(c) \leftrightarrow(g, h)$

24-h VP excretion

$\leftrightarrow(i)$

$\downarrow($ (i)

$\uparrow(j)$

neurosecretory activity

urine secretion or water intake

$\downarrow$ (i)

$\uparrow(\mathrm{g}, \mathrm{k}, \mathrm{l}), \leftrightarrow(\mathrm{i}) \quad \uparrow(\mathrm{m})$

$\uparrow(d)$

(ml/24 h/100 g body weight)

renal concentrating ability

$\downarrow(k, l) \quad \downarrow(c)$

aZbuzek and Wu 1982, bZbuzek et al. 1983, cMiller 1985, dFliers and Swaab 1983, eRavid et al. 1987, Sladek et al. 1981, sSilverman et al. 1990, hDorsa and Bottemiller 1982, iPhelps et al. 1989. jGoudsmit et al. 1988a, kBengele et al. 1981, 1Beck and Yu 1982, mMiller 1987. 
implications of changes in the latter systems are less clear because their functions are less well understood.

\subsection{Water homeostasis and the hypothalamo-neurohyphyseal system in aging}

Aging is accompanied by changes in water homeostasis (Table 2). It has been demonstrated that the renal ability to concentrate urine is decreases in rats with aging (Beck and Yu 1982, Bengele et al. 1981, Dicker and Nunn 1958, Miller 1985). Different findings have been made to explain this decreased renal concentrating ability. cAMP production in the renal papilla of Fischer 344 rats was impaired upon stimulation with VP (Beck and Yu 1982). A decreased number of VP receptors were found in old Brown-Norway rats (Ravid et al. 1987). Corman and Roinel (1991) found a decreased number of functional glomeruli in the kidneys of female Wistar rats with age. A number of disturbances in water homeostasis have also been observed in humans. There is an increased prevalence of hypo- and hypernatremia (Lye 1985), a decreased thirst response (Philips et al. 1984), reduced renal concentrating ability (Dontas et al. 1972, Lewis and Alving 1938, Lindeman et al. 1966, Miller and Shock 1953, Rowe et al. 1976), delayed excretion of a water load (Crowe et al. 1987) and an increased osmoreceptor sensitivity (Helderman et al. 1978).

Renal concentrating ability is determined under conditions of increased osmolality installed by water deprivation. To find out whether water homeostasis is changed with age under basal conditions different parameters related to water homeostasis have been determined in human subjects and rats of different ages. However, findings in rats have been at variance. Plasma VP concentrations have been found to be reduced, increased or unaltered with age in rats. Plasma VP concentrations have been found to be reduced with age in Sprague-Dawley rats (30-month-old vs 3- and 12-month-old) and Fischer 344 rats (30-month-old vs 2-and 12-month-old), increased in Long-Evans rats (20-23-month-old vs 3-and 8-month-old) and Wistar rats (32-month-old vs 3- and 11 -month-old), and unaltered in Brown-Norway rats. An increased water intake or urine production has been observed in Fischer 344 rats (4-month-old vs 6- and 12month-old), Long-Evans rats (14- and 16-month-old vs 4-month-old) and BrownNorway rats (33-month-old vs 3-month-old), whereas a reduced water intake or urine production has been found in Sprague-Dawley rats (20-month-old vs 3-month-old) and Wistar rats (32-month-old vs 3 - and 11-month-old).

Different data have also been obtained about changes in plasma VP concentrations in humans. Helderman et al. (1978) and Rowe et al. (1982) reported unaltered VP concentrations in aged subjects compared with young subjects. Others, however, have observed increases in plasma VP concentrations with age (Frolkis et al. 1982, Kirkland et al. 1984, Rondeau et al. 1982). Irrespective of whether increased or unaltered concentrations of VP were found, basal plasma osmolality did not seem to be affected (Helderman et al. 1978, Os et al. 1985).

Changes in VP concentrations in the hypothalamus and pituitary gland with age have been studied in rats as well as in humans. Concentrations of VP in the 
hypothalamus are reduced in aged rats of the Sprague-Dawley and Long-Evans strains, and reduced or equal in the Fischer 344 strain. Concentrations of VP in the pituitary gland of rats are equal (Sprague-Dawley, Fischer 344, Long-Evans) or reduced (Fischer 344, Long-Evans) in rats. Morphometrical findings on the neuroendocrine nuclei in humans are consistent with an increased neurosecretory activity in old age (Fliers et al. 1985b, Hoogendijk et al. 1985, Van der Woude et al. 1991).

On the basis of the above results a clear picture does not emerge about changes in the hypothalamo-neurohypophyseal system in rats with aging. The disparity of the findings may be related to strain differences, a circannual rhythm of plasma VP concentration (Zbuzek and Wu 1979), the ages of the rats used and their health status. Goudsmit (1991), in his thesis, explores the possibility that the changes in water homeostasis with age between strains of rats are related to the occurence of kidney pathology. Kidney pathology is less severe in Wistar and Brown-Norway rats than in Sprague-Dawley and Fischer 344 rats. Surprisingly, however, this pathology does not appear to lead to an activation of the neurosecretory cells with age (see Table 2), suggesting a response of the brain to a change in the kidney other than a response to an alteration in kidney water handling. Alternatively, Sprague-Dawley and Fischer 344 rats may differ from Wistar and Brown-Norway rats in changes in the regulation of VP release with age. Miller (1987) found disturbances in Long-Evans rats already at 7 months of age and concluded that increased release of VP is a early manifestation of aging. The absence of early changes in plasma VP concentration in other strains of rats may be related to the fact that Long-Evans rats are rather atypical with respect to water homeostasis. Long-Evans rats drink little (Fregly et al. 1990) and produce a highly concentrated urine (Miller and Moses 1971), which may result in renal dysfunction relatively early in life.

Furthermore, there are several technical problems with experiments on the effect of age on VP secretion. Single measurements of plasma VP may be unreliable (Ravid et al. 1987). Twenty-four-hour urine measurements, as used by several investigators, may be more reliable, were it not the case that the social isolation necessary for this type of measurement has unexplained effects on plasma VP concentration (Phelps et al. 1989). There are also problems with the interpretation of the data obtained. The body weight of rats still increases when they have reached sexual maturity, and the question arises whether, for instance, water intake should be corrected for body weight or not. Ravid et al. (1987) observed an increased 24-h VP excretion in aged BrownNorway rats and interpreted this result as being indicative of an activated hypothalamoneurohypophyseal system. However, they compared relatively young, growing rats with senescent animals. Thus, the increased 24-h VP excretion in that study may reflect a difference in body size, rather than something else. Increased plasma VP concentrations were found in a few studies (Fliers and Swaab 1983, Miller 1985), but Silverman et al. (1990) argued that this reflects increased handling stress in aged rats.

From the above, it appears that the only consistent change in water homeostasis in rats with age is a reduced renal concentrating ability, the primary cause of which may lie in the kidney itself or in the hypothalamus. Ravid et al. (1987) advanced the notion 
that the reduced number of VP receptors in the kidney tubuli of the senescent BrownNorway rat is the primary deficit in water homeostasis, because kidney disease is not typical to this strain. Miller (1987) reported a rise in VP excretion in adult male LongEvans rats which preceded changes in water metabolism, suggesting hypervasopressinemia may down regulate renal VP receptors and thus be a cause rather than an effect of diminished renal responsiveness to VP. Goudsmit et al. (1988a) noticed that the observation that the number of immunocytochemically VP binding in the kidneys of senescent rats homozygous for hereditary diabetus insipidus is also reduced (Ravid, unpublished observation), would argue against a causal role for VP in a kidney deficit. Miller (1985), on the other hand, observed that water intake does not increase with age in rats heterozygous for diabetus insipidus. These rats have half the VP secretory capacity of normal rats with correspondingly reduced plasma VP concentration. From these observations it may be argued that different causes may contribute to renal dysfunction with age.

\subsection{VP and cardiovascular changes with age}

Besides changing water homeostasis, VP may be involved in cardiovascular changes with age. The arterial baroreflex control of heart rate becomes impaired with age in humans (Gribben et al. 1971, Komer et al. 1974, Lowenthal et al. 1983). Changes in heart rate are considered to represent the parasympathetic limb of the baroreflex. Studies using indirect estimations of the sympathetic limb of the baroreflex have shown elevated plasma norepinephrine levels in elderly subjects (Esler et al. 1989, Pfeifer et al. 1983, Shimada et al. 1985, Ziegler et al. 1976). Although there has been no direct assessment of baroreflex control of sympathetic activity in humans, these studies have suggested a decreased parasympathetic and increased sympathetic influence with age. Studies in rats have also shown an impaired baroreflex control of heart rate (Buwalda et al.1990, Rothbaum et al. 1974) and elevated norepinephrine levels with age (Chiueh et al. 1980). Besides changes in the efferent limbs of the baroreflex with age, changes in target organs have also been reported. The $\beta$ adrenergic sensitivity of the heart and blood vessels has been shown to be diminished in both humans and rats (Frolkis et al. 1975), while it has recently been found that the cholinergic sensitivity of the heart is increased in rats (Ferrari et al. 1991). A role for central nervous system transmitters, including VP, in the altered baroreflex control with age has yet to be established. A role for VP in a vagally mediated stress response has been hypothesized (Bohus et al. 1990), and recent studies in old and senescent rats have shown this response to diminish with age (Nyakas et al. 1990).

\subsection{The testosterone-dependent vasopressinergic system with aging}

Changes in VP concentrations outside the neuroendocrine system have been studied in Long-Evans rats (Dorsa and Bottemiller 1982). These authors found reduced 
concentrations of VP in the dorsal septum, vascular organ of the lamina terminalis, and locus coeruleus, but not in the lateral septum, medial septum, or ventral tegmentum. Fliers et al. (1985a) found that the influence of age on changes in immunocytochemical staining of VP fibers in the brain of Brown-Norway rats resembled the effect of castration and concluded that the age-related changes were caused by a decreased testosterone status of aged rats. In their study, testosterone status was not assessed, but later studies clearly showed that testosterone status is much declined in the strain of rats used (Goudsmit et al. 1988b, Ravid et al. 1987). Staining for VP was reduced in all areas showing a testosterone dependence, except the lateral septum. Furthermore, reduced staining was found in the nucleus ambiguus, an area in the brain stem innervated by the paraventricular nucleus. In another study, Goudsmit et al. (1988b) found reductions of VP staining in the central gray and locus coeruleus. They were able to demonstrate that testosterone suppletion increased immunocytochemical staining in aged rats, suggesting that the reduced staining was caused by decreased testosterone status. In still another study, Goudsmit et al. (1990) did not observe age-reductions in VP concentrations in the lateral septum and medial amygdala of Brown-Norway rats. The absence of an effect of age on VP concentrations in this particular study was ascribed to the fact that testosterone levels were not much declined in the aged animals relative to the young animals. In the study of Dorsa and Bottemiller (1982), a general decline in androgen-dependent VP innervation was not observed either. From these findings it may be concluded that extrahypothalamic changes may vary within strains and possibly between strains.

It can be hypothesized that the age-related changes in vasopressinergic innervation caused by a reduced testicular function with age can be mimicked by the effects of castration. From what is known about the functions of the streroid-dependent vasopressinergic system, aged rats may show alterations in, for instance, memory processes, increased fever during infectious disease, and decreased aggressive behavior. Of course, other systems also change with age and will affect the outcome of vasopressinergic changes with age on the processes mentioned. It therefore remains to be investigated how vasopressinergic function alters with age.

Finally, it is important to mention that the vasopressinergic system of the suprachiasmatic nuclei is affected with aging in rats (Roozendaal et al. 1987) as well as in humans, and to an exaggerated extent in Alzheimer's disease (Swaab et al. 1985). As mentioned above VP-containing nuclei in the suprachiasmatic nuclei are involved in regulation of circadian rhythms. Disruption of circadian rhythms is considered a possible factor in aging, i.e, aging may originate from the loss of co-ordination among the many interdependent oscillating systems (Samis 1968, Van Gool and Mirmiran 1986). From this point of view changes in the vasopressinergic system of the suprachiasmatic nuclei may contribute to aging. 
Criteria to decide whether a substance is involved in aging were outlined above. The first criterion, that the substance should be involved in processes that decline with age, appears to be fulfilled for VP. The second criterion that VP concentrations should show age-related changes needs to be corroborated in view of the different findingd reported in the literature. The main objective of the present studies is to assess agerelated changes in the hypothalamo-neurohypophyseal system and extrahypothalamic brain regions of rats. This is not a simple task since many confounders have been mentioned: strain, ages, and number of age groups used, health status, time of day, time of year, stress. In the present studies, we tried to control for these confounders. To assure optimum health status barrier-reared rats were used that were kept under specific pathogen-free conditions. The strains of rats used did not suffer from specific pathologies (see discussion chapter 8), except for the incidence of prolactin secreting tumors in Wistar rats. Animals with macroscopical tumors were not used for experiments. In most of the studies, three or more age groups were used, or the control group consisted of rats that were fully matured (one-year-old rats) to be sure that maturation would not be a confounding factor as it was in many studies in which not fully grown animals were compared with aged rats (Coleman et al. 1990).

Before any of the questions on age-related changes in VP concentrations could be answered, a means to determine these changes had to be developed. The literature describes many radioimmunoassays for VP. However, the reported methods were not satisfactory because they rely heavily on very sensitive antibodies against VP and do not control for nonspecific influences.

This thesis is organized into four parts. The first part deals with methodological issues concerning the radioimmunoassay for VP (chapter 2), the second part is concerned with age-related changes in plasma VP concentration and osmolality in rats and humans (chapters 3,4 and 5), the third part describes studies on concentrations of VP in the rat brain in relation to age (chapters 6,7 and 8), and the fourth part is about changes in VP-converting enzymes with age in the brains of rats and in neocortical autopsy material from brains of patients with Alzheimer's disease (chapters 9 and 10).

In part 1 methods for the determination of VP in plasma and brain tissue are described with special emphasis on reliability and simplicity (chapter 2). A simple method for the extraction of VP from brain tissue with high recovery was developed. Methods for the internal standardization of the radioimmunoassay are provided and extensively evaluated.

A point of concern in studies on the influence of age on fluid balance in rats are possible daily fluctuations in plasma VP concentration and osmolality. To properly assess the changes in plasma VP concentration and osmolality with aging in Wistar rats, these parameters were determined at several time points during the day (chapter 3). Correlations between plasma osmolality and plasma VP concentration could be used to assess the physiological relevance of changes in these parameters observed in rats of different ages at different time points.

Osmoreceptor sensitivity is increased in aged humans (Helderman et al. 1978), 
possibly resulting in VP hypersecretion. To obtain some insight into the causes of the changes in plasma VP concentration in rats, it was determined whether the osmoregulation of VP release was altered with aging (chapter 4).

It has been demonstrated that water homeostasis in humans is disturbed under stimulatory conditions (Lewis and Alving 1938, Lindeman et al. 1966, Miller and Shock 1953, Rowe et al. 1976). The question arises whether changes in water homeostasis can be monitored under every day conditions. We determined whether plasma osmolality is increased after an overnight fast (chapter 5), since this is the time of day when plasma osmolality is likely to increase. It is highly relevant to determine early changes in the milieu intérieur, since it has been shown that elevated plasma osmolality is a predictor of increased mortality in the elderly (McLean et al. 1990, O’Neill et al. 1990).

VP concentrations in the extrahypothalamic rat brain have only been studied in a few strains of rats and findings have not been conclusive. These studies mostly used two age groups only, namely of young not fully matured animals and aged animals, and provided limited quantitative information. To provide more quantitative information, VP concentrations in brains of male Wistar rats of four different ages were determined by radioimmunoassay (chapter 6 ).

It has been suggested that both hypothalamic changes and extrahypothalamic changes in concentrations of VP may be related to decreased testosterone concentrations (Goudsmit et al. 1988b, Ravid et al. 1987). The effects of castration and aging on VP concentrations were compared in order to determine to what extent decreased testosterone concentrations can explain the effect of aging (chapter 7).

The discrepancies in studies on the influence of age on brain VP concentrations may be related to the strains of rats used or to seasonal fluctuations in VP concentrations (Prechel et al. 1983, Zbuzek and Wu 1979). VP concentrations in rats of three different strains and of three different ages were determined to investigate whether the effect of aging can be generalized over strains (chapter 8). The effect of season was investigated in Lewis rats of different ages.

In vitro, VP is converted by a number of peptidases. These peptidases might be involved in the degradation of VP in vivo after its release at the synapse or in the intracellular turnover of the peptide. The possible contribution of these peptidases to age-related vasopressinergic dysfunction was investigated in chapter 9. VP concentrations are affected in several brain regions in Alzheimer's disease (AD) (Mazurek et al. 1986), and it is possible that changes in peptidase activities are the cause of reduced VP concentrations in AD. Some VP-converting enzymes were measured in neocortical brain samples from patients with AD (chapter 10). The relevance of the findings of this study with respect to reduced VP concentrations in $\mathrm{AD}$ has to await future investigations, because VP is not present in the cortex and it is uncertain whether these enzymes convert VP in vivo. However, since the VPconverting enzymes are involved in the general degradation of peptides and proteins, the studies provide information about changes in peptide turnover with age and in AD. 


\section{References}

Ader R, De Wied D. The effects of lysine VP on passive avoidance learning. Psychonomic Science 1972;29:46-8.

Alescio-Lautier B, Devigne C, Soumireu-Mourat B. Hippocampal lesions block behavioral effects of central but not of peripheral pre-test injection of arginine vasopressin in an appetitive learning task. Behav Brain Res 1987;26:159-69.

Alexinsky T, Alliot J. Vasopressin injections impair working memory in a delayed matching to sample task in rats. Bchav Naural Biol 1987;48:167-82.

Alliot J, Alexinsky T. Repeated posttrial vasopressin injections on appetitively motivated leaming in rats. Physiol Behav 1982;28:525-30.

Aravich PF, Sladek JR Jr. Aging of rodent VP systems. In: Gash DM, Boer GJ, eds. Vasopressin. Principles and properties. New York: Plenum, 1987:579-610.

Audigier S, Barberis C. Pharmacological characterization of two specific binding sites for neurohypophyseal hormones in hippocampal synaptic plasma membranes of the rat. EMBO J 1985;4:1407-12.

Barberis C. $\left[{ }^{3} \mathrm{H}\right]$ Vasopressin binding to rat hippocampal synaptic plasma membrane. FEBS 1983;162:400-5.

Bargmann W. Uber die neurosekretorische Verknüpfung von Hypothalamus und Neurohypophyse. Zeitschrift für Zellforschung 1949;34:610-34.

Barry J. Neurocrinie el synapses 'neurosecretoires'. Archives Anatomic Microskopie 1954;43:310-20.

Beck N, Yu BP. Effect of aging on urinary concentrating mechanism and vasopressin-dependent cAMP in rats. Am J Physiol 1982;243:F121-5.

Beckwith BE, Tinius TP, Miller DH. Arginine vasopressin facilitates reversal and impairs retention of a brightness discrimination in albino rats. Psychobiol 1987;15:329-35.

Bengele HH, Mathias RS, Perkins JH, Alexander EA. Urinary concentrating defect in the aged rat. Am J Physiol 1981;240:F147-50.

Berridge M, Irvine RF. Inositol triphosphate, a novel second messenger in cellular signal transduction. Nature 1984;312:315-21.

Berridge MJ. The molecular basis of communication within the cell. Scientific American 1985;253:124-34.

Bjorksten J. The crosslinkage theory of aging. J Am Geriatrics Soc 1968;16:408-27.

Bluthé R-M, Dantzer R. Social recognition does not involve vasopressinergic neurotransmission in female rats. Brain Res 1990;535:301-4.

Bluthe R-M, Schoenen J, Dantzer R. Androgen-dependent vasopressinergic neurons are involved in social recognition in rats. Brain Res 1990;519:150-7.

Bockaert J, Roy C, Rajerison R, Jard S. Specific binding of [ $\left.{ }^{3} \mathrm{H}\right]$ lysine-vasopressin to pig kidney plasma membranes. J Biol Chem 1973;248:5922-31.

Bohus B. Effects of desglycinamide-lysine vasopressin (DG-LVP) on sexually motivated T-maze behavior of the male rat. Horm Behav 1977;8:52-61.

Bohus B. Neuropeptides and memory. In: Isaacson RL, Spear NE, eds. The expression of knowledge. New York: Plenum, 1982:141-77.

Bohus B, Gispen WH, De Wied D. Effect of lysine vasopressin and ACTH-(4-10) on conditioned avoidance behavior op hypophysectomized rats. Neuroendocrinology 1973;11:137-43.

Bohus B, Urban I, Van Wimersma Greidanus TjB, De Wied D. Opposite effects of oxytocin and vasopressin on avoidance behavior and hippocampal theta rhythm in the rat. Neuropharmacology 1978;17:239-47.

Bohus B, Koolhaas JM, Luiten PGM, Versteeg CAM, Korte SM, Jaarsma D. Vasopressin and related peptides: involvement in central cardiovascular regulation. In: Nijkamp FP, De Wied D, eds. Hypertension, brain catecholamines and peptides. Amsterdam: Elsevier, 1989:99-110.

Bohus B, Koolhaas JM, Nyakas C, Luiten PGM, Versteeg CAM, Korte SM, Jaarma D, Timmerman W, Eisenga W. Neuropeptides and behavoural and physiological stress response: the role of vasopressin and related peptides. In: Puglisi-Allegra S, Oliverio A, eds. Psychobiology of stress. Dordrecht:Kluwer, 1990:10323.

Bone EA, Fretten P, Palmer S, Kirk M, Michell RH. Rapid accumulation of inositol phosphates in isolated rat superior cervical sympathetic ganglia exposed to V1-vasopressin and muscarinic cholinergic stimuli. 
Biochem J 1984;221:803-11.

Brattstrom A, De Jong W, De Wied D. Central vasopressin impairs the baroreceptor heart rate reflex in conscious rats. J Cardiovasc Pharmacol 1990;15:114-7.

Brody JA, Brock DW. Epidemiologic and statistical characteristics of the united states elderly population. New York: Van Nostrand Reinhold, 1985:3-26.

Brownstein MJ, Russel JT, Gainer H. Synthesis, transport, and release of posterior pituitary hormones. Science 1980;207:373-8.

Butlen D, Guillon G, Rajerison RM, Jard S. Structural requirements for activation of vasopressin-sensitive adenylate cyclase, hormone binding, and antidiurectic actions: effects of highly potent analogues and competitive inhibitors. Mol Pharmacol 1978; 14:1006-17.

Buwalda B, Nyakas C, Koolhaas JM, Bohus B. Effects of neonatal administration of vasopressin on cardiac and behavioral responses to emotional stress in adult male rats. Physiol Behav 1991; vol. 50:929-32.

Buwalda B, Nyakas C, Strubbe JH, Hoes M, Bohus B. Age-related reduction in parasympathetic autonomic responses in the rat. In: Van Bezooijen CFA, Ravid R, Verhofstad AAJ, eds. From gene to man gerontological research in The Netherlands. Rijswijk: Stichting Gerontologie en Geriatrie, 1990:90-4.

Buijs RM. Putative functions of VP. In: Gash DM, Boer GJ, eds. Vasopressin. Principles and properties. New York: Plenum, 1987:91-I15.

Buijs RM, Pévet P, Masson-Pévet M, Pool CW, De Vries GJ, Canguilhem B, Vivien-Roels B. Seasonal variation in vasopressin innervation in the brain of the European hamster (Cricetus cricetus). Brain Res 1986:371:193-6.

Buijs RM, Swaab DF, Dogterom J, Van Leeuwen FW. Intra- and extrahypothalamic vasopressin and oxytocin pathways in the rat. Cell Tissue Res 1978; 186:423-33.

Caffe AR, Van Leeuwen FW. Vasopressin-immunoreactive cells in the dorsomedial hypothalamic region, medial amygdaloid nucleus and locus coeruleus of the rat. Cell Tissue Res 1983;233:23-33.

Caffé AR, Van Leeuwen FW, Luiten PGM. Vasopressin cells in the medial amygdala of the rat project to the lateral septum and the ventral hippocampus. J Comp Neurol 1987;261:237-52.

Chiueh CC, Nespor SM, Rapoport SI. Cardiovascular, sympathetic and adrenal cortical responsiveness of aged Fischer 344 rats to stress. Neurobiol Aging 1980;1:157-63.

Coleman P, Finch C, Joseph J. The need for muluple time points in aging studies. Neurobiol Aging 1990;11:1-2.

Cooper KE, Naylor AM, Veale WL. Evidence supporting a role for endogenous vasopressin in fever suppression in the rat. J Physiol (Lond) 1987;387:163-72.

Cooper KE, Kasting NW, Lederis K, Veale WL. Evidence supporting a role for vasopressin in natural suppression of fever in sheep. J Physiol (Lond) 1979;295:33-45.

Cooper RC, McNamara MC, Thompson WG. Vasopressin and conditioned flavor aversion in aged rats. Neurobiol Aging 1980;1:53-7.

Corman B, Roinel N. Single-nephron filtration rate and proximal reabsorption in aging rats. Am J Physiol 1991;29:F75-80.

Couk DI, Beckwith BE. Effects of desmopressin acetate (DDAVP) on the learning of a brightness discrimination. Peptides 1982;3:521-6.

Cowley AW, Liard J-F. Cardiovascular actions of vasopressin. In: Gash DM, Boer GJ, eds.Vasopressin. Principles and properties. New York: Plenum Press, 1987:389-433.

Crowe MJ, Forsling ML, Rolls BJ, Phillips PA, Ledingham JGG, Smith RF. Altered water excretion in healthy elderly men. Age Ageing 1987:16:285-93.

Danguir J. Sleep deficits in rats with hereditary diabetus insipidus. Nature 1983;163-4.

Dantzer R, Bluthé R-M, Koob GF, Le Moal M. Modulation of social memory in male rats by neurohypophyseal peptides. Psychopharmacology 1987;91:363-8.

Dantzer R, Koob GF, Bluthé R-M, Le Moal M. Septal vasopressin modulates social memory in male rats. Brain Res 1988;457:143-7.

Davis LG, Arentzen R, Reid JM, Manning RW, Wolfson B, Lawrence KL, Balbino F Jr. Glucocorticoid sensitivity of vasopressin mRNA levels in the paraventricular nucleus of the rat. Proc Natl Acad Sci USA 1986;83:1145-9.

De Vries GJ, Buijs RM. The origin of the vasopressinergic and oxytocinergic innervation of the rat brain, with 
special reference to the lateral septum. Brain Res 1983;303:233-40.

De Vries GJ, Buijs RM, Van Leeuwen FW, Caffe AR, Swaab DF. The vasopressinergic innervation of the brain in normal and castrated rats. J Comp Neurol 1985;233:236-54.

$\mathrm{De}$ Wied $\mathrm{D}$. The influence of the posterior and intermediate lobe of the pituitary and pituitary peptides on the maintenance of a conditioned avoidance response in rats. Int J Neuropharmacol 1965;4:157-67.

De Wied D. Effects of peptide hormones on behavior. In: Ganong WF, Martini L, eds. Frontiers in Neuroendocrinology. New York: Oxford University Press, 1969:97-140.

De Wied D. Long term effect of vasopressin on the maintenance of a conditioned avoidance response in rats. Nature 1971;232:58-60.

De Wied. Behavioral effects of intraventricularly administered vasopressin and vasopressin fragments. Life Sci 1976;19:685-90.

De Wied D. Central actions of neurohypophyseal peptides. In: Cross BA, Leng G, eds. The neurohypophysis: structure, function and control. Amsterdam: Elsevier, 1983:155-67. (Progress in Brain Research; vol 60).

De Wied D, Bohus D. Long term and short term effects on retention of a conditioned avoidance response in rats by treatment with long acting pitressin and $\alpha-M S H$. Nature 1966;212:1484-6.

De Wied D, Joells M, Burbach JPH, De Jong W, De Kloet ER, Gaffori OWJ, Urban IJA, Van Ree JM, Van Wimersma Greidanus TjB, Veldhuis HD, Versteeg DGH, Wiegant VM. Vasopressin effects on the central nervous system. In: Negro-Vilar A, Conn PM, eds. Peptide hormones: effects and mechanisms of action; vol 1. Boca Raton: CRC Press, 1988:97-140.

Dicker SE, Nunn J. Antidiuresis in adult and old rats. J Physiol 1958;141:332-6.

Dontas AS, Marketos SG, Papanayiotou P. Mechanisms of renal tubular defects in old age. Postgrad Med J 1972;48:295-303.

Dorsa DM, Bottemiller L. Age-related changes of vasopressin content of microdissected areas of the rat brain. Brain Res 1982;242:151-6.

Dunn FL, Brennan TJ, Nelson AE, Robertson GL. The role of blood osmolality and volume in regulating vasopressin secretion in the rat. J Clin Invest 1973;52:3212-9.

Duursma SA, Raymakers JA. Clinical and pharmacological aspects of osteoporosis. In: Van Bezooijen CFA, Ravid R, Verhofstad AAJ, eds. From gene to man - gerontological research in The Netherlands. Rijswijk: Stichting Gerontologie en Geriatrie, 1990:375-9.

Esler M, Lambert G, Jennings G. Influence of aging on catecholamine metabolism. In: Amery A, Staessen J, eds. Hypertension in the elderly. Amsterdam: Elsevier, 1989:85-98. (Handbook of hypertension; vol 12).

Everiu A, Meites J. Aging and anti-aging effects of hormones. J Gerontol 1989;44:B 139-47.

Ferrari AU, Daffonchio A. Gerosa S, Mancia G. Alterations in cardiac parasympathetic function in aged rats. Am J Physiol 1991;260:H647-9.

Ferris CF, Potegal M. Vasopressin receptor blockade in the anterior hypothalamus suppresses agression in hamsters. Physiol Behav 1988;44:235-9.

Ferris CF, Meenan DM, Axelson JF, Albers HE. A vasopressin antagonist can reverse dominant/subordinate behavior in hamsters. Physiol Behav 1986;38:135-8.

Ferris CF. Singer EA, Meenan DM, Albers HE. Inhibition of vasopressin-stimulated flank marking behavior by V1-receptor antagonists. Eur J Pharmacol 1988;154:153-9.

Fibiger HC. Cholinergic mechanisms in learning, memory and dementia: a review of recent evidence. TINS 1991:14:220-3.

Finch CE, Landfreld PW. Neuroendocrine and autonomic functions in aging mammals. In: Finch CE, Schneider EL, eds. Handbook of the biology of aging. New York: Van Nostrand Reinhold, 1985:567-94. (Birren JE, ed. The handbooks of aging; vol 1).

Fliers E, Swaab DF. Activation of vasopressinergic and oxylocinergic neurons during aging in the Wistar rat Peptides 1983;4:165-70.

Fliers E, De Vries GJ, Swaab DF. Changes with aging in the vasopressin and oxytocin innervation of the rat brain. Brain Res 1985a:348:1-8.

Fliers E, Swaab DF, Pool CW, Verwer RWH. The vasopressin and oxytocin neurons in the human supraoptic and paraventricular nucleus; changes with aging and in senile dementia. Brain Res 1985b;342:45-53.

Fregly MJ, Paulding W, Rowland NE. Comparison of the dipsogenic responsiveness of Long-Evans and 
Sprague-Dawley rats. Physiol Behav 1990;47:1187-92.

Frolkis VV, Berzrukov BB, Shevchuk VG. Hemodynamics and its regulation in old age. Exp Gerontol 1975; 10:251-71.

Frolkis VV, Golovchenko SF, Medved VI, Frolkis RA. Vasopressin and cardiovascular system in aging. Gerontology 1982;28:290-302.

Gainer H, Same Y, Brownstein MJ. Biosynthesis and axonal transport of rat neurohypophysial proteins and peptides. J Cell Biol 1977;73:366-81.

Gash DM, Herman JP, Thomas GJ. Vasopressin and animal behavior. In: Gash DM, Boer GJ, eds. Vasopressin. Principles and Properties. New York: Plenum Press, 1987:517-47.

Gillies GE, Linton EA, Lowry PF. Corticotropin releasing activity of the new CRF is potentiated several times by vasopressin. Nature 1982;299:355-7.

Gold PE. Glucose effects of memory storage processing. Behav Neural Biol 1986;45:342-9.

Goudsmit E. Neural activation during aging and in Alzheimer's disease: the role of sex steroids and osmotic stimulation (Thesis). Amsterdam, The Netherlands: Amstcrdam University, 1991. 175p.

Goudsmit E, Fliers E, Swaab DF. Vasopressin and oxytocin excretion in the Brown-Nonway rat in relation to ageing, water metabolism and testosterone. Mech Ageing Dev 1988a:44:241-52.

Goudsmit E, Fliers E, Swaab DF. Testosterone supplementation restores vasopressin innervation in the senescent rat brain. Brain Res 1988b;473:306-13.

Goudsmit E, Luine VN, Swaab DF. Testosterone locally increases vasopressin content but fails to restore choline acetyltuansferase activity. Neurosci Lett 1990;112:290-6.

Grantham JJ, Burg MB. Effect of vasopressin and cyclic AMP on permeability of isolated collecting tubules. Am J Physiol 1966;211:255-9.

Gribben B, Pickering TC, Sleight P, Peto R. Effect of age and high blood pressure on baroreflex sensitivity in man. Circ Res 1971;29:424-31.

Hajduczok G, Chapleau MW, Francois MA. Rapid adaptation of central pathways explains the suppressed baroreflex with aging. Neurobiol Aging 1991;12:601-4.

Hall DA, Varney DM. Effect of vasopressin on electrical potential difference and chloride transport in mouse medullary thick ascending limb of Henle's loop. J Clin Invest 1980;66:792-802.

Harman D. The aging process. Proc NaL Acad Sci USA 1981;78:7124-8.

Harman SM, Talbert GB. Reproductive aging. In: Finch CE, Schneider EL, eds. Handbook of the biology of aging. 2nd edn. New York: Van Nostrand Reinhold, 1985:457-510.

Harmanci $M$, Kachadorian W, Valtin $H$, diScala VA. Antidiurectic hormone-induced intramembrancous alterations in mammalian collecting ducts. Am J Physiol 1978;235:F440-3.

Harmanci MC, Stern W, Kachadorian WA, Valtin H, diScala VA. Vasopressin and collecting duct intramembraneous particle clusters: a dose-response relationship. Am J Physiol 1980;239:F560-4.

Hayflick L. Theories of biological agíng. Exp Gerontol 1985;20:145-59.

Hedge GA, Huffman LJ. Vasopressin and endocrine function. In: Gash DM, Boer GJ, eds. Vasopressin. Principles and properties. New York: Plenum Press, 1987:435-75.

Helderman JH, Vestal RE, Rowe JW, Tobin JD, Andres R, Robenson GL. The response of arginine vasopressin to intravenous ethanol and hypertonic saline in man: the impact of aging. J Gcrontol 1978;33:39-47.

Hems DA, Whitton PD. Control of hepatic glycogenolysis. Phys Rev 1980; 60:1-50.

Henry JP, Stephens PM. Stress, health, and the social environment. A sociobiological approach to medicin. Berlin: Springer, 1977.

Hoffman PL. Central nervous system effects of neurohypophyseal peptides. In: Smith CW, ed. Chemistry, biology, and medicine of neurohypophyseal hormones and their analogs. Orlando: Academic Press, 1987:239. 95. (In: Udenfriend S, Meienhofer J, eds. The peptides. Analysis, synthesis, biology; vol 8).

Hoogendijk JE, Fliers E, Swaab DF, Verwer RW. Activation of vasopressin neurons in the human supraoptic and paraventricular nucleus in senescence and dementia. J Neurol Sci 1985:69:291-9.

Hoorneman EMD, Buijs RM. Vasopressin fiber pathways in the rat brain following suprachiasmatic lesioning. Brain Res 1982;243:235-41.

Horn AM, Lightman SL.Vasopressin-stimulated turnover of phosphatidylinositol in the decentralised cervical ganglion in the raL Brain Res 1988;455:18-23. 
Homykiewicz O. Parkinson's disease: from brain homogenate to treatment. Fed Proc 1973;32:183.

Hostetter G, Jubb SL, Kozlowski GP. Vasopressin affects the behavior of rats in a positively rewarded discrimination task. Life Sci 1977;21:1323-8.

Ingram D. Analysis of age-related impairments in learning and memory in rodent models. Ann NY Acad Sci 1985;44:312-31.

Jard S, Gaillard RC, Guillon G, Marie J, Schoenenberg P, Muller AF, Manning M, Sawyer WH. Vasopressin antagonists allow demonstration of a novel type of vasopressin receptor in the rat adenohypophysis. Mol Pharmacol 1986;30:171-7.

Jolles J. Vasopressin and human behavior. In: Gash DM, Boer GJ, eds. Vasopressin. Principles and properties. New York: Plenum Press, 1987:549-78.

Kalsbeek A, Buijs RM, Van Heerikhuize JJ, Arts M, Van der Woude TP. Vasopressin-containing neurons of the suprachiasmatic nuclei inhibit corticosterone release. Brain Res 1992;580:62-7.

Kasting NW. Criteria for establishing a physiological role for brain peptides. A case in point: the role of vasopressin in thermoregulation during fever and antipyresis. Brain Res Rev 1989;14:143-53.

Keppens S, DeWulf $\mathrm{H}$. The nature of the hepatic receptors involved in vasopressin-induced glycogenolysis. Biochim Biophys Acta 1979;588;63-9.

Kirkland J, Lye M, Goddard C, Vargas E, Davies I. Plasma arginine vasopressin in dehydrated elderly patients. Clin Endocrinol 1984;20:451-6.

Kirkwood TBL. Repair and its evolution: survival versus reproduction. In: Townsend CR, Calow P, eds. Physiological ecology: an evolutionary approach to resource use. Oxford: Blackwell, 1981:165-89.

Kirkwood TBL. Comparative and evolutionary aspects of Iongevity. In: Finch CE, Schneider EL, eds. Handbook of the biology of aging. 2nd edn. New York: Van Nostrand Reinhold, 1985:27-44.

Knigge KM, Piekut DT, Berlove DJ, Junig JT, Melrose PA. Staining of magnocellular neurons of the supraoptic and paraventricular nuclei with vasopressin anti-idiotype antibody: a potential method for receptor immunocytochemistry. Mol Brain Res 1987:2:69-78.

Koob GF, LeMoal M, Gaffori OWJ, Manning M, Sawyer WH, Rivier J, Bloom FE. Arginine vasopressin and a vasopressin antagonist peptide: opposite effects on extinction of active avoidance in rats. Reg Peptides 1981;2:153-63.

Korner PI, West MJ, Shaw J, Uther JB. 'Steady state' properties of the baroreceptor-heart rate reflex in essential hypertension in man. Clin Exp Pharmacol Physiol 1974;1:65-76.

Land H, Grez M, Ruppert S, Schmale H, Richter D. Nucleotide sequence of cloned cDNA encoding bovine arginine vasopressin-neurophysin II precursor. Nature 1982;295:299-303.

Lande S, Witter A, De Wied D. Pituitary peptides. An octapeptide that stimulates conditioned avoidance acquisition in hypophysectomized rats. J Biol Chem 1971;246:2058-62.

Le Moal M, Koob GF, Koda LY, Bloom FE, Manning M, Sawyer WH, Rivier J. Vasopressor receptor antagonist prevents behavioral effects of vasopressin. Nature 1981;291:491-3.

Lewis WH Jr, Alving AS. Changes with age in the renal function in adult men. Am J Physiol 1938;123:500- 15.

Lindeman RD, Lee TD Jr, Yiengst MJ, Shock NW. Influence of age, renal disease, hypertension, diuretics, and calcium on the antidiuretic responses to suboptimal infusions of vasopressin. J Clin Med 1966;68:206-23.

Lowenthal DT, Kim KE, Affrine B, Falkner B. Overview of physiology in senescence. Chest 1983;83:408-9.

Lye $\mathrm{M}$. The milieu interieur and aging. In: Brocklehurst JC, ed. Textbook of geriarric medicine and gerontology. 3rd edn. Edinburgh: Churchill Livingstone, 1985;201-29.

Matsuguchi H, Sharabi FM, Gordon FJ, Johnson AK, Schmid PG. Blood pressure and heart rate responses to microinjection of vasopressin into the nucleus tractus solitarius of the rat. Neuropharmacology 1982;21:68793.

Mazurck MF, Beal MF, Bird ED, Martin JB. Vasopressin in Alzheimer's disease: a study of post mortem brain concentrations. Ann Neurol 1986;20:665-70.

McLean K, O'Neill PA, Davics I. Relationship of plasma osmolality to survival in acutely ill elderly patients. Age Ageing 1990;19:P7.

Mcites J, Goya R, Takahashi S. Why the neuroendocrine system is important in aging processes. Exp Biol 1987;22:1-15.

Meites J. Neuroendocrine basis of aging in the rat. Interdiscipl Topics Geront 1988; vol 24:37-50. 
Messing RB, Sparber SB. Facilitation of appetitively motivated leaming and memory by desglycinamide arginine vasopressin (DG-AVP). Eur J Pharmacol 1983;89:43-51.

Michell RH, Kirk CJ, Billah MM. Hormonal stimulation of phosphatidyl inositol breakdown with particular reference to the hepatic effects of vasopressin. Biochem Soc Trans 1979;7:861-5.

Miller JH, Shock NW. Age differences in renal tubular response to antidiuretic hormone. J Guruntul 1953;8:44650.

Miller M. Influence of aging on vasopressin secrecion and water regulation. In: Schrier RW, ed. Vasopressin. New York: Raven, 1985:249-58.

Miller M. Increased vasopressin secretion: an early manisfestation of aging in the rat. J Gerontol 1987;42:3-7.

Miller M, Moses AM. Radioimmunoassay of urinary antidiuretic hormone with application to the study of the Bratuleboro rat. Endocrinology 1971;88:1389-96.

Moratalla R, Vallejo M, Lightman SL. Vasopressin stimulates inositol phospholipid metabolism in rat medulla oblongata in vivo. Brain Res 1988;450:398-402.

Morgan T, Berliner RW. Permeability of the loop of Henle, vasa recta, and collecting duct to water, urea and sodium. Am J Physiol 1968;215:198-215.

Murphy HM, Wideman $\mathrm{CH}$, Vasopressin deficiency and the modulation of consummatory behavior. Peptides 1991;12:319-22.

Nordmann JJ. Stimulus-secretion coupling. Prog Brain Res 1983;60:281-304.

North WG. Biosynthesis of vasopressin and neurophysins. In: Gash DM, Boer GJ, eds. Vasopressin. Principles and properties. New York: Plenum, 1987:175-209.

North WG, Valtin H, Cheng S, Hardy GR. The neurophysins. Production and turnover. Prog Brain Res 1983;60;217-25.

Nyakas C, Prins AJA, Bohus B. Cardiac responses and behavioral reacuivity to emotional stress in aged rats. Proc 27th Dutch Fed Meet 295, 1986.

Nyakas C, Prins AJA, Bohus B. Age-related alterations in cardiac response to emotional stress: relations to behavioral reactivity in the rat. Physiol Behav 1990;47:273-80.

Ochs AL, Newberry J, Lenhardt ML, Harkins SW. Neural and vestibular aging associated with falls. In: Birren JE, Schaie KW, eds. New York: Van Nostrand Reinhold, 1985:378-99.

Oliver H, Schăfer EA. On the physiological action of extracts of the pituitary body and certain other glandular organs. J Physiol (Lond) 1895;18:277-9.

O'Neill PA. Faragher EB, Davies I, Wears R, McLean KA, Fairweather DS. Reduced survival with increasing plasma osmolality in elderly continuing-care patients. Age Ageing 1990;19:68-71.

Os I, Kjelsen SE, Aakesson I, Skjøtø J, Eide I, Hjermann I, Leren P. Evidence of age-related variation in plasma vasopressin of normotensive men. Scand J Clin Invest 1985;45:263-8.

Penit J, Faure M, Jard S. Vasopressin and angiotensin II receptors in rat aortic smooth muscle cells in culture. Am J Physiol 1983;244:E72-82.

Perry EK, Tomlinson BE, Blessed G, Bergmann K, Gibson PH, Perry RH. Correlation of cholinergic abnormalities with senile plaques and mental test scores in senile dementia. Br Med J 1978;ii:1457-9.

Pfeiffer MA, Weinberg CR, Cook D, Best JD, Rennan A, Halter JB. Differential changes of autonomic nervous system function with age in man. Am J Med 1983;75:249-58.

Phelps CJ, Carlson SW, Gallagher MJ, Sladek CD. Vasopressin in aged rats: longitudinal studies of vasopressin excretion in Sprague-Dawley and Fischer 344 strains. Neurobiol Aging 1989;10:233-9.

Phillips PA, Rolls BJ, Ledingham JGG, Forsling ML, Morton JJ, Crowe MJ, Wollner L. Reduced thirst after water deprivation in healthy elderly men. N Engl J Med 1984;311:753-9.

Piekut DT, Joseph SA. Relationship of CRF-immunostained cells and magnocellular ncurons in the paraventricular nucleus of rat hypothalamus. Peptides 1985;6:873-82.

Pittman QJ, Franklin LG. Vasopressin antagonist in nucleus tractus solitarius/vagal area reduces pressor and tachycardia responses to paraventricular nucleus sumulation in rats. Neurosci Lell 1985;56:155-60.

Pittman QJ, Lawrence D, McLean L. Central effects of arginine vasopressin on blood pressure in rats. Endocrinology 1982;110:1058-60.

Pittman QJ, Malkinson TJ, Kasting NW, Veale WL. Enhanced fever following castration: possible involvement of brain arginine vasopressin. Am J Physiol 1988;254:R513-7. 
Prechel MM, Audhya TK, Schlesinger DH. A seasonal variation in arginine vasotocin immunoactivity in rat pineal glands. Endocrinology 1983;112:1474-8.

Ravid R, Fliers E, Swaab DF, Zurcher C. Changes in vasopressin and testostcrone in the senescent BrownNorway (BN/BiRij) rat. Gerontology 1987;33:87-98.

Refinetti R, Ma HM, Satinoff E. Body temperature rhythms, cold tolerance, and fever in young and old rats of both genders. Exp Gerontol 1990;25:533-43.

Reppert SM, Schwartz WJ, Uhl GR. Arginine vasopressin: a novel peptide rhythm in cerebrospinal fluid. TINS 1987;10:76-80.

Richter D. Biochemistry and biology of vasopressin, oxytocin, and their corresponding neurophysins. In: Smith $\mathrm{CW}, \mathrm{ed}$. Chemistry, biology, and medicine of neurohypophyseal hormones and their analogs. Orlando: Academic Press, 1987:41-72. (In: Udenfriend S, Meienhofer J, eds. The peptides. Analysis, synthesis, biology; vol 8).

Robinson AG, Verbalis JG. Clinical disorders of the neurohypophysis. In: Smith CW, ed. Chemistry,biology, and medicine of neurohypophyseal hormones and their analogs. Orlando: Academic Press, 1987:1-25. (In: Udenfriend S, Meienhofer J, eds. The peptides. Analysis, synthesis, biology; vol 8).

Robertson GL, Athar S. The interaction of blood osmolality and blood volume in regulating plasma vasopressin in man. J Clin Endocrinol Melab 1976;42:613-20.

Rogers J, Bloom FE. Neurotransmitter metabolism and function in the aging central nervous system. In: Finch CE, Schneider EL, eds. Handbook of the biology of aging. 2nd edn. New York: Van Nostrand Reinhold, 1985:645-91. (Birren JE, ed. The handbooks of aging; vol 1).

Roozendaal B, Van Gool WA, Swaab DF, Hoogendijk JE, Mirmiran M. Changes in vasopressin cells of the rat suprachiasmatic nucleus with aging. Brain Res 1987;409:259-64.

Rondeau E, deLima J, Caillens H, Ardaillou R, Vahanian A, Acar J. High plasma antidiuretic hormone in paticnts with cardiac failure: influence of age. Mineral Electrolyte Metab 1982;8:267-74.

Roth KA, Weber E, Barchas JD, Shang D, Shang JK. Science 1983;219:189-91.

Rothbaum DA, Shaw DJ, Angell CS, Shock NW. Age differences in the baroreceptor response of rats. J Gerontol 1974;29:488-92.

Rowe JW, Shock NW, De Fronzo RA. The influence of age on the renal response to water deprivation in man. Nephron 1976;17:270-8.

Rowe JW, Minaker KL, Sparrow D, Robertson GL. Age-related failure of volume pressor mediated vasopressin release. J Clin Endocrinol Metab 1982;54:661-4.

Sachs H, Fawcelt $P$, Takabatake Y, Portanova R. Biosynthesis and release of vasopressin and neurophysin. Rec Progr Horm Res 1969;25:447-91.

Sahgal A, Wright C. A comparison of the effects of vasopressin and oxytocin with amphetamine and chlordiazepoxide on passive avoidance behaviour in rats. Psychopharmacology 1983;80:88-92.

Samis HV Jr. Aging: loss of temporal organization. Perspect Biol Med 1968;3:95-102.

Sara SJ, Barnetl J, Toussaint P. Vasopressin accelerates appetitive discrimination learning and impairs its reversal. Behav Process 1982;7:215-28.

Sasaki S, Imai M. Effects of vasopressin on water and $\mathrm{NaCl}$ transport across the in vitro perfused medullary thick ascending limb of Henle's loop mouse, rat and rabbit kidneys. Pflügers Arch 1980;383:215-21.

Sawchenko PE, Swanson LW. Immunohistochemical identification of neurons in the paraventricular nucleus of the hypothalamus that project to the medulla or to the spinal cord in the rat. J Comp Neurol 1982;205:260-72.

Scharrer E, Scharrer B. Hormones produced by neurosecretory cells. Rec Progr Horm Res 1954;10:183-240.

Shewey LM, Dorsa DM. V1-type vasopressin receptors in rat brain septum: binding characteristics and effects on inositol phospholipid metabolism. J Neuroscience 1988;8:1671-7.

Shimada K, Kitazumi T, Sadakane N, Ogura H, Ozawa T. Age-related changes in baroreflex function, plasma norepinephrine and blood pressure. Hypertension Dallas 1985:7:113-7.

Silverman WD, Aravich PA, Sladek JR Ir, Sladek CD. Physiological and biochemical indices of neurohypophyseal function in the aging Fischer rat. Neuroendocrinology 1990:52:181-90.

Sladek JR Jr, Sladek CD. Anatomical reciprocity between magnocellular peptides and nordrenaline in putative cardiovascular pathways. In: Cross BA, Leng G, eds. The neurohypophysis: structure, function and control. Amsterdam: Elsevier, 1983:437-44. (Progress in Brain Research; vol. 60). 
Sladek CD, McNeill TH, Gregg CM, Blair ML. Vasopressin and renin response to dehydration in aged rats. Neurobiol Aging 1981;2:293-302.

Sodersten $\mathrm{P}$, Henning M, Melin P, Ludin S. Vasopressin alters female sexual behavior by acting on the brain independently of alterations in blood pressure. Nature 1983;301:608-10.

Sofroniew MV. Vasopressin, oxytocin and their related neurophysins. In: Björklund A, Hökfelt T, eds. GABA and neuropeptides in the CNS; par I. Amsterdam: Elsevier, 1985a:93-165. (Handbook of chemical neuroanatomy; vol 4).

Sofroniew MV. Vasopressin- and neurophysin-immunoreactive neurons in the septal region, medial amygdala and locus coeruleus in colchicine-treated rats. Neurosci 1985b;15:347-58.

Sofroniew MV, Schrell U. Evidence for a direct projection from oxytocin and vasopressin neurons in the hypothalamic paraventricular nucleus to the medulla oblongata: immunohistochemical visualization of both the horseradish peroxidase transported and the peptide produced by the same neurons. Neurosci Lelt 1981;22:211-17.

Strehler BL. Time, cells and aging. New York: Academic Press, 1977.

Swaab DF, Fliers E, Hoogendijk JE. Vasopressin in relationship to human aging and dementia. In: Gash DM, Boer GJ. New York: Plenum PTess, 1987:611-25.

Swaab DF, Fliers E, Partiman TS. The suprachiasmatic nucleus of the human brain in relation to sex, age and senile dementia. Brain Res 1985;342:37-44.

Swaab DF, Pool CW, Nijveldt F. Immunofluorescence of vasopressin and oxytocin in the rat hypothalamoneurohypophyseal system. J Neural Transm 1975;36:195-215.

Swann W, Gonzalez CB, Birket SD, Pickering BT. Precursors in the biosynthesis of vasopressin and oxytocin in the rat. $J$ Biochem 1982;408:339-49.

Swanson LW, Sawchenko PE. The paraventricular nucleus of the hypothalamus: cytoarchitectonic subdivisions and organization of projections to the pituitary, dorsal vagal complex and spinal cord as demonstrated by retrograde fluorescence double-labeling methods. J Comp Neurol 1980;194:555-70.

Swanson LW, Sawchenko PE. Hypothalamic integration: organization of the paraventricular and supraoptic nuclei. Ann Rev Neurosci 1983;6:269-324.

Tribollet E, Barberis C, Jard S, Dubois-Dauphin M, Dreifuss JJ. Localization and pharmacological characterization of high affinity binding sites for vasopressin and oxytocin in the rat brain by light microscopic autoradiography. Brain Res 1988;442:105-18.

Trinh-Tran-Tan M-M, Grïnfeld JP, Diaz M, Bankir AAL. ADH-dependent nephron heterogeneity in rats with hereditary hypothalamic diabetes insipidus. Am J Physiol 1981;240:F372-80.

Ullrich KJ, Rumrich G, Fuchs G. Wasserpermeabilităt und transtubulärer Wasserfluss corticaler Nephronabschnitte bei verschiedenen Diuresezuständen. Pflügers Arch 1964:280:99-1 19.

Unger T, Rohmeiss P, Becker H, Ganten D, Lang RE, Petty MA. Sympathetic activation following central vasopressin stimulation in conscious rats. J Hypertens 1984; vol 2 (Suppl 3):25-7.

Unger T, Rohmeiss P, Demmert G, Ganten D, Lang RE, Luft FC. Differential modulation of the baroreceptor reflex by brain and plasma vasopressin. Hypertension Dallas 1986; vol 8 (Suppl II):II-157-62.

Valtin H. Physiological effects of vasopressin on the kidney. In: Gash DM, Bocr GJ, eds. Vasopressin. Principles and properties. New York: Plenum, 1987:369-88.

Van der Woude PF, Goudsmit E, Wierda M. Purba JS. Hofman MA, Bogte H, Swaab DF. Vasopressin cell number in the human paraventricular nucleus increases with aging, but not in Alzheimer's discase. Brain Res 1991 (submitted).

Vandesande F, Dierickx K, De Mey J. Identification of vasopressin-neurophysin producing neurons of the rat suprachiasmatic nuclei. Cell Tissue Res 1975;156:377-80.

Van Gool WA, Mirmiran M. Aging and circadian rhythms. In: Swaab DF, Fliers E, Mirmiran M, Van Gool WA, Van Haren F, eds. Aging of the brain and Alzheimer's disease. Amsterdam: Elsevicr, 1986:255-77. (Progress in brain research; vol 70).

Van Leeuwen FW, Caffe AR. Immunoreactive vasopressin cell bodies in the rat bed nucleus of the stria terminalis. Cell Tissue Res 1983;228:525-34.

Van Leeuwen FW, Wolters P. Light microscopic autoradiographic localization of [ $\left.{ }^{3} \mathrm{H}\right]$ argininc vasopressin binding sites in the rat brain and kidney. Neurosci Lett 1983;41:61-6. 
Van Wimersma Grcidanus TjB, Veldhuis HD. Vasopressin: site of behavioral action and role in human mental performance. Peptides 1985; vol 6 (Suppl 2):177-80.

Van Wimersma Greidanus TjB, Bohus B, De Wied D. The role of vasopressin in memory processes. Amsterdam: Elsevier, 1975a:135-41. (Progress in brain res; vol 42).

Van Wimersma Greidanus TjB, Dogterom J, De Wied D. Intraventricular administration of antivasopressin serum inhibits memory processes. Life Sci 1975b;16:637-44.

Van Wimersma Greidanus TjB, Bohus B, Kovács GL, Versteeg DHG, Burbach JPH, De Wied D. Sites of behavioral and neurochemical action of ACTH-like pepides and of neurohypophyseal hormones. Neurosci Biobehav Rev 1983;7:453-63.

Van Wimersma Greidanus $\Upsilon \mathrm{jB}$, Kroodsma JM, Pot MLH, Stevens M, Maigret C. Neurohypophyseal hormones and excessive grooming behaviour. Eur J Pharmacol 1990;187:1-8.

Verbalis JG, Robinson AG. Neurophysin and vasopressin: newer concepts of secretion and regulation. In: Imura H, ed. The pituitary, comprehensive endocrinolgy series. New York: Raven Press, 1984:307-39.

Vemey EB. The antidiuretic hormone and the factors which determine its release. Proc Roy Soc Lond (Biol) 1947:135:25-106.

von Weizsacker CF. Ageing as a process of evolution. In: Conference on Structural Pathology in DNA and the biology of ageing. Bonn: Deutsche Forschungsgemeinschaft, 1980:11-20.

Vijg J. In: Van Bezooijen CFA, Ravid R, Verhofstad AAJ, eds. From gene to man. Rijswijk: Stichting Gcrontologie en Geriatrie, 1990:IV.

Walford RL. The immunologic theory of aging. Baltimore: Williams and Wilkins, 1969:1-48.

Watts AG. Disturbance of fluid homeostasis leads to temporally and anatomically distinct responses in neuropeptide and tyrosine hydroxylase mRNA levels in the paraventricular and supraoptic nuclei of the rat. Neuroscience 1992;46:859-79.

Wideman $\mathrm{CH}$, Murphy HM. Effects of vasopressin replacement during food-restriction stress. Peptides 1991;12: 285-8.

Williams GC. Pleiotropy, natural selection and the evolution of senescence. Evolution 1957;11:398-411.

Woolhouse HW. The nature of senescence in plants. In: Woolhouse HW, ed. Aspects of the biology of ageing, symposia of the society for expcrimental biology; no XXI. Cambridge: Cambridge University Press, 1967:179-213.

Yamanouchi K, Arai Y. The septum as origin of a lordosis-inhibiting influence in female rats. Physiol Behav 1987:48:351-5.

Zbuzek VK, Wu W. Seasonal variations in vasopressin secretion in rats. Experientia 1979;35:1523-4.

Zbuzek VK, Wu W. Age-related vasopressin changes in rat plasma and the hypothalamo-hypophyseal system. Exp Gcrontol 1982;17:133-8.

Zbuzck VK, Zbuzek V, Wu W. The effect of aging on vasopressin system in Fischer 344 rats. Exp Gerontol $1983 ; 18: 305-11$.

Zicgler MG, Lake CR, Kopin IJ. Plasma noradrenaline increases with age. Nature (Lond) 1976;261:333-5. 


\section{PART ONE}

METHODOLOGICAL SECTION 



\title{
RADIOIMMUNOASSAY OF VASOPRESSIN IN RAT BRAIN AND PLASMA
}

\author{
Dirk Terwel, Marjanne Markerink, Jellemer Jolles
}

\begin{abstract}
A highly sensitive radioimmunoassay (RLA) to measure vasopressin (VP) immunoreactivity in brain tissue and plasma was developed. VP was extracted from brain tissue in a two step procedure. The first step involved extraction with boiling $1 \mathrm{M}$ acetic acid. The second step involved re-extraction from the freeze-dried residue with $50 \%$ ethanol. Immunoreactive material was extracted from plasma by adsorption to Vycor® glass powder. The effects of coating on the separation of free and bound fractions were tested for a dose range of charcoal concentrations. The data provide evidence that coating increases the selectivity of charcoal for the free ligand. Ficoll $400 \otimes$ and serum albumin appeared to be better suited as coating materials than the commonly used dextran. The RIA was internally standardized to correct for methodological variability and nonspecific effects. Internal standards consisted of 1-ml portions of VP-free tissue homogenate or plasma to which known amounts of VP had been added. VP-free plasma was obtained by pre-extraction with glass powder. VP-free tissue homogenate was obtained by homogenization in water and 3 $\mathrm{h}$ incubation at $37{ }^{\circ} \mathrm{C}$ prior to acidification. Displacement of tracer by extracted intemal standards versus the amounts of VP added to the portions of plasma or tissue homogenate served as internal standard curve. The sensitivity of the assay was 0.2 $\mathrm{pmol} / \mathrm{I}$ plasma or $0.4 \mathrm{pmol} / \mathrm{g}$ protein. The present assay does not depend on the availability of a high-affinity antiserum. The brain distribution of VP found agreed with that of immunocytochemical observations. VP largely disappeared from limbic brain structures after castration. An osmotic stimulus or a volume reduction in rats resulted in increases in plasma VP concentration which were linearly related to osmolality and exponentially to volume change.
\end{abstract}

\section{$1 \quad$ Introduction}

\subsection{General aspects of radioimmunoassay}

The introduction of the radioimmunoassay (RIA) by Yalow and Berson (1959) has been of great importance to almost the whole field of clinical and biological sciences. It enables researchers to determine amounts of every biological substance against which an antibody can be raised. In principle, RIA is the comparison of the competition between a known amount of radioiodinated ligand (so-called tracer) and an unknown amount of unlabeled ligand with that between standard amounts of unlabeled and labeled ligand for a known amount of antibody. The binding of tracer is plotted against the known amount of ligand and unknown amounts are determined by interpolation (Fig. 1). The highest sensitivity of the assay is obtained at a concentration of antiserum at which $50 \%$ of tracer is bound. This concentration is determined by serial dilution of antiserum (Fig. 1). As a source of antibodies can be used either serum of immunized rabbits or larger animals, or the culture medium of hybridomas of lymphocytes of immunized mice and myeloma cells.

If other methods of assay are already available RIA is generally more efficient and 

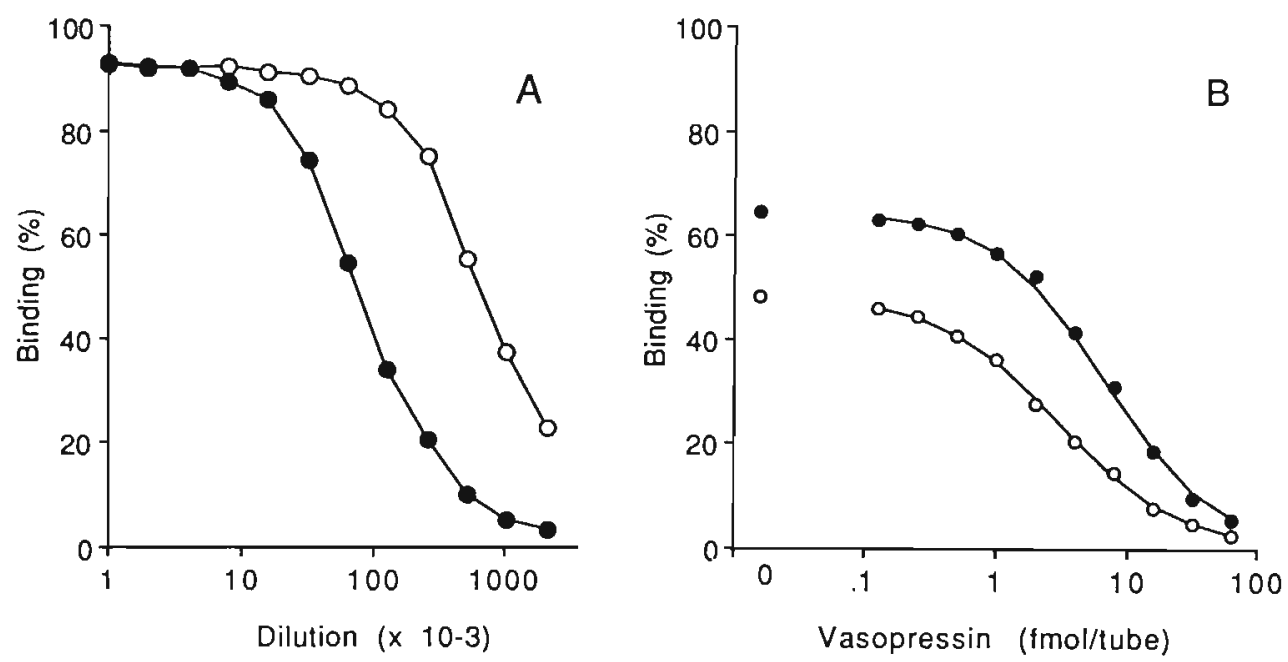

Fig. 1. Antibody dilution curves (A) and standard curves (B) for the VP recognizing antisera W1 ( $)$ and W4 (O). The dilution of antiserum in the standard series was 1:512,000 for Wl and 1:32,000 for W4.

sensitive. The high sensitivity of RIA is especially important for the determination of low concentrations of hormones and neuropeptides present in biological samples. The only alternative to RIA of ten is bioassay - a method by which the magnitude of a physiological response is used to quantitate an amount of hormone. The advantage of RIA over bioassay is that in principle the same technique can be used for the determination of many substances, the only difference being the type of antibody and tracer used. Unlike many techniques in analytical chemistry RIA is not a procedure for the direct determination of a substance. Therefore, when using RIA one must be ever alert of disturbances of the binding of antibody to the ligand by substances present in the sample (nonspecific interference) and crossreaction with substances resembling the substance of interest. The level of nonspecific interference is generally reduced by extraction of the substance of interest prior to RIA. Extraction procedures usually are relatively quick and simple, because they have to be applied to large numbers of samples on a routine base. Consequently, sample extracts still contain many impurities, which may interfere with RIA. In order to anticipate this pitfall, Yalow (1987) states that the effect of interfering substances should be tested and that it must be assured that the milieu of the unknown sample is identical with that of the known standards. As to the problem of the presence of substances resembling the ligand of interest, the use of antibodies with a high affinity for the specific ligand and low crossreactivity with resembling substances is a prerequisite for reliable RIA. Still other problems with RIA have to do with the low antigenicity of the substance of interest, its particular low concentration and biodegradability. 


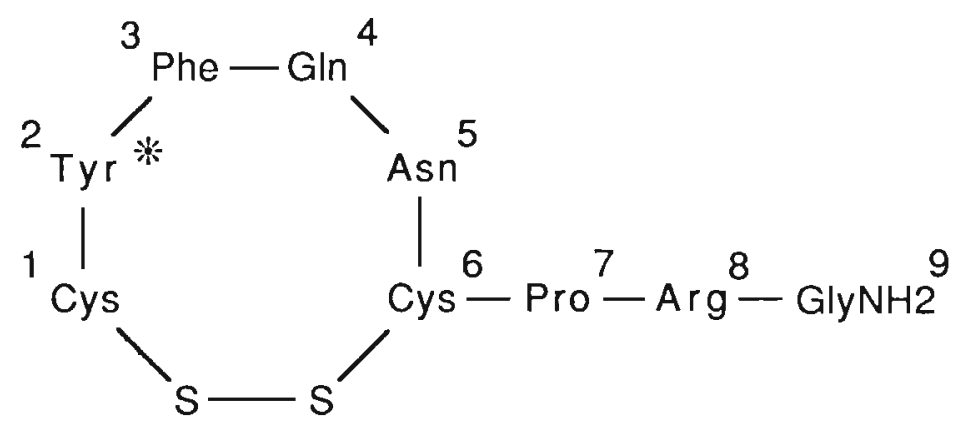

Fig. 2. The 9-aminoacid arginine-vasopressin molecule. Position 1 and 6 are interconnected by a disulphide bridge to form the characteristic ring structure. Tyrosin, which is radioiodinated during the labeling procedure, is indicated by an asterisk. Theoretically, monoclonal antibodies recognize one specific site. The polyclonal antibody subspecies have affinity for different sites of the molecule.

\subsection{RIA of vasopressin}

Arginine-vasopressin is a cyclic nona-aminoacid peptide (Fig. 2). It is transported to the posterior pituitary from the paraventricular and supraoptic nuclei. From the pituitary vasopressin (VP) is secreted into the peripheral circulation, where it exerts antidiuretic and vasopressor actions at kidney tubular cells (Valtin 1987) and arterioles (Schmid and Patel 1987), respectively. Within the central nervous system VP is involved in such diverse processes as temperature regulation (Kasting 1989), central cardiovascular regulation (Unger et al. 1986), learning and memory processes (Van Wimersma Greidảnus and Burbach 1986, Van Wimersma Greidanus and Van Ree 1990), and regulation of aggressive (Ferris and Potegal 1988) and reproductive behavior (Södersten et al. 1983).

Quantitative analysis of concentrations of VP1 has greatly increased our understanding of the various actions of VP. Many RIAs have been reported for the determination of plasma VP concentrations (for e.g. see Baylis and Heath 1977, Beardwell 1971, Johnston 1972, Morton et al. 1975, Robertson et al. 1973, Rooke and Baylis 1982, Skowsky and Fisher 1974). Fewer RIAs have been described for the determination of VP in brain tissue (Brinton et al. 1983, Epstein et al. 1983, Glick and Brownstein 1980, Hawthorn et al. 1980, Hawthorn et al. 1984, Valiquette et al. 1985). Data on concentrations of VP in the brain vary a great deal between various laboratories, and even in reports from one laboratory (Hawthorn et al. 1980, Hawthorn

\footnotetext{
I Wherever concentration of VP is mentioned in this text, concentration of VP immunoreactivity is meant.
} 
et al. 1984), indicating the importance of careful analyzing RIA procedures for the measurement of VP concentrations.

Despite this abundance of reports, the novice who wishes to use a VP RIA is confronted with a number of difficulties. Assays on brain tissue so far are poorly validated and important experimental details are lacking, making it is impossible to use reported protocols. Assays that have to rely on antisera with low affinity towards VP invariably suffer from nonspecific interference (Baylis and Heath 1977, Beardwell 1971, Johnston 1972, Morton et al. 1975), as also reported by Rooke and Baylis (1982). Since antibodies normally raised against VP are of a low affinity, this is a serious drawback.

The purpose of the present study was to provide a means for the reliable RIA of VP in brain tissue and plasma, even with low-affinity antisera. Methods were devised to determine VP concentrations with a low-affinity antiserum with high sensitivity and with internal correction for nonspecific interference and recovery losses. We also evaluated whether coating improves the separation of bound and free fractions with charcoal. Physiological validation was obtained by studying changes in the concentrations of immunoassayable material in plasma in response to osmotic and pressure stimuli and in the brain in response to castration. Along with our own experiences, some of the experiences made by others with the RIA of VP will be discussed. VP RIA is considered particularly difficult, because it involves many of the problems observed in RIA in general. The procedures discussed below therefore are relevant to the RIA of other substances as well.

\section{RIA procedures}

\subsection{Production of antisera against VP}

The antigenicity of small peptides can be enhanced by conjugation to a protein carrier (Goodfriend et al. 1964). Several investigators have raised antibodies against a conjugate of VP and some carrier, either coupled with glutaraldehyde or carbodiimide (Oyama et al. 1971, Skowsky and Fisher 1972). Rabbits that produce a high affinity antibody against VP become polyuric (Morton and Waite 1972). Some of the antibodies raised are susceptible to proteins and salts (Robertson et al. 1970, Robertson et al. 1973, Rooke and Baylis 1983). This warns against the direct measurement of VP in plasma or tissue samples. So far, direct measurement has been attempted with success only once (Fyhrquist et al. 1976). When direct measurement is used, special measures have to be taken to prevent slow degradation of VP. Fyhrquist et al. (1976) used $\varepsilon$-aminocaproic acid for this purpose.

We raised antisera in six male white New Zealand rabbits (code W1-W6). ArginineVP (500 IU/mg pressor activity, obtained from Organon, Oss, the Netherlands) was conjugated to bovine thyroglobulin (Type I, Sigma, St. Louis, USA) with carbodiimide (Sigma) according to Skowsky and Fisher (1972). Briefly, VP (10 mg), thyroglobulin $(50 \mathrm{mg})$ and carbodiimide $(2.3 \mathrm{mg})$ were dissolved in $2 \mathrm{ml}$ bidistilled 

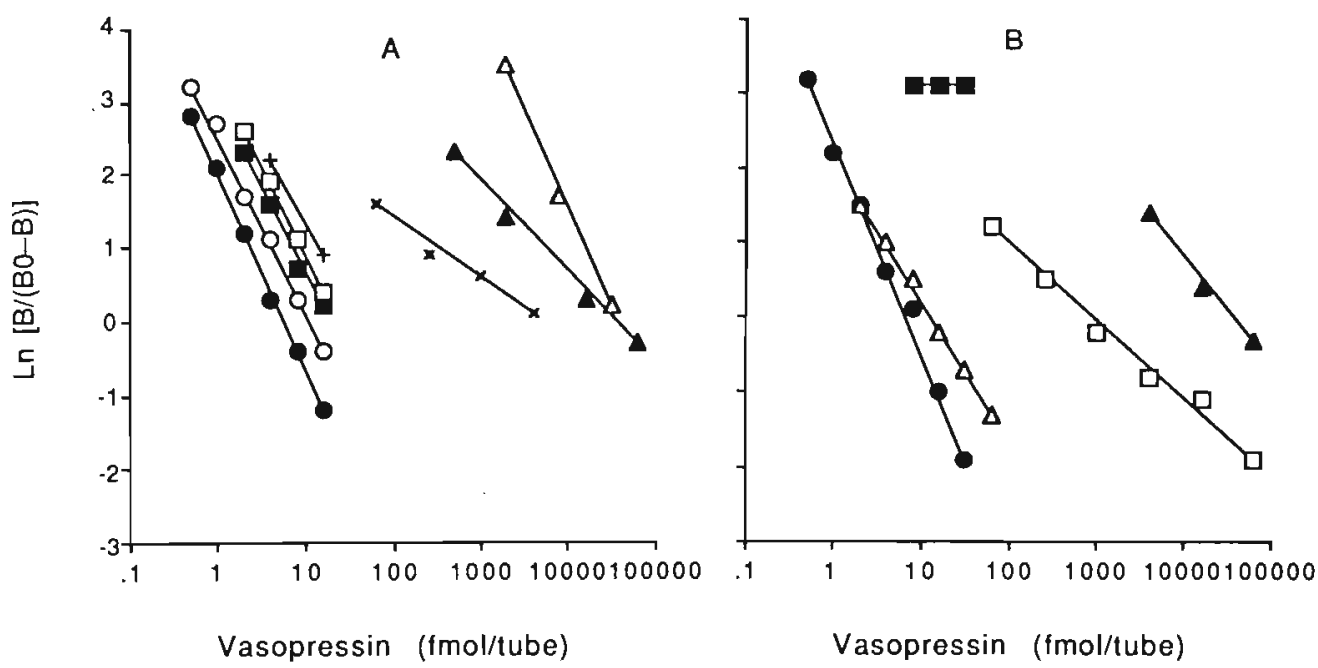

Fig. 3. Crossreactivities of antisera W1 (A) and W4 (B) with VP fragments and oxytocin. Data were logit-log transformed according to Rodbard's equation. Left: VP-(1-9), Q; VP-(2-9), O; VP-(3-9), 口;

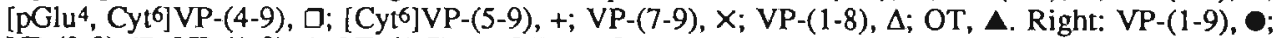
VP-(3-9), $\square$; VP-(1-8), $\Delta$; VP-(1-7), 口; OT, $\Delta$. Crossreactivities on a molar basis (as a percentage of the $\mathrm{ED}_{50}$ of the antiserum for VP-(1-9)) are as follows: W1: VP-(1-9): 56, VP-(3-9): 25, VP-(4-9): 20 , VP-(5-9): 13, VP-(7-9): 0.05, OT: 0.004, VP-(1-8): 0.004; W4: VP-(3-9): 0, VP-(1-8): 56, VP-(1-7): 0.31, OT: 0.004 . VP fragments were kindly provided by Organon (The Netherlands, Oss).

water. The reaction was allowed to proceed at ambient temperature ovemight. The mixture was diluted ten times and freshly emulsified in an equal volume of complete Freund's adjuvant (Difco Laboratories, Detroit, USA). The rabbits were given six injections of $0.5 \mathrm{ml}$ emulsion intramuscularly with 2-week intervals. Thereafter, the animals received booster injections every two months. Small portions of blood of each animal were obtained by puncture of the lateral ear vein one week after each injection and allowed to clot. A freshly prepared aliquot of serum was used to test binding capacity and titer (see Fig. 1). When the titer did not change much anymore the animals were bled by heart puncture. Three of the animals (Wl, -3 and -4 ) produced useful antisera. The specificities of W1 and -4 were determined by comparing the displacement of tracer from the antibody by VP, oxytocin and VP fragments (Fig. 3). It appeared that W1 mainly recognizes the C-terminus of the VP molecule and that W4 has affinity mainly for the $\mathrm{N}$-terminus. Most of the antibodies against VP reported in the literature have a $K_{a}$ near $1011 \mathrm{M}-1$. Few antibodies have been obtained with a $K_{a}$ higher than $10^{12} \mathrm{M}^{-1}$ (Oyama et al. 1971, Rooke and Baylis 1982). It was calculated by Scatchard analysis from data presented in Fig. 1 that W1 has a $K_{a}$ of $1.55 \times 1011 \mathrm{M}$ 1 and that $\mathrm{W} 4$ has $\mathrm{K}_{\mathrm{a}}$ of $10^{11} \mathrm{M}^{-1}$. Antibodies Glick-1, Skowsky-71 and $\mathrm{W} 1$ have been used in numerous studies. 
Table 1. Protocol for the radioiodination of VP

1. Add to a $12 \times 75 \mathrm{~mm}$ glass tube:

- $50 \mu \mathrm{l}$ of $0.5 \mathrm{M}$ phosphate buffer, $\mathrm{pH} 7.5$.

- $10 \mu \mathrm{g}$ peptide dissolved in $10 \mu \mathrm{l} 0.2 \mathrm{M}$ acetic acid,

- $1 \mathrm{mCi}$ Na125I dissolved in $10 \mu \mathrm{l}$ dilute $\mathrm{NaOH}$ solution (Amersham, $\mathrm{UK}$ ),

$-40 \mu \mathrm{g}$ chloramine- $\mathrm{T}$ dissolved in $10 \mu \mathrm{l} 50 \mathrm{mM}$ phosphate, $\mathrm{pH} 7.5$.

2. Mix the contents of the tube with a few finger flicks.

3. After $60 \mathrm{~s}$ add $1 \mathrm{ml}$ of a suspension of $150 \mathrm{~g} / \mathrm{l}$ Dowex $1 \times 8(\mathrm{Cl} \cdot$ form).

4. Transfer the supernatant to a Sephadex G-25 column $(45 \mathrm{~cm} \times 0.9 \mathrm{~cm})$ equilibrated with a solution containing $0.01 \mathrm{M}$ acetic acid and $1.25 \mathrm{~g} / \mathrm{BSA}$. Elute with the same solution at a rate of $12 \mathrm{ml}$ per h.

\subsection{Iodination of VP}

In the radioiodination of VP generally chloramine-T is used as the oxidizing agent of iodine (Greenwood et al. 1963). Despite the fact that Iodogen $\circledast$ has been reported to be a milder oxidant than chloramine-T (Salacinski et al. 1981), which of the two is used does not result in differences in immunogenicity of the tracer. Iodination conditions should be chosen such as to prevent formation of the diiodinated species, since this species is unstable (Husain et al. 1973). The iodination reaction is stopped by scavenging the iodide with Dowex $1 \times 8$ (100-200 mesh in $\mathrm{Cl}-$ form) or another anion-exchange resin (Beardwell 1971, Czernichow et al. 1975, Skowsky et al. 1974) or by the addition of serum albumin (Roth et al. 1966). Metabisulphite can not be used to this end, since it will reduce the disulphide bridge of the VP molecule. After iodination, free iodide, and labeled and unlabeled components in the reaction mixture can be readily separated by high performance liquid chromatography (HPLC) (Seidah et al. 1980), although good separation can also be obtained by chromatography on a Sephadex G-25 column when eluting with low concentrations acetic acid containing $1.25 \mathrm{~g}$ serum albumin per 1 to prevent adsorption of the peptide to the column (Czernichow et al. 1975). Table 1 gives a detailed protocol for the iodination of VP. Rather than going through these quite laborious procedures, to date, iodinated VP of high specific activity can be obtained commercially (Amersham, Buckinghamshire, UK).

\subsection{Preparative procedures}

\subsection{Preparation of plasma}

Plasma of rats is obtained according to the protocol described in Table 2. Blood from human subjects is collected into ice-cold Greiner Vacuette (Greiner, Alphen a/d Rijn, The Netherlands) tubes. Subsequently, the tubes are placed on ice. No further 
Table 2. Plasma sample preparation. All steps should be carried out at $40 \mathrm{C}$, unless indicated otherwise.

1. For reasons of reproducibility, transport animals at least 30 minutes before decapitation to the (quiet) room where they will be decapitated. Experiments should always take place around the same time of day.

2. Add $100 \mu \mathrm{l}$ of a $5 \mathrm{~g} / \mathrm{l}$ heparin (Leo, Ballerup, Denmark) solution to ice-cold polypropylene tubes. Place plastic funnels in the tubes.

3. Take the animals quietly from their cage, decapitate them quickly, and collect trunk blood (8-10 $\mathrm{ml}$ ) into the tubes.

4. Close the tubes and gently mix the blood with the heparin. Place the tubes immediately on ice until centrifugation within $1 \mathrm{~h}$.

5. Centrifuge the tubes $(2000 \mathrm{~g}, 30$ minutes $)$.

6. Collect plasma into tubes and store at $-20^{\circ} \mathrm{C}$ until use.

precautions are needed to prevent degradation of VP, except when blood of pregnant women is collected. Pregnancy plasma contains high levels of cystine-aminopeptidase activity (Tuppy and Nesvadba 1957). This activity can be inhibited sufficiently by addition of $0.1 \mathrm{ml}$ of a solution of $60 \mathrm{~g} / 1,10$-phenanthroline to the tubes (Davison et al. 1984). This inhibitor does not interfere with the RIA.

\subsubsection{Extraction from plasma samples}

VP has been extracted from plasma in various ways. Originally, gel filtration was used to separate VP from other plasma components (Robertson et a1. 1973). This laborious method was soon replaced by extraction with organic solvents, using acetone and petroleum ether (Husain et al. 1973, Robertson et al. 1973) or extraction by adsorption to a solid phase, such as glass powder (Beardwell 1971, Dogterom et al. 1978, Morton et al. 1975, Rooke and Baylis 1982) or diatomaceous earth (Skowsky et al. 1974). Recently, extraction on $\mathrm{C} 18$ or $\mathrm{C} 8$ cartridges has come into use (Bevilacqua et al. 1985, Brownfield et al. 1988, Van de Heijning et al. 1991, La Rochelle et al. 1980). We use either extraction with Vycor glass powder, essentially according to Dogterom et al. (1978), or extraction on Bond Elut C8 cartridges (Analytichem Int, Cambridge, UK) (Van de Heijning et al. 1991). The recovery of extraction of iodinated VP from $2 \mathrm{ml}$ plasma with Vycor was $83 \%$, extraction on Bond Elut C8 cartridges was $96 \%$. Tables 3 and 4 provide protocols for both extraction techniques.

\subsubsection{Dissection of rat brain}

Rat brains can be dissected either at the macrolevel or at the microlevel. Macrodissection is performed with a pair of sharp forceps (Inox No. 7). The brain is

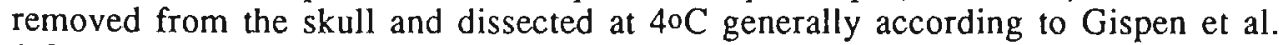
(1972) into a number of different structures, such as the septum, hypothalamus, hippocampus, and medulla oblongata. For the dissection we make use of external landmarks, such as the sulcus rhinalis and chiasma opticum. Internal landmarks, such 
Table 3. Exuraction of VP from plasma samples on solid phase Bond Elut C8-silica columns

1. Connect $\mathrm{C} 8$ columns to a vacuum manifold column processor and activate the columns by passing through $4 \mathrm{ml}$ methanol.

2. Wash with $4 \mathrm{ml} \mathrm{H} \mathrm{H}_{2} \mathrm{O}$. Do not let the columns run dry.

3. Add $4 \mathrm{ml} 0.1 \mathrm{M} \mathrm{HCl}$ to $1-\mathrm{ml}$ acidified (HAc) plasma samples (standards and unknowns).

4. Apply mixtures to the columns. Allow at least 5 minutes for the mixtures to run through.

5. Apply $4 \mathrm{ml} 10 \%(\mathrm{v} / \mathrm{v})$ acetonitrile in $0.1 \%$ trifluoro-acetic acid (TFA) to wash impurities from the columns.

6. Elute with $1.5 \mathrm{ml} 60 \%$ acetonitrile in $0.1 \%$ TFA. Preserve eluates for step 8 .

7. Cleanse the columns with $4 \mathrm{ml} 100 \%$ acetonitrile, $4 \mathrm{ml} 8 \mathrm{M}$ urea and $4 \mathrm{ml} \mathrm{H}_{2} \mathrm{O}$. Columns can be reused up to 20 times.

8. Evaporate the eluates in a Speed Vac Concentrator (Savant). Residues are dissolved and subjected to RIA.

Table 4. Procedure for the extraction of VP from plasma with Vycor. All steps should be carried out at $4{ }^{\circ} \mathrm{C}$, unless indicated otherwise. Use polystyrene tubes resistant to $60 \%$ acetone.

1. Vycor glass powder (mesh 140, Coming Glass Works, New York, USA) should be activated at $700^{\circ} \mathrm{C}$ for at least $24 \mathrm{~h}$ in advance of the experiment. Vycor can be kept indefinitely at $700 \circ \mathrm{C}$.

2. Thaw frozen stocks at $4 \circ \mathrm{C}$. Centrifuge the stocks (2000 $\mathrm{g}, 10$ minutes) to spin coagulated protein down.

3. Pipette samples of $0.5-2 \mathrm{ml}$ from the stocks (standard medium and unknowns) into tubes (preferably in triplicate). Standards and unknowns should have the same volume.

4. Add to the tubes with standard medium $50 \mu \mathrm{l}$ Veronal buffer, containing no - for determination of zero and nonspecific binding - or known amounts of VP $(0.125-64 \mathrm{fmol})$.

5. Add to the tubes $100 \mu \mathrm{l}$ from a constantly stirred suspension containing $2 \mathrm{~g} / \mathrm{V} \mathrm{V}$ cor and Vortex.

6. Let the tubes tumble in a rotary tumbler for 30 minutes.

7. Centrifuge the tubes $(2000 \mathrm{~g}, 10$ minutes).

8. Remove supernatants of the standards by suction. Decant and pool supernatants of the unknowns, and store these at $-20 \propto \mathrm{C}$. This material can be used as internal standard medium in a next extraction procedure.

9. Resuspend Vycor pellets in $0.5 \mathrm{ml} \mathrm{H}_{2} \mathrm{O}$ on a Vortex.

10. Centrifuge at $2000 \mathrm{~g}$ for 10 minutes. Remove supernatants by suction.

11. Resuspend Vycor pellets in $0.5 \mathrm{ml} 1 \mathrm{M} \mathrm{HCl}$.

12. Centrifuge at $2000 \mathrm{~g}$ for 10 minutes. Remove supernatants by suction.

13. Resuspend Vycor pellets in $0.5 \mathrm{ml}$ acetone $/ \mathrm{H}_{2} \mathrm{O}(60: 40, \mathrm{v} / \mathrm{v})$.

14. Let tubes tumble in a rotary tumbler for 30 minutes.

15. Centrifuge at $2000 \mathrm{~g}$ for 10 minutes.

16. Decant acetone $/ \mathrm{H}_{2} \mathrm{O}$ fractions into polystyrene tubes.

17. Vacuum evaporate until dryness in a Speed Vac.

as the anterior commissure and corpus callosum are made visible by a transversal cut at the optic chiasm. Dissected brain structures are put in an Eppendorf vial and stored 
at $-800 \mathrm{C}$. Before and after weighing and before homogenization the tissue samples are kept frozen by keeping the Eppendorf vials afloat in a vessel with liquid nitrogen.

Microdissection is performed by a punch technique. The punch technique was originally developed by Palkovits (1973), but we introduced some practical improvements. Palkovits takes punches from frozen brain slices, whereas we use lyophilized brain slices. The way lyophilized brain slices are prepared is especially important, since in a conventional freeze-drier, brain slices become distorted and cracked. Shape and volume of the brain slices do not change when a $-200 \mathrm{C}$ freezer with a water trapping device is used for lyophilization. The slices obtained are soft and elastic and punches can be made from them easily. Punches from bilateral halves of the same coupes obtained with the old and new punch technique contained identical amounts of VP. Punch needles can be made of stainless steel hypodermic needles (Delvo, Switzerland). Needles are first made blunt end and then sharpened. A short piece of a $10-\mathrm{ml}$ syringe is used as a shaft. Punches are removed from the lumen of the needle with a stainless steel rod. Depending on the size of the nucleus needles of different internal diameters can be chosen.

\subsubsection{Extraction from samples of brain tissue}

Mostly, VP has been extracted from brain tissue by the boiling acetic acid method (Brinton et al. 1983, Epstein et al. 1983, Glick and Brownstein 1980, Valiquette et al. 1985). Some used extraction with Vycor glass powder or elution through Seppak cartridges after the boiling acetic acid method for further purification of the peptide material (Dogterom et al. 1978, Hawthom et al. 1980, Hawthorn et al. 1984). The use of acetic acid in the extraction procedure makes it unnecessary to use enzyme inhibitors to prevent degradation of VP during extraction, since the peptide is degraded by neutral peptidases only (Burbach et al. 1987).

Recovery and binding of iodinated VP after several extraction procedures were determined for comparison. Tissue was homogenized in $1 \mathrm{M}$ acetic or $0.1 \mathrm{M}$ hydrochloric acid in a Wheaton tissue grinder. The homogenates were boiled for 5 minutes and subsequently centrifuged at 50,000 $\mathrm{g}$ for 30 minutes. The supernatants were frozen at $-800 \mathrm{C}$ and evaporated under vacuum (Speed Vac Concentrator, Savant). The residues obtained after acetic acid extraction were resuspended in $1 \mathrm{ml}$ $50 \%$ ethanol (v/v) and insoluble material was spun down (50,000 g, 30 minutes). Supernatants were again evaporated under vacuum. One-milliliter samples of $0.1 \mathrm{M}$ hydrochloric acid supernatants were extracted with Vycor glass powder or passed through Seppak C18 cartridges (Waters Associates, Milford, MA). Samples were passed through cartridges three times. The cartridges were washed with $10 \mathrm{ml} 0.1 \mathrm{M}$ hydrochloric acid. VP was eluted with $4 \mathrm{ml}$ ethanol/0.1 $\mathrm{M} \mathrm{HCl}(60: 40, \mathrm{v} / \mathrm{v})$ in 4 minutes. For details of the extraction of VP from plasma with Vycor see section 2.3.2.

Recovery and binding of tracer after several extraction methods are given in Table 5. Recovery after extraction with $1 \mathrm{M}$ acetic acid from $8 \mathrm{mg}$ tissue was $33.8 \%$. This was quite surprising, since VP is usually extracted from brain tissue in boiling acetic acid. The low recovery of VP is caused by the poor ability of buffer to solubilize VP from the residue obtained after freeze drying, since VP was quantitatively recovered in 
Table 5. Comparison of extraction methods

\begin{tabular}{llll}
\hline Method & $\begin{array}{l}\text { Weight or } \\
\text { volume }\end{array}$ & $\begin{array}{l}\text { Recovery } \\
(\%)\end{array}$ & $\begin{array}{l}\text { Binding } \\
(\%)\end{array}$ \\
\hline no extraction & - & - & 48.1 \\
1 M acetic acid & $8 \mathrm{mg}$ tissue & 34 & 37.0 \\
& $1 \mathrm{mg}$ & 70 & - \\
$1 \mathrm{M}$ acetic acid & $8 \mathrm{mg}$ tissue & 94 & 38.7 \\
$50 \%$ cthanol & $1 \mathrm{mg}$ & 93 & 47.9 \\
$\begin{array}{l}\text { Vycor glass } \\
\text { powder }\end{array}$ & $8 \mathrm{mg}$ tissue & 81 & 34.6 \\
& $2 \mathrm{mI}$ plasma & 83 & 42.2 \\
Seppak C18 & $0.5 \mathrm{mI}$ & 80 & 47.3 \\
\hline
\end{tabular}

Tissue was dissected from neocortex and homogenized in thirty volumes $1 \mathrm{M}$ acetic acid or $0.1 \mathrm{M} \mathrm{HCl}$. To $2 \mathrm{ml}$ plasma or $1 \mathrm{ml}$ tissue homogenate containing 32 $\mathrm{mg}$ tissue $1 \mathrm{fmol}$ iodinated VP dissolved in $50 \mu \mathrm{l}$ buffer was added to follow VP recovery. Binding was determined in tubes containing $50 \mu \mathrm{l}$ extract from $8 \mathrm{mg}$ tissue or from $2 \mathrm{ml}$ plasma.

the supernatant after acetic acid extraction. In studies on the RIA of VP with acetic acid extraction it is not mentioned that the residue obtained after freeze drying in not soluble in buffer. The recovery was greatly increased (to $93.5 \%$ ) by subsequent extraction of the residue with $50 \%$ ethanol. Most of the freeze dried residue was insoluble in 50\% ethanol, so that VP was removed from this material with some selectivity. Other more elaborate procedures after acetic acid extraction (extraction with Vycor or on Seppak) yielded results comparable to extraction with $50 \%$ ethanol. Recovery was virtually indepent of the amount of tissue or plasma volume extracted. Binding decreased with increasing amount of tissue or plasma volume extracted, indicating that the extraction procedures were not able to eliminate all nonspecific interference.

\subsection{Standardization of the RIA for VP}

Extraction of peptides from biological samples tends to co-purify substances that resemble peptides in physico-chemical properties. These substances will interfere with antibody-antigen binding characteristics in many cases, leading to erroneous data if this is not anticipated (Robertson et al. 1973, Rooke and Baylis 1983). Furthermore, 


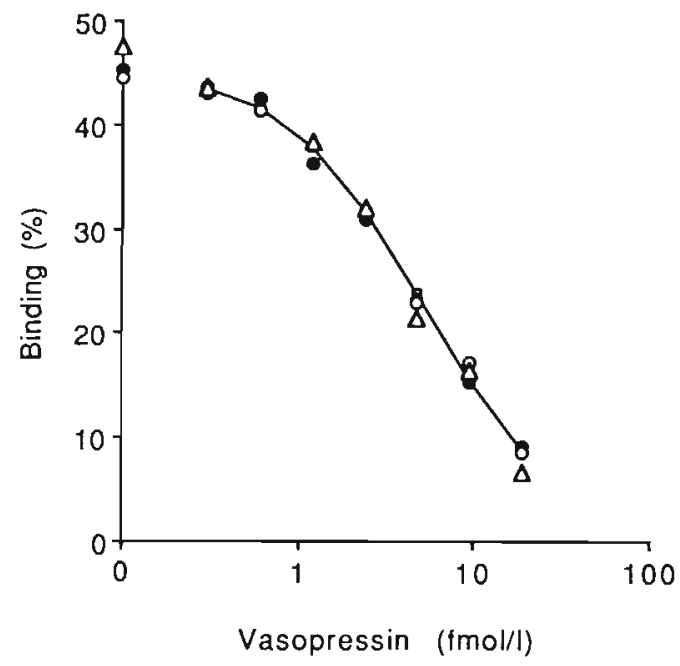

Fig. 4. Displacement of tracer from antibody by internal standard extracts. Plasma from Brattleboro $(\bullet)$ and dehydrated rats $(O)$, and preextracled plasma $(\Delta)$ was used as intemal standard medium.

recovery losses will occur during extraction due to volume losses or inefficiency of the extraction procedure. To correct for nonspecific interference and recovery losses we use internal standardization, that is standard amounts of antigen go through the same extraction procedure as unknown amounts and it is made sure that standard extracts are of the same composition as sample extracts. Displacement by internal standard extracts (portions of tissue homogenate or plasma devoid of the endogenous substance to which known amounts of antigen have been added) serves as an internal standard curve. Often, external standardization is used to relate binding with known amounts of antigen. Standards, then, exist of known amounts of antigen in buffer. External standardization, however, does not correct for nonspecific interference. In our opinion, internal standardization should always be used, if only to assure that nonspecific effects do not occur.

\subsubsection{Standardization of RIA in plasma}

Plasma internal standard medium, i.e.VP-free plasma, can be obtained from Brattleboro rats (which are unable to synthesize VP) or overhydrated rats. Since for the preparation of a single internal standard in triplicate one rat is needed, internal standardization is both not ethical and financially affordable on a routine scale if plasma of Brattleboro or overhydrated rats is used. Therefore, we investigated the possibility to use pre-extracted plasma, left over from the extraction of samples, for the preparation of internal standards. Internal standard extracts of pre-extracted plasma yielded a parallel displacement with those of plasma from Brattleboro rats (Fig. 4), indicating that pre-extracted plasma can indeed be used as an internal standard medium. 
Table 6. Characteristics of standard curves for the RIA of VP in brain tissue and plasma

\begin{tabular}{|c|c|c|c|c|c|c|c|}
\hline Extraction & $\begin{array}{l}\text { Tissue weight } \\
\text { or plasma volume }\end{array}$ & $\begin{array}{l}\text { Binding } \\
(\%)\end{array}$ & $\begin{array}{l}\mathrm{ED}_{\mathrm{so}} \\
\text { (fmol/tube) }\end{array}$ & $\begin{array}{l}\text { Detection } \\
\text { limit } \\
\text { (fmol/tube) }\end{array}$ & $r^{2}$ & $\begin{array}{l}\text { Coef } \\
\text { of va } \\
\text { Intra }\end{array}$ & $\begin{array}{l}\text { ficient } \\
\text { riation (\%) } \\
\text { Inter }\end{array}$ \\
\hline No & & 48.1 & 3.1 & 0.19 & 0.999 & 9.5 & - \\
\hline \multirow[t]{4}{*}{$50 \%$ ethanol } & $1.0 \mathrm{mg}$ & 47.4 & 3.8 & 0.24 & 0.996 & & - \\
\hline & $2.0 \mathrm{mg}$ & 46.0 & 3.8 & 0.25 & 0.997 & 8.9 & - \\
\hline & $4.0 \mathrm{mg}$ & 44.3 & 4.3 & 0.29 & 0.995 & 5.7 & - \\
\hline & $8.0 \mathrm{mg}$ & 41.8 & 5.7 & 0.41 & 0.998 & 10.6 & 12.1 \\
\hline Vycor & $2.00 \mathrm{ml}$ & 42.2 & 5.1 & 0.36 & 0.999 & 7.1 & 8.6 \\
\hline
\end{tabular}

Binding $=($ counts $-\mathrm{NS}) / \mathrm{T}-\mathrm{NS})$, in which counts $=$ nonadsorbed counts, NS $=$ nonspecifically bound counts and $T=$ total counts. Binding data were transformed according to Rodbard's logit-log equation: $\ln \left(B /\left[B_{0}-B\right]\right)=-n \cdot \ln V P+b$, and the parameters of this equation were estimated with the least squares method. From these parameters $\mathrm{ED}_{50}$ was calculated according to $\mathrm{ED}_{50}=\mathrm{eb} / \mathrm{n}$. The limit of detection is defined as the amount of VP at which $B=B_{0}-3 . S D$. Coefficients of determination $\left(r^{2}\right)$ were calculated for the logit-log transformed data. Intra- and inter-assay coefficients of variation ( $\mathrm{SD} /$ mean) are based on 12 determinations on pools of plasma or tissue homogenate containing 4 $\mathrm{pmol} / \mathrm{l}$ synthetic VP.

\subsubsection{Standardization of RIA in tissue}

VP-free tissue homogenates to which known amounts of VP have been added can serve as tissue internal standard solutions. VP free tissue homogenate is obtained by the homogenization of the cortex and cerebellum in bidistilled water and incubation at $37 \circ \mathrm{C}$ for $3 \mathrm{~h}$. After incubation, the homogenate is acidified to $1 \mathrm{M}$ acetic acid. Endogenous VP is degraded by amino- and endopeptidases during incubation (Burbach et al. 1987). It must be assured that the tissue concentration in the unknown samples is the same as in the internal standards. From the intemal standards VP is extracted the same way as VP is extracted from unknown samples. Dependent on the amount of VP expected, VP is extracted from different amounts of tissue. The amount of tissue extracted appeared to affect the internal standard curve. Table 6 summarizes the characteristics of the internal standard curves for different weights of tissue extracted with $1 \mathrm{M}$ acetic acid and 50\% ethanol. Binding was dependent on the weight of tissue extracted. $\mathrm{ED}_{50}$ was also dependent on the weight of tissue extracted. From their characteristics it is clear that internal and external standard curves were not superimposable, indicating that it is necessary to use internal standardization. Increasing the amount of tissue lowered the detection limit per $\mathrm{g}$ protein, but from Table 6 it can be concluded that it is not much use to extract from more than $8 \mathrm{mg}$ tissue when the incubation volume is $100 \mu$ l. 


\subsection{Incubation conditions}

A small incubation volume is used in the present RIA. The advantuge of a small incubation volume is that it increases sensitivity, especially when the antiserum is of low affinity in comparison to the amount of immunoassayable material. The disadvantage is that interfering substances, which extraction did not eliminate, are concentrated. To correct for nonspecific interference with the displacement of tracer from the antibody we routinely use internal standardization (see section 2.4).

A Veronal buffer is used as a diluent and contains $20 \mathrm{mmol} / \mathrm{l}$ 5,5-diethyl barbituric acid (Merck, Germany, Darmstadt), $10 \mathrm{mmol} / \mathrm{l} \mathrm{Na} 2$ EDTA (Sigma), $155 \mathrm{mmol} / \mathrm{NaCl}$, $66 \mu \mathrm{mol} / \mathrm{l} \mathrm{L}$-cystine (Merck) and $4 \mathrm{~g} / \mathrm{l}$ human serum albumin (Sigma). All chemicals used should be of analytical grade. To polystyrene tubes $50 \mu \mathrm{l}$ appropriately diluted tissue- or plasma extract (from standards or unknown samples), $25 \mu \mathrm{l}$ tracer solution $(1 \mathrm{fmol}(2 \mathrm{nCi})$ [3-iodotyrosyl2, arginyl8] vasopressin) and $25 \mu \mathrm{l}$ diluted antiserum W1 (final dilution 1:512,000) or antiserum W4 (final dilution 1:32,000) is added. The tubes are incubated for $72 \mathrm{~h}$. The whole procedure is carried out at $4 \circ \mathrm{C}$. Altematively, tracer is added $24 \mathrm{~h}$ after the addition of antiserum to the plasma- or tissue extract. Delayed tracer addition increases sensitivity 2 -fold (data not shown).

\subsection{Separation of free VP from antibody-bound VP}

Separation of bound and free VP has been achieved by precipitation of the antibody with second antibody or polyethylene glycol, binding of antibody to second antibody coupled to a solid phase (Sac-Cel) and adsorption of the free peptide to coated charcoal. The use of coated charcoal and Sac-Cel is the simplest and both are used at our laboratories; precipitation by second antibody requires another $24 \mathrm{~h}$ before separation can be completed, polyethylene glycol precipitation involves the addition of $\gamma$-globulin in order to assure precipitation.

The principle of coating charcoal to improve separation in RIA is controversial. Herbert et al. (1965) were the first to use charcoal for the separation of antibodybound and free antigen in a RIA. Different materials have been used for the coating of charcoal (Brooker et al. 1979, Herbert et al. 1965, Palmieri et al. 1971). According to Herbert et al. (1965), the coating acts as a molecular seive that permits small molecules to bind to charcoal, rejecting large molecules. It was originally thought that coating molecules bound to the charcoal surface, leaving small pores open. This model was later revised: charcoal particles are porous structures and coating molecules enter large pores and thereby block the entrance of large molecules, whereas small molecules can still enter small pores. However, others felt that dextran only reduces the surface area available for binding (Binoux and Odell 1973, Ekins 1969, Palmieri et al. 1971). The same effect would be obtained by merely reducing the amount of charcoal. It was in fact convincingly demonstrated by Binoux and Odell (1973) that coating did not affect the binding of iodinated hCG and iodinated hCGantibody complex to charcoal in a differential way. Since it is not clear whether this 
Nonspecific

Conditions ${ }^{1}$

\begin{tabular}{lll}
\hline $4 \mathrm{H} / 40 \mathrm{C}$ & 11.1 & 3.1 \\
$4 \mathrm{H} / 40 \mathrm{C}, 7.5 \mathrm{D}$ & 25.7 & 0.6 \\
$4 \mathrm{H} / 40 \mathrm{C}, 45 \mathrm{D}$ & 26.6 & 1.7 \\
$4 \mathrm{H} / 40 \mathrm{C}, 2.5 \mathrm{~F}$ & 43.5 & 2.2 \\
$4 \mathrm{H} / 40 \mathrm{C}, 7.5 \mathrm{~F}$ & 46.2 & 1.9 \\
$4 \mathrm{H} / 40 \mathrm{C}, 22.5 \mathrm{~F}$ & 49.8 & 1.4 \\
$4 \mathrm{H} / 40 \mathrm{C}, 1 \mathrm{~B}$ & 39.3 & 3.1 \\
$4 \mathrm{H} / 40 \mathrm{C}, 4 \mathrm{~B}$ & 47.4 & 3.9 \\
$4 \mathrm{H} / 5 \mathrm{C}$ & 45.6 & 2.3 \\
$1 \mathrm{H} / 40 \mathrm{C}$ & -0.5 & -1.0 \\
$1 \mathrm{H} / 5 \mathrm{C}$ & 37.8 & 3.8 \\
$1 \mathrm{H} / 40 \mathrm{C}, 7.5 \mathrm{~F}$ & 47.1 & 2.2 \\
$1 \mathrm{H} / 40 \mathrm{C}, 4 \mathrm{~B}$ & 47.9 & 3.1 \\
\hline
\end{tabular}

Table 7. Effect of coating on binding in RIA of VP

The code left from the slash refers to the amount of HSA in the incubation medium $(1 \mathrm{H}: 1$ g/l HSA, 4H: 4 g/l HSA). The codes right from the slash refer to the amount of charcoal and the type and amount of coating material in the separation medium (D: dextran, F: Ficoll, B: bovine serum albumin). Numbers indicate $g$ substance per l.

conclusion can be generalized for other separations, we thought it would be worthwhile to re-evaluate the effect of coating on the separation of free and antibodybound VP.

To optimize separation of bound and free ligand the effects of separation conditions on apparent binding was studied. First, the concentration and type of coating material were varied at a fixed concentration of charcoal. Second, the concentration of protein already present in the incubation medium was varied. Third, the concentration of charcoal was varied, keeping other conditions constant. To be sure that the best separation conditions were chosen, the mechanism of charcoal coating was further delineated by determination of the effects of changing the charcoal concentration on binding of antibody and tracer at fixed concentrations of coating material. Furthermore, the effect of variation of the concentration of charcoal with different concentrations of protein in the incubation medium was determined. The determination of antibody binding to charcoal was as follows. Iodinated VP (10 $\mathrm{pmol} / \mathrm{l}$ ) was bound to excess antibody (W1, dilution 1:1000), and the iodinated VPantibody complex was used to follow the binding of antibody to charcoal. Charcoal suspension $(100 \mu \mathrm{l})$ was added to $100 \mu \mathrm{l}$ of a solution of the ligand-antibody complex. The tubes were centrifuged at $2000 \mathrm{~g}$ for 10 minutes and the radioactivity in the pellets was determined.

The effects of charcoal coating on binding were tested with an incubation medium containing $4 \mathrm{~g} / \mathrm{l} \mathrm{HSA}$ and a separation medium containing $40 \mathrm{~g} / \mathrm{l}$ charcoal. With this incubation medium coating of charcoal with dextran, Ficoll or HSA resulted in higher apparent binding (Table 7). Changing the amount of coating material had less effect than the type of coating material used (Table 7; dextran 7.5 and $45 \mathrm{~g} / 1$, Ficoll 2.5, 7.5 and $22.5 \mathrm{~g} / \mathrm{l}$, BSA 1 and $4 \mathrm{~g} / \mathrm{l}$ ). Coating with Ficoll and BSA gave better results than 


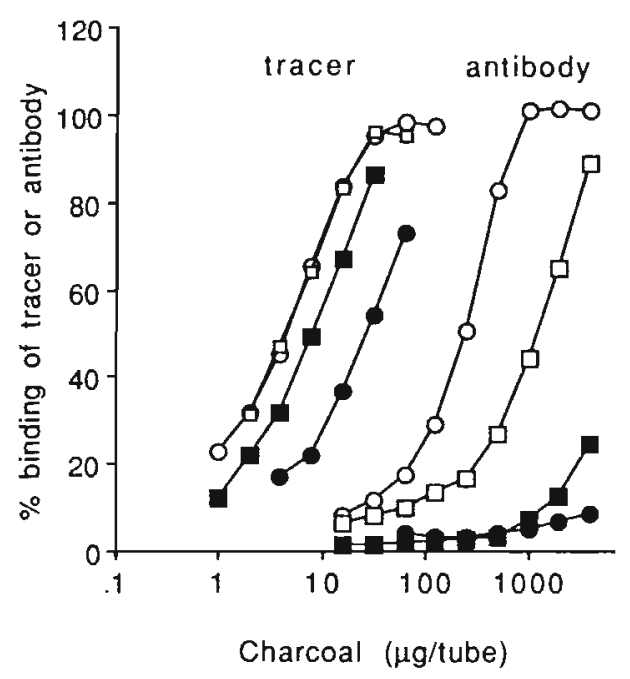

Fig. 5. Binding of iodinated VP and antibody to charcoal as a function of charcoal concentration. The incubation medium contained $0.1 \mathrm{~g} / \mathrm{HSA}$. The separation medium contained no coating material (O), 3.75g/l dextran ( $\square$ ), $1 \mathrm{~g} / 1 \mathrm{HSA}(\boldsymbol{\square})$, $3.75 \mathrm{~g} / 1$ Ficoll (O).

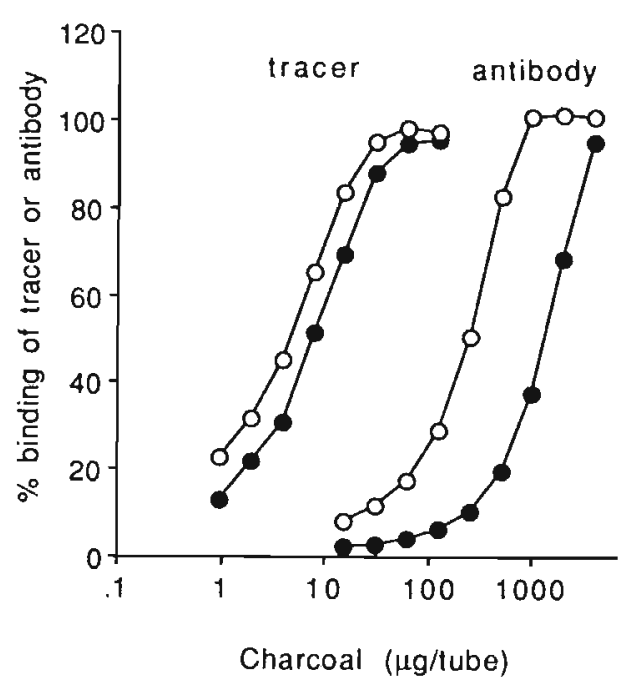

Fig. 6. Binding of antibody and tracer to charcoal as a function of the concentration of coated charcoal. The incubation medium contained $0.1 \mathrm{~g} / 1 \mathrm{HSA}(\mathrm{O})$ or $1 \mathrm{~g} / 1 \mathrm{HSA}(0)$.

coating with dextran. In the absence of coating, a higher apparent binding was observed with low concentrations of charcoal (Table 7;5 and $40 \mathrm{~g} / \mathrm{l}$ charcoal). In the absence of coating, changing the protein concentration of the incubation medium (1 $\mathrm{g} / \mathrm{l}$ versus $4 \mathrm{~g} / \mathrm{l} \mathrm{HSA}$ ) also affected binding, with higher protein concentrations yielding higher binding. Protein concentration had no effect on binding when charcoal was coated with Ficoll or BSA (Table 7).

As it was clear that protein in the incubation medium affected separation, further studies on charcoal coating were performed at low concentrations of protein in the incubation medium. Fig. 5 shows the effects of coating and charcoal concentration on the binding of iodinated VP and HSA to charcoal. VP bound to charcoal at a much lower charcoal concentrations than antibody. Coating with dextran did not influence the affinity of charcoal for VP, whereas the affinitity for antibody decreased at least eightfold. Coating with Ficoll decreased the affinity of charcoal for VP sixfold, but prevented binding of antibody completely in the concentration range tested. Coating with BSA decreased the affinity of charcoal for VP twofold.

To further elucidate the effects of protein in the incubation medium on separation, binding of antibody and tracer as a function of the charcoal concentration was determined at two different buffer protein concentrations (Fig. 6). Increasing the protein concentration of the incubation medium from 0.1 to $1 \mathrm{~g} / \mathrm{l}$ decreased the affinity of the antibody for charcoal more than fourfold. The binding of tracer was also affected by the protein concentration, but only twofold. The use of coated charcoal has 


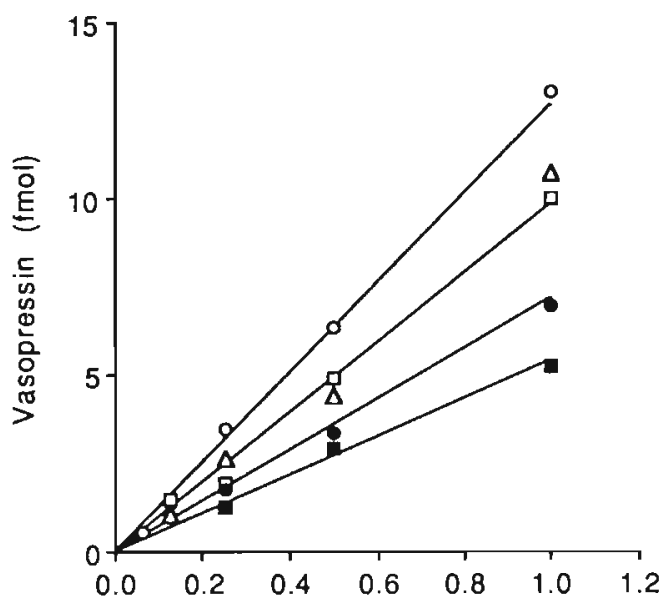

Relative amount of extract
Fig. 7. Quantities of VP, as determined by RIA, in dilutions of extract from plasma $(O)$, thalamus $(\Delta)$, hippocampus $(\square)$, midbrain $(\bullet)$ and medulla oblongata (ם). VP was extracted in triplicate from 1-ml portions plasma of $24 \mathrm{~h}$ waterdeprived male Wistar rats or brain tissue homogenate of nondeprived animals containing $1-8 \mathrm{~g} / \mathrm{l}$ tissue. Extracts were diluted in appropriate standard medium extract.

been criticized by Binoux and Odell (1973). It was argued that coating only reduced the surface area available for binding. The present finding that an increase in binding was obtained by reducing the amount of charcoal suggests that this is how coatings work. However, the observation that the concentration of coating material could be varied without affecting binding a great deal suggests that coating does something more than merely reduce the surface area available for binding. By variating the charcoal concentration we could demonstrate that coating influenced the binding of iodinated VP to charcoal to a lesser extent than the binding of the iodinated VPantibody complex, which provides evidence that coating with charcoal increases the selectivity of charcoal for the free ligand. Binoux and Odell (1973), using the same methods, found that coating did not affect the binding of iodinated $h C G$ and iodinated hCG-antibody complex to charcoal in a differential way. The fact that in the present study such an effect was observed for the separation of free and bound VP indicates that the conclusions drawn with regard to the separation of free and bound hCG are not generally applicable. This is an important observation since it invalidates the criticism of the use of coated charcoal. The effect of changing the protein concentration in the incubation medium on binding indicated that protein acted as an instantaneous coating. By changing the charcoal concentration at different protein concentrations we demonstrated that this was indeed the case, but protein in the incubation medium increased selectivity to a lesser extent than protein in the separation medium. Although satisfactory results were obtained without precoating (coating material in the separation medium), the apparent beneficial effect of precoating is that it renders binding independent of the concentration of charcoal over a wide range. It is important to recognize the effect of protein in the incubation medium on separation, since it may lead to erroneous results when samples are of a different composition than the standard solution. 

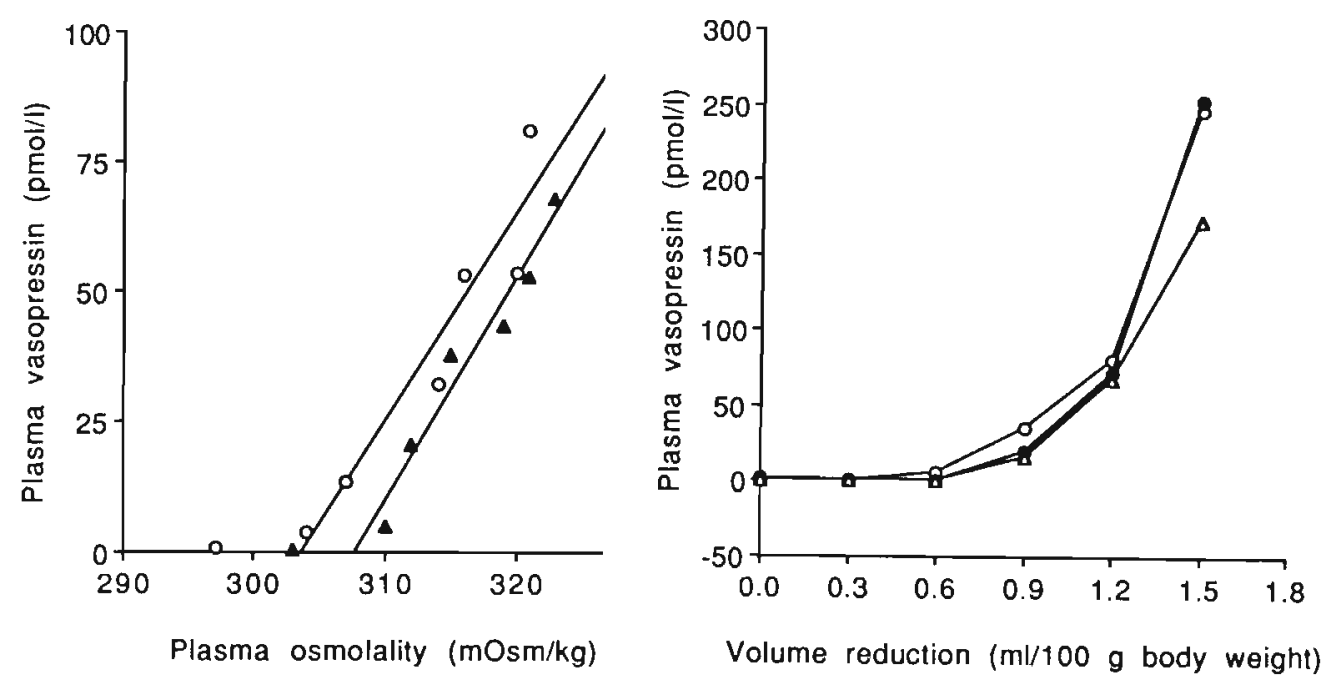

Fig. 8. Responses of male Lewis rats to graded blood volume reduction ( $7 \%$ reduction each 5 minutes), left panel, and salt infusion (intravenous infusion of a $9 \%$ salt solution at a rate of 30 $\mu 1 /$ minute), right panel. Symbols indicate individual animals.

\section{Validation}

The validity of a RIA can be tested in a number of ways. None of these tests is sufficient. Therefore, as many as possible should be performed.

1. A classical criterion for demonstrating immunochemical identity of standard and unknown is represented by superimposibility of their dilution curves or, what amounts to the same thing, the plot of the amount of extract versus amount of VP should be a straight line through the origin. The criterion was met for the immunoreactive material in plasma, and several brains regions (Fig. 7).

2. Synthetic peptide and immunoreactive material should elute in the same fractions during HPLC and account for all the immunoreactivity measured in the RIA.

\begin{tabular}{lll}
\hline & \multicolumn{2}{c}{ Antiserum } \\
\cline { 2 - 3 } Treatment & $\mathrm{W} 1$ & $\mathrm{~W} 4$ \\
\hline none & $1.7 \pm 0.4$ & $1.2 \pm 0.3$ \\
24 h water-deprived & $12.4 \pm 0.3$ & $12.6 \pm 0.3$ \\
\hline
\end{tabular}

Table 8. Plasma VP concentrations (pmol/1 \pm SEM) of nondeprived and water-deprived male Wistar rats, as measured by RIA using antisera W1 and W4. Plasmas of the two groups were pooled each before extraction. Each value is the mean of 5 determinations. 


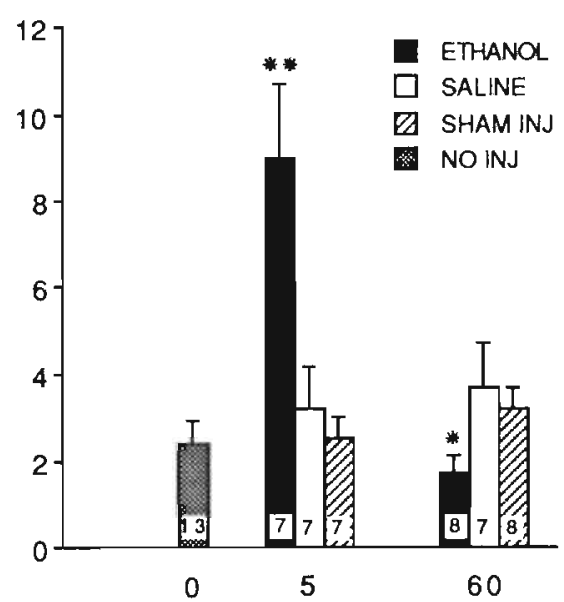

Fig. 9. Mean ( \pm SEM) VP concentrations (pmol/l) in plasma from rats decapitated 5 or 60 minutes after i.p. injection of ethanol $(2 \mathrm{~g} / \mathrm{kg}$ $15 \%(\mathrm{v} / \mathrm{v})$ absolute ethanol in $0.9 \%$ saline), saline, or sham injection. Other rats (0 minutes after treatment) were neither injected nor disturbed until decapitation. ${ }^{*} p<0.05$ compared to sham, ${ }^{* *} p<0.01$ compared to sham, $p<0.05$ compared to saline. Numbers of animals are indicated in bars. (From Colbern et al. 1985.)

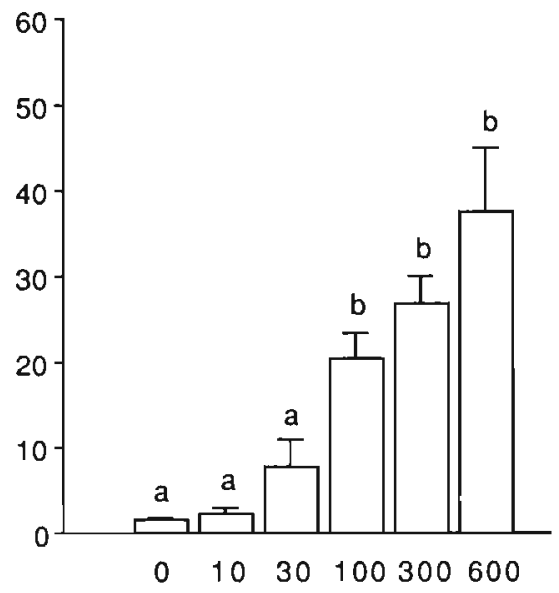

Fig. 10. Plasma VP concentrations (pmol/l \pm SEM) 5 minutes after i.c.v. injection of graded doses histamine. Abscissa: $\mu \mathrm{g}$ histamine. Each group consisted of 7 to 10 animals. One-way ANOVA revealed an effect of dose $\left(\boldsymbol{F}_{5,47}=5.9\right.$, $\mathrm{p}<0.002$ ). Significant different values are indicated by different characters (NewmanKeuls test, p < 0.05). (From Ten Haaf et al. 1986.)

Immunoreactive material in plasma extracts showed identical behavior with synthetic VP (Van de Heijning et al. 1991). However, up to $40 \%$ of the immunoreactive material in extracts of extrahypothalamic brain structures did nor elute with the intact molecule, but with VP fragments (Burbach et al. 1984, Burbach 1986).

3. Physiological or pharmacological manipulations known to affect the concentration of the hormone should also affect the concentration of immunoreactive material. We tested the effects of a number of manipulations on the plasma VP concentration in rats, namely dehydration, salt infusion, hemorrhage, intracerebroventricular (i.c.v.) histamine administration, and intraperitoneal (i.p.) ethanol administration. The first three stimuli are known to increase VP release from the pituitary gland, whereas ethanol suppresses VP release. Dehydration resulted in an increase of the plasma VP concentration (Table 8). Salt infusion resulted in a linear increase in the plasma VP concentration with osmolality and hemorrhage resulted in an exponential increase with volume change (Fig. 8). I.p. ethanol administration had a biphasic effect on plasma VP concentration (Fig. 9), and i.c.v. administration of histamine increased plasma VP concentration dose-dependently (Fig. 10). In conclusion, our findings are in accordance with those from the literature with respect to the effects of various stimuli on plasma VP concentration, the effect of ethanol shortly after administration 
has not been determined by others in rats. It is not yet well established which physiological or experimental manipulations affect concentrations of VP at different brain sites. One physiological manipulation that unequivocally affects VP concentrations in some brain areas is castration (De Vries et al. 1985). As assessed with our assay, castration greatly reduced the concentrations of VP in the septum, amygdala and the hippocampus of male rats (Table 9).

4. Concentrations of VP determined with antisera that recognize different epitopes should be identical, if it is assumed that the VP immunoreactive material consists mainly of the native VP-(1-9). In plasma extracts identical concentrations of $\mathrm{N}$ - and C-terminal immunoreactivity were detected before and after osmotic stimulation (Table 8). The concentrations of N-terminal immunoreactivity were lower in the septum and amygdala (117 \pm 10 and $93 \pm 23 \mathrm{pmol} / \mathrm{g}$ protein, respectively) than the concentrations of C-terminal immunoreactivity (199 \pm 17 and $139 \pm 35 \mathrm{pmol} / \mathrm{g}$ protein, respectively). There were high correlations between $\mathrm{C}$ - and $\mathrm{N}$-terminal immunoreactivity ( $\mathrm{r}$ values 0.89 and 0.99 for the septum and amygdala, respectively; $p$ values $<0.001)$. Together with the HPLC data of Burbach et al. (1984), it can be concluded that in the septum and amygdala a fixed percentage of the VP immunoreactivity exists as C-terminal fragments of VP. No difference was found between $\mathrm{C}$ - and $\mathrm{N}$-terminal immunoreactivity in the posterior pituitary and hypothalamus.

5. Measurements of VP should be similar to data obtained by others. The concentrations of C-terminal immunoreactivity in different brain regions as assessed with antiserum W1, are given in Table 10. Highest concentrations of C-terminal immunoreactivity were found in the pituitary gland, $6.9 \mu \mathrm{mol} / \mathrm{g}$ protein. The concentration of C-terminal immunoreactivity found in the hypothalamus was three orders of magnitude lower than in the pituitary gland, $6.2 \mathrm{nmol} / \mathrm{g}$ protein. The concentration of C-terminal immunoreactivity found in other brain regions were at least two orders of magnitude lower than in the hypothalamus. The concentrations of VP in the cortex and cerebellum were negligible and often below the detection limit (< $0.4 \mathrm{pmol} / \mathrm{g}$ protein). Most (94\%) of the VP in the brain was found in the hypothalamus.

\begin{tabular}{llr} 
Structure & Control & Castrated \\
\hline Septum & $121.5 \pm 5.6$ & $10.7 \pm 1.3^{*}$ \\
Amygdala & $37.8 \pm 3.0$ & $8.9 \pm 0.3^{*}$ \\
Hippocampus & $7.5 \pm 0.6$ & $1.7 \pm 0.3^{*}$ \\
\hline
\end{tabular}

Table 9. Effect of castration on concentrations of VP (pmol/g protein) in extrahypothalamic brain structures of rats. Data are expressed as means \pm SEM. Significant differences are indicated by asterisks $(p<0.001)$. 
Table 10. Concentrations (pmol/g protein) and total contents (pmol/stnucture) of VP in macrodissected brain structures of male Wistar rats. Data are expressed as means \pm SEM. Ten animals were used.

\begin{tabular}{lcc}
\hline Structure & Concentration & Content \\
\hline Posterior & & \\
pituitary $\left(\times 10^{-6}\right)$ & $6.9 \pm 0.4$ & $1.6 \pm 0.1$ \\
Hypothalamus $\left(\times 10^{-3}\right)$ & $6.2 \pm 1.1$ & $54 \pm 9$ \\
Anterior pituitary & $250 \pm 50$ & $274 \pm 59$ \\
Amygdala & $139 \pm 35$ & $1400 \pm 510$ \\
Septum & $199 \pm 17$ & $179 \pm 14$ \\
Pineal gland & $67 \pm 20$ & $11 \pm 3$ \\
Thalamus & $66 \pm 5$ & $641 \pm 43$ \\
Midbrain & $27 \pm 2$ & $277 \pm 15$ \\
Preoptic area & $24 \pm 4$ & $202 \pm 32$ \\
Olfactory bulb & $23 \pm 3$ & $85 \pm 11$ \\
Striatum & $18 \pm 6$ & $73 \pm 24$ \\
Hippocampus & $12 \pm 2$ & $114 \pm 19$ \\
Medulla oblongata & $8.8 \pm 0.8$ & $197 \pm 17$ \\
Cortex & $0.8 \pm 0.3$ & $13 \pm 4$ \\
Cerebellum & $0.6 \pm 0.3$ & $20 \pm 11$ \\
& & \\
\hline
\end{tabular}

The distribution of VP found in the present study was in excellent agreement with immunocytochemical data of De Vries et al. (1985). In a qualitative sense our data also agreed with RIA data reported by others (Brinton et al. 1983, Epstein et al. 1983, Glick and Brownstein 1980, Hawthom et al. 1980, Hawthorn et al. 1984, Valiquette et al. 1985). Absolute comparison, however, was not possible because of the methodological uncertainties of other studies.

6. Recovery of a fixed amount of antigen added to a biological sample should be reproducible and ideally quantitative. For the extraction of VP from plasma two techniques used at our laboratories are described. The extraction on Bond Elut C8 columns yielded a recovery of $96 \%$, but satisfactory results were obtained with extraction with Vycor (a recovery of $83 \%$ ), with the important additional advantage of the concomitant production of plasma internal standard medium (sc. the supernatant of Vycor extracted plasma). For extraction of VP from tissue a simple technique, including a centrifugation step at relatively high g-force and extraction with $50 \%$ ethanol yielded a recovery of $94 \%$. The extraction procedures were highly reproducible, since repeatedly performed extractions did not differ by more than $1 \%$. 7. The coefficient of variation (CV) of repeated determinations of the same sample within one assay and between different assays, is an important parameter for determining the reproducibility of the procedure. CVs were well within the generally accepted range (Table 6). 
RIA of VP is difficult, especially if one wishes to measure basal plasma concentrations. Antibodies with a $\mathrm{K}_{\mathrm{a}}$ much higher than $10^{11} \mathrm{M}^{-1}$ can hardly be raised, whereas basal plasma concentrations are as low as 10-11 $\mathrm{M}$. Rather large volumes have to be concentrated to obtain enough VP for RIA. When working with rat plasma, volumes cannot exceed a few milliliters if one wishes to determine VP concentrations in triplicate. To obtain a sensitive enough assay, we optimized sample preparation, incubation and separation conditions, only use tracer with a high specific activity, and incubate in a small volume. It is possible to measure concentrations of VP as low as $0.2 \mathrm{pmol} / \mathrm{l}$ plasma or $0.4 \mathrm{pmol} / \mathrm{g}$ protein with our assay, or even lower when delayed tracer addition is used. Our assay is as sensitive as the most sensitive assays reported (Robertson et al. 1973, Rooke and Baylis 1982), although we use an antibody that is much less sensitive than those used by others. Our antibody is of a sensitivity normally obtained for anti-VP antibodies. Therefore, the methods described herein are of general importance to the RIA of VP.

Although a number of methods for the determination of VP concentrations in brain tissue have been described, these methods were validated very poorly (Brinton et al. 1983, Glick and Brownstein 1980, Hawthorn et al. 1980). The possible effects of matrix factors were not tested; extraction recoveries were not assessed adequately. Since important experimental details are lacking in reports on the RIA of VP in brain tissue, it is impossible to conclude whether they suffered from nonspecific interference. However, in the present study it was observed that extraction methods adopted from the literature were not able to eliminate nonspecific interference entirely. Moreover, they yielded low recoveries. Therefore, procedures were developed to correct for nonspecific interference and to extract VP from tissue with high recovery, involving internal standardization and extraction with $50 \%$ ethanol after extraction with boiling acetic acid. Several steps in the procedures described may be applicable in the field of immunoassays for (small) peptides. Internal standardization has been used once before by Skowsky et al. (1974) in a RIA of VP. They concluded that they did not need it. They extracted VP from $1 \mathrm{ml}$ plasma and dissolved the residue in a volume of $1.5 \mathrm{ml}$ for RIA. Others concentrated $5-20 \mathrm{ml}$ (Beardwell 1971, Johnston 1972, Morton and Waite 1975) in a volume of $0.5-1.5 \mathrm{ml}$. Their assays probably suffered from nonspecific interference, indicated by the fact that they measured detectable concentrations of VP immunoreactivity in overhydrated subjects, as also stressed by Rooke and Baylis (1982).

Although many criteria can be met for the validity of a RIA, as described in section 3 , no RIA is perfect. Different RIAs (using different antibodies and/or different extraction techniques) for the same ligand will reflect different aspects of the same material. Even if results are not exactly 'right' according to some (hypothetical) absolute reference the RIA is still immensely valuable if it serves to distinguish, on a routine base, between normal and stimulated or decreased levels of the substance under study. 


\section{References}

Baylis $\mathrm{PH}, \mathrm{Heath}$ DA. The development of a radioimmunoassay for the measurement of human plasma arginine vasopressin. Clin Endocrinol 1977;7:91-102.

Beardwell CG. Radioimmunoassay of arginine vasopressin in human plasma. J Clin Endocrinol Metab 1971;33:254-60.

Bevilacqua M, Meroni R, Dagani R, Renesto E, Baruto C. Norbiato G. Role of blood osmolality in the regulation of vasopressin secretion in man: application of a new radioimmunoassay method for vasopressin. $J$ Endocrinol Invest 1985;8:97-101.

Binoux MA, Odell WD. Use of dextran-coated charcoal to separate antibody-bound from free hormone: a critique. J Clin Endocrinol Metab 1973;36:303-10.

Brinton RE, Desmukh PP, Chen A, Davis TP, Hsia S, Yamamura HI. A nonequilibrium 24-hour vasopressin radioimmunoassay: development and basal levels in the rat brain. Brain Res 1983:266:344-7.

Burbach JPH. Proteolytic conversion of oxytocin, vasopressin, and related peptides in the brain. In: Ganten D, Pfaff D, ed. Berlin: Springer-Verlag, 1986:55-90. (Current Topics in Neuroendocrinology; vol 6).

Burbach JPH, Terwel D, Lebouille JLM. Measurement and distribution of vasopressin-converting enzyme activity in rat brain. Biochem Biophys Res Commun 1987;144:726-31.

Burbach JPH, Wang X-C. Ten Haaf JA, De Wied D. Substances resembling C-terminal vasopressin fragments are present in the brain but not in the pituitary gland. Brain Res 1984;306:384-7.

Colbern DH, Ten Haaf JA, Tabakoff B, Van Wimersma Greidanus TjB. Ethanol increases plasma vasopressin shortly after intraperitoneal injection in rats. Life Sci 1985;37:1029-32.

Czemichow P, Merkelbach U, Valloton MB. Radioimmunoassay of [8-arginine]-vasopressin. Acta Endocrinol 1975;80:440-52.

Davison JM, Gilmore EA, Durr J, Robertson GL, Lindheimer MD. Altered osmotic thresholds for vasopressin secretion and thirst in human pregnancy. Am J Physiol 1984;246:F105-9.

De Vries GJ, Buijs RM, Van Leeuwen FW, Caffe AR, Swaab DF. The vasopressinergic innervation of the brain in normal and castrated rats. J Comp Neurol 1985;233:236-54.

Dogterom J, Van Wimersma Greidanus TjB, De Wied D. Vasopressin in cerebrospinal fluid and plasma of man, dog and rat. Am J Physiol 1978;234:E463-7.

Ekins. Charcoal. In: Margoulics, ed. Protein and polypeptide hormones; pan III. Amsterdam: Exerpta Medica Foundation, 1968:633-5. (Exerpta Medica; no 161).

Epstein Y, Castel M, Glick. SM, Sivan N, Ravid R. Changes in hypothalamic and extrahypothalamic vasopressin content of water-deprived rats. Cell Tissue Res 1983;233:99-111.

Ferris CF, Potegal M. Vasopressin receptor blockade in the anterior hypothalamus suppresses agression in hamsters. Physiol Behav 1988:44:235-9.

Fyhrquist F, Wallenius M, Hollemans HJG. Radioimmunoassay of vasopressin in unextracted plasma. Scand J Clin Lab Invest 1976:36:841-7.

Gispen WH, Schouman P, De Kloet ER. Brain RNA and hypophysectomy; a topographical study. Ncurocndocrinology 1972;9:285-96.

Glick S. Brownstein MJ. Vasopressin content of rat brain. Life Sci 1980;27:1103-10.

Goodfriend TL, Levine L, Fasman GD. Antibodies to bradykinin and angiotensin: a use of carbodiimides in immunology. Science 1964:144:1344-6.

Greenwood FC. Hunter WM, Glover IS. The preparation of 131I-labelled human growth hormone with a high specific radioactivity. Biochem J 1963;89:114-23.

Hawthom J, Ang VTY, Jenkins JS. Localization of vasopressin in the rat brain. Brain Res 1980;197:75-81.

Hawthom J, Ang VTY, Jenkins JS. Comparison of the distribution of oxytocin and vasopressin in the rat brain. Brain Res 1984;307:289-94.

Herter V, Lau K-S, Gotlieb W, Bleicher SI. Coated charcoal immunoassay of insulin. J Clin Endocrinol 1965; 25:1375-84.

Husain MK, Fernando N, Shapiro M, Kagan A, Glick SM. Radioimmunoassay of arginine vasopressin in human plasma. J Clin Endocrinol Metab 1973;37:616-25. 
Johnston CI. Radioimmunoassay for plasma antidiuretic hormone. J Endocrinol 1972;52:69-78.

Kasting NW. Criteria for establishing a physiological role for brain peptides. A case in poinc: the role of vasopressin in themoregulation during fever and antipyresis. Brain Res Rev 1989;14:143-53.

LaRochelle FT Jr, North WG, Stern P. A new extraction of arginine vasopressin from blood: the use of octadecasyl-silica. Pflügers Arch 1980;387:79-81.

Morton JJ, Waite MA. The possible relationship between the affinity of arginine vasopressin antibodies and the degree of polyuria and polydipsia in actively immunized rabbits. J Endocrinol 1972;54:523-4.

Morton JJ, Padfield PL, Forsling ML. A radioimmunoassay for plasma arginine-vasopressin in man and dog: application to physiological and pathological states. J Endocrinol 1975;65:411-24.

Oyama SN, Kagan A, Glick SM. Radioimmunoassay of vasopressin: application to unextracted human urine. J Clin Endocrinol Metab 1971;33:739-44.

Palkovits M. Isolated removal of hypothalamic or other brain nuclei of the rat. Brain Res 1973:59:449-50.

Palmieri GMA. Adsorbent techniques for the separation of antibody-bound from free peptide hormones in radioimmunoassay. Horm Metab Res 1971;3:301-5.

Robertson GL, Klein LA, Roth J, Gorden P. Immunoassay of plasma vasopressin in man. Proc Nau Acad Sci USA 1970;66:1298-305.

Robertson GL, Mahr EA, Athar S, Sinha T. Development and clinical application of a new method for the radioimmunoassay of arginine vasopressin in human plasma. J Clin Invest 1973;52:2340-52.

Rooke P, Baylis PH. A new sensitive radioimmunoassay for plasma arginine vasopressin. J Immunoassay 1982;3:115-31.

Rooke P, Baylis PH. Effect of plasma interference on different vasopressin antisera. J Immunoassay 1983;3:13343.

Roth J, Glick SM, KJein LA, Peterson MJ. Specific antibodies to vasopressin in man. J Clin Endocrinol Metab 1966;25:671-5.

Salacinski PRP, McLean C, Sykes JEC, Clement-Jones VV, Lowry PJ. Iodination of proteins, glycoproteins, and peptides using a solid phase oxidizing agent, 1,3,4,6-tetrachloro-3 $\alpha, 6 \alpha$-diphenyl glycoluril (lodogen). Anal Biochem 1981;117:136-46.

Schmid PG, Patel KP. Cardiovascular effects of neurohypophyseal peptides. In: Smith CW, ed. Chemistry, biology, and medicine of neurohypophyseal hormones and their analogs. London: Academic Press, 1987:293-5. (Udenfriend S, Meienhofer J, eds. The peptides. Analysis, synthesis, biology; vol 8).

Seidah NG, Dennis M, Corvol P, Rochemont J, Chretien M. A rapid high-performance liquid chromatography purification method of iodinated polypeptide hormones. Anal Biochem 1980;109:185-91.

Skowsky WR, Fisher DA. The use of thyroglobulin to induce antigenicity to small molecules. J Lab Clin Med 1972;80:134-44.

Skowsky WR, Rosenbloom AA, Fisher DA. Radioimmunoassay measurement of arginine vasopressin in serum: development and apllication. J Clin Endocrinol Metab 1974;38:278-87.

Södersten $P$, Henning M, Melin P, Ludin S. Vasopressin alters female sexual behaviour by acting on the brain independently of alteration in blood pressure. Nature 1983;301:608-10.

Ten Haaf JA, Van Wimersma Greidanus TjB, Maigret C, De Wied D. Effect of the opioid peptide $\beta$-endorphin on the in vivo release of vasopressin in rats under various conditions. Neuroendocrinology 1986;44:102-107.

Tuppy $\mathrm{H}$, Nesvadba A. Über die Aminopeptidaseaktivităt des Schwangerenserums und ihre Beziehung zu dessen Vermögen, Oxytocin zu inaktivieren. Med Chem 1957;88:977-88.

Unger T, Rohmeiss P, Demmert G, Ganten D, Lang RE, Luft FC. Differential modulation of the baroreceptor reflex by brain and plasma vasopressin. Hypertension 1986;8:157-66.

Valtin H. Physiological effects of vasopressin on the kidney. In: Gash DM, Boer GJ, eds. Vasopressin Principles and properties. New York: Plenum Press, 1987:579-610.

Valiquette G, Haldar J, Abrams GM, Nilaver G, Zimmerman EA. Extrahypothalamic neurohypophyscal peptides in the rat central nervous system. Brain Res 1985;331:176-9.

Van de Heijning BJM, Koekkoek-Van de Herik I, Ivány T, Van Wimersma Greidanus TjB. Solid phase extraction of plasma vasopressin: evaluation, validation and application. J Chromatography 1991;565:15971.

Van Wimersma Greidanus TjB, Burbach JPH. Vasopressin and oxytocin their presence in the central nervous 
system and their functional significance in brain processes related to behaviour and memory. Acta Endocrinol 1986; (Suppl 276):85-94.

Van Wimersma Greidanus TjB, Van Ree JM. Behavioral effects of vasopressin. Berlin: Springer-Verlag, 1990: 61-79. (Current Topics in Neuroendocrinology; vol 10).

Yalow RS. Radioimmunoassay: historical aspects and general considerations. In: Radioimmunoassay in basic and clinical pharmacology. Patrono C, Peskar BA, eds. Berlin: Springer-Verlag, 1987:1-6. (In: Born GVR, Cuatrecasas P, Herken H, Schwartz A, eds. Handbook of experimental pharmacology; vol 82).

Yalow RS, Berson SA. Assay of plasma insulin in human subjects by immunological methods. Nature 1959;184:1648-9. 


\section{PART TWO}

PLASMA VASOPRESSIN AND OSMOLALITY IN AGING 



\title{
CHANGES IN PLASMA VASOPRESSIN CONCENTRATION AND PLASMA OSMOLALITY IN RELATION TO AGE AND TIME OF DAY IN THE MALE WISTAR RAT
}

\author{
Dirk Terwel, Jeroen A ten Haaf, Marjanne Markerink, Jellemer Jolles
}

\begin{abstract}
The influence of age on several parameters related to water balance was studied in Wistar rats. Plasma AVP concentration and plasma osmolality were increased at midday in 21-month-old as compared with 3-and 4-month-old rats. Daily water intake per $100 \mathrm{~g}$ body weight was reduced in 14- and 21 -month-old rats as compared with 3- and 4-month-old rats, but total water intake was unaltered. These results suggest that there is a change in water balance in Wistar rats with age. In order to obtain information about the influence of age on daily fluctuations in plasma AVP concentration and osmolality these paramcters were determined in 4month-old Wistar rats sacrificed at $2 \mathrm{~h}$ intervals during the day and in 20- and 31month-old rats sacrificed at $8 \mathrm{~h}$ intervals. Plasma AVP concentrations were low during the light period and high during the dark period in 4-month-old rats. The relationship between plasma osmolality and plasma AVP concentration was dependent on the time of day in 4-month-old rats. Plasma AVP concentrations were higher at 16.00 than at 08.00 and 24.00 in 20-month old rats, and higher at 24.00 than at 08.00 and 16.00 in 31 -month-old rats. In contrast to the plasma AVP concentration during the light period, the average daily AVP concentration (average of plasma AVP concentrations at $08.00,16.00$ and 24.00 ) was increased in 31 -month-old rats only. The relationship between plasma osmolality and plasma AVP concentration was not age-related. The results of the present study suggest that there is a circadian rhythm of plasma AVP concentration in Wistar rats which is age-related but which does not fully correlate with plasma osmolality.
\end{abstract}

\section{Introduction}

Reports about the effects of aging on parameters related to fluid balance in rats are inconsistent. For instance, unaltered as well as reduced concentrations of plasma AVP have been found in 30-month-old Fischer-344 rats (Sladek et al. 1981, Zbuzek et al. 1983). In contrast, 32-month-old Wistar rats (Fliers and Swaab 1983) and 20-23month-old Long-Evans rats (Miller 1985) show increased plasma AVP concentrations. The daily urinary excretion of AVP was found to be increased in 34-month-old BrownNorway rats (Goudsmit et al. 1988). Miller (1985) found increases in urine production in 14- and 16-month-old Long-Evans rats, whereas other authors observed increases in urine production in rats at a more advanced age only, if at all (Beck and Yu 1982, Bengele et al. 1981, Goudsmit et al. 1988, Silverman et al. 1990). However, as these latter studies were performed in other strains of rats, inconsistencies among studies on the influence of aging on the fluid balance in rats may be largely strain dependent. However, other potentially relevant factors have to do with a circannual rhythm of plasma AVP concentration (Zbuzek et al. 1983), with the ages of the rats used, and their health status.

Data on the effect of aging on water balance in Wistar rats are scarce and have 
never been verified since the initial study of Fliers and Swaab (1983). For instance, data on urine or plasma osmolality in relation to aging are not available for Wistar rats, and plasma AVP concentrations have not been determined in middle-aged animals. To date it is recognized that inclusion of middle-aged rats in aging studies is especially important (Coleman et al. 1990, Finch 1991). Moreover, detailed data on several strains of rats are necessary to select a model that best fits the age-related changes in water homeostasis found in humans.

A further point of concern in studies on the influence of age on fluid balance are possible daily fluctuations in plasma AVP concentration and osmolality. It is not clear whether plasma AVP concentration shows a circadian rhythm in rats. Greeley et al. (1982) reported that there is a circadian rhythm in plasma AVP concentrations in Sprague-Dawley rats, whereas Schwartz et al. (1983) found that Long-Evans rats had a constant plasma AVP concentration throughout the day. Greeley et al. (1982) suggested that the daily variation in plasma AVP concentration is regulated by corticosterone, but did not consider other factors, in particular osmolality. In view of the fact that age-related changes in circadian rhythms of hormones have been reported in man as well as in rats (Van Gool and Mirmiran 1986), changes in a circadian rhythm of plasma AVP concentration in relation to age seem possible.

Therefore, the present study was designed to obtain information on the influence of age and time of day on plasma AVP concentration and osmolality in rats. Two separate experiments were performed. The first experiment concerned the influence of age on plasma AVP concentration, plasma osmolality and water intake. The effects of age on daily fluctuations in plasma AVP concentration and osmolality were determined in the second experiment. The results from these experiments are deemed important for a better understanding of alterations in fluid balance with age.

\section{Materials and methods}

In the present sludy male Wistar rats [Bor:WISW(SPFCpb)] were used. The rats were supplied by Winkelmann (Borchen, FRG) at an age of two months and were kept under controlled environmental conditions (a light:dark cycle of $12 \mathrm{~h}$ light and $12 \mathrm{~h}$ darkness (lights on at $07.30 \mathrm{~h}$ ), free access to food and water). The $50 \%$ survival age of the strain of rats used is 28 months. Animals were handled once a day in the two weeks preceding the experiments.

In the first experiment 60 rats were used, divided into four groups of 3-, 4-, 14- and 21 -month-old animals. The rats were housed singly a month in advance of the experiment to allow determination of daily water intake. Water intake and body weights were determined daily in the two weeks preceding the experiment. Rats were sacrificed between 11.00 and 13.00 .

In the second experiment 4-, 20- and 31-month-old rats were used. Groups of 4 animals of 4 months of age were sacrificed at 2-h intervals during the day. Groups of 5-6 animals of 20 or 31 months of age were killed by decapitation at $08.00,16.00$ and 24.00. Trunk blood was collected into chilled heparinized tubes and centrifuged at $1000 \times \mathrm{g}$ for $30 \mathrm{~min}$. Plasma samples were stored at -20 - $\mathrm{C}$ until determination of plasma AVP concentration or kept on ice until determination of plasma osmolality within one hour.

\section{Radioimmunoassay of AVP.}

Plasma AVP concentrations were determined in triplicates. AVP was extracted from plasma samples using heat activated Vycor ${ }^{\circledR}$ glass powder (Coming Glass Works, New York, USA) 
(Dogterom et al. 1978). The recovery of $1 \mathrm{fmol}$ [125I]AVP was about $75 \%$ with this method. Antiserum W1 used in this study has been characterized before (Burbach et al. 1984) and is directed at the C-terminus of the vasopressin molecule. As a diluent a Veronal/HSA buffer, pH 8.0, containing 20 $\mathrm{mmol} / \mathrm{l}$ Veronal, $10 \mathrm{mmol} / \mathrm{EDTA}, 155 \mathrm{mmol} / \mathrm{l} \mathrm{NaCl}, 66 \mu \mathrm{mol} / \mathrm{l}$ cystine and $5 \mathrm{~g} / \mathrm{HSA}$ was used. To polystyrene tubes $50 \mu \mathrm{l}$ appropriately diluted plasma extract, $25 \mu \mathrm{l}$ tracer solution (1 fmol [125ITyr ${ }^{2}$ ]AVP, $2000 \mathrm{Ci} / \mathrm{mmol}$, Amersham) and $25 \mu \mathrm{l} 128 \times 10^{\beta}$ times diluted antiserum were added. After $72 \mathrm{~h}$ of incubation, bound and free ligand were separated with Ficoll-dextran-coated charcoal ( $375 \mu \mathrm{g}$ Ficoll (Pharmacia), $375 \mu \mathrm{g}$ dextran (Sigma) and $4 \mathrm{mg}$ charcoal (Sigma) in $100 \mu \mathrm{l} 50 \mathrm{mmol} / \mathrm{l}$ phosphate, pH 7.4 (Ten Haaf et al. 1992)). The assay was intemally standardized. Intemal standards were prepared from 1-ml porions of AVP-free plasma to which known amounts of AVP (Sigma) had been added. AVP-free plasma was obtained by pre-extraction with Vycor ${ }^{\circledR}$ glass powder. Displacement of tracer by extracted intemal standards versus the amounts of AVP added to the portions of plasma served as an intemal standard curve. The intra- and interassay coefficients of variation were $7.1 \%$ and $8.6 \%$, respectively. Nonspecific binding was $<3 \%$ and binding of tracer by excess antibody was $90 \%$ with our assay. The detection limit was $0.2 \mathrm{fmol} /$ tube.

\section{Osmometry}

Osmolalities were determined in $50 \mu \mathrm{l}$ freshly prepared plasma samples in triplicate by freezingpoint depression, using a cryoscopic osmometer (Osmostat 030; Gonotec. Berlin, FRG). Special care was taken to follow the recommendations of Bevilacqua et al. (1985). The intra-assay coefficient of variation of median values of samples measured in triplicate was $0.3 \%$. The inter-assay coefficient of variation cannot be determined reliably in frozen plasma samples, since freezing has a variable effect on plasma osmolalities. The intra-assay coefficient of variation of median values of the standard measured in triplicate was $0.31 \%$. The apparatus was carefully calibrated before use.

\section{Statistics}

A statistics package was used for statistical analysis (SAS, Cary, USA). The data were subjected to a one factor (age or time of day) or two factor (age $x$ time of day) analysis of variance (GLM procedure with correction for unequal cell sizes), followed by the Duncan-Waller test for post hoc multiple comparisons. When variances were nonhomogeneous, rank scores were used for statistical analysis (Conover and Iman 1981). When appropriate, data on plasma osmolalities and plasma AVP concentrations were analyzed using linear regression analysis and Pearson's correlation test. Relationships between plasma osmolality and plasma AVP concentration were tested for parallelism and coincidence according to the general regression theory (Seber 1977).

Table 1. Parameters related to water homeostasis in male Wistar rats of different ages. Data represent means \pm SEM.

\begin{tabular}{llllll}
$\begin{array}{l}\text { Age } \\
\text { (months) }\end{array}$ & $\begin{array}{l}\text { Weight } \\
(\mathrm{g})\end{array}$ & $\begin{array}{l}\text { Plasma AVP } \\
\text { concentration } \\
(\mathrm{pmol} / \mathrm{l})\end{array}$ & $\begin{array}{l}\text { Plasma } \\
\text { osmolality } \\
(\mathrm{mOsm} / \mathrm{kg})\end{array}$ & $\begin{array}{l}\text { Water intake } \\
(\mathrm{m} / 100 \mathrm{~g} / \\
\text { body weigh/24 h) }\end{array}$ & $\begin{array}{l}\text { Total water } \\
\text { intake } \\
(\mathrm{ml} / 24 \mathrm{~h})\end{array}$ \\
\hline & & & & & $25.3 \pm 0.7 \mathrm{a}$ \\
3 & $272 \pm 3^{\mathrm{a}}$ & $0.57 \pm 0.12^{\mathrm{a}}$ & $293.5 \pm 0.8^{\mathrm{a}}$ & $9.29 \pm 0.26^{\mathrm{a}}$ & $25.4 \pm 0.7^{\mathrm{a}}$ \\
14 & $318 \pm 9^{\mathrm{b}}$ & $0.33 \pm 0.10^{\mathrm{a}}$ & $290.3 \pm 0.7^{\mathrm{b}}$ & $7.98 \pm 0.21 \mathrm{~b}$ & $24.9 \pm 0.7^{\mathrm{a}}$ \\
21 & $465 \pm 10^{\mathrm{c}}$ & $1.12 \pm 0.18 \mathrm{~b}$ & $293.8 \pm 1.1^{\mathrm{a}}$ & $5.36 \pm 0.16^{\mathrm{c}}$ & $26.9 \pm 2.1^{\mathrm{a}}$ \\
\hline
\end{tabular}

Values with different superscripts differ significantly $(p<0.05)$. Values with identical superscript do not differ significantly. 


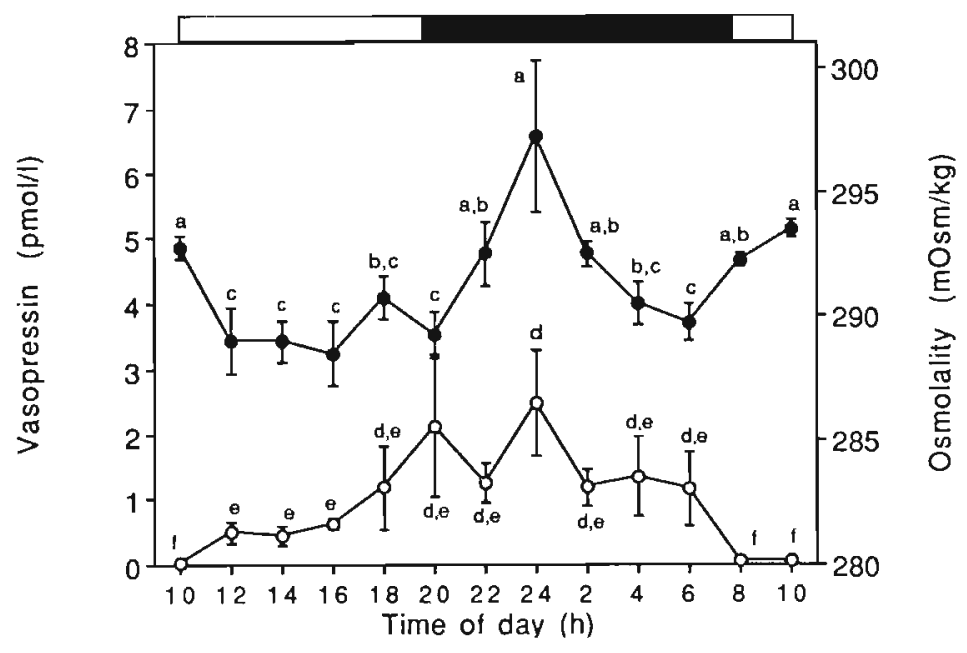

Fig. 1. Concentrations of plasma AVP $(O)$ and osmolality (๑) at $2 \mathrm{~h}$ intervals during the day in 4month-old male Wistar rats. The dark- and light period are indicated by a black and white bar. Data represent means \pm SEM. Values significantly different are indicated by different letters. Values not different are indicated by the same letter.

\section{Results}

In the first experiment it was found that the AVP concentration and osmolality of plasma collected between 11.00 and 13.00 were age-related ( $\mathrm{p}$ values $<0.001$, Table 1). The plasma AVP concentration was increased in 14- and 21-month-old animals compared with 3- and 4-month-old rats. Osmolality was increased in 21-month-old rats as compared to 3- and 4-month-old rats, and in 14- and 21 -month-old rats as compared with 4-month-old rats. Daily water intake was age-dependent $(p<0.001$, Table 1): 4-month-old rats drank less than 3-month-old rats, and 14- and 20-month-old rats drank less than 3-and 4-month-old rats.

In the second experiment it was found that both plasma AVP concentration and osmolality changed during the day in 4-month-old rats ( $p$ values $<0.01$, Fig. 1). The Duncan-Waller test revealed the following differences: the concentration of plasma AVP was lower at 08.00 and 10.00 than at all other time points and was higher at 24.00 than at 08.00 to 16.00 . Osmolality was higher at 10.00 and 24.00 than at the other time points, except for $22.00,02.00$ and 08.00 . Osmolality was lower at 06.00 , 12.00 to 16.00 and 20.00 than at 22.00 to 02.00 and 08.00 to 10.00 .

Furthermore, it was found in the second experiment that plasma AVP concentration was influenced by age and time of day ( $p$ values $<0.001$ and $<0.01$, respectively; Fig. $2 A)$. In addition, there was a significant interaction between these variables ( $p<$ 0.001 ). In 4- and 31-month-old rats, the highest AVP concentration was found at 24.00; in the 20-month-old rats at 16.00. Osmolality was also related to age and time of day ( $\mathrm{p}$ values $<0.01$ and $<0.05$, respectively; Fig. $2 \mathrm{~B}$ ). Osmolality was highest at 


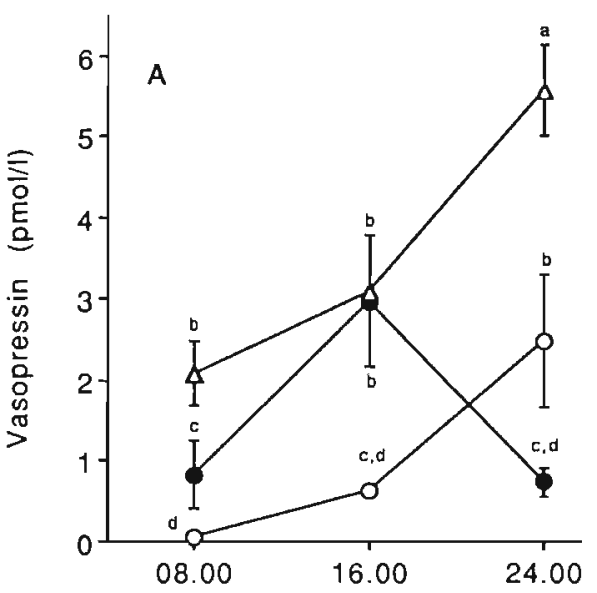

Time of day (h)

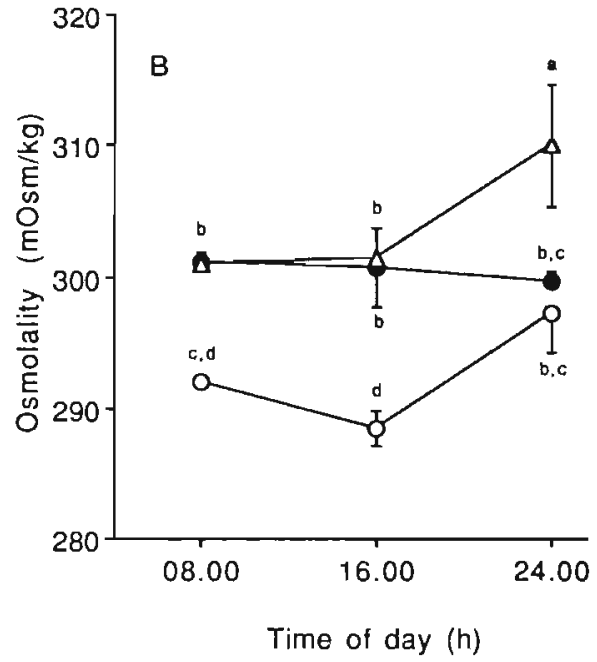

Fig. 2. Concentrations of plasma AVP (A) and plasma osmolality (B) at $8 \mathrm{~h}$ intervals during the day in 4- $(O), 20-(\bullet)$ and 31-month-old $(\Delta)$ male Wistar rats. Data represent means $\pm S E M$. Values significantly different between the time of day, age or time of day and age are indicated by different letters.. Values not different are indicated by the same letter.

24.00 in 4 - and 31 -month-old rats. Osmolality was not dependent on time of day in 20 month-old rats. The average daily plasma AVP concentration and osmolality (averages of data obtained with plasma of rats killed at $0800,16.00$ and 24.00) were age-related ( $\mathrm{p}$ values $<0.001$, Table 2). The average daily AVP concentration was increased in 31-month-old rats as compared with 4- or 20-month-old rats. The average daily osmolality was increased in 20 - and 31 -month-old rats as compared with 4month-old rats. Table 3 gives relationships and correlations between plasma osmolality

Table 2. Average daily plasma AVP concentration and osmolality in male Wistar rats of different ages. Data represent means \pm SEM.

\begin{tabular}{llll}
$\begin{array}{l}\text { Age } \\
\text { (months) }\end{array}$ & $\begin{array}{l}\text { Weight } \\
(\mathrm{g})\end{array}$ & $\begin{array}{l}\text { Plasma osmolality } \\
(\mathrm{mOsm} / \mathrm{kg})\end{array}$ & $\begin{array}{l}\text { Plasma AVP concentration } \\
(\mathrm{pmol} / \mathrm{l})\end{array}$ \\
\hline 4 & $335 \pm 6 \mathrm{a}$ & $292.6 \pm 1.5^{\mathrm{a}}$ & $1.05 \pm 0.40 \mathrm{a}$ \\
20 & $477 \pm 9 \mathrm{~b}$ & $300.6 \pm 1 . \mathrm{b}^{\mathrm{b}}$ & $1.60 \pm 0.36 \mathrm{a}$ \\
31 & $407 \pm 17 \mathrm{c}$ & $303.7 \pm 1.8^{\mathrm{b}}$ & $3.44 \pm 0.50^{\mathrm{b}}$ \\
\hline
\end{tabular}

Values with different superscripts differ significantly $(p<0.05)$. Values with identical superscript do not differ significantly. 
osmolality and plasma AVP concentration for different ages and time points or periods. To obtain more reliable relationships for 4-month-old rats, data from three consecutive time points were taken together (morning: 08.00, 10.00 and 12.00, afternoon: $14.00,16.00$ and 18.00, etc.). Relationships for the 24-h period are based on plasma data of rats killed at $8.00,16.00$ and 24.00 . The interdependence of plasma osmolality and plasma AVP concentration in 4-month-old rats was affected by the time of day (test for parallelism and coincidence, $p$ values $<0.001$ ). Time of day did not affect the interrelation in 20- and 31-month-old rats ( $p$ values $>0.05$ ). Age affected the relationship between the osmolality and AVP concentration of plasma collected between 11.00 and 13.00 (test for parallelism, $p>0.05$; test for coincidence, $p<0.001$ ), but not the average daily relationship ( $p$ values $>0.05$ ).

Table 3. Relationship between plasma osmolality and plasma AVP concentration at different time points or periods of the day in Wistar rats of different ages.

\begin{tabular}{|c|c|c|c|c|c|}
\hline $\begin{array}{l}\text { Age } \\
\text { (months) }\end{array}$ & $\begin{array}{l}\text { Time point } \\
\text { or period }\end{array}$ & Relationship & $N$ & $r$ & $\mathbf{p}$ \\
\hline 4 & morning & $Y=31.3-0.107 \mathrm{X}^{\mathbf{2}}$ & 16 & 0.812 & $<0.01$ \\
\hline 4 & afternoon & $Y=-50.7+0.178 X$ & 12 & 0.492 & ns \\
\hline 4 & evening & $Y=-63.2+0.222 X$ & 12 & 0.917 & $<0.001$ \\
\hline 4 & night & $Y=-86.6+0.302 X$ & 12 & 0.580 & $<0.05$ \\
\hline 20 & $08.00 \mathrm{~h}$ & $Y=-165.8+0.556 X$ & 6 & 0.533 & ns \\
\hline 20 & $16.00 \mathrm{~h}$ & $Y=-46.9+0.163 X$ & 7 & 0.918 & $<0.01$ \\
\hline 20 & $24.00 \mathrm{~h}$ & $\mathrm{Y}=3.79+0.010 \mathrm{X}$ & 6 & 0.055 & ns \\
\hline 31 & $08.00 \mathrm{~h}$ & $Y=-13.6+0.052 X$ & 5 & 0.095 & ns \\
\hline 31 & $16.00 \mathrm{~h}$ & $Y=-89.1+0.306 X$ & 6 & 0.924 & $<0.01$ \\
\hline 31 & $24.00 \mathrm{~h}$ & $Y=-13.9+0.063 X$ & 5 & 0.531 & ns \\
\hline 3 & 11.00 to $13.00 \mathrm{~h}$ & $Y=-27.3+0.095 X$ & 16 & 0.664 & $<0.05$ \\
\hline 4 & 11.00 to $13.00 \mathrm{~h}$ & $Y=-25.7+0.091 X$ & 12 & 0.362 & ns \\
\hline 14 & 11.00 to $13.00 \mathrm{~h}$ & $Y=-15.7+0.057 X$ & 16 & 0.346 & ns \\
\hline 21 & $11.001013 .00 \mathrm{~h}$ & $Y=-43.7+0.154 X$ & 16 & 0.500 & $<0.05$ \\
\hline 4 & 24-h period & $Y=-63.2+0.220 X$ & 12 & 0.816 & $<0.05$ \\
\hline 20 & 24-h period & $Y=-25.7+0.091 X$ & 19 & 0.260 & ns \\
\hline 31 & 24-h period & $Y=-59.6+0.208 X$ & 16 & 0.751 & $<0.05$ \\
\hline
\end{tabular}

$\mathrm{A} Y$ = plasma AVP concentration (pmol/1), $\mathrm{X}=$ plasma osmolality $(\mathrm{mOsm} / \mathrm{kg})$. 


\section{Discussion}

In this study we investigated the changes in plasma AVP concentration and osmolality in male Wistar rats in relation to age and time of day.

Plasma AVP concentrations and plasma osmolalities were increased in 21-monthold rats between 11.00 and 13.00 as compared with 3 - and 4-month-old rats. The relationship between plasma osmolality and plasma AVP concentration at midday seemed to be affected by age (but see also below). Daily water intake per $100 \mathrm{~g}$ body weight diminished with age, but total water intake was unaltered until 21 months of age. Total water intake was not determined in 31-month-old rats in the present study, but in other studies we did not find alterations in total water intake until 32 months of age (unpublished results). In the literature water intake is usually corrected for body weight. This may not be a reliable procedure, since water intake is probably related to food intake, which has been found not to change in Wistar rats with age (Van den Berg et al. 1990). Therefore, total water intake is probably a better functional measure of water homeostasis than water intake per $100 \mathrm{~g}$ body weight. From the above findings it can be concluded that the regulation of fluid balance is affected in Wistar rats at a relatively early age, although the total water intake remains unaltered.

In the second experiment we observed clearcut daily fluctuations in plasma AVP concentration and osmolality in 4-month-old rats. It is likely that nocturnal rises in plasma osmolality and plasma AVP concentration are related to water- and food intake, and resorption of water and nutrients. However, the observation that time of day influenced the relationship between plasma osmolality and plasma AVP concentration in 4-month-old rats indicates that factors other than osmolality are involved in the generation of the rhythm in plasma AVP concentration. It is possible that the secretion of AVP into the blood is regulated by a circadian oscillator. The most important biological clock in mammals is the suprachiasmatic nucleus (Moore 1983). Since neurons of this nucleus secrete AVP into the cerebrospinal fluid in a circadian fashion (Carter and Murphy 1989, Earnest and Sladek 1987, Reppert et al. 1987), it is tempting to speculate that these neurons also secrete AVP into the blood. However, it has not been demonstrated that fibers originating from the suprachiasmatic nucleus terminate abutting blood vessels. Furthermore, the rhythm of AVP concentration in cerebrospinal fluid is opposite to that in blood (Reppert et al. 1987). Therefore the role of the suprachiasmatic nucleus in the generation of the rhythm in plasma AVP concentration is unclear as yet.

Irrespective of absolute values, daily patterns of plasma AVP concentration and plasma osmolality resembled each other in 4- and 31-month-old rats, but were different in 20-month-old rats. This is not surprising if one considers the multiple factors that may influence AVP release with aging, such as (circadian) changes in kidney function, locomotion, and concentrations of neurotransmitters, hormones and receptor densities. Statistical analysis according to the general regression theory did not reveal an effect of time of day on the relationship between plasma osmolality and plasma AVP concentration in 20-month-old rats, although the observation that plasma AVP concentration was related to the time of day and plasma osmolality was not, 
would suggest otherwise. The influence of time of day on the relationship between plasma AVP concentration and plasma osmolality approached statistical significance in 31-month-old rats (test for coincidence, $\mathrm{p}=0.072$ ).

The relationship between plasma osmolality and plasma AVP concentration between 11.00 and 13.00 seemed to be age-related, but the average daily relationship did not. This apparent inconsistency probably reflects the change in the circadian pattern of plasma AVP concentration with age. It can be concluded that osmoreceptor sensitivity does not change in Wistar rats with aging.

In contrast to the plasma AVP concentration during the light period, the average daily AVP concentration was increased in 31-month-old Wistar rats only. This is in accordance with the results of Fliers and Swaab (1983), who obtained morphometrical evidence for an increased neurosecretory activity in the paraventricular nuclei of 32 month-old Wistar rats.

Although the present findings are consistent with the findings of Fliers and Swaab (3), they are not consistent with those of others (Ravid et al. 1987, Silverman et al. 1990, Sladek et al. 1981, Zbuzek and Wu 1982, Zbuzek et al. 1983). Factors that may have contributed to the conflicting data on the fluid balance in aging studies are increased handling stress in old rats (Silverman et al. 1990), a seasonal rhythm in plasma AVP concentration (Zbuzek and Wu 1979, Zbuzek et al. 1983) and strain differences. With respect to our findings the influence of stress can be excluded. Firstly, we handled our rats prior to experimentation. Secondly, plasma osmolality and plasma AVP concentration showed a high correlation in aged rats. This would not have been the case if stress was the cause of the increased plasma AVP concentrations. It can also be excluded that our data are affected by a seasonal rhythm in plasma AVP concentration, since irrespective of the season we always found plasma AVP concentrations of about $0.5 \mathrm{pmol} / \mathrm{l}$ in Wistar rats (measured in Nov, Feb, June and Aug in 9 to 16 animals of 3 to 4 months of age, $p>0.05$, ns; unpublished results). The influence of age on fluid balance seems to vary less within strains than between strains. So it seems reasonable to assume that there are real strain differenccs in this respect.

The present findings with respect to the altered fluid balance in aged Wistar rats, in general, resemble findings made in aged human subjects. Reduced kidney function is generally found in humans. Although we did not measure kidney function, the present findings suggest a reduced sensitivity of the kidney to AVP in aged Wistar rats. Most studies also report increased plasma AVP concentrations in human subjects (Frolkis et al. 1982, Helderman 1978, Kirkland et al. 1984, Os et al. 1985, Rondeau et al. 1982, Rowe et al. 1982), but not increased plasma osmolalities (Helderman et al. 1978, Os et al. 1985). However, plasma osmolalities reported in the literature may not be reliable, because frozen plasma samples were used, and freezing increases the intra-assay coefficient of variation (Bevilacqua et al. 1985). We found a gradual increase in osmolality in healthy human volunteers aged 17 to 60 years (unpublished results) when we used a protocol quite similar to that of Os et al. (1985), who did not find an increase in osmolality. Taken together, it can be concluded that Wistar rats may provide an appropriate model for the study of the influence of aging on fluid balance 
in humans.

In conclusion, the present findings suggest that plasma AVP concentration and plasma osmolality increase with age in male Wistar rats, and that the daily pattern of plasma AVP concentration and plasma osmolality change during the aging process. We did not find a changed relationship between plasma AVP concentration and osmolality with age, lending support to the notion that the primary disturbance in water homeostasis is a kidney deficit as opposed to an increased release of AVP into the blood. The total water intake appeared to be constant in Wistar rats during aging, so that a decreased kidney function is offset by a higher osmolality and a subsequent rise in plasma AVP concentration.

\section{References}

Beck N, Yu BP. Effect of aging on urinary concentrating mechanism and vasopressin-dependent cAMP in rats. Am J Physiol 1982;243:F121-5.

Bengele HH, Mathias RS, Perkins JH, Alexander EA. Urinary concentrating defect in the aged rat. Am J Physiol 1981;240:F147-50.

Bevilacqua M, Meroni R, Dagani R, Renesto E, Baruto C, Norbiato G. Role of blood osmolality in the regulation of vasopressin secretion in man: application of a new radioimmunoassay method for vasopressin. $J$ Endocrinol Invest 1985;8:97-101.

Burbach JPH, Wang X-C, Ten Haaf JA, De Wied D. Substances resembling C-terminal vasopressin fragments are present in the brain but not in the pituitary gland. Brain Res 1984;306:384-7.

Carter DA, Murphy M. Diurnal rhythm of vasopressin mRNA specics in the rat suprachiasmatic nuclcus: independence of neuroendocrine modulation and maintenance in explant culturc. Mol Brain Res 1989;6:2339.

Coleman P, Finch C, Joseph J. The need for multiple time points in aging studies. Neurobiol Aging 1990;11:1-2.

Conover WJ, Iman RL. Rank transformations as a bridge between parametric and nonparametric statistics. The American Statistician 1981;35:124-33.

Dogterom J, Van Wimersma Greidanus TjB, De Wied D. Vasopressin in cerebrospinal fluid and plasma in man, dog, and rat. Am J Physiol 1978;234:E463-7.

Eamest DJ, Sladek CD. Circadian vasopressin release from perifused rat suprachiasmatic explants in vitro: effects of acute stimulation. Brain Res 1987;442:398-402.

Finch CE. Middle age: an evolving frontier in gerontology. Neurobiol Aging 1991;12:1-2.

Fliers E, Swaab DF. Activation of vasopressinergic and oxytocinergic neurons during aging in the Wistar rat. Peptides 1983:4:165-70.

Frolkis VV, Golovchenko SF, Medved VI, Frolkis RA. Vasopressin and cardiovascular system in aging. Gerontology 1982;28:290-302.

Goudsmit E, Fliers E, Swaab DF. Vasopressin and oxytocin excretion in the Brown-Norway rat in relation to ageing, water metabolism and testosterone. Mech Ageing Dev 1988;44:241-52.

Greeley GH Jr, Morris M, Eldridge JC, Kizer JS. A diumal plasma vasopressin rhythm in rats. Life Sci 1982; 31:2843-6.

Helderman JH, Vestal RE, Rowe JW, Tobin JD, Andres R, Robertson GL. The response of arginine vasopressin to intravenous ethanol and hypertonic saline in man: the impact of aging. J Gerontol 1978;33:3947.

Kirkland J, Lye M, Goddard C, Vargas E, Davies I. Plasma arginine vasopressin in dehydrated elderly patients. Clin Endocrinol 1984;20:451-6.

Miller M. Influence of aging on vasopressin secretion and water regulation. In: Schrier RW, ed. Vasopressin. New York: Raven Press, 1985:249-58. 
Moore RY. Organization and function of a central nervous system circadian oscillator: the suprachiasmatic hypothalamic nucleus. Fed Proc 1983;42:2783-9.

Os I, Kjelsen SE, Aakesson I, Skjøı J, Eide I, Hjermann I, Leren P. Evidence of age-related variation in plasma vasopressin of normotensive men. Scand J Clin Invest 1985;45:263-8.

Ravid R, Fliers E, Swaab DF, Zurcher C. Changes in vasopressin and testosterone in the senescent BrownNorway (BN/BiRij) rat. Gerontology 1987;33:87-98.

Reppert SM, Schwartz WJ, Uhl GR. Arginine vasopressin: a novel peptide rhythm in cerebrospinal fluid. TINS 1987:10:76-80.

Rondeau E, deLima J, Caillens H, Ardaillou R, Vahanian A, Acar J. High plasma antidiuretic hormone in patients with cardiac failure: influence of age. Mineral Electrolyte Metab 1982;8:267-74.

Rowe JW, Minaker KL, Sparrow D, Robertson GL. Age-related failure of volume pressure mediated vasopressin relcase. J Clin Endocrinol Metab 1982;54:661-4.

Schwartz WJ, Coleman RJ, Reppert SM. A daily vasopressin rhythm in rat cerebrospinal fluid. Brain Res 1983;263:105-12.

Seber GAF. Straight line regression. In: Seber GAF, ed. Linear regression analysis. New York: Wiley, 1977:177-213.

Silverman WF, Aravich PA, Sladek JR Jr, Sladek CD. Physiological and biochemical indices of neurohypophyseal function in the aging Fischer rat. Neuroendocrinology 1990:52:181-90.

Sladek CD, McNeill TH, Gregg CM, Blair ML, Baggs RB. Vasopressin and renin response to dehydration in aged rats. Neurobiol Aging 1981;2:293-302.

Ten Haaf JA, Terwel D, Van de Heijning HJM, Van Wimersma Greidanus TjB. Radioimmunoassay: a goal or a tool? J Control Rel 1992 (in press).

Van den Berg H, Bode W, Mocking JAJ, Lowik MRH. Effect of aging on vitamin B-6 metabolism and vitamin B-6 needs. In: Van Bezooijen CFA, Ravid R, Verhofstad AAJ, eds. From gene to man. Gerontological research in the Netherlands. Rijswijk: Stichting Gerontologie en Geriatrie, 1990:423-7.

Van Gool WA, Mirmiran M. Aging and circadian rhythms. In: Swaab DF, Fliers E, Van Gool WA, Van Haaren F, eds. Aging of the brain and Alzheimer's disease. Amsterdam: Elsevier, 1986:255-77. (Progress in Brain Research; vol 70).

Zbuzck VK, Wu W. Seasonal variations in vasopressin secretion in rats. Experientia 1979;35:1523-4.

Zbuzek VK, Wu, W. Age-related vasopressin changes in rat plasma and the hypothalamo-hypophysial system. Exp Gerontol 1982;17:133-8.

Zbuzek VK, Zbuzck V, Wu W. The effect of aging on vasopressin system in Fischer 344 rats. Exp Gerontol 1983;18:305-11. 


\title{
OSMORECEPTOR SENSITIVITY IS REDUCED IN OLD MALE LEWIS RATS
}

\author{
Dirk Terwel, Marjanne Markerink, Jellemer Jolles
}

\begin{abstract}
Kidney dysfunction has been observed in aged rats, the primary cause of which may reside in the kidney itself or in the hypothalamus. The latter possibility is suggested by the increased release of vasopressin (VP) in response to salt infusion in humans. The changed relation between plasma osmolality and plasma VP concentration has never been verified in an animal model. We therefore infused a salt solution into adult and aged rats, and measured plasma VP concentration by radioimmunoassay and osmolality by freezing-point depression. Basal plasma VP concentrations and osmolality were not altered in aged Lewis rats as compared with adult animals, and a significant correlation between these parameters was only observed in adult animals. Total water intake was unchanged in aged Lewis rats, but was reduced per $100 \mathrm{~g}$ body weight. Thus, under basal conditions there were no overt disturbances in water homeostasis in aged animals. Infusion of a salt solution resulted in a linear increase in plasma osmolality in both adult and aged rats. Plasma osmolality increased more with time in aged animals than in adult animals. This finding is interpreted in terms of an age-related difference in kidney function during salt infusion. Osmoreceptor sensitivity appeared to be decreased by approximately $50 \%$ in aged rats at relatively low osmolalities. There was no age-related difference in osmoreceptor sensitivity at higher osmolalities. This may be related to changes in autonomic regulation in aged rats, as has been reported previously.
\end{abstract}

\section{Introduction}

Aging in rats is accompanied by changes in water homeostasis. The precise nature of these changes appears to be strain-dependent (see Aravich and Sladek (1987) for a review). For instance, overt kidney dysfunction is already apparent in 7-month-old Long-Evans rats (Miller 1987), whereas the reduced concentrating ability of the kidneys of Fischer 344 rats is only observed at 30 months of age (Beck and Yu 1982, Bengele et al. 1981). In several strains of rats plasma VP concentrations have been observed to increase with age [Long-Evans (Miller 1985), Wistar (Terwel et al. 1992), Brown-Norway (Terwel et al., unpublished observation)]. In Fischer 344 rats, however, no change in plasma VP concentration has been observed with age (Silverman et al. 1990). An inability to release sufficient VP has been observed in Fischer 344 rats during water deprivation (Sladek et al. 1981). This reduced release of VP could reflect a decreased osmoreceptor sensitivity or insufficient synthesis of VP. In humans, an increased osmoreceptor sensitivity has been observed with age (Helderman et al. 1978). Surprisingly, osmoreceptor sensitivity in relation to age has never been investigated in rats. Since alterations in osmoreceptor sensitivity may be important determinants in the changes of water homeostasis in rats with age (see Miller 1985 for a discussion), we determined the effects of salt infusion on plasma VP concentration in 12-and 28-month-old Lewis rats. 


\section{Materials and methods}

\section{Animals}

In the present study male Lewis rats (LEW/CrlBR) of 12 and 28 months of age were used. The rats were bred and kept in our own facilities and had free access to food and water. The temperature of the animal house was approximately $21{ }^{\circ} \mathrm{C}$ and the humidity was $55 \%$. Lights were on from 09.00 to 21.00 . The $50 \%$ survival age of this rat strain is $28-30$ months. Therefore the 28 -month-old rats used can be considered senescent.

Animals were anesthetized with Nembutal $@(60 \mathrm{mg} / \mathrm{kg}$ pentobarbital, $0.1 \mathrm{ml} / 100 \mathrm{~g}$ body weight), and polyethylene cannulas (ID $0.28 \mathrm{~mm}$ OD $0.61 \mathrm{~mm}$ ) were inserted into the femoral artery and the contralateral femoral vein. Cannulas were exteriorized and secured at the back of the neck. The animals were allowed to recover from surgery for $24 \mathrm{~h}$ during which time cannulas were flushed twice with $0.25 \mathrm{ml}$ heparin solution. The indwelling cannulas were extended with polyethylene tubing (L $0.5 \mathrm{~m}$, ID $0.75 \mathrm{~mm}$, OD $1.45 \mathrm{~mm}$ ) for infusion of salt solution through the femoral vein and blood sampling through the femoral artery. A blood sample of $1 \mathrm{ml}$ was withdrawn by means of a syringe, and then a $9 \%$ salt solution was infused at a rate of $30 \mu \mathrm{l} / \mathrm{minute}$. Every 10 minutes a $1-\mathrm{ml}$ blood sample was taken. Blood samples were immediately centrifuged, and plasma samples were taken for the determination of VP concentration. Plasma was replaced with donor plasma and blood cells were resuspended. Blood samples were heated to $37^{\circ} \mathrm{C}$ and retumed to the animals between samplings.

\section{$V P$ radioimmunoassay}

The VP radioimmunoassay was carried out as described previously with some slight modifications (Ten Haaf et al. 1992). VP was extracted from plasma with heat-activated Vycor® glass powder. To $250 \mu \mathrm{l}$ plasma sample was added $50 \mu \mathrm{l}$ of a suspension containing $20 \mathrm{~g} / \mathrm{l}$ glass powder. The extraction was as reported previously (Ten Haaf et al. 1992). The radioimmunoassay was internally standardized. Internal standards were prepared from $250-\mu l$ portions of VP-free plasma to which known amounts of VP (Sigma, St Louis, USA) had been added. VP-free plasma was obtained by preextraction with $V y c o r ß)$ glass powder. Displacement of tracer by extracted internal standards versus the amounts of VP added to the portions of plasma served as an intemal standard curve. The intra- and interassay coefficients of variation were $7.1 \%$ and $8.6 \%$, respectively. Nonspecific binding was less than $3 \%$, and binding of tracer by excess antibody was more than $90 \%$. The detection limit was 0.2 fmol/tube.

\section{Osmometry}

Osmolality was determined in triplicate by freezing-point depression in $50 \mu$ freshly prepared plasma samples, using a cryoscopic osmometer (Osmostat 030; Gonotec, Berlin, FRG). Special care was taken to follow the recommendations of Bevilacqua et al. (1985). The intra-assay coefficient of variation of median values of samples measured in triplicate was $0.18 \%$. The interassay coefficient of variation of median values of the standard measured in triplicate was $0.31 \%$. The apparatus was carefully calibrated before use.

\section{Statistics}

Data on the increase in osmolality with infusion time were analyzed by a one-factorial (age) analysis of variance on the values averaged over all time points (general mean) and on the orthogonal trend components calculated over all time points. The general mean evaluates whether there is a difference in the overall increase in osmolality. The orthogonal trend components define dimensions in terms of which differences in the shape of curves can be described (Winer 1971). Further analyses was carried out with the Bonferroni t-test to determine the source of the detected significance in the analysis of variance. When appropriate, Student's t-test was used for comparison of groups of data. Differences were considered significant when $p<0.05$. 
Table 1. Parameters related to water metabolism in adult and aged Lewis rats. Values represent means \pm SEM. Each age group consisted of 15 animals.

\begin{tabular}{llllll}
\hline $\begin{array}{l}\text { Age } \\
(\text { months })(\mathrm{g})\end{array}$ & $\begin{array}{l}\text { Total water } \\
\text { intake } \\
(\mathrm{ml} / 24 \mathrm{~h})\end{array}$ & $\begin{array}{l}\text { Water intake } \\
(\mathrm{m} / 24 \mathrm{~h} / 100 \mathrm{~g} \\
\text { body weight) }\end{array}$ & $\begin{array}{l}\text { Plasma } \\
\text { osmolality } \\
(\mathrm{mOSm} / \mathrm{kg})\end{array}$ & $\begin{array}{l}\text { PlasmaVP } \\
\text { concentration } \\
(\mathrm{pmol} / \mathrm{l})\end{array}$ \\
\hline & $480 \pm 15$ & $25.0 \pm 0.5$ & $5.2 \pm 0.1$ & $301.9 \pm 1.1$ & $1.72 \pm 0.31$ \\
12 & $612 \pm 18^{*}$ & $25.1 \pm 1.3$ & $4.1 \pm 0.2^{*}$ & $304.1 \pm 1.0$ & $2.29 \pm 0.24$ \\
\hline
\end{tabular}

Significantly different values are indicated by asterisks $(p<0.001)$.

\section{Results}

Table 1 gives some parameters related to basal water homeostasis in adult and aged male Lewis rats. Aged animals were heavier than adult animals $(p<0.001)$ but consumed the same amount of water $(p>0.05)$. Water intake per $100 \mathrm{~g}$ body weight was reduced in aged rats as compared with adult rats $(p<0.001)$. Plasma osmolality and plasma VP concentration were unaltered with age $(p>0.05)$. In contrast, a significant correlation was found between plasma osmolality and plasma VP concentration in adult animals (plasma VP $=0.210$ (plasma osmolality - 293.8), $\mathrm{r}^{2}=$ $0.59, \mathrm{p}<0.01)$, but not in aged animals $\left(\mathrm{r}^{2}=0.00, \mathrm{p}>0.05\right)$.

As shown in Fig. 1, infusion of $9 \%$ salt solution markedly increased plasma osmolality in Lewis rats. The increase in osmolality was characterized by a general

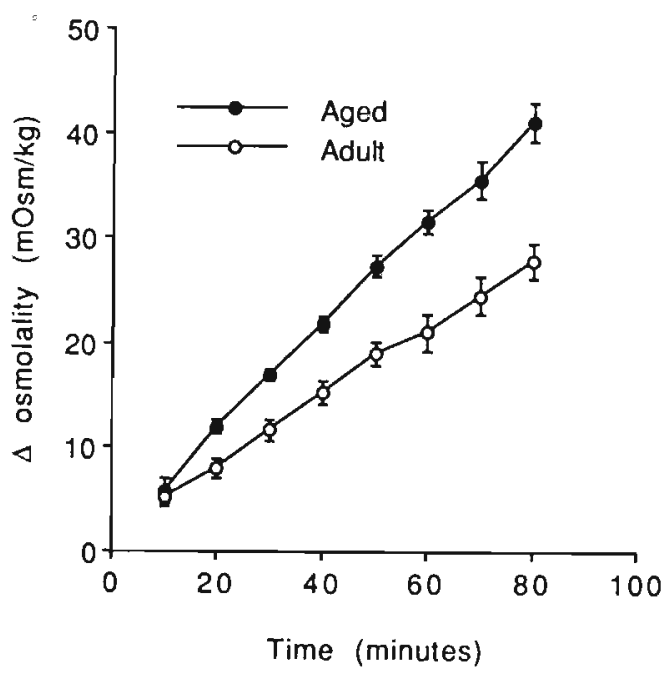

Fig. 1. Change in plasma osmolality in adult and aged Lewis rats during infusion of $9 \%$ salt solution. Data represent means \pm SEM. Each age group consisted of 6 animals. 

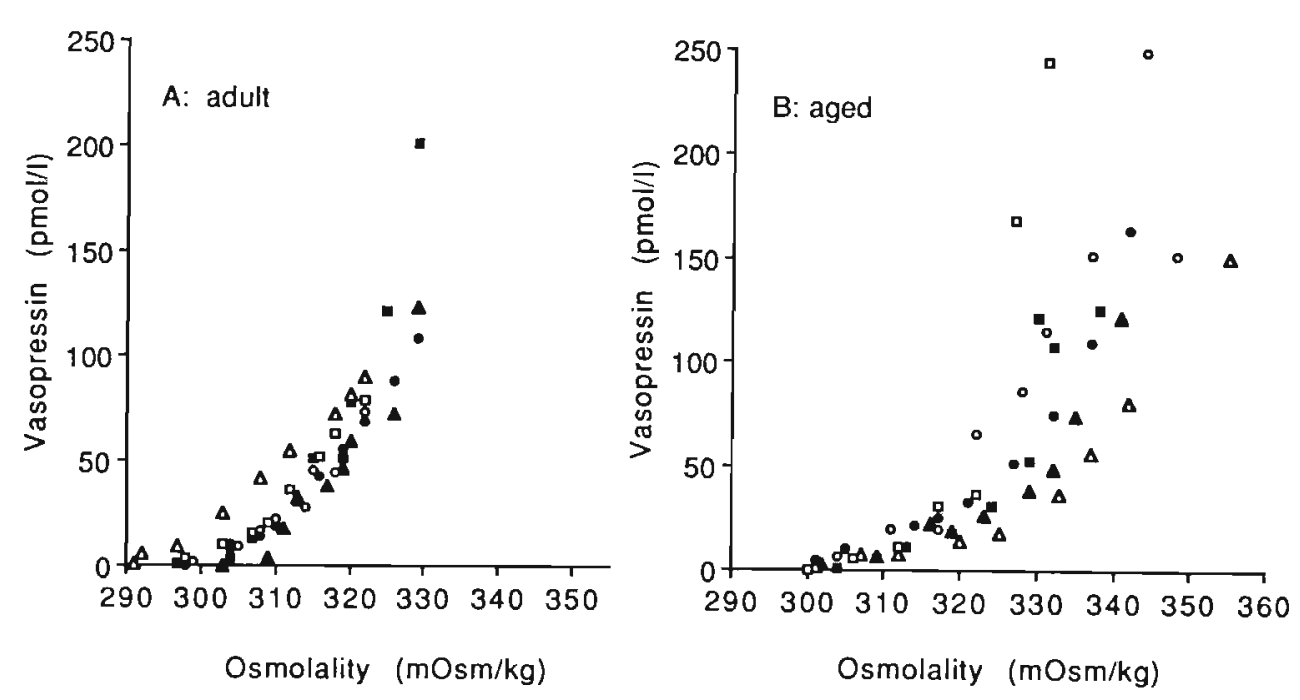

Fig. 2. Relationship between plasma osmolality and plasma VP concentration in adult (A) and aged (B) Lewis rats. Symbols indicate individual rats.

linear trend in both the adult and aged rats. The linear trend covered $99 \%$ of the total variation over successive time points. The age-groups differed with respect to the linear trend components. Bonferroni statistics revealed that the plasma osmolality increase was significantly higher in 12-month-old rats than in 28-month-old rats from the 20-minute time point onwards. Fig. 2A shows the relationship between plasma osmolality and plasma VP concentration for individual adult rats. Data were fitted to a linear $(\mathrm{Y}=\mathrm{aX}+\mathrm{b})$ and an exponential $(\mathrm{Y}=\mathrm{a}$.eb.osmolality $)$ equation. There were no differences in the goodness-of-fit for data from adult animals in these two models ( $\mathrm{r}$ values were $0.955 \pm 0.014$ and $0.942 \pm 0.015$ for the linear and exponential model, respectively; $p>0.05$ ). Parameters $a$ and $b$ for the linear equation were $3.78 \pm 0.43$

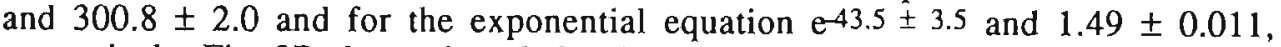
respectively. Fig. 2B shows the relationship between plasma osmolality and plasma VP concentration in individual aged rats. For aged rats the fit of the data to the exponential equation was superior to the fit to the linear equation ( $\mathrm{r}$ values were 0.881 \pm 0.024 and $0.976 \pm 0.017$ in the linear and exponential model, respectively; $p<0.05$ ). Parameters $a$ and $b$ of the exponential equation were e-30.6 ( \pm 5.27$)$ and $0.105 \pm 0.017$ for aged rats. Parameter a was significantly different between adult and aged rats $(\mathrm{p}<$ $0.05)$. Parameter $b$ just failed to be significantly affected by age $(p=0.070)$. Inspection of the data showed that at relatively low osmolalities the increase in plasma VP concentration with plasma osmolality was lower in aged rats than in adult rats. When the first halves of the curves were compared according to the linear model a significant difference was found between the slopes of the curves (slopes were $2.12 \pm$ 0.21 and $1.13 \pm 0.014$ for adult and aged rats, $\mathrm{p}<0.01$; thresholds were $298.1 \pm 1.7$ and $299.2 \pm 1.2, \mathrm{p}>0.05)$. When the first halves of the curves were compared 
according to the exponential model, significant differences were observed between the parameters $a$ and $b$ for adult and aged rats ( $a$ was $0.26 \pm 0.03$ and $0.13 \pm 0.013$ and $b$ was $78.3 \pm 10.0$ and $35.7 \pm 1.9$, p-values $<0.01$ ). Significant differences were not observed when the second halves of the curves were compared according to either model ( $\mathrm{p}$ values $>0.05$ ).

\section{Discussion}

There is some debate as to whether the relationship between plasma osmolality and plasma VP concentration is linear or exponential. Robertson (1987) stated that the assays now available are not sufficiently precise to distinguish clearly between the relatively small differences in plasma VP concentration predicted by the two models. Indeed, data for adult rats showed equally good fits to the linear and exponential equations. However, data for aged rats fitted the exponential equation best. This may be because higher osmolalities were reached in aged animals or because the curves for aged rats have a different shape. The data do not distinguish between these two possibilities.

The relationship between plasma osmolality and plasma VP concentration was quite different under basal conditions from that under conditions of acute osmotic change, i.e., the slope of the relationship was much less steep under basal conditions than under conditions of acute osmotic change (slope 0.210 versus 2.12 ). This observation is of considerable importance for the interpretation of studies on the physiology of VP release. As far as we know from the literature, this is the first direct comparison of the relationship between plasma osmolality and VP concentration under conditions of slowly and rapidly changing osmolality.

In the present study the plasma VP concentration did not change with age in Lewis rats. Decreased baroreceptor sensitivity as assessed in this study may be expected to result in decreased plasma VP concentrations. However, since the relationship between plasma osmolality and plasma VP concentration was considerably different under basal conditions, the altered baroreceptor sensitivity cannot explain changes in plasma VP concentration with age. In contrast to the present findings in Lewis rats, basal plasma VP concentration did increase with age in Wistar rats (Terwel et al. 1992). However, since plasma VP concentration may fluctuate during the day (Terwel et al. 1992), 24-h VP release in not necessarily unaltered in Lewis rats with age.

Salt infusion resulted in a greater increase in osmolality in aged rats than in adult rats. Both adult and aged rats were infused at the same rate, despite the higher body weight of the aged rats. Since aged rats contain more body water, the observed difference in the increase in osmolality may be underestimated. These results resemble those obtained by Cheng and North (1986) in a study of Brattleboro and Long-Evans rats. Brattleboro rats showed a lower increase in osmolality during salt infusion than Long-Evans rats. This was explained by the observation that Brattleboro rats have a lower glomerular filtration rate than Long-Evans rats. It is not unreasonable to assume that the same argument could be used to explain the smaller increase in osmolality in 
adult rats during salt infusion. Alternatively, adult rats may have an increased glomerular filtration rate during salt infusion, whereas aged rats do not, comparable to the occurrence of hyperfiltration in adult rats after a meal and the absence of it in aged rats (Corman et al. 1988).

For relatively low osmolalities, the increase in plasma VP concentration with osmolality was greater in adult rats than in aged rats, according to the linear model. One could take issue with the approach of splitting the data. Because the data were split, a correction can be made for post hoc multiple comparison. When this correction is made the difference between aged and adult rats was still significant.

In contrast to the present observation in rats, in humans the increase in plasma VP concentration with plasma osmolality is greater in elderly subjects than in adult subjects (Helderman et al. 1978). This has been explained by the observation that the baroreflex is blunted in aged subjects. Salt infusion increases blood pressure, and the increase in blood pressure suppresses the release of VP. When the baroreflex is blunted, blood pressure is not adjusted, which results in an increased secretion of VP. The alternative explanation, that osmoreceptor sensitivity is increased in humans, is probably incorrect. Information is conveyed from the osmoreceptors to both the pituitary, to suppress VP release, and to the cerebral cortex to bring about consciousness of the sensation of thirst. Reduced thirst sensation in humans can be taken to indicate reduced osmoreceptor sensitivity (Phillips et al. 1991). However, the difference between humans and rats in the age-related change in sensitivity of the hypothalamo-neurohypophyseal system to an osmotic stimulus needs to be explained. As is clear from the above, the release of VP is governed by mechanisms that counteract each other. In rats, the baroreflex mechanism may be blunted less severely than in humans, whereby a reduced osmoreceptor sensitivity is revealed.

In conclusion, osmoreceptor sensitivity appears to be reduced rather than increased in aged Lewis rats. Why this reduced osmoreceptor sensitivity does not result in reduced basal plasma VP concentrations in Lewis rats is a matter of further investigation. Since kidney dysfunction is observed in both humans and rats and osmoreceptor sensitivity is affected differently, osmoreceptor function is unlikely to be involved in the etiology of reduced kidney function.

\section{References}

Aravich PF, Sladek JR Jr. Aging of rodent vasopressin systems. Morphometric and functional consideration. In: Gash PM, Boer GJ, cds. Vasopressin. Principles and properties. New York: Plenum, 1987:497-516.

Beck N, Yu BP. Effect of aging on urinary concentrating mechanism and vasopressin-dependent cAMP in rats. Am J Physiol 1982;243:F121-5.

Bengele $\mathrm{HH}$, Mathias RS, Perkins JH, Alexander EA. Urinary concentrating defect in the aged rat. Am J Physiol 1981;240:F147-50.

Bevilacqua M, Meroni R, Dagani R, Renesto E, Baruto C, Norbiata G. Role of blood osmolality in the regulation of vasopressin secretion in man: application of a new radioimmunoassay method for vasopressin. $J$ Endocrinol Invest 1985;8:97-101.

Cheng SWT, North WG. Responsiveness of oxytocin-producing neurons to acute salt Ioading in rats: 
comparisons with vasopressin-producing neurons. Neuroendocrinology 1986;42:174-80.

Corman B, Chami-Khazraji S, Schaeberbeke J, Michel JB. Effect of feeding on glomerular filtration rate and proteinuria in conscious rats. Am J Physiol 1988;255:F250-6.

Helderman JH, Vestal RE, Rowe JW, Tobin JD, Andres R, Robertson GL. The response of arginine vasopressin to intravenous ethanol and hypertonic saline in man: the impact of aging. J Gerontol 1978;33:39-47.

Miller M. Influence of aging on vasopressin secretion and water regulation. In: Schrier RW, ed. Vasopressin. New York: Raven Press, 1985:249-58.

Miller M. Increased vasopressin secretion: an early manifestation of aging in the rat. J Gerontol 1987;42:3-7.

Phillips PA, Bretherton M, Johnston CI, Gray L. Reduced osmotic thirst in healthy elderly men. Am J Physiol 1991;261:R166-71.

Robertson GL. Physiology of ADH secretion. Kidney Int 1987; vol 32 (Suppl):20-6.

Silverman WF, Aravich PA, Sladek JR Jr, Sladek CD. Physiological and biochemical indices of neurohypophyseal function in the aging Fischer rat. Neuroendocrinology 1990;52:181-90.

Sladek CD, McNeill TH, Gregg CM, Blair ML, Baggs RB. Vasopressin and renin response to dehydration in aged rats. Neurobiol Aging 1981;2:293-302.

Ten Haaf JA, Terwel D, Van de Heijning HJM, Van Wimersma Greidanus TjB. Radioimmunoassay: a goal or a tool? J Control Rel 1992 (in press).

Terwel D. Ten Haaf JA, Markerink M, Jolles J. Changes in plasma vasopressin concentration and plasma osmolality in relation to age and time of day in the male Wistar rat. Acta Endocrinol (Coph) 1992;126:35762.

Winer BJ. Statistical principles in experimental design. 2nd ed. New York: McGraw-Hill, 1971. 


\title{
THE INFLUENCE OF AGE ON PLASMA SODIUM AND OSMOLALITY IN HEALTHY INDIVIDUALS AFTER AN OVERNIGHT FAST
}

\author{
Nico Bohnen, Dirk Terwel, Germa Wijnen
}

\begin{abstract}
Changes in plasma sodium and osmolality with age were examined in 67 healthy volunteers (aged 17-60) after an ovemight dehydration. The subjects were free from medication or evidence of diseases known to adversely affect renal function. It is generally accepted that plasma osmolality or sodium do not change after ovemight dehydration with advancing age. However, using sensitive techniques we found that a significant increase in fasting plasma osmolality and sodium with increasing age.
\end{abstract}

\section{Introduction}

Water homeostasis depends primarily on the maintenance of a balance between water input and output, which is controlled by the hypothalamo-neurohypophyseal system and the kidneys. The predominate solutes of plasma and other extracellular fluids are sodium and its anions. In healthy adults, plasma osmolality and sodium concentration are normally maintained within a very narrow range: they rarely deviate by more than 1 to $2 \%$ from the basal value of about $287 \mathrm{mOsm} / \mathrm{kg}$ and $140 \mathrm{mEq} / \mathrm{l}$ (Robertson 1983). VP release and its subsequent regulation of fluid balance occurs primarily in response to alterations in blood tonicity and blood volume, which are kept relatively constant (Baylis 1987).

It has been found that the ability to concentrate urine decreases with age, as judged by the maximal urine osmolality after dehydration (Lindeman et al. 1960, Rowe 1985) or administration of VP (Miller and Shock 1953). It is generally accepted that, under normal circumstances, age has no effect on body fluid osmolality or on the ability to maintain a normal extracellular fluid volume (Rowe 1985). Because studies on aging and water metabolism have primarily focused on urinary concentration ability, the present study was performed to determine age-related differences in levels of plasma osmolality and sodium in healthy subjects.

\section{Subjects and methods}

\section{Subjects}

Subjects were recruited by circular advertisements and were selected if they had no chronic serious illness and if they had not been treated for an acute medical condition in the past three months. Subjects with nephrolithiasis, urinary tract infection, gout, congestive heart failure, diabetes mellitus and a history of renal or endocrine diseases were excluded from the study. Pregnant females were not eligible. Thinty-three male and 34 female physically and mentally healthy normotensive subjects (aged 17-60) 
were selected and paid for their participation in the study. All subjects were free from medication, except one subject who used $10 \mathrm{mg}$ diazepam daily (i.e. a dose that does not adversely affect renal function).

The study was approved by the medical ethical council of the University Hospital and all subjects gave their informed consent.

\section{Procedure}

Each subject was instructed not to take anything by mouth from midnight until the next morningwhen blood was collected between 8.30 and 9.30 .

Plasma osmolality was measured by freezing point depression (Gonotec Osmostat 030). Each sample was immediately measured in triplicate after plasma separation and repeated calibration of the osmometer before each assay; the coefficient of variation was $0.18 \%(n=28)$. Plasma sodium was measured with an autoanalyser equiped with an ion selective electrode (Dupont Dimension, day to day coefficient of variation $0.7 \%)$.

\section{Statistical analysis}

Data were analysed using standard statistical methods, including regression analysis and Pearson's correlation test. Probabilities greater than 0.05 were considered non-

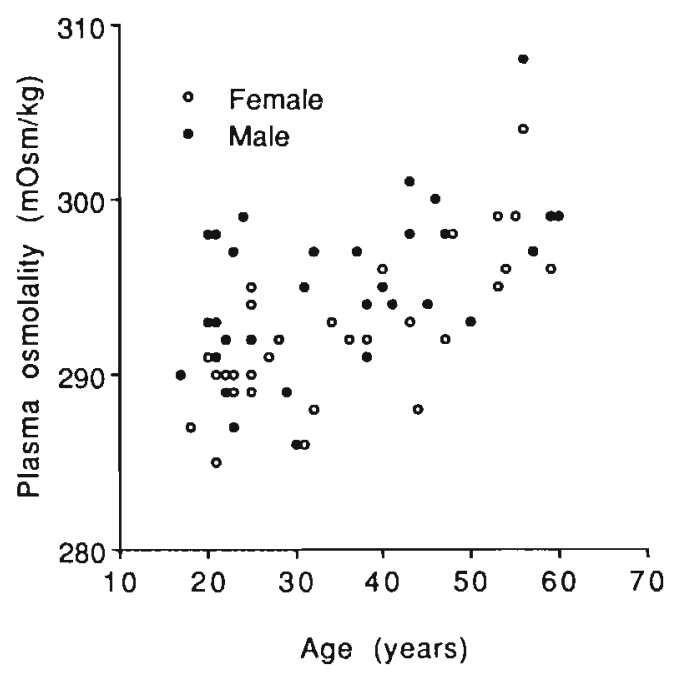

Fig. 1. Relationship between age and plasma osmolality in males and females.

\section{Results}

Regression analysis indicated that fasting plasma osmolality and sodium values 
increase significantly with advancing age with males having higher values than females (see also Fig. 1). The (best-fitted) significant linear relationship between age, sex and fasting plasma osmolality can be described as: plasma osmolality $=290.5+$ 0.21 age (years) $-2.65 * \operatorname{sex}($ male $=1$, female $=2$ ); the regression coefficients were significant, as determined with t-statistics: for age $\mathrm{T}=6.4(\mathrm{P}<0.001)$ and for $\operatorname{sex} \mathrm{T}=$ $3.1(\mathrm{P}<0.01)$. For plasma sodium: $\mathrm{P}_{\mathrm{Na}}=141.6+0.06^{*}$ age (years) $-1.0 *$ sex; regression coefficients were significant for age $T=3.7(\mathrm{P}<0.001)$ and for $\operatorname{sex} T=$ $2.5(\mathrm{P}<0.05)$.

\section{Discussion}

Renal functions decline with age and the effect of age on glomerular filtration rate as measured by creatinine clearance is well documented (Rowe 1985). Various authors have reported a decrease in the ability of the kidney to concentrate urine, as measured by urine osmolality after dehydration, with age in man (Lindeman et al. 1960, Rowe et al. 1976) as well as in experimental animals (Beck and Yu 1982, Bengele et al. 1981). It appears that this decrease is independent of changes in creatinine clearance. This is consistent with the lack of a significant effect of creatinine clearance on urine osmolality and flow rate irrespective of age (Rowe et al. 1976).

Lye (1984) suggested that aging may be considered to result in the development of a form of acquired partial nephrogenic diabetes insipidus. Although it is generally assumed that there is no effect of aging on plasma osmolality and sodium after an overnight dehydration in healthy individuals (Helderman et al. 1978, Os et al. 1987, Rowe et al. 1976), we found a significant increase in fasting plasma osmolality and sodium with age. Probably the age-associated increase in plasma osmolality was detected because of the increased reliability of the assay, as manifested by an intraassay coefficient of $0.18 \%$ instead of $1.2 \%$ obtained with single determinations or even larger when frozen samples are used (Bevilacqua et al. 1985). With respect to a possible mechanism underlying the age related increase in plasma osmolality, it is possible that urea or glucose could have contributed to the increase in plasma osmolality, but sodium levels were increased as well. Whether the increase of plasma sodium with age is related to the development of an age-associated partial type of nephrogenic diabetes insipidus (Lye 1984), remains to be elucidated. The reason for the difference between male and female subjects could be due to menstrual factors.

It can be concluded that, after an overnight fast, plasma osmolality and sodium concentrations increases significantly with advancing age with males having higher values than females, and that middle-aged subjects are less able to maintain body fluid osmolality during dehydration than younger subjects. 


\section{References}

Aravich PF, Sladek JR Jr. Aging of rodent vasopressin systems. Morphometric and functional considerations. In: Gash DM, Boer GJ, eds. Vasopressin. Principles and properties. New York: Plenum Press, 1987:579-610.

Baylis PH. Osmoregulation and control of vasopressin secretion in healthy humans. Am J Physiol 1987;253:R671-8.

Beck N, Yu BP. Effect of aging on urinary concentrating mechanism and vasopressin-dependent cAMP in rats. Am J Physiol 1982;243:F121-5.

Bengele $\mathrm{HH}$, Mathias RS, Perkins JH, Alexander EA. Urinary concentrating defect in the aged rat. Am J Physiol 1981;240:F147-50.

Bevilacqua M, Meroni R, Dagani R, Renesto E, Baruto C, Norbiato G. Role of blood osmolality in the regulation of vasopressin secretion in man: application of a new radioimmunoassay method for vasopressin. $\mathrm{J}$ Endocrinol Invest 1985;8:97-101.

Helderman JH, Vestal RE, Rowe JW, Tobin JD, Andres R, Robertson GL. The response of arginine-vasopressin to intravenous ethanol and hypertonic saline in man: the impact of aging. J Gerontol 1978;33:39-47.

Lindeman RD, Van Buren HC, Raisz LG. Osmolar renal concentrating ability in healthy young and hospitalized patients without renal disease. N Engl J Med 1960;262:1306-9.

Lye M. Electrolyte disorders in the elderly. Clin Endocrinol Metab 1984;13:377-98.

Miller JW, Shock NW. Age differences in the renal tubular response to antidiuretic hormone. J Gerontol 1953;8:446-50.

Os I, Kjeldsen SE, Westheim A, Ákesson I, Eide I, Skjøtø J, Hjermann I, Leren P. Aging and urinary vasopressin excretion in healthy men. Scand J Urol Nephol 1987;21:235-9.

Robertson GL. Thirst and vasopressin function in normal and disordered states of water balance. J Lab Clin Med 1983;101:351-71.

Rowe JW. Aging and renal function. In: Arieff AI. DeFronzo RA, eds. Fluid, electrolyte, and acid-base disorders; vol 2. New York: Churchill, 1985:1231-46.

Rowe JW, Shock NW, DeFronzo RA. The influence of age on the renal response to water deprivation in man. Nephron 1976;17:270-8. 


\section{PART THREE}

BRAIN VASOPRESSIN IN AGING 



\title{
AGE-RELATED CHANGES IN CONCENTRATIONS OF VASOPRESSIN IN THE CENTRAL NERVOUS SYSTEM AND PLASMA OF THE MALE WISTAR RAT
}

\author{
Dirk Terwel, Marjanne Markerink, Jellemer Jolles
}

\begin{abstract}
The results of studies on the influence of age on concentrations of vasopressin (VP) in blood plasma, and hypothalamic and extrahypothalamic brain sites have not been unequivocal. Studies on extrahypothalamic concentrations of VP in the aging rat are scarce and have mainly provided semiquantitative data. For these reasons we determined, by radioimmunoassay, the concentrations of VP in thirteen brain structures and in the plasma of 3-, 10-, 20- and 28-month-old male Wistar rats. Age-related decreases in VP concentrations were found in the pituitary gland, hypothalamus, thalamus, midbrain, medulla oblongata, amygdala and pincal gland, while an increase was noted in plasma. Decreases in the concentration of VP in the amygdala and pineal gland occurred between 3 and 10 months of age and probably represent developmental changes. In the pituitary, thalamus, midbrain, medulla oblongata and plasma, differences in the concentration of VP were also found between 10-month-old and older animals and are probably related to aging. The finding of increased plasma VP concentrations in aged animals agrees with the notion that neuronal function does not necessarily decline with age and suggests that neurons may even be activated. Age-related changes in VP concentrations were not observed in the other structures examined. It has been reported that the VP innervation of a number of brain structures depends on testosterone. Despite reports to the contrary VP concentrations do not generally decline in these structures with aging.
\end{abstract}

\section{Introduction}

Studies on age-related changes in concentrations of neuropeptides in the rat central nervous system have mainly focused on the neuroendocrine system (Reymond et al. 1989). Interest in these changes has arisen from the notion that the most elementary characteristic of the aging process is a loss of integration (Meites et al. 1987). Neuropeptides are important integratory principles in extrahypothalamic sites in the brain. However, only a limited number of reports on the influence of age on the concentrations of neuropeptides in extrahypothalamic brain areas have appeared (Barden et al. 1981, Dupont et al. 1981, Gambert et al. 1980, Miller et al. 1990, Ogawa et al. 1986). Studies on vasopressin (VP) have been most extensive, because this peptide is implicated in a number of central and peripheral processes that display changes associated with aging (Aravich and Sladek 1987, Ferguson et al. 1983, Gallagher and Pelleymounter 1988, Wei et al. 1985), such as cardiovascular regulation (Cowley and Liard 1987), thermoregulation (Kasting 1989), regulation of fluid balance (Verney 1947) and memory (Hoffman 1987). VP is synthesized in the neuroendocrine nuclei of the hypothalamus, suprachiasmatic nuclei, bed nucleus of the stria terminalis, medial amygdala, locus coeruleus (for e.g. see De Vries et al. 1985 
and Sofroniew 1985) and probably the pineal gland (Liu and Burbach 1991). From these sites VP is transported to its sites of action.

Data concerning the effects of aging on the hypothalamo-neurohypophyseal system are inconsistent (Aravich and Sladek 1987, Miller 1985). For instance, increased, unaltered and reduced concentrations of plasma VP have been found in aged rats of the Long-Evans strain (Miller 1985), the Fischer 344 strain (Silverman et al. 1990, Sladek et al. 1981), and the Sprague-Dawley and Fischer 344 strains (Zbuzek and Wu 1982, Zbuzek et al. 1983), respectively. Similarly, concentrations of VP in the hypothalamus were reduced in aged rats of the Sprague-Dawley (Zbuzek an Wu 1982) and Long-Evans strains (Dorsa and Bottemiller 1982, Miller 1985) and reduced (Zbuzek et al. 1983) or equal (Silverman et al. 1990, Sladek et al. 1981) in the Fischer 344 strain. Concentrations of VP in the pituitary gland were equal (Sprague-Dawley (Zbuzek and Wu 1982), Fischer 344 (Zbuzek et al. 1983), Long-Evans (Dorsa and Bottemiller 1982) or reduced (Fischer 344 (Sladek et al. 1981), Long-Evans (Miller 1985)).

Reports about the influence of age on extrahypothalamic VP concentrations are more scarce (Dorsa and Bottemiller 1982, Fliers et al. 1985, Goudsmit et al. 1988b, Goudsmit et al. 1990). Dorsa and Bottemiller (1982) assessed, by radioimmunoassay, extrahypothalamic concentrations of VP in 3- and 26-month-old Long-Evans rats. These authors found reduced concentrations of VP in the dorsal septum, vascular organ of the lamina terminalis and locus coeruleus. Fliers et al. (1985) and Goudsmit et al. (1988b) used immunocytochemistry to study staining of vasopressinergic fibers in 3- and 34-, and 5- and 34-month-old Brown-Norway rats. In the former study reduced staining of vasopressinergic fibers was found in a number of extrahypothalamic brain regions, such as the lateral septum, the lateral habenula, the medial amygdala and the central gray, but in the latter study a significant reduction was found in the central gray and locus coeruleus only. Recently, a study of Goudsmit et al. (1990) did not confirm an age-related decrease in VP content, as measured by radioimmunoassay, in the lateral septum and medial amygdala of Brown-Norway rats.

In the present study we measured VP concentrations in the hypothalamus, pituitary, plasma and extrahypothalamic brain structures of 3-, 10-, 20- and 28-month-old male Wistar rats. We performed this study for several reasons. First, information on extrahypothalamic changes in rats is scarce and inconclusive. Second, with one exception (Goudsmit et al. 1990), previous studies examined two age groups only. This has the drawback that it is very difficult to infer whether differences found between two age groups are a manifestation of brain development or brain aging (Coleman et al. 1990). Third, up to now most information has been obtained in semiquantitative studies, the limitations of which are obvious. Fourth, little is known about the course of extrahypothalamic changes in rats with age, which necessitates investigations with more than two age groups. Moreover, data on changes in the hypothalamo-neurohypophyseal system of Wistar rats are scarce. The Wistar rat is relevant in this respect, since from available data it seems that changes in the fluid balance in this strain (Fliers and Swaab 1983) resemble those in humans (for e.g. see Kirkland et al. 1984 and Os et al. 1985). 


\section{Materials and methods}

\section{Experimental animals}

In the present study male outbred Wistar rats (Bor:WISW(SPFCpb)) were used. The rats were purchased from Winkelmann (Borchen, F.R.G.) at 2 months of age and were kept under controlled environmental conditions (a light:dark cycle of $12 \mathrm{~h}$ light and $12 \mathrm{~h}$ darkness, free access to food and water). The $50 \%$ survival age of the strain of rats used is 28 months. Animals were handled once a day in the week preceding the experiment. A total of 28 rats were used, divided over four groups of 3-, 10-, 20- and 28-month-old animals.

\section{Brain dissection and plasma collection}

Rats were decapitated at midday and trunk blood was collected in heparinized tubes for the determination of plasma VP concentrations. The brains were removed from the skull and dissected in a cold room for the determination of VP concentrations in different parts of the brain. The brain was cut at the optic chiasm to make anatomical landmarks visible. The tissue block delimited by the corpus callosum, ventricles and the fimbria hippocampus was taken as the septum. The tissue rostral from the transversal cut and ventral to the septum, anterior commissure and fissura rhinalis was taken as the preoptic area. The midbrain and hypothalamus-thalamus were separated by a cut rostral to the mamillary bodies. The rest of the dissection was performed according to Gispen et al. (1972).

\section{Extraction of $V P$ and radioimmunoassay of $V P$}

VP was extracted from plasma and brain samples, and concentrations of VP were determined as reported elsewhere (Ten Haaf et al. 1992). Briefly, acidic brain tissue homogenates were boiled, centrifuged and lyophilized. The freeze-dried material was washed in 50\% ethanol and spun down. Ethanol fractions were evaporated under vacuum. Residues were taken up in assay buffer. Radioimmunoassay was performed in a volume of $100 \mu \mathrm{l}$ using antiserum W1, characterized by Burbach et al. (1984), in a dilution of 1:512,000. Assay tubes contained $1 \mathrm{fmol}$ of iodinated VP purchased from Amersham (Buckinghamshire, U.K.). After $72 \mathrm{~h}$ bound and free ligand were separated with Ficoll@-dextran-coated charcoal. The intra- and interassay coefficient of variation were $7.1 \%$ and $8.6 \%$, respectively. Nonspecific binding was $<3 \%$ and binding of tracer by excess antibody was $90 \%$ with our assay. The detection limit was $0.5 \mathrm{pmol} / \mathrm{g}$ protein.

\section{Statistics}

The data were subjected to a one factor (age) analysis of variance, followed by the Newman-Keuls test for post hoc multiple comparisons. For data on brain VP concentrations, Pearson's correlation coefficients were calculated and assessed for significance using the Student t-test. 


\section{Results}

Fig. $1 \mathrm{~A}, \mathrm{~B}, \mathrm{C}$ shows concentrations of VP in the hypothalamo-neurohypophyseal system of Wistar rats of different ages. Age-related changes were observed for plasma (Fig. 1A, p < 0.001), the hypothalamus (Fig. 1B, p < 0.05) and the posterior lobe of the pituitary (Fig. 1B, p < 0.01). Post hoc multiple comparison revealed that the concentration of VP in the hypothalamus was lower in 20- and 28-month-old rats than in 3- and 10-month-old rats. The level of VP in the posterior pituitary lobe was lower in 20-month-old rats than in 3-month-old rats and lower in 28-month-old than in 10month-old rats. Plasma VP concentrations were similar in 3- and 10-month-old rats but thereafter increased with age.
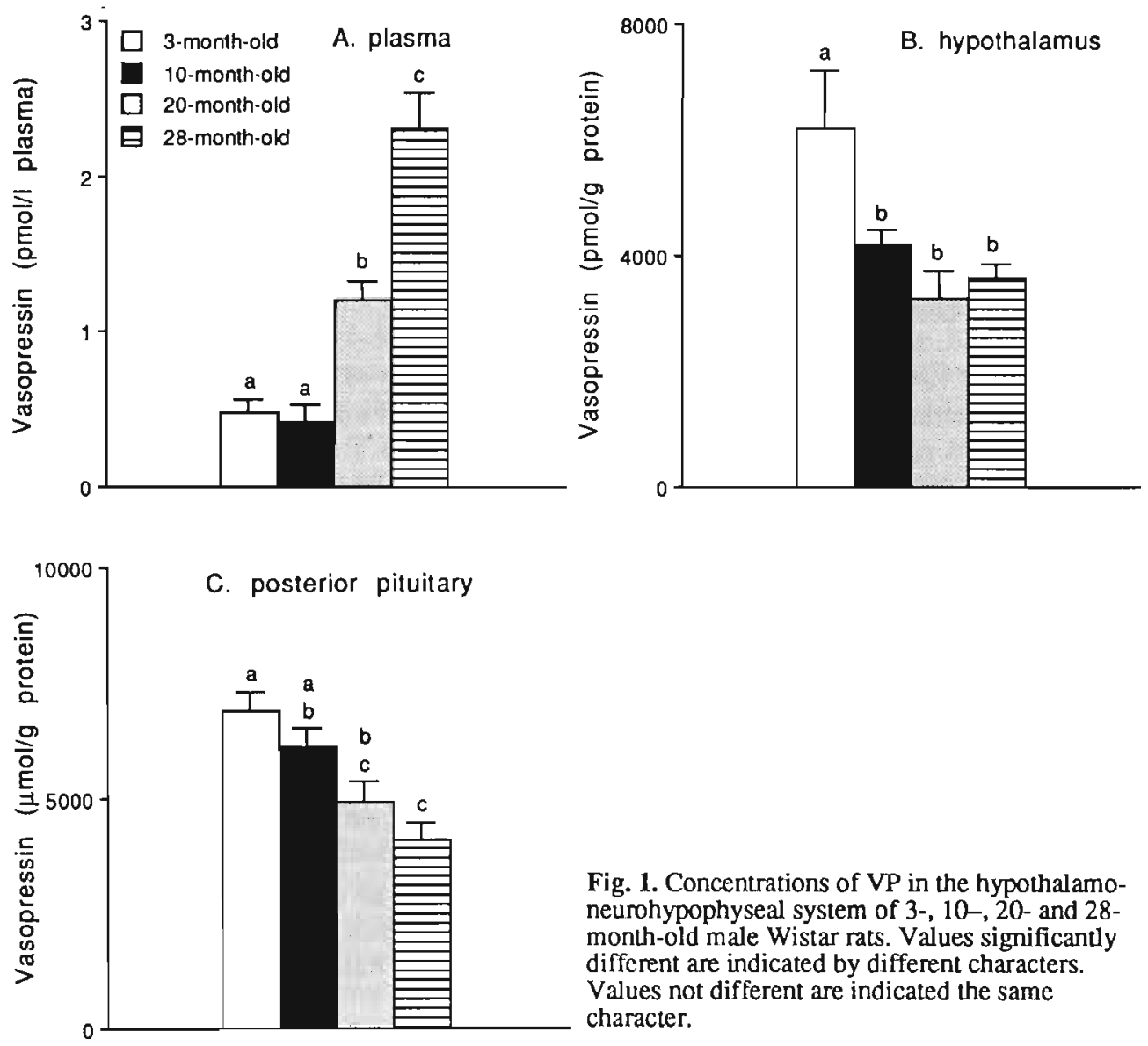

Fig. 1. Concentrations of VP in the hypothalamoneurohypophyseal system of 3-, 10-,20- and 28month-old male Wistar rats. Values significantly different are indicated by different characters. Values not different are indicated the same character. 

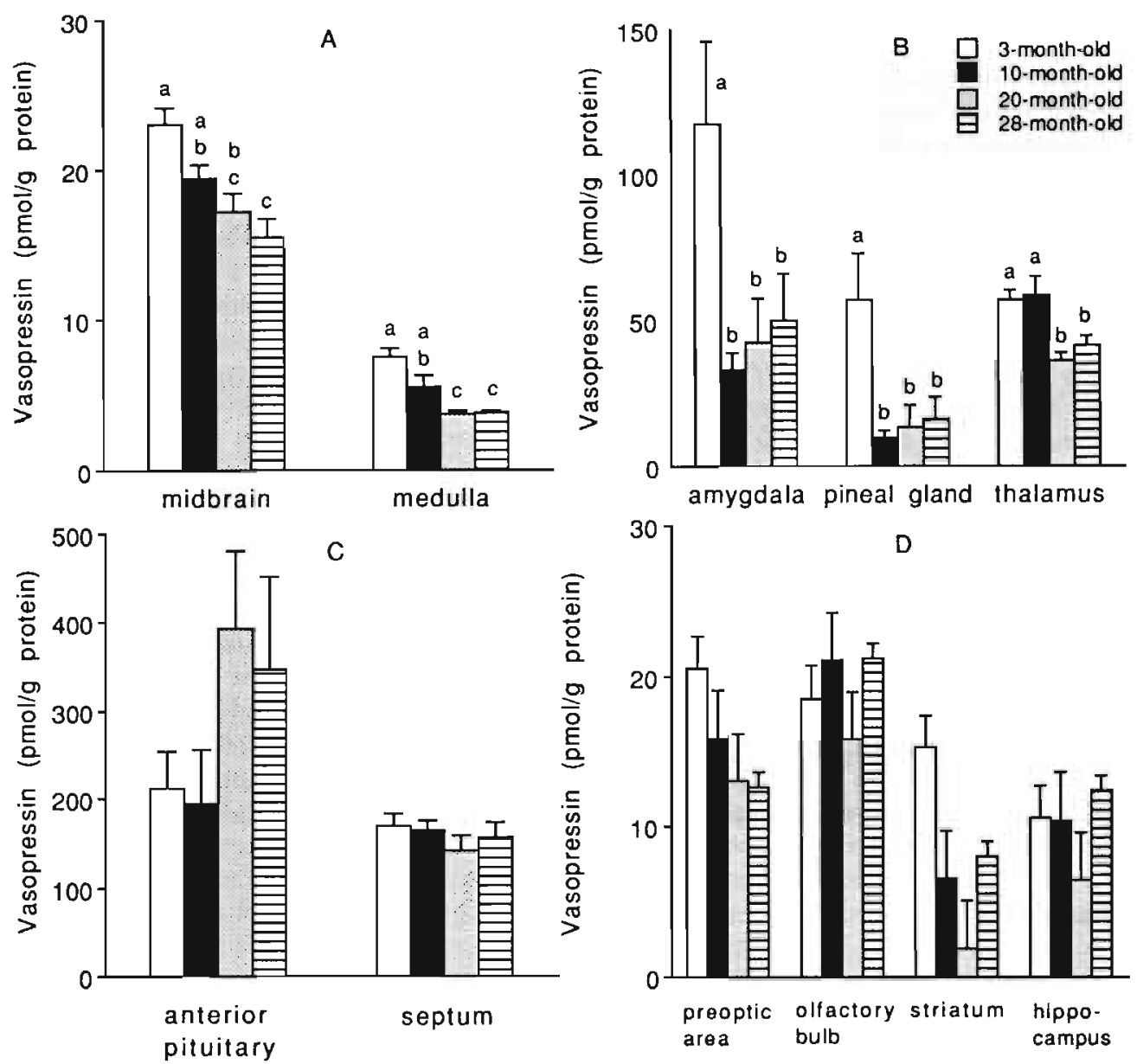

Fig. 2. Concentrations of VP in extrahypothalamic brain regions of 3-, 10-, 20- and 28-month-old male Wistar rats. Values significantly different are indicated by different characters. Values not different are indicated by the same character.

Age-related changes in concentrations of VP were also observed in various extrahypothalamic areas (Fig. 2A,B). The VP concentrations showed age-related changes in the midbrain ( $p<0.001$ ), medulla oblongata $(p<0.001)$ (Fig. $2 A)$, amygdala $(p<0.05)$, pineal gland $(p<0.05)$ and thalamus $(p<0.01)$ (Fig. 2B). Concentrations of VP in the amygdala and pineal gland were highest in 3-month-old rats. VP concentrations in the medulla oblongata and midbrain decreased with age and those in the thalamus were lower in 20- and 28-month-old rats than in 3- and 10month-old rats.

No significant changes in concentrations of VP were observed with age in the anterior pituitary, septum, preoptic area, olfactory bulb, striatum and hippocampus (Fig. 2C,D; p values >0.05). 
To investigate whether the decreases in VP concentrations were related, correlation coefficients were calculated for data on plasma and brain structures. A high correlation was found between the concentrations of VP in the amygdala and pineal gland $\left(\mathrm{r}^{2}=0.97, \mathrm{p}<0.001\right.$, Fig. 3$)$. Other correlations were not significant.

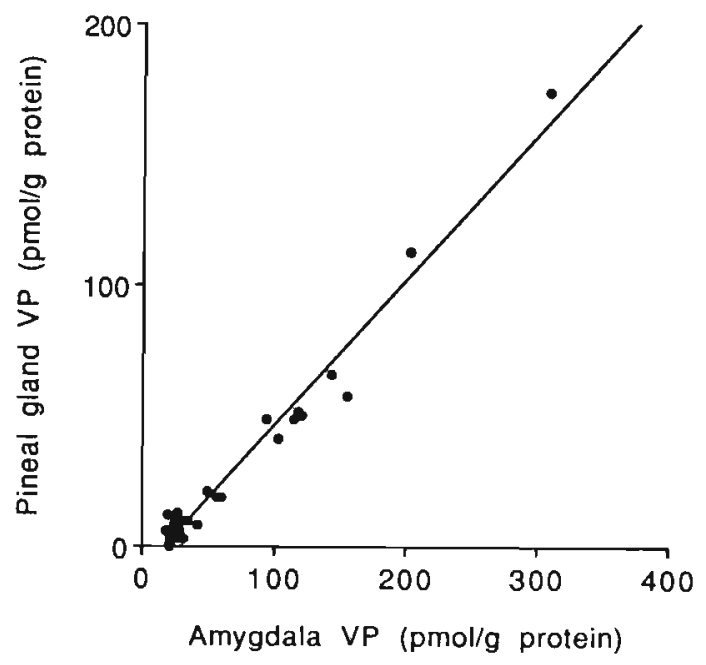

Fig. 3. Relationship between concentrations of VP in the amygdala and pineal gland.

\section{Discussion}

Not all differences observed between young adult and old rats can be attributed to aging. Young adult rats, for instance, may not have matured completely, which implies that developmental changes contribute to the differences. This is why we used four age groups to discriminate between aging and development. Indeed, changes in the concentration of VP were observed between 3 and 10 months of age, in the hypothalamus, amygdala and pineal gland, and these are thus probably associated with development. Changes in the pituitary, medulla oblongata, midbrain, thalamus and plasma continued after 10 months of age and can be taken to reflect aging.

The literature on the influence of aging on the hypothalamo-neurohypophyseal system is conflicting. These discrepancies cannot be attributed entirely to strain differences. The present results confirm the finding of Fliers and Swaab (1983) that the basal plasma VP concentration increases with age in Wistar rats. These investigators observed increased plasma VP concentrations in 32-month-old Wistar rats (Fliers and Swaab 1983) as compared to animals younger than 11 months of age. We already observed increased plasma VP concentrations in Wistar rats of 20 months, which can be regarded as middle-aged, but not old. It is important to note that we handled our rats before experimentation and that the animals showed no signs of 
stress. This was done to control for the possibility, suggested by Silverman et al. (1990) that the increased plasma VP concentrations in old animals reflect an increased sensitivity to stress. This is the first time that the influence of age on pituitary and hypothalamic contents in Wistar rats has been determined by radioimmunoassay. The decreased concentrations of VP in the pituitary of aged rats do not imply a reduced neurosecretory activity, since plasma VP concentrations were clearly increased. In fact, the picture observed in aged Wistar rats is not unlike that observed in young animals undergoing osmotic stress (Negro-Vilar and Samson 1979). In rats, a decline in VP concentration in the pituitary has been observed after three days of water deprivation. Three days' dehydration did not alter VP concentrations in the hypothalamus, which is probably indicative of increased synthesis and transport of the hormone within the hypothalamo-neurohypophyseal system (Zerbe and Palkovits 1984). Our findings thus underscore the notion that the hypothalamoneurohypophyseal system becomes activated with age. It has been suggested that a reduced kidney function activates the neurosecretory cells (Ravid et al. 1987). However, Miller (1985) suggested that the increased VP concentration is the cause of a decreased kidney function. This opinion would seem less likely in view of the fact that in some strains of rats a rise in plasma VP concentration is not observed, whereas kidney function is diminished (Bengele et al. 1981, Goudsmit et al. 1988a). The discrepancies in the studies on the influence of age on the fluid state may be related to the "use it or loose it" principle advocated by Swaab (1989). In rats, a disturbance in kidney function may be the trigger that activates neurosecretory cells. When kidney function does not decline or declines "too late", activation may no longer be possible. Subtle differences between groups of rats in, for instance, water intake and kidney function may alter the course of alterations in fluid state in rats with age.

VP disappears from a number of brain structures after castration (De Vries et al. 1985), including the septum, hippocampus, amygdala and midbrain. Although the testosterone status decreases with age in several strains of rats (Chambers and Phoenix 1984, Goudsmit et al. 1988b, Kaler and Neaves 1981), changes in the VP innervation dependent on testosterone have not been consistently found (Fliers et al. 1985, Goudsmit et al. 1988b). Fliers et al. (1985) noticed a remarkable similarity between the decreased vasopressinergic fiber density with age and the decreased VP innervation after castration, but Goudsmit et al. (1988b) only found a significant diminished staining in the central gray and locus coeruleus. They argued that the intense staining in their study as compared to the study of Fliers et al. (1985) may have contributed to this difference. In the present study changes in VP concentrations in some of the structures of which the VP innervation depends on testosterone, were not observed with radioimmunoassay either. In accordance with the previous reports mentioned (Fliers et al. 1985, Goudsmit et al. 1988b) a decline in the VP concentration in the midbrain was found. Therefore, the only consistent decline in VP concentration related to a testicular decline in aged rats, appears to be observed in the midbrain. This is an important finding, since the release of VP in midbrain structures appears to be especially important for improved performance of rats in the passive avoidance test (Hoffman 1987). In this context, it is interesting to note that the 
impairment in conditioned taste aversion in old rats can be restored by administration of VP (Cooper et al. 1980).

The high correlation between concentrations of VP in the amygdala and pineal gland suggests that the concentration of VP in these structures is regulated by a common factor. This factor cannot be testosterone since the decrease in plasma testosterone concentration is too modest to explain the sharp decrease in VP concentration in the amygdala and pineal gland between 3 and 10 months of age. Another alteration that occurs with maturation in Wistar rats is the loss of $\beta$-adrenergic receptors in the pineal gland during the light period after three months of age (Dax and Sugden 1988). Whether this alteration is related to the decrease in the concentration of VP in the pineal gland and how the concentrations in the pineal gland and amygdala are synchronized remains to be demonstrated. Significant correlations between changes in other structures were not observed. This may be related to the fact that the VP content at terminals is probably too variable to allow correlations in concentrations to be seen or that the changes have different underlying causes. With respect to the medulla oblongata, VP appears to be involved in central regulation of the cardiovascular reflex (Cowley and Liard 1987). The gradual decline in the concentration of VP in the medulla oblongata may be related to cardiovascular changes, and changes in the autonomic nervous system with age (e.g., decreased contractility of the cardiac muscle (Capasso et al. 1983), decreased sensitivity of target organs (Davies and Sever 1988), reduced parasympathetic (Buwalda et al. 1990) or increased sympathetic drive (Tanabe and Bunag 1989)). In fact, it has been shown that administration of VP in aged rats reinstates stress-related parasympathetic control of cardiac functioning (Nyakas et al. 1986).

In summary, vasopressinergic systems in the brain show different changes with age. The hypothalamo-neurohypophyseal system appears to be activated from middle-age onwards in Wistar rats. Changes observed in the amygdala and pineal gland are better characterized as being related to maturation rather than to aging. Structures of which the VP innervation is testosterone-dependent did not generally show a decline in VP concentrations with age. The present results indicate that it is important to use more than two age groups in aging studies in which young and old are compared. In addition, the observation that aging in relation to the vasopressinergic systems is already apparent in middle-age deserves further investigation.

\section{References}

Aravich PF, Sladek JR Jr. Aging of rodent VP systems. In: Gash DM, Boer GJ, eds. Vasopressin. Principles and properties. New York: Plenum Press, 1987:579-610.

Barden N, Dupont A, Labrie F, Mérand Y, Rouleau D, Vaudry H, Boissier JR. Age-dependent changes in $\beta$ endorphin content of discrete rat brain nuclei. Brain Res 1981;208:209-12.

Bengele HH, Mathias RS, Perkins JH, Alexander EA. Urinary concentration defect in the aged rat. Am J Physiol 1981;240:F147-50.

Burbach JPH, Wang X-T, Ten Haaf JA, De Wied D. Substances resembling C-terminal vasopressin fragments are present in the brain but not in the pituitery gland. Brain Res 1984;306-7. 
Buwalda B, Nyakas C, Strubbe JH, Hoes M, Bohus B. Age-related reduction in parasympathetic responses in the rat. In: Van Bezooijen CFA, Ravid R, Verhofstad AAJ, eds. From gene to man. Gerontological research in the Netherlands. Rijswijk: Stichting Gerontologie en Geriatrie, 1990:90-4.

Capasso JM, Ashwani M, Remily RM, Scheuer J, Sonnenblick EH. Effects of age on mechanical and electrical performance of rat myocardium. J Am Physiol 1983;245:H72-81.

Chambers KC, Phoenix $\mathrm{CH}$. Testosterone and the decline in sexual behavior in aging male rats. Behav Neural Biol 1984;40:87-97.

Coleman P. Finch C, Joseph J. The need for multiple time points in aging studies. Neurobiol Aging 1990;11:1-2.

Cooper RC, MCNamara MC, Thompson WG. Vasopressin and conditioned flavor aversion in aged rats. Neurobiol Aging 1980;1:53-7.

Cowley AW, Liard JF. Cardiovascular actions of vasopressin. In: Gash DM, Boer GJ, eds. Vasopressin. Principles and properties. New York: Plenum Press, 1987:389-433.

Davies IB, Sever PS. Adrenoceptor function. In: Bannister R, ed. A textbook of clinical disorders of the autonomic nervous system. Oxford: Oxford University Press, 1988:348-66.

Dax EM, Sugden D. Age-associated changes in pineal adrenergic receptors and melatonin synthesizing enzymes in the Wistar rat. J Neurochem 1988;50:468-72.

De Vries GJ, Buijs RM, Van Leeuwen FW, Caffe AR, Swaab DF. The vasopressinergic innervation of the brain in normal and castrated rats. J Comp Neurol 1985;233:236-54.

Dorsa DM, Bottemiller LM. Age-related changes of vasopressin content of microdissected areas of the rat brain. Brain Res 1982;242:151-6.

Dupont A, Savard P, Mérand Y, Labrie F, Boissier JR. Age-related changes in central nervous system enkephalins and substance P. Life Sci 1981;29:2317-22.

Ferguson AV, Bauce L, Cooper KE. An investigation of the age-related deficits in the fibrile response of the rabbit. Am J Physiol 1983;245:R379-85.

Fliers E, Swaab DF. Activation of vasopressinergic and oxytocinergic neurons during aging in the Wistar rat Peptides 1983;4:165-70.

Fliers E, De Vries E, Swaab DF. Changes with aging in the vasopressin and oxytocin innervation of the rat brain. Brain Res 1985;348:1-8.

Gallagher M, Pelleymounter A. Spatial learning deficits in old rats: a model for memory decline in the aged. Neurobiol Aging 1988;9:549-56.

Gambert SR, Garthwaite TL, Pontzer CH, Hagen TC. Age-related changes in central nervous system betaendorphin and ACTH. Neuroendocrinology 1980;31:252-5.

Gispen WH, Schotman P, De Kloet E. Brain RNA and hypophysectomy; a topographical study. Neuroendocrinology 1972;9:285-96.

Goudsmit E, Fliers E, Swaab DF. Vasopressin and oxytocin excretion in the Brown-Norway rat in relation to ageing, water metabolism and testosterone. Mech Ageing Dev 1988a;44:241-52.

Goudsmit E, Fliers E, Swaab DF. Testostcrone supplementation restores vasopressin innervation in the senescent rat brain. Brain Res 1988b;473:306-13.

Goudsmit E, Luine VN, Swaab DF. Testosterone locally increases vasopressin content but fails to restore choline acetyltransferase activity in other regions in the senescent male rat brain. Neurosci Lell 1990;112:2906.

Hoffman PL. Central nervous system effects of neurohypophyseal peptides. In: Udenfriend S, Meienhofer J, eds. Chemistry, biology, and medicine of neurohypophyseal hormones and their analogs. Orlando: Academic Press, 1987:239-95.

Kaler LW, Neaves WB. The androgen status of aging male rats. Endocrinology 1981;108:712-9.

Kasting NW. Criteria for establishing a physiological role for brain peptides. A case in point: the role of vasopressin in thermoregulation during fever and antipyresis. Brain Res Rev 1989;14:143-53.

Kirkland J, Lye M, Goddard G, Vargas E, Davies I. Plasma arginine vasopressin in dehydrated elderly patients. Clin Endocrinol 1984;20:451-6.

Liu B, Burbach JPH, Fernstrom JD, Antoni FA. The hypothalamus is not the origin of vasopressin and oxytocin in the rat pineal gland. Neuroendocrinology 1991;53:523-7.

Meites J, Goya R, Takahashi S. Why the neuroendocrine system is important in aging processes. Exp Biol 
1987;22:1-15.

Miller M. Influence of aging on vasopressin secretion and water regulation. In: Schrier RW, ed. Vasopressin. New York: Raven Press, 1985:165-70.

Miller MM, Joshi D, Billiar RB, Nelson JF. Loss of LH-RH neurons in the rostral forebrain of old female C57BL/6J mice. Neurobiol Aging 1990;11:217-21.

Negro-Vilar A, Samson WK. Dehydration-induced changes in immunoreactive vasopressin levels in specific hypothalamic structures. Brain Res 1979;169:585-9.

Nyakas C, Prins AJA, Bohus B. Cardiac responses and behavioral reactivity to emotional stress in aged rats. Proc 27th Dutch Fed Meeting, 1986:295.

Ogawa N, Hirose Y, Nomura M. Biochemical and functinal aspects of neuropeptides and their receptors in aged-rat brain. In: Yoshida H, ed. Recent research on transmitter receptors. Amsterdam: Excerpta Medica, 1986;56-71.

Os I, Kjelsen SE, Aakesson I, Skjøtø J, Eide I, Hjermann I, Leren P. Evidence of age-related variation in plasma vasopressin of normotensive men. Scand J Clin Invest 1985;45:263-8.

Ravid R, Fliers E, Swaab DF, Zurcher C. Changes in vasopressin and testosterone in the senescent BrownNorway (BN/BiRij) rat. Gerontology 1987;33:87-98.

Reymond MJ, Donda A, Lemarchand-Béraud T. Neuroendocrine aspects of aging: experimental data. Horm Res 1989;31:32-8.

Silverman WF, Aravich PA, Sladek JR Jr, Sladek CD. Physiological and biochemical indices of neurohypophyseal function in the aging Fischer rat. Neuroendocrinology 1990;52:181-90.

Sladek CD, McNeill TH, Gregg CM, Blair ML. Vasopressin and renin response to dehydration in aged rats. Neurobiol Aging 1981;2:293-302.

Sofroniew MV. Vasopressin, oxytocin and their related neurophysins. In: Bjorklund AJ, Hökfelt T, eds. Handbook of chemical neuroanatomy; vol 4: GABA and neuropeptides in the CNS; part I. Amsterdam: Elsevier, 1985:93-165.

Swaab DF. Brain aging and Alzheimer's disease, "wear and tear" versus "use it or lose it". Neurobiol Aging 1989:12:317-24

Tanabe TS, Bunag RD. Age-related central and baroreceptor impairment in female Sprague-Dawley rats. Am J Physiol 1989;256:H1399-406.

Ten Haaf JA, Terwel D, Van de Heijning HJM, Van Wimersma Greidanus TjB. Radioimmunoassay: a goal or a tool? J Control Rel 1992 (in press).

Verney EB. The antidiuretic hormone and the factors which determine its release. Proc Roy Soc 1947;B 135:25106.

Wei JY, Mendelowitz D, Anastasi N, Rowe JW. Influence of age on cardiovascular reflex response in aneschetized rats. Am J Physiol, 1985;249:R31-8.

Zbuzek VK, Wu W. Age-related vasopressin changes in rat plasma and the hypothalamo-hypophyseal system. Exp Gerontol 1982;17:133-8.

Zbuzck VK, Zbuzek V, Wu W. The effect of aging on vasopressin system in Fischer 344 rats. Exp Gerontol 1983;18:305-11.

Zerbe RL, Palkovits M. Changes in the vasopressin content of discrete brain regions in response to stimuli for vasopressin secretion. Neuroendocrinology 1984;38:285-9. 


\title{
EFFECTS OF AGING AND CASTRATION ON VASOPRESSIN CONCENTRATIONS IN THE BRAIN OF MALE BROWN-NORWAY RATS
}

\author{
Dirk Terwel, Marjanne Markerink, Jellemer Jolles
}

\begin{abstract}
The purpose of the prescnt study was to investigate whether changes in vasopressin (VP) concentrations with aging can be explained by changes in testicular function. VP concentrations were determined by radioimmunoassay in cleven brain structures and blood plasma of adult intact, adult castrated and aged Brown-Norway rats. Castration resulted in a profound reduction $(>80 \%)$ in the concentration of VP in the septum, amygdala, mesencephalon, hippocampus and anterior part of the medulla oblongata. Lower concentrations (approximately 30\%) of VP were found in the same brain structures with aging. Castration did not affect the neurosecretory activity of the hypothalamo-neurohypophyseal system (HNS) but aging did. Concentrations of VP in the hypothalamus and pituitary gland of aged rats were reduced by $40 \%$ to $50 \%$. Testicular weight was much reduced in aged animals, indicating a decreased testosterone status. The results of the present study suggest that a reduction in the testosterone status of aged rats leads to a reduction in VP concentrations in areas in which the vasopressinergic innervation depends on testosterone. As testosterone does not appear to affect neurosecretory activity by a direct action on the brain, reduced testicular function cannot explain reduced neurosecretory activity with age.
\end{abstract}

\section{Introduction}

There is extensive literature on the effects of aging and castration on vasopressinergic systems in the brain. Effects of aging on the hypothalamoneurohypophyseal (HNS) as well as on other vasopressinergic systems in the brain have been reported (see Aravich and Sladek (1987) for a review). The HNS has been found to be activated in old Wistar rats (Fliers and Swaab 1983, Terwel et al. 1992) and a reduced staining of extrahypothalamic vasopressinergic fibers has been reported in aged Brown-Norway rats (Fliers et al. 1985, Goudsmit et al. 1988b). Castration has been reported to increase neurosecretory activity in the HNS (Swaab and Jongkind 1970) but to arrest vasopressin (VP) synthesis in extrahypothalamic neurons (De Vries et al. 1985).

Concentrations of circulating testosterone decrease with age in several strains of laboratory rats (Chambers and Phoenix 1984, Goudsmit et al. 1988b, Kaler and Neaves 1984), which may explain the effects of age on concentrations of VP in the brain. However, reduced concentrations of VP with age have not been consistently found. For instance, in a previous study with Wistar rats we did not find reduced concentrations of VP in various brain structures in which the vasopressinergic innervation depends on testosterone (Terwel and Markerink 1990).

The purpose of the present study was to determine to what extent changes in VP concentrations with age can be explained by a decline in testicular function. The effects of aging and castration were assessed simultaneously in Brown-Norway rats. 
Brown-Norway rats were used, because a decline in testicular function with aging (Ravid et al. 1987, Goudsmit et al. 1988b) and a reduction in immunocytochemical staining for VP have been reported in this strain (Fliers et al. 1985).

\section{Materials and methods}

\section{Experimental animals}

Young ( 4 weeks) and aged (25-30-month-old) Brown-Norway rats (BN/BiRij) were purchased from IVEG TNO (Rijswijk, The Netherlands) in two shipments and were housed under controlled temperature $(21 \circ \mathrm{C})$ and humidity $(55 \%)$ with free access to food and water. Lights were on from 09.00 to 21.00 . The young animals $(n=8)$ were 7 months old and the old animals $(n=9)$ were $28-33$ months old when used. Five 3-month-old rats (BN/BiRij) of our own stock were castrated and five other animals were sham operated. Five months later the 8-month-old animals were used for experiments.

\section{Brain dissection and plasma collection}

Rats were decapitated at midday and trunk blood was collected into chilled heparinized tubes. Eleven discrete brain regions were dissected from the brain essentially according to Gispen et al. (1972).

\section{Determination of VP concentrations in brain tissue and plasma}

Tissuc- and plasma VP concentrations were determined in triplicate as reported previously (Ten Haaf et al. 1992). Briefly, brain tissue samples were homogenized in $1 \mathrm{M}$ acetic acid. These homogenates were boiled and centrifuged $(50,000 \mathrm{~g}, 30$ minutes, $4 \circ \mathrm{C})$. Supernatants were evaporated under vacuum and the dry residues obtained were washed with $50 \%$ ethanol; the wash fluid was lyophilized. VP was extracted from plasma samples using heat-activated Vycor ${ }^{\circledR}$ glass powder (Coming Glass Works, New York) (Dogterom et al. 1978). Residues obtained with extraction were resuspended and diluted in assay buffer. VP concentrations were measured by radioimmunoassay at a volume of $100 \mu \mathrm{l}$, using antiserum $W 1$ in a final dilution of 1:512,000 (Burbach et al. 1984). Assay tubes contained 1 fmol iodinated VP $(2 \mathrm{nCi})$, purchased from Amersham. After $72 \mathrm{~h}$ of incubation, bound and free ligand were separated with Ficoll®-dextran-coatcd charcoal (Ten Haaf et al. 1992). The assay was internally standardized to correct for nonspecific interference and recovery losses. Internal standards were prepared from 1 -ml portions of VP-free plasma or homogenate of rat brain tissue to which known amounts of VP (Sigma) had been added. VP-free plasma was obtained by preextraction with glass powder. VP-free tissue homogenate was obtained by homogenization of the cortex and cerebellum in bidistilled water and incubation at $37{ }^{\circ} \mathrm{C}$ for $3 \mathrm{~h}$, which degrades endogenous VP. After incubation, the homogenate was acidified to $1 \mathrm{M}$ acetic acid. The tissue concentration in the internal tissue standards was always the same as in the unknown sample homogenates. Displacement of tracer by extracted intemal standards versus the amounts of VP added to the portions of plasma or tissue homogenate served as intemal standard curves. Intra- and interassay coefficients of variation for the determination in plasma were $7.1 \%$ and $8.6 \%$, respectively. Recovery as traced with iodinated VP was approximately $90 \%$ for the extraction from tissue and $80 \%$ for the extraction from plasma. The intra- and inter-assay coefficients of variation for the determination in tissue were $10.6 \%$ and $12.1 \%$, respectively. Nonspecific binding was $<3 \%$ and binding of tracer by excess antibody was $90 \%$. The detection limit was $0.4 \mathrm{pmol} / 1 \mathrm{plasma}$ or $0.4 \mathrm{pmol} / \mathrm{g}$ protein.

\section{Osmometry}

Osmolality was determined in $50-\mu \mathrm{l}$ samples of freshly prepared plasma in triplicate by freezingpoint depression, using a cryoscopic osmometer (Osmostat 030; Gonotec, Berlin, FRG). The intraassay cocfficient of variation of median values of samples measured in triplicate was $0.18 \%$. The interassay coefficient of variation of median values of the standard measured in triplicate was $0.31 \%$. The apparatus was carefully calibrated with a standard supplied by the manufacturer. 


\section{Statistics}

A statistics package was used for statistical analysis (StatView $512+{ }^{\text {TM }}$ ). Data were subjected to unpaired Student's t-tests.

Table 1. Parameters related to water metabolism in intact and castrated Brown-Norway rats. Values represent means \pm SEM. Significant differences are indicated by asterisks.

\begin{tabular}{|c|c|c|c|c|c|}
\hline $\begin{array}{l}\text { Rat weight } \\
\text { (g) }\end{array}$ & $\begin{array}{l}\text { Testicular } \\
\text { weight } \\
\text { (g) }\end{array}$ & $\begin{array}{l}\text { Water intake } \\
(\mathrm{ml} / 24 \mathrm{~h} / \\
100 \mathrm{~g})\end{array}$ & $\begin{array}{l}\text { Total water } \\
\text { intake } \\
(\mathrm{ml} / 24 \mathrm{~h})\end{array}$ & $\begin{array}{l}\text { Plasma } \\
\text { osmolality } \\
(\mathrm{mOsm} / \mathrm{kg})\end{array}$ & $\begin{array}{l}\text { Plasma VP } \\
\text { concentration } \\
\text { (pmol//) }\end{array}$ \\
\hline
\end{tabular}

$\begin{array}{llcccll}\text { Intact } & 353 \pm 3 & 3.5 \pm 0.4 & 5.6 \pm 0.1 & 19.9 \pm 0.3 & 304 \pm 1 & 1.4 \pm 0.3 \\ \text { Castrated } & 308 \pm 16^{*} & - & 6.3 \pm 0.2 & 18.5 \pm 0.9 & 310 \pm 2^{*} & 2.9 \pm 0.9\end{array}$

${ }^{*} \mathrm{p}<0.01$

\section{Results}

Fig. 1 shows the effects of castration on concentrations of VP in a number of brain structures. Concentrations of VP were reduced by $91 \%, 82 \%, 97 \%$ and $77 \%$, and below detectable levels in the septum, amygdala, mesencephalon and hippocampus, and anterior part of the medulla oblongata, respectively ( $<<0.001$, Fig. 1C,D,E). Concentrations of VP remained unaltered in the neurointermediate lobe of the pituitary gland (Fig. 1A), hypothalamus (Fig. 1B), thalamus, olfactory bulb, posterior part of the medulla oblongata and pineal gland (Fig. 1C,D,E) $(p>0.05)$. Total water intake, water intake per $100 \mathrm{~g}$ body weight and plasma VP concentration were unaltered by castration $(\mathrm{p}>0.05)$, but osmolality was increased by $6 \mathrm{mOsm} / \mathrm{kg}(\mathrm{p}<$ 0.05 ) (Table 1). Body weight was lower in castrated rats compared with intact rats ( $p$ $<0.05$, Table 1).

Tabel 2. Parameters related to water metabolism in adult and aged Brown-Norway rats. Values represent means $\pm S E M$. Significant differences are indicated by asterisks.

\begin{tabular}{|c|c|c|c|c|c|}
\hline & $\begin{array}{l}\text { Testicular } \\
\text { weight } \\
\text { (g) }\end{array}$ & $\begin{array}{l}\text { Water intake } \\
(\mathrm{ml} / 24 \mathrm{~h} / \\
100 \mathrm{~g})\end{array}$ & $\begin{array}{l}\text { Total water } \\
\text { intake } \\
\text { (ml/24h) }\end{array}$ & $\begin{array}{l}\text { Plasma } \\
\text { osmolality } \\
\text { (mOsm/kg) }\end{array}$ & $\begin{array}{l}\text { Plasma VP } \\
\text { concentration } \\
\text { (pmol/h) }\end{array}$ \\
\hline
\end{tabular}

$\begin{array}{lllllll}\text { Adult } & 362 \pm 7 & 3.5 \pm 0.1 & 8.4 \pm 0.5 & 30.3 \pm 1.6 & 308 \pm 1 & 1.7 \pm 0.5 \\ \text { Aged } & 429 \pm 9^{* *} & 1.6 \pm 0.2^{* *} & 8.7 \pm 0.5 & 37.5 \pm 2.3^{*} & 310 \pm 1 & 5.5 \pm 1.3^{*}\end{array}$

${ }^{*} \mathrm{P}<0.05,{ }^{* * \mathrm{P}}<0.001$ 

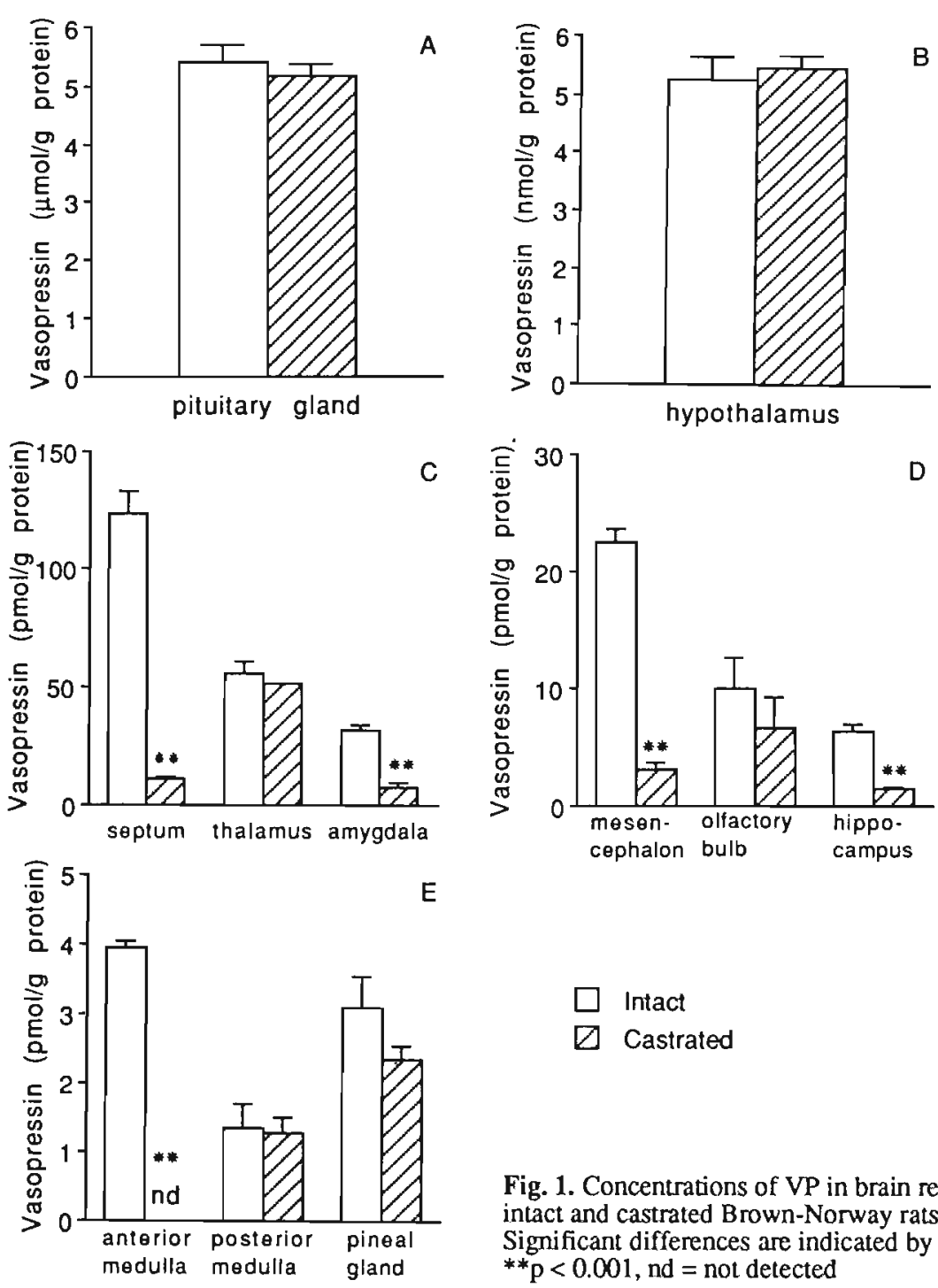

Fig. 1. Concentrations of VP in brain regions of intact and castrated Brown-Norway rats.

Significant differences are indicated by asterisks. ${ }^{* *} \mathrm{p}<0.001$, nd $=$ not detected

In aged rats compared with adult rats concentrations of VP were reduced in most areas in which VP disappeared after castration: by $28 \%$ in the septum, $\mathrm{p}<0.001$; by $31 \%$ in the amygdala, $\mathrm{p}<0.05$; by $32 \%$ in the mesencephalon, $\mathrm{p}<0.001$; and by $53 \%$ in the anterior part of the medulla oblongata, $p<0.05$ (Fig. 2C,D,E). Concentrations of VP were also reduced in areas in which the concentration of VP was not affected by castration: by $48 \%$ in the pituitary gland, $p<0.001$ (Fig. $2 \mathrm{~A}$ ); by $43 \%$ in the 
hypothalamus, $\mathrm{p}<0.001$ (Fig. 2B); and by $40 \%$ in the posterior part of the medulla oblongata, $\mathrm{p}<0.001$ (Fig. 2E). VP concentrations were not altered in the olfactory bulb, hippocampus and pineal gland ( $p>0.05$, Fig. 2D,E). Total water intake was higher in aged than in adult rats $(p<0.05)$, but water intake per $100 \mathrm{~g}$ body weight was unaltered ( $p>0.05)$; plasma VP concentration was increased $(p<0.05)$, but plasma osmolality was unaltered in aged rats as compared with adult rats $(p>0.05)$; testicular weight was reduced by $64 \%$ in aged as compared with adult animals $(\mathrm{p}<$ 0.05 ) (Table 2).
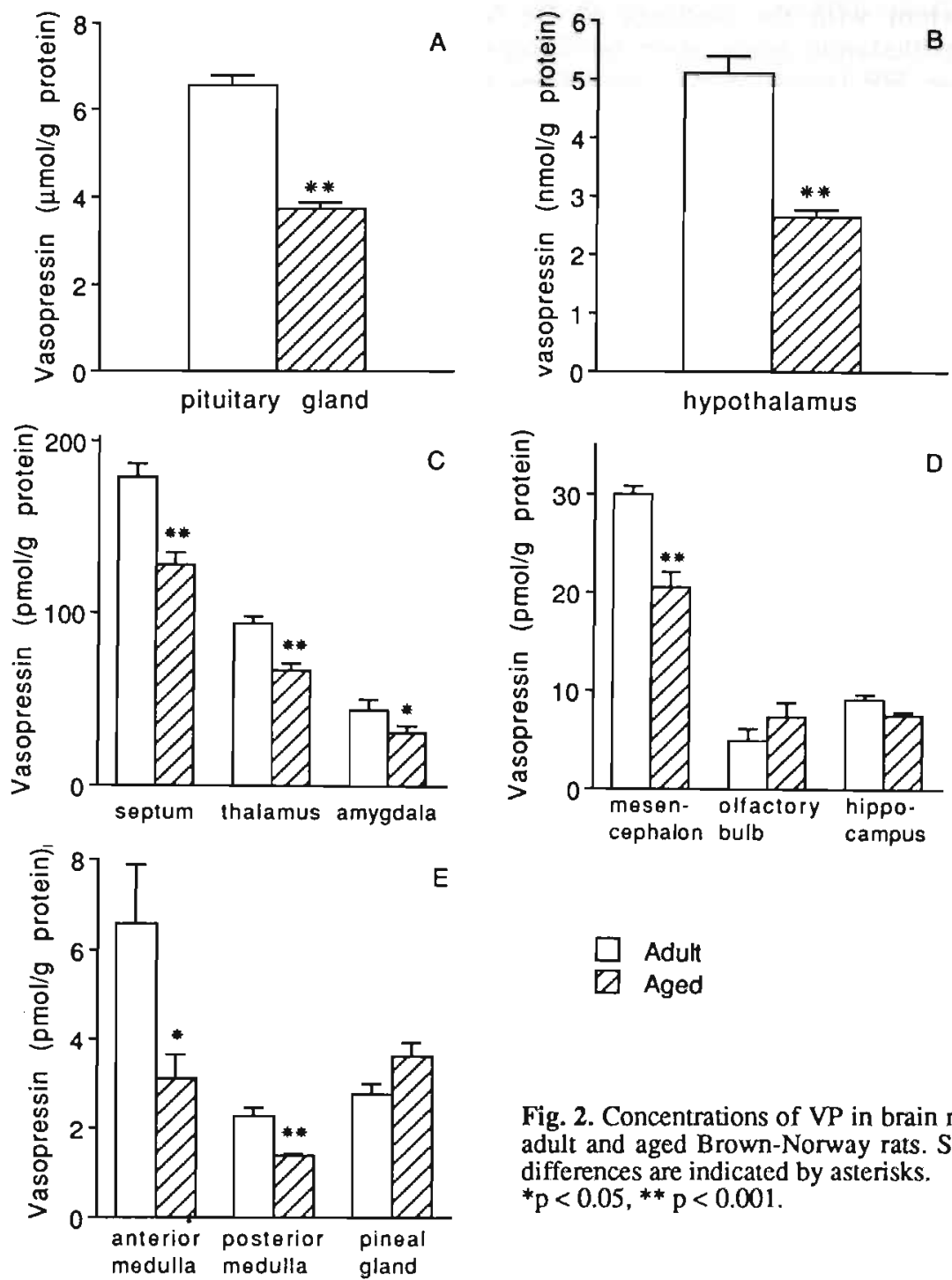

Fig. 2. Concentrations of VP in brain regions of adult and aged Brown-Norway rats. Significant differences are indicated by asterisks. ${ }^{*} p<0.05,{ }^{* *} p<0.001$. 


\section{Discussion}

VP concentration, water intake and osmolality were different in the control groups used in the castration and aging experiments. These differences can probably be ascribed to the fact that the animals were obtained from different suppliers, even though the Brown-Norway strain is an inbred strain. These differences do not invalidate the present findings if it is assumed that the effects of aging and castration can be generalized over colonies of rats. This is a topic we are currently investigating.

The effects of castration on extrahypothlamic concentrations of VP agreed to a large extent with the findings of De Vries et al. (1985) with respect to the extrahypothalamic innervation by vasopressinergic fibers after castration. After castration, VP largely disappeared from the amygdala, septum, hippocampus and mesencephalon. We did not note a decline in the VP concentration of the thalamus after castration, despite the fact that the piece of brain tissue taken as the thalamus contained the bed nucleus of the stria terminalis and the lateral habenula, the former containing neurons and the latter fibers from which VP disappears after castration (De Vries et al. 1985). It is possible that the VP content of these structures does not contribute significantly to the total amount of VP present in the thalamus.

VP did not disappear from the olfactory bulb and pineal gland after castration, which may indicate that these structures do not receive inputs from nuclei in which the synthesis of VP depends on testosterone, i.e. the medial amygdala and bed nucleus of the stria terminalis (De Vries et al. 1985). It has recently been reported that VP concentration in the pineal gland changes during the oestrous cycle in rats (Moujir et al. 1990). Testosterone is converted into oestradiol by an aromatase in some brain structures (Roselli et al. 1985). Since castration did not result in changed VP concentrations in the pineal gland, either the changes in VP concentration in the pineal gland during the oestrous cycle do not seem to be brought about by changes in the plasma oestradiol concentration or the site at which oestradiol acts to influence the concentration of VP in the pineal gland is unable to convert testosterone. In addition to a vasopressinergic innervation (De Vries et al. 1985), the anterior part of the medulla oblongata contains the vasopressinergic neurons of the locus coeruleus (Caffé and Van Leeuwen 1983). To explain the disappearance of VP from this structure, it must be assumed that VP disappeared from both the VP-containing fibers derived from the bed nucleus of the stria terminalis and from cell bodies of the locus coeruleus.

Several sources of the vasopressinergic innervation of the septum have been indicated. Vasopressinergic inputs from the bed nucleus of the stria terminalis and the medial amygdala to the lateral septum were demonstrated using lesioning, and anterograde and retrograde tract-tracing methods (Caffé et al. 1987). Recently, a vasopressinergic connection from the paraventricular nucleus to the lateral septum was visualized with a double-labeling method (Staiger and Nürnberger 1989). However, the present observation that castration reduced the VP content of the septum by $91 \%$, together with the fact that castration has not been shown to affect immunocytochemical staining for VP in any of the subdivisions of the paraventricular nucleus (Bluthé et al. 1990), suggests that the vasopressinergic input from the 
paraventricular nucleus to the septum is of minor importance.

It has been reported that neurosecretory activity is both increased (Swaab and Jongkind 1970) and reduced (Crofton et al. 1985) in castrated male rats. Our results do not corroborate either of these findings, in that changed VP concentrations were not found in the HNS and plasma after castration. In the present study, concentrations of VP were measured five months after castration, whereas in other studies this was carried out only after a few weeks. In contrast to others, Crofton et al. (1985) used animals that were castrated when they were three weeks of age. These experimental differences may well explain the observed differences in the effect of castration on neurosecretory activity. First, water homeostasis may not have attained a steady state a few weeks after castration. Second, immature animals should not be used in castration studies as castration may interfere with development. Our results suggest that in the long term castration does not affect neurosecretory activity.

The effects of aging on VP concentration in the HNS were not identical with the effects of castration. Decreased concentrations of VP were observed in the hypothalamus and pituitary with age and increased concentrations were observed in blood plasma, whereas castration did not affect VP concentrations. Thus age-related changes in neurosecretory activity do not appear to result from reduced concentrations of circulating testosterone in aged rats.

Since testicular function cannot explain the changes in VP concentration in the HNS and plasma with age, they must be explained by other factors. For instance, aging is accompanied by a decrease in renal concentrating ability (Beck and Yu 1982, Bengele et al. 1981, Miller 1985). Whether this reduced kidney function, which is monitored under conditions of increased osmolality, also leads to changes in water homeostasis under basal conditions is the subject of a long-standing debate which has been clouded by strain differences and many other variables which are difficult to control in aging studies (Aravich and Sladek 1987). In the present study we used a strain of rat that does not suffer from specific pathologies, such as pituitary tumors, testis tumors or chronic nephrosis (Zurcher and Hollander 1982) and which has been used a great deal for aging studies in The Netherlands. Parameters related to water metabolism in Brown-Norway rats have been measured in two previous studies. Ravid et al. (1987) found an unaltered urine volume per $100 \mathrm{~g}$ body weight, but an increased urine VP concentration, whereas Goudsmit et al. (1988a) found an increased urine volume, but an unaltered urine VP concentration. In the present study we found an unaltered water intake per $100 \mathrm{~g}$ body weight, but an increased total water intake and plasma VP concentration in aged rats compared with adult rats. It has been argued (Terwel et al. 1992) that total water intake or urine production may be a better measure of water homeostasis than water intake or urine production per $100 \mathrm{~g}$ body weight. Thus basal kidney function may be affected differently from one study to another. The release of VP into the blood is probably increased to sustain kidney function. However, it cannot be excluded that the release of VP is increased by factors other than kidney dysfuntion or reduced testosterone concentrations. It has even been suggested that the increased plasma VP concentration in aged rats represents increased handling stress (Silverman et al. 1990). However, with respect to our findings the 
influence of stress can be excluded. First, we handled our rats prior to experimentation. Second, plasma osmolality and plasma VP concentration showed a high correlation in aged rats (plasma VP concentration $=(-294.3+$ plasma osmolality) $\times 0.76, r=0.72, p<0.05)$. Previously, we made similar observations in Wistar rats (Terwel et al. 1992). Silverman et al. (1990) did not find increased plasma VP concentrations in Fischer 344 rats with age, although these rats increased their water intake. It may be concluded that Wistar and Brown-Norway rats are different from Fischer 344 rats in changes in water homeostasis with age. It is possible that in Wistar and Brown-Norway rats neurosecretory cells are activated with age due to a kidney dysfunction, while in Fischer 344 rats neurosecretory activity cannot respond to kidney dysfunction.

The structures in which the concentrations of VP were affected by castration were also affected by age, but to a far less extent. In other words, a decreased testicular function with age, clearly indicated by the reduced testicular weight, only moderately affected concentrations of VP in the brain compared with castration. Fliers et al. (1985) found that areas from which VP disappears after castration were affected by aging; however, as they used immunocytochemistry they presented only semiquantitative data. The concentration of VP in the posterior part of the medulla oblongata was not affected by castration, but it was affected by age. The vasopressinergic innervation of this part of the brain is derived from the paravocellular part of the paraventricular nucleus, and therefore, the paraventricular vasopressinergic system may be affected by age. To what extent the decline in extrahypothalamic concentrations of VP impairs neuronal function is a matter of future research, but administration of VP to aged animals has been shown to reinstate certain age-related impairments in cardiovascular function (Nyakas et al. 1986) and performance in behaviors designed to evaluate memory (Cooper et al. 1980).

In summary, age-related changes in concentrations of VP in the HNS do not appear to be related to a changed testosterone status in Brown-Norway rats. Most of the alterations in VP concentrations in extrahypothalamic areas may be related to a decreased testosterone status, but these changes are quite modest compared to the changes observed as a result of castration.

\section{References}

Aravich PF, Sladek JR Jr. Aging of rodent VP systems. In: Gash DM, Bœer GJ, eds. Vasopressin. Principles and properties. New York: Plenum, 1987:579-610.

Beck N, Yu BP. Effect of aging on urinary concentrating mechanism and vasopressin-dependent cAMP in rats. Am J Physiol 1982;243:F121-5.

Bengele HH, Mathias RS, Perkins JH, Alexander EA. Urinary concentrating defect in the aged rat. Am J Physiol 1981;240:F147-50.

Bluthe R-M, Schoenen J, Dantzer R. Androgen-dependent vasopressinergic neurons are involved in social recognition in rats. Brain Res 1990;519:150-7.

Burbach JPH, Wang X-C. Ten Haaf JA, De Wied D. Substances resembling C-terminal vasopressin fragments are present in the brain but not in the pituitary gland. Brain Res 1984;306:384-7. 
Caffé AR, Van Leeuwen FW. Vasopressin-immunoreaclive cells in the dorsomedial hypothalamic region, medial amygdaloid nucleus and the locus coeruleus of the rat Cell Tissuc Res 1983:233:23-33.

Caffe AR, Van Leeuwen FW, Luiten PGM. Vasopressin cells in the medial amygdala of the rat project to the lateral septum and ventral hippocampus. J Comp Neurol 1987;261:237-52.

Chambers $\mathrm{KC}$, Phoenix $\mathrm{CH}$. Testosterone and the decline of sexual behavior in aging male rats. Behav Neural Biol 1984;40:87-97.

Cooper RC, McNamara MC, Thompson WG. Vasopressin and conditioned flavor aversion in aged rats. Neurobiol Aging 1980;1:53-7.

Crofton JT, Baer PG, Share L, Brooks DP. Vasopressin release in male and female rats: effocts of gonadectomy and treatment with gonadal steroid hormones. Endocrinology 1985;117:1195-200.

De Vries GJ, Buijs RM, Van Leeuwen FW, Caffé AR, Swaab DF. The vassopressinergic innervation of the brain in normal and castrated rats. Comp Neurol 1985;233:239-54.

Dogterom J, Van Wimersma Greidanus TjB, De Wied D. Vasopressin in cerebrospinal fluid and plasma in man, dog, and rat. Am J Physiol 1978;234:E463-7.

Fliers E, Swaab DF. Activation of vasopressinergic and oxytocinergic neurons during aging in the Wistar rat. Peptides 1983;4:1-8.

Fliers E, De Vries GJ, Swaab DF. Changes with aging in the vasopressin and oxytocin innervation of the rat brain. Brain Res 1985;348:165-70.

Gispen WH, Schotman P, De Kloet ER. Brain RNA and hypophysectomy; a topographical study. Neuroendocrinology 1972;9:285-96.

Goudsmit E, Fliers E, Swaab DF. Vasopressin and oxytocin excretion in the Brown-Norway rat in relation to ageing, water metabolism and testosterone. Mech Ageing Dev 1988a;44:241-52.

Goudsmit E, Fliers E, Swaab DF. Testosterone supplementation restores vasopressin innervation in the senescent rat brain. Brain Res 1988b;473:306-13.

Kaler LW, Neaves WB. The androgen status of aging male rats. Endocrinology 1981;108:712-9.

Miller M. Influence of aging on vasopressin secretion and water regulation.In: Schrier RW, ed. Vasopressin. New York: Raven, 1985:249-58.

Moujir F, Sanchez Franco F, Santana C, Cacicedo L, Alonso R. Immunoreactive levels of pineal arginine vasopressin change during the rat estrous cycle. J Pineal Res 1990;8:359-66.

Nyakas C, Prins AJA, Bohus B. Cardiac responses and behavioral reactivity to emotional stress in aged rats. Proc 27th Dutch Fed Meeting 1986:295.

Ravid R, Fliers E, Swaab DF, Zurcher C. Changes in vasopressin and testosterone in the senescent BrownNorway (BN/BiRij) rat. Gerontology 1987;33:87-98.

Roselli CE, Horton LE, Resko JA. Distribution and regulation of aromatase activity in the rat hypothalamus and limbic system. Endocrinology 1985;117:2471-7.

Silverman WF, Aravich PA, Sladek JR Jr, Sladek CD. Physiological and biochemical indices of neurohypophyseal function in the aging Fischer rat. Neuroendocrinology 1990;52:181-90.

Skowsky WR, Swan L, Smith P. Effects of sex steroid hormones on arginine vasopressin in intact and castrated male and female rats. Endocrinology 1979;104:105-8.

Staiger JF, Nürnberger F. Pattem of afferents to the lateral septum in the puinea pig. Cell Tissue Res $1989 ; 257: 471-90$.

Swaab DF, Jongkind J. The hypothalamic neurosecretory activity during the oestrous cycle, pregnancy, parturition, lactation, and persistent oestrous, and after gonadectomy, in the rat. Neuroendocrinology 1970;6:133-45.

Ten Haaf JA, Terwel D, Van de Heijning HJM, Van Wimersma Greidanus TjB. Radioimmunoassay, a goal or a tool? J Control Rel 1992 (in press).

Terwel D, Markerink M. Age-related changes in vasopressin in the rat brain. In: Van Bezooijen CFA, Ravid R, Verhofstad AAJ eds. From gene to man - gerontological research in The Netherlands. Rijswijk: Stichting Gerontologie en Geriatrie, 1990:178-81.

Terwel D, Ten Haaf JA, Markerink M, Jolles J. Changes in plasma vasopressin concentration and plasma osmolality in relation to age and time of day in the male Wistar rat. Acta Endocrinol 1992;126:357-62.

Zurcher C, Hollander CF. Multiple pathological changes in aging rat and man. Exp Biol Med 1982;7:55-62. 



\title{
ALTERATIONS IN VASOPRESSINERGIC SYSTEMS IN THE RAT BRAIN IN RELATION TO AGE, STRAIN AND SEASON
}

\author{
Dirk Terwel, Marjanne Markerink, Jellemer Jolles
}

\begin{abstract}
Staining of vasopressinergic fibers has been reported to be strongly reduced with age in many brain regions of Brown-Norway rats, while only a few moderate decreases in concentrations of vasopressin (VP) have been found in Wistar rats. It is not known whether these disparate findings are due to real strain differences. The present study therefore is concemed with the comparison of VP concentrations in relation to age in three different strains of rats (ages 3,12 and 28 months; strains Lewis, Wistar and Brown-Norway). Since the factor time of year was considered a possible confounder, seasonal effects on VP concentrations were studied in Lewis rats. Independent of strain, the VP concentration in the pituitary was reduced in aged rats as compared with young and middle-aged rats. Since pituitary weight increased with age, total content of VP first increased in the pituitary and thereafter decreased. Effects of age on the hypothalamus were strain-dependent. VP concentrations in the hypothalamus did not change in Wistar rats with aging, but declined in the other strains examined. The midbrain was the only extrahypothalamic area in which a strain-independent effect of age on the concentration of VP was found. VP concentrations in the midbrain were lower in aged rats than in young and middle-aged rats. Strain-related differences in changes in concentrations of VP with age were observed in the medulla oblongata and hippocampus. VP concentrations in the medulla oblongata showed a continuous decline with age in Wistar and BrownNorway rats, but did not decline past middle-age in Lewis rats. VP concentrations in the hippocampus of Lewis rats were highest at middle-agc. It was also noticed in the present study that concentrations of VP differ in several brain regions among strains. Seasonal fluctuations in concentrations of VP were observed in the pincal gland only and occurred in all age groups. In the present study, reductions in testicular weight were found in aged Brown-Norway and Lewis rats, but not in aged Wistar rats, probably reflecting reduced testicular function in at least the former two strains. However, concentrations of VP did not generally decline with age in areas influenced by testosterone in any of the strains examined.
\end{abstract}

\section{Introduction}

The neuroendocrine hypothesis of aging states that there is a general decline in body functions with age, associated with a decrease in the ability to maintain homeostasis (Everitt and Meites 1989, Meites 1988). The literature presents a number of examples that describe relations between and within organs in favor of this hypothesis. Well known examples are the reduced secretion of hormones which results in impaired organ function (Meites 1988) and reduced transmitter synthesis in the brain which appears to be responsible for motor and memory impairments (Ingram 1985, Marshall and Berrios 1982, Rogers and Bloom 1985). Recently, studies have been carried out that describe age-related alterations in the brain in relation to altered levels of steroid hormones. Corticosterone secretion (Sapolsky 1992) and testosterone secretion are altered in aged rats (Chambers and Phoenix 1984, Goudsmit et al. 1988, Kaler and Neaves 1981). Interestingly, there are research findings that suggest that 
changes in testosterone levels with age influence VP concentrations in the brain. Testosterone influences the synthesis of VP in the medial amygdala and bed nucleus of the stria terminalis (De Vries et al. 1985) and it has been found that the influence of age on staining of vasopressinergic fibers resembled the effect of castration (Fliers et al. 1985). Staining for VP was reduced in all areas showing testosterone dependence, except the lateral septum. However, in a recent study in Wistar rats we only found modest decreases in concentrations of VP at a few extrahypothalamic sites (Terwel et al. 1992a). This presented us with the question whether age-related changes in concentrations of VP are strain-dependent and whether findings vary within a single strain.

While extrahypothalamic VP concentrations may be affected by decreased testicular function, concentrations of VP in the hypothalamus may be affected by decreased kidney function (Terwel et al. 1992a). Findings on this subject are inconsistent (see Aravich and Sladek 1987 for a review) and need to be re-assessed in independent studies using different strains of rats.

It has been reported that concentrations of VP change with season in the pineal gland, plasma and pituitary gland (Liu and Burbach 1987, Prechel et al. 1983, Zbuzek and Wu 1979). Therefore the possibility exists that season is a confounding factor in aging studies on VP concentrations, as suggested by Aravich and Sladek (1987) and Zbuzek and Wu (1982).

To assess whether the decline in renal and testicular function is associated with alterations in the vasopressinergic systems of the brain, concentrations of VP were determined simultaneously in various brain regions of rats of three different strains and of three different ages. Furthermore, concentrations of VP were determined in Lewis rats of different ages at different times of year to control for seasonal influences.

\section{Materials and methods}

\section{Animals}

In the present study Lewis (LEW/CrIBR), Brown-Norway (BN/BiRij) and Wistar (Bor:WISW(SPFCpb) rats were used. The Lewis and Brown-Norway strains are inbred strains. The Wistar strain is an outbred strain. Lewis and Brown-Norway rats were of our own stock and Wistar rats were purchased from Winkelmann (Borchen, FRG) at two months of age. The animals had free access to food (standard rat chow purchased from Hope Fanms, Woerden) and water, and were kept under standard controlled conditions (ambient temperature $21{ }^{\circ} \mathrm{C}$, relative humidity $55 \%$ ). The lights in the animal house were on from 09.00 to 21.00. In experiment 1 (determination of VP concentrations in rats of different strains and different ages) Lewis, Brown-Norway and Wistar rats of 3,12 and 28 months of age were used. Groups consisted of 5-8 animals. For experiment 2 (seasonal determination of VP concentrations) Lewis rats of three months of age were decapitated in May, July, August, September, November, February. Lewis rats of 12 and 28 months of age were decapitated in May, July and August. Groups consisted of 5 animals. Animals were decapitated in the late morning or early aftemoon and trunk blood was collected into chilled heparinized tubes. Brains were removed from the skull and dissected into a number of structures using a pair of sharp forceps. 
Tissue was homogenized in $1 \mathrm{M}$ acetic acid in a Wheaton tissue grinder (tissue concentration maximally $32 \mathrm{~g} / 1$ ). The homogenates were boiled for 5 minutes and subsequently centrifuged at $50,000 \mathrm{~g}$ for 30 minutes. Supematants were frozen at $-80^{\circ} \mathrm{C}$ and evaporated under vacuum (Speed Vac Concentrator). The residues obtained after acetic acid extraction were resuspended in $1 \mathrm{ml} 50 \%$ ethanol $(v / v)$ and insoluble material was spun down $(50,000 \mathrm{~g}, 30$ minutes). Supematants were again evaporated under vacuum. The residues were resuspended in assay buffer and small amounts of insoluble material were spun down. Aliquots of the supernatants were appropriately diluted for radioimmunoassay.

\section{Radioimmunoassay of $V P$}

Antiserum W1 used in this study was a gift of Dr. Tj.B. van Wimersma Greidanus (University of Utrecht, The Netherlands). Radioimmunoassay of VP was carried out as described previously (Ten Haaf et al. 1992). A Veronal buffer, pH 8.0, was used as a diluent and contained, unless otherwise indicated, $20 \mathrm{mmol} / \mathrm{l}$ 5,5-diethylbarbituric acid, $10 \mathrm{mmol} / \mathrm{h} \mathrm{Na}{ }_{2}$ EDTA, $155 \mathrm{mmol} / / \mathrm{NaCl}, 66 \mu \mathrm{mol} / \mathrm{L} \mathrm{L}$ cystine and $4 \mathrm{~g} / \mathrm{l}$ human serum albumin. To polystyrene tubes $50 \mu \mathrm{l}$ appropriately diluted tissue extract, $25 \mu$ tracer solution ( $1 \mathrm{fmol}(2 \mathrm{nCi})$ [3-iodotyrosyl2arginyl ${ }^{8}$ ]vasopressin, Amersham) and 25 $\mu \mathrm{l}$ diluted antiserum (final dilution 1:512,000) were added. After $72 \mathrm{~h}$ incubation at $40 \mathrm{C}, 100 \mu \mathrm{l}$ of a charcoal (Sigma) suspension was added to separate bound from free ligand. The charcoal suspension contained $3.75 \mathrm{~g} / \mathrm{l}$ Ficoll $400 \otimes$ (Pharmacia), $3.75 \mathrm{~g} / \mathrm{l}$ dextran, $40 \mathrm{~g} / \mathrm{l}$ charcoal and $50 \mathrm{mmol} / \mathrm{l}$ phosphate, $\mathrm{pH} 7.4$. The assay was corrected for nonspecific interference by addition of equivalent amounts of tissue extract devoid of VP to the tubes as of unknown sample extracts (Ten Haaf et al. 1992). Recovery of iodinated VP was $>90 \%$. No correction was made for recovery losses.

\section{Statistics}

For statistical analysis a statistics package (SuperANOVA, Abacus) was used. Data were subjected to a two factor (season $x$ age or strain $x$ age) analysis of variance. When main effects were found (with no interaction between factors), data were subjected to one factor (age or strain) analysis of variance and the post hoc Student-Newman-Keuls test for multiple comparison. When interactions between factors were found, analysis of variance for data on separate strains or ages was carried out, followed by the Student-Newman-Keuls multiple comparison test.

\section{Results}

Testicular weight, brain tissue weights, and pituitary and pineal gland protein contents. Tissue weights and protein contents are given in Table 1. Testicular weight was determined as a measure of testicular function with age. Brain tissue weight was determined because of the possible relevance for the interpretation of age-related changes in VP concentrations. For technical reasons pineal- and pituitary gland protein contents were determined instead of weight. Tissue weights or protein contents were affected by age, except pineal gland protein content (Appendix I). Main effects of strain were found on weights of the testes, medulla oblongata, amygdala and hypothalamus, and protein contents of the pituitary and pineal gland, but not on weights of the mesencephalon, hippocampus and septum (Table 1, see also Appendix I). Interactions between age and strain occurred on weights of the testes and hypothalamus (Table 1, see also Appendix I). Student-Newman-Keuls post hoc multiple comparison between age groups demonstrated the following differences. The weight of the medulla oblongata and the pituitary protein content were lowest in 3- 
Table 1. Testicular weight, brain tissue weights or protein contents in Lewis (L), Wistar (W) and BrownNorway $(B N)$ rats. Data represent means $\pm S D$.

\begin{tabular}{|c|c|c|c|c|c|c|c|}
\hline \multirow{5}{*}{$\begin{array}{l}\mathrm{LA}^{\mathrm{A}} \\
\mathrm{W}^{\mathrm{B}} \\
\mathrm{BNB}\end{array}$} & \multicolumn{3}{|c|}{ Testes ( $\mathrm{g}$ fresh weight) } & \multirow[b]{3}{*}{$\mathrm{L}^{\mathrm{A}}$} & \multicolumn{3}{|c|}{ Medulla oblongata (mg fresh weight) } \\
\hline & \multirow{2}{*}{$\begin{array}{l}\text { Young } \\
2.82 \pm 0.30^{\mathrm{a}}\end{array}$} & \multicolumn{2}{|c|}{ Middle-agedA Aged ${ }^{B}$} & & \multirow{2}{*}{$\begin{array}{l}\text { Young A } \\
248 \pm 13\end{array}$} & \multicolumn{2}{|c|}{ Middle-aged ${ }^{B}$ Aged $C$} \\
\hline & & $2.77 \pm 0.17 \mathrm{a}$ & $1.80 \pm 0.38^{b}$ & & & $294 \pm 11$ & $304 \pm 18$ \\
\hline & $3.10 \pm 0.26^{c}$ & $3.22 \pm 0.29 c$ & $3.00 \pm 0.39 c$ & $W^{B}$ & $222 \pm 16$ & $264 \pm 24$ & $276 \pm 10$ \\
\hline & $3.16 \pm 0.13^{c}$ & $3.47 \pm 0.40^{c}$ & $1.76 \pm 0.18^{b}$ & $\mathrm{BNC}$ & $204 \pm 11$ & $243 \pm 15$ & $262 \pm 7$ \\
\hline \multirow{5}{*}{$\begin{array}{l}L^{A} \\
W^{B} \\
B N^{A}\end{array}$} & \multicolumn{3}{|c|}{ Pituitary ( $\mu \mathrm{g}$ protein) } & & \multicolumn{3}{|c|}{ Amygdala (mg fresh weight) } \\
\hline & YoungA & \multicolumn{2}{|c|}{ Middle-aged ${ }^{\mathrm{B}}$ AgedC } & & Young A & \multicolumn{2}{|c|}{ Middle-aged ${ }^{B}$ Aged $^{B}$} \\
\hline & $210 \pm 37$ & $283 \pm 28$ & $329 \pm 42$ & $\mathrm{LA}^{\mathrm{A}}$ & $117 \pm 9$ & $127 \pm 8$ & $135 \pm 8$ \\
\hline & $232 \pm 48$ & $330 \pm 56$ & $416 \pm 80$ & $W^{B}$ & $105 \pm 11$ & $114 \pm 12$ & $111 \pm 15$ \\
\hline & $221 \pm 36$ & $289 \pm 28$ & $383 \pm 15$ & $\mathrm{BN}^{\mathrm{B}}$ & $103 \pm 9$ & $119 \pm 4$ & $123 \pm 6$ \\
\hline & \multicolumn{3}{|c|}{ Mesencephalon (mg fresh weight) } & & \multicolumn{3}{|c|}{ Hypothalamus (mg fresh weight) } \\
\hline & Young A & \multicolumn{2}{|c|}{ Middle-aged ${ }^{B}$ Aged ${ }^{B}$} & & Young A & \multicolumn{2}{|c|}{ Middle-aged ${ }^{B}$ AgedC } \\
\hline $\mathrm{LA}^{\mathrm{A}}$ & $114 \pm 6$ & $130 \pm 3$ & $134 \pm 5$ & LA & $209 \pm 9 a$ & $238 \pm 8^{b}$ & $252 \pm 13^{c}$ \\
\hline WA & $114 \pm 14$ & $129 \pm 5$ & $125 \pm 8$ & WB & $177 \pm 18^{c}$ & $217 \pm 10^{\mathrm{d}}$ & $225 \pm 11^{d}$ \\
\hline \multirow[t]{3}{*}{ BNA } & $104 \pm 5$ & $125 \pm 16$ & $121 \pm 5$ & $\mathrm{BNC}$ & $179 \pm 7 c$ & $196 \pm 12^{e}$ & $214 \pm 8^{f}$ \\
\hline & \multicolumn{3}{|c|}{ Hippocampus (mg fresh weight) } & & \multicolumn{3}{|c|}{ Pineal gland ( $\mu$ g protein) } \\
\hline & YoungA & \multicolumn{2}{|c|}{ Middle-aged ${ }^{\mathrm{B}}$ Aged $^{\mathrm{B}}$} & & Young A & \multicolumn{2}{|c|}{ Middle-agedAAgedA } \\
\hline LA & $99 \pm 5$ & $107 \pm 6$ & $119 \pm 9$ & LA & $180 \pm 24$ & $201 \pm 23$ & $212 \pm 30$ \\
\hline WA & $96 \pm 9$ & $111 \pm 9$ & $108 \pm 12$ & $W^{B}$ & $217 \pm 22$ & $256 \pm 85$ & $248 \pm 70$ \\
\hline $\mathrm{LA}^{\mathrm{A}}$ & $95 \pm 8$ & $104 \pm 7$ & $116 \pm 6$ & $\mathrm{BNC}$ & $134 \pm 31$ & $168 \pm 32$ & $168 \pm 32$ \\
\hline
\end{tabular}

Septum (mg fresh weight)

\begin{tabular}{llll}
\cline { 2 - 4 } & Young & \multicolumn{2}{c}{ Middle-aged ${ }^{\text {B }}$ Aged $^{B}$} \\
LA & $16.8 \pm 1.8$ & $18.3 \pm 1.7$ & $18.8 \pm 1.5$ \\
BN $^{B}$ & $15.0 \pm 1.9$ & $15.5 \pm 1.4$ & $17.6 \pm 1.7$
\end{tabular}

Different capital characters indicate differences between strains and ages. When a significant interaction was found between strain and age separate comparisons were carried out. Values with different lower case characters are significantly different.

month-old, and highest in 28-month-old rats. Weights of the amygdala, mesencephalon and hippocampus were lowest in 3-month-old rats. Student-NewmanKeuls test on data for strains demonstrated that weights of the medulla oblongata, 
hypothalamus and that the weight of the medulla oblongata was lowest in BrownNorway rats. Pineal gland protein content was highest in Wistar rats and lowest in Brown-Norway rats. Testicular weight was lowest in Lewis rats. Statistical analysis of data on separate strains demonstrated that the weight of the hypothalamus was different between all ages in Lewis and Brown-Norway rats and lowest in 3-monthold Wistar rats $\left(F_{2,12}=27.2, F_{2,18}=34.1, F_{2.20}=27.9\right.$ respectively, $p<0.001$; StudentNewman-Keuls, $p<0.05$ ). Testicular weight was significantly lower at 28 months of age than at 3 and 12 months of age in Lewis and Brown-Norway rats $\left(F_{2,12}=23.5\right.$ and $\mathrm{F}_{2,20}=20.2$, respectively, $\left.\mathrm{p}<0.001\right)$. Testicular weight was not influenced by age in Wistar rats $(F 2,20=0.17, p>0.05)$.

$V P$ concentrations in the hypothalamo-neurohypophyseal system in relation to age and strain. VP concentrations in the hypothalamus, and concentration and content in the pituitary gland of rats of different strains and ages are given in Table 2. Results of analysis of variance on VP concentrations for the factors strain and age are summarized in Appendix II. Main effects of age and strain were found on the VP concentration and VP content in the pituitary gland. The VP concentration in the hypothalamus was affected by age only. An interaction between age and strain occurred on the VP concentration in the hypothalamus. With respect to age, post hoc statistical analysis demonstrated the following differences. Concentrations of VP were reduced in the pituitary gland of 28-month-old rats as compared with 3-and 12-monthold rats, and the VP content in the pituitary gland was higher in 12-month-old rats than in 3- and 28-month-old rats. One factor (age) analysis of variance on data for separ

Table 2. VP concentrations in the hypothalamo-neurohypophyseal system in relation to age in Lewis $(\mathrm{L})$, Wistar (W) and Brown (BN) rats.

\begin{tabular}{|c|c|c|c|c|c|c|c|}
\hline \multirow[b]{3}{*}{ LA } & \multicolumn{3}{|c|}{ Pituitary gland ( $\mu \mathrm{mol} / \mathrm{g}$ protein) } & & \multicolumn{3}{|c|}{ Pituitary content $(\mu \mathrm{mol})$} \\
\hline & \multirow{2}{*}{$\begin{array}{l}\text { YoungA } \\
3.29 \pm 0.42\end{array}$} & \multicolumn{2}{|c|}{ Middle-agedA Aged ${ }^{B}$} & \multirow[b]{2}{*}{ LA } & \multirow{2}{*}{$\begin{array}{l}\text { Young }{ }^{B} \\
6.82 \pm 0.41\end{array}$} & \multicolumn{2}{|c|}{ Middle-aged^Aged ${ }^{B}$} \\
\hline & & $3.48 \pm 0.14$ & $2.62 \pm 0.39$ & & & $10.4 \pm 0.4$ & $8.65 \pm 0.60$ \\
\hline WB & $5.09 \pm 0.28$ & $4.53 \pm 0.62$ & $3.00 \pm 0.27$ & WB & $11.6 \pm 0.7$ & $14.3 \pm 1.0$ & $12.3 \pm 1.1$ \\
\hline $\mathrm{BN}^{\mathrm{B}}$ & $5.19 \pm 0.34$ & $4.73 \pm 0.25$ & $2.70 \pm 0.31$ & $\mathrm{BN}^{\mathrm{B}}$ & $11.2 \pm 0.3$ & $13.7 \pm 0.7$ & $10.3 \pm 1.1$ \\
\hline
\end{tabular}

Hypothalamus (nmol/g protein)

\begin{tabular}{|c|c|c|c|}
\hline & Young A & Middle-aged 6 & AgedC \\
\hline LA & $4.45 \pm 0.342$ & $3.60 \pm 0.21^{b}$ & $2.99 \pm 0.19 \mathrm{~b}$ \\
\hline WAB & $4.79 \pm 0.76$ & $3.23 \pm 0.20 \mathrm{ab}$ & $2.97 \pm 0.18 \mathrm{ab}$ \\
\hline $\mathrm{BNB}$ & $5.31 \pm 0.24^{2 c}$ & $4.72 \pm 0.36 \mathrm{c}$ & $2.43 \pm 0.22^{b}$ \\
\hline
\end{tabular}

Different capital characters indicate strain and age differences. When an interaction between strain and age was found separate comparisons were carried out. Values with different lower case characters are significantly different. 
separate strains followed by post hoc multiple comparison indicated that the VP concentration in the hypothalamus was higher in 3-month-old Lewis rats than in 12and 28-month-old animals $\left(\mathrm{F}_{2,12}=9.54, \mathrm{p}<0.01\right)$. The VP concentration was lowest at 28 months of age in Brown-Norway rats $\left(F_{2,18}=25.9, p<0.001\right)$. Separate comparisons between age groups for the factor strain showed that the VP concentration in the hypothalamus was higher in middle-aged Brown-Norway rats as compared with middle-aged Lewis and Wistar rats $\left(F_{2,13}=8.84, p<0.01\right)$.

Extrahypothalamic VP concentrations in relation to age and strain. Extrahypothalamic VP concentrations in rats of different strains and ages are given in Table 3 (continued). Results of statistical analysis on VP concentrations are summarized in Appendix II. Concentrations of VP were affected by age in the medulla oblongata and mesencephalon, but not in the hippocampus, septum, amygdala and pineal gland. Effects of strain were found on VP concentrations in the hippocampus, septum, medulla oblongata and mesencephalon. An interaction occurred between strain and age on the VP concentrations in the medulla oblongata and pineal gland. The VP concentration in the mesencephalon was lower in aged rats as compared with the other

Table 3. Extrahypothalamic VP concentrations (pmol/g protein) in relation to age and strain.

\begin{tabular}{|c|c|c|c|c|c|c|c|}
\hline & \multicolumn{3}{|c|}{ Hippocampus } & & \multicolumn{3}{|l|}{ Septum } \\
\hline & Young & Middle-aged & Aged & & Young & Middle-aged & Aged \\
\hline$L^{A}$ & $2.20 \pm 0.35$ & $3.03 \pm 0.14$ & $2.56 \pm 0.14$ & LA & $73.9 \pm 2.0$ & $92.0 \pm 5.7$ & $69.1 \pm 4.3$ \\
\hline WB & $7.56 \pm 1.15$ & $7.81 \pm 2.15$ & $9.43 \pm 2.44$ & WB & $165 \pm 13$ & $160 \pm 10$ & $151 \pm 17$ \\
\hline \multirow[t]{3}{*}{$\mathrm{BNC}$} & $5.42 \pm 0.27$ & $6.31 \pm 0.55$ & $5.84 \pm 0.64$ & $\mathrm{BNC}$ & $111 \pm 5$ & $98.7 \pm 7.9$ & $102 \pm 10$ \\
\hline & \multicolumn{3}{|c|}{ Medulla oblongata } & & \multicolumn{3}{|c|}{ Mesencephalon } \\
\hline & YoungA & \multicolumn{2}{|c|}{ Middle-aged A Aged $B$} & & Young A & \multicolumn{2}{|c|}{ Middle-agedAAgedB } \\
\hline $\mathrm{LA}^{\mathrm{A}}$ & $5.48 \pm 0.46^{2}$ & $3.55 \pm 0.23 \mathrm{~b}$ & $3.21 \pm 0.34 b$ & LA & $10.0 \pm 1.4$ & $10.3 \pm 0.5$ & $6.81 \pm 0.16$ \\
\hline WA & $4.95 \pm 0.40 \times 6$ & $3.78 \pm 0.49 \mathrm{~b}$ & $2.58 \pm 0.11^{\mathrm{c}}$ & WB & $18.1 \pm 2.3$ & $14.9 \pm 0.7$ & $11.9 \pm 0.9$ \\
\hline \multirow[t]{3}{*}{$\mathrm{BN}^{\mathrm{B}}$} & $2.41 \pm 0.35 c$ & $2.70 \pm 0.07 \mathrm{c}$ & $1.52 \pm 0.14^{d}$ & $\mathrm{BN}^{\mathrm{B}}$ & $15.9 \pm 1.1$ & $17.1 \pm 0.9$ & $11.7 \pm 1.1$ \\
\hline & \multicolumn{3}{|l|}{ Amygdala } & & \multicolumn{3}{|l|}{ Pineal gland } \\
\hline & Young & Middle-aged & Aged & & Young & Middle-aged & Aged \\
\hline $\mathrm{L}$ & $14.4 \pm 0.9$ & $22.5 \pm 2.2$ & $21.5 \pm 3.9$ & $\mathrm{~L}$ & $22.3 \pm 4.2^{\mathrm{a}}$ & $21.2 \pm 2.6^{\mathrm{a}}$ & $39.4 \pm 9.8^{\mathrm{ac}}$ \\
\hline w & $70.8 \pm 17.0$ & $19.8 \pm 3.5$ & $31.3 \pm 10.2$ & W & $28.2 \pm 8.1^{\mathrm{a}}$ & $4.95 \pm 1.22^{b}$ & $8.05 \pm 3.86^{b}$ \\
\hline $\mathrm{BN}$ & $39.2 \pm 7.2$ & $31.5 \pm 2.5$ & $37.8 \pm 11.0$ & $\mathrm{BN}$ & $12.1 \pm 3.0^{\mathrm{a}}$ & $18.5 \pm 2.6^{\mathrm{a}}$ & $21.4 \pm 2.0 c$ \\
\hline
\end{tabular}

Different capital characters indicate strain and age differences. When an interaction between strain and age was found separate comparisons were carried out. Values with different lower case characters are significanty different. 
Table 4. Vasopressin concentrations (pmol/g protein) in the brain structures in Lewis rats at different times of year. Values represent means \pm SEM.

\begin{tabular}{|c|c|c|c|c|c|c|c|c|}
\hline \multirow[b]{2}{*}{ Structure } & \multicolumn{5}{|c|}{ Time of year } & \multirow[b]{2}{*}{ February } & \multirow[b]{2}{*}{$\mathrm{F}$} & \multirow[b]{2}{*}{$\mathrm{p}$} \\
\hline & May & July & August & September & November & & & \\
\hline Pituitary gland $\times 10^{-6}$ & $3.74 \pm 0.13$ & $3.18 \pm 0.42$ & $3.86 \pm 0.32$ & $4.14 \pm 0.09$ & $3.98 \pm 0.18$ & $4.03 \pm 0.42$ & 1.34 & 0.28 \\
\hline Hypothalamus $\times 10^{-3}$ & $3.62 \pm 0.17$ & $4.45 \pm 0.34$ & $3.81 \pm 0.32$ & $3.53 \pm 0.30$ & $3.73 \pm 0.38$ & $3.55 \pm 0.27$ & 1.43 & 0.25 \\
\hline Hippocampus & $3.00 \pm 0.34$ & $2.20 \pm 0.35$ & $2.52 \pm 0.12$ & $2.83 \pm 0.30$ & $3.08 \pm 0.33$ & $2.85 \pm 0.43$ & 1.02 & 0.43 \\
\hline Septum & $79.0 \pm 11.2$ & $73.9 \pm 2.01$ & $77.2 \pm 3.3$ & $76.9 \pm 6.8$ & $80.7 \pm 6.5$ & $97.1 \pm 9.6$ & 1.29 & 0.30 \\
\hline Medulla & $4.70 \pm 0.49$ & $5.48 \pm 0.46$ & $4.40 \pm 0.40$ & $5.43 \pm 0.90$ & $4.09 \pm 0.02$ & $6.23 \pm 1.04$ & 1.40 & 0.26 \\
\hline Mesencephalơn & $8.46 \pm 0.31$ & - & $10.0 \pm 1.4$ & $8.88 \pm 0.41$ & $10.9 \pm 1.2$ & $9.07 \pm 0.46$ & 1.25 & 0.32 \\
\hline Amygdala & $40.3 \pm 20.0$ & $14.4 \pm 0.9$ & $22.5 \pm 9.0$ & $16.0 \pm 2.5$ & $16.7 \pm 2.5$ & $13.1 \pm 0.9$ & 1.27 & 0.31 \\
\hline Pineal gland & $214 \pm 16.2$ & $22.2 \pm 4.2 \mathrm{~b}$ & $10.3 \pm 2.4 b$ & $9.30 \pm 1.60 \mathrm{~b}$ & $9.14 \pm 0.75 b$ & $18.7 \pm 0.8 b$ & 212 & $<0.001$ \\
\hline
\end{tabular}

Values with different characters are significantly different. Values with identical or without a character are not significantly different. 
Table 5. VP concentrations (pmol/g protein) in the pineal gland of Lewis rats of different ages in May, July and August. Values represent means \pm SEM.

\begin{tabular}{|c|c|c|c|}
\hline \multirow[b]{2}{*}{ Time of year } & \multicolumn{2}{|r|}{ Age } & \\
\hline & 3-month-oldA & 12 -month-old $\mathrm{B}$ & 28-month-oldA \\
\hline MayA & $241 \pm 16.2^{\mathrm{a}}$ & $97.9 \pm 8.0^{b}$ & $375 \pm 55^{c}$ \\
\hline JulyB & $22.3 \pm 9.5^{d}$ & $21.2 \pm 2.6^{\mathrm{d}}$ & $39.4 \pm 9.8^{d}$ \\
\hline August ${ }^{B}$ & $10.3 \pm 22.4 \mathrm{~d}$ & $17.9 \pm 1.3^{\mathrm{d}}$ & $18.9 \pm 3.5^{\mathrm{d}}$ \\
\hline
\end{tabular}

Different capital characters indicate differences between ages and time of year. Values with different lower case characters are significantly different.

age groups, as revealed by the Student-Newman-Keuls test $(p<0.05)$. VP concentrations in the hippocampus and septum were different between all three strains (Student-Newman-Keuls, $\mathrm{p}<0.05$ ). The VP concentration in the medulla oblongata was lower in the Brown-Norway strain than in the other strains. Statistical analysis on data for separate strains indicated that the concentration of VP was reduced in the medulla oblongata of aged Wistar and Brown-Norway rats as compared with the young animals $\left(\mathrm{F}_{2,20}=10.5\right.$ and $\mathrm{F}_{2,23}=16.0$, respectively, $\left.\mathrm{p}<0.001\right)$. VP concentrations in the medulla oblongata were lower in middle-aged and aged Lewis rats than in young Lewis rats $\left(F_{2,12}=4.61, p<0.05\right)$. Concentrations of VP were reduced in the pineal gland of middle-aged and aged Wistar rats $\left(\mathrm{F}_{2,20}=4.02, \mathrm{p}<\right.$ $0.05)$.

Effects of season and age on VP concentrations in the Lewis rat. Firstly we investigated the influence of season on VP concentrations in 3-month-old Lewis rats. Season did not affect concentrations of VP in any of the brain structures examined, except in the pineal gland (Table 4). The VP concentration in the pineal gland was highly increased in May in comparison to other times of year. Concentrations of VP were also determined in May, July and August in 12- and 28-month-old Lewis rats (Table 5).

Main effects were found for the factors time of year and age $\left(F_{2,34}=166\right.$ and 27.8, respectively; $\mathrm{p}<0.001)$ and there was an interaction between these factors $\left(\mathrm{F}_{4,34}=\right.$ $22.1, \mathrm{p}<0.001)$. VP concentrations in the pineal gland were higher in May than in July and August, as also found in 3-month-old rats. The VP concentration in the pineal gland in May was lowest in 12-month-old rats and highest in 28-month-old rats. Season did not influence the concentration of VP in brain structures other than the pineal- and pituitary gland, but the influence in the pituitary gland was very small and inconsistent (data not shown). Data obtained for animals killed in different months, therefore, were pooled according to age (Table 6). Age-related changes on this larger 
number of animals confirmed the results obtained in the strain $x$ age comparison, except that an additional age-related effect was found in the hippocampus (see Appendix III for results of statistical analysis).

Table 6. VP concentrations (pmol/g protein) in different brain structures in Lewis rats of different ages. Values represent means \pm SEM.

\begin{tabular}{llll}
\hline & \multicolumn{3}{c}{ Age } \\
\cline { 2 - 3 } Structure & 3-month-old & 12-month-old & 28-month-old \\
\hline & & & \\
Pituitary & & & \\
concentration $\left(\times 10^{-6}\right)$ & $3.60 \pm 0.19^{\mathrm{a}}$ & $3.80 \pm 0.10^{\mathrm{a}}$ & $2.71 \pm 0.13^{\mathrm{b}}$ \\
content $\left(\times 10^{-5}\right)$ & $7.84 \pm 0.29 \mathrm{a}$ & $10.8 \pm 0.2^{\mathrm{b}}$ & $8.76 \pm 0.27^{\mathrm{a}}$ \\
Hypothalamus $\left(\times 10^{-3}\right)$ & $3.96 \pm 0.17^{\mathrm{a}}$ & $3.68 \pm 0.11^{\mathrm{a}}$ & $2.78 \pm 0.14 \mathrm{~b}$ \\
Hippocampus & $2.57 \pm 0.18^{\mathrm{a}}$ & $3.89 \pm 0.35^{\mathrm{b}}$ & $2.83 \pm 0.12^{\mathrm{a}}$ \\
Medulla oblongata & $4.87 \pm 0.27^{\mathrm{a}}$ & $4.01 \pm 0.3^{\mathrm{b}}$ & $3.66 \pm 0.26^{\mathrm{b}}$ \\
Septum & $76.6 \pm 3.8^{\mathrm{a}}$ & $86.7 \pm 4.3^{\mathrm{a}}$ & $77.3 \pm 5.2^{\mathrm{a}}$ \\
Mesencephalon & $9.25 \pm 0.72^{\mathrm{a}}$ & $9.72 \pm 0.44^{\mathrm{a}}$ & $7.00 \pm 0.20^{\mathrm{b}}$ \\
Amygdala & $25.7 \pm 7.4^{\mathrm{a}}$ & $28.7 \pm 3.9^{\mathrm{a}}$ & $19.4 \pm 2.3^{\mathrm{a}}$ \\
\hline
\end{tabular}

Values with a different superscript differ significantly.

\section{Discussion}

The present article is concerned with VP concentrations in the brain in relation to aging in different rat strains.

In aging studies on rats it is important to use multiple age groups (Coleman et al. 1990) and multiple strains to assess whether the phenomena found are associated with aging and can be generalized for the entire genus. Rats should preferably not suffer from age-associated specific pathology, for instance a high incidence of particular kinds of tumors. Especially the occurrence of kidney and testicular pathology are relevant to the present study. Testicular tumors occur infrequently (Kroes et al. 1981, Zurcher and Hollander 1982) and renal lesions appear to be mild in the three strains used (Bell et al. 1984, Burek 1978, Elema and Arends 1975, Gray et al. 1982, Ravid et al. 1987). Brown-Norway rats are considered suiting for aging studies, since these animals show a high degree of random pathology (Zurcher and Hollander 1982). This also applies for Wistar rats, except for the incidence of prolactin secreting tumors (Kroes et al. 1981). Wistar rats in which a macroscopic tumor was found, therefore, were excluded from the studies. General data on age-associated pathology in Lewis rats are not available as far as we know. 
Effects of age on VP concentrations in rats were observed in the hypothalamus, pituitary gland, pineal gland, medulla oblongata and mesencephalon. The age-related changes in VP concentrations in the pineal gland and medulla oblongata were straindependent. It is important to discriminate between maturation and aging effects. Changes that occur between 3 and 12 months of age probably are associated with maturation, especially when they do not continue beyond 12 months of age. Decreases in VP concentrations with aging in this strict sense were observed in the medulla oblongata of Wistar and Brown-Norway rats, and in the hypothalamoneurohypophyseal system and mesencephalon of all three strains examined. In conclusion, the only alterations in VP concentrations with aging which were strainindependent occurred in the hypothalamo-neurohypophyseal system and mesencephalon. A way in which maturation could affect VP concentrations is the different speed at which vasopressinergic systems develop and general growth procedes. The process of myelinization may be especially relevant in this respect (Norton and Podulso 1973). For instance, the concentration of VP declined between 3 and 12 months of age in the medulla oblongata of Lewis rats, but total content of VP did not change. General growth had stopped by 12 months of age, except in the pituitary gland.

It has been suggested that different findings on the effect of aging on VP concentrations may result from seasonal changes in synthesis and secretion of VP. A seasonal rhythm in VP concentration has been found in the pituitary gland and plasma in Sprague-Dawley rats (Zbuzek and Wu 1979). Large increases in VP content of the pineal gland have been monitored in August in several strains of rats (Liu and Burbach 1987, Liu et al. 1991, Prechel et al. 1983). To be sure that our findings would not be influenced by season this factor was taken into account. Profound seasonal effects on VP concentration were observed in the pineal gland only. Five- to 10-fold increases in the concentration of VP were observed in the pineal gland in all age groups in May rather than in August, as reported in the literature. Since it is not known how the seasonal rhythm is regulated, it cannot be easily explained what may have caused this. It may be that our rats were more effectively insulated from outside influences, because they were barrier-reared. Nevertheless, it can be concluded that the seasonal change in VP concentration in the pineal gland is a recurring event with age. The VP concentration in the pineal gland seemingly was affected by age. This need not be a genuine age effect, because of rapid alterations in VP concentrations and slight differences in synchronization of the rhythm between groups of rats.

Previous studies on changes in VP concentrations with aging are conflicting. In one laboratory similar findings were obtained in Fischer 344 and Sprague-Dawley rats (Zbuzek and Wu 1982, Zbuzek et al. 1983). By contrast, in another study unaltered urinary VP excretion has been observed with age (Phelps et al. 1989). These disparate findings may be reconciled by the fact that rats of different ages were compared. However, plasma VP concentration or urinary VP excretion were increased in Wistar (Fliers and Swaab 1983, Terwel et al. 1992b), Long-Evans (Miller 1985) and BrownNorway rats (Terwel et al., unpublished data). The VP concentration in the hypothalamus was reduced in aged Sprague-Dawley (Zbuzek and Wu 1982) and Long- 
Evans strains (Miller 1985) and reduced or equal in Fischer 344 rats (Sladek et al. 1981, Zbuzek et al. 1983). VP concentrations in the pituitary gland expressed per wet weight were reduced (Sladek et al. 1981) or equal (Zbuzek et al. 1983) in Fischer 344 rats and unaltered in Sprague-Dawley rats (Zbuzek and Wu 1982). Since pituitary weight increases with age total pituitary content was unaltered or increased with age. It has been suggested that increased neurosecretory activity is related to declined renal function (Ravid et al. 1987). In favor of such a notion, Ravid et al. (1987) found a decreased number of VP receptors in the kidneys. This may also explain why renal susceptibility to VP is decreased as reflected by reduced renal ability to concentrate urine solutes (Bengele et al. 1981) and decreased formation of cAMP following receptor stimulation (Beck and Yu 1982). On the other hand increases in plasma VP concentration with age do not always occur in strains of rats in which concentrating ability declines with age (Zbuzek and Wu 1982, Zbuzek et al. 1983). Typically, these are strains in which kidney pathology is most severe (Bolton et al. 1976, Coleman et. al. 1977, Gray et al. 1982). The absence of increased plasma VP concentration despite renal pathology may be related to the possibility that renal pathology limits the renin secretory activity, as suggested by Sladek et al. (1981).

We found increases in plasma VP concentration in Wistar and Brown-Norway rats with aging in previous studies (Terwel et al. 1992b and unpublished data). In the present study it was observed that the concentration of VP decreased in the rat pituitary gland with aging. It is difficult to interpret changes in VP concentration in the pituitary with age, since the pituitary weight increases with aging. It may be that the pituitary weight increases with aging to sustain functional capacity. VP content of the pituitary first appeared to increase with age, probably as a result of general growth, but then decreased despite developing hypertrophy. This does not reflect an exhaustion of VP stores but merely a changed steady state concentration, because plasma VP secretion is increased. In conclusion, both changes in the kidney and pituitary gland are observed with age. The body tries to compensate for functional loss by organ enlargement. From the present results it cannot be decided whether the kidney or the pituitary gland first starts to increase with age. From data on Wistar rats not presented in this study (Terwel et al., unpublished data) it was clear that kidney hypertrophy preceded pituitary hypertrophy. The VP concentration in the hypothalamus was more affected by age in Brown-Norway rats than in Lewis and Wistar rats. This may indicate that with age a greater demand is made on the neurohypophyseal system in Brown-Norway rats.

Data in the literature suggest that changes in the testosterone-dependent vasopressinergic system vary in rats. First, Fliers et al. (1985) observed that immunocytochemical staining of vasopressinergic fibers was much reduced in aged Brown-Norway rats as compared with young controls. Second, Goudsmit et al. (1988) found that staining of vasopressinergic fibers showed a moderate reduction in BrownNorway rats with age. Third, concentrations of VP were not affected by age in the lateral septum and medial amygdala of Brown-Norway rats in still another study (Goudsmit et al. 1990). Fourth, Dobie et al. (1991) found that the level of mRNA coding for VP declined with aging in the bed nucleus of the stria terminalis of Fischer 
344 rats. In the present study changes in concentrations of VP were not generally found in structures of which the vasopressinergic innervation depends on testosterone. It is possible to ascribe these disparate findings to the fact that the impact of age on plasma testosterone levels varies within the Brown-Norway strain and between strains of rats. No data on plasma testosterone concentrations were presented by Fliers et al. (1985), but they noted that the pattern of vasopressinergic changes with age resembled the pattern of changes after castration. Ravid et al. (1987) and Goudsmit et al. (1988) found that plasma testosterone levels were reduced by $70 \%$ in aged Brown-Norway rats compared with young controls, while Goudsmit et al. (1990) only found that plasma testosterone level was reduced by $30 \%$ in Brown-Norway rats with age. Dobie et al. (1991) and others (Chambers and Phoenix 1984, Chambers et al. 1991) found that with age plasma testosterone level in Fischer 344 rats is reduced by $>80 \%$.

Concentrations of circulating testosterone have been shown to be correlated with testicular weight in Sprague-Dawley (Kaler and Neaves 1981) and Brown-Norway rats (Goudsmit et al. 1988, Ravid et al. 1987). In the present study, a decline in testicular weight was observed with aging in Lewis and Brown-Norway rats, but not in Wistar rats, suggesting that plasma testosterone level may have been reduced in at least the former two strains. Since concentrations of VP were reduced with age in only a few extrahypothalamic structures in rats, notably the mesencephalon and medulla oblongata, plasma testosterone levels appear not to have been reduced enough to affect the testosterone-dependent vasopressinergic system in general. It is even possible that the reduced VP concentrations were not related to a declined testosterone status.

A striking observation was the large strain differences in VP concentrations. Concentrations of VP were lower in the pituitary gland, hippocampus, septum and mesencephalon of Lewis rats as compared with the other strains of rats. The VP concentration in the medulla oblongata was lower in Brown-Norway rats than in members of the other rat strains. Recently it has been shown that Lewis rats are hyporesponsive to stress (Smith et al. 1992). Since it has been claimed that VP acts as a second generation stress hormone in the brain (Bohus et al. 1990), it may be that the low VP concentrations in Lewis rats are related to the reduced stress response. If this were the case this would mean that one and the same peptidergic system is directly or indirectly affected by different steroid hormones. The differences in VP concentrations may underlie the bad performance of Lewis rats on active avoidance tests (Blokland et al., unpublished results). This suggestion is strenghtened by the fact that it has recently been reported that rats selected on poor performance in a brightness discrimination task had low hippocampal VP concentrations (Hess et al. 1992). BrownNorway rats also perform bad on active avoidance tests, although Brown-Norway rats were not that much different from Wistar rats in concentrations of VP. However, Brown-Norway rats are different on still other neurochemical markers, i.e., choline acetyltransferase (Gilad and Gilad 1981).

In conclusion, changes in peripheral organ function with aging result in slight alterations in amounts of VP in the hypothalamo-neurohypophyseal system. Evidence that the presumed testicular dysfuntion affects extrahypothalamic VP concentrations 
could not be obtained. Since kidney function decreases with age, the ability to maintain water homeostasis decreases on the part of the kidney; this ability appears to be less decreased on the part of the hypothalamus with age. Testicular function probably is decreased in aged rats, but not enough yet to affect extrahypothalamic VP concentrations.

\section{References}

Aravich PF, Sladek JR Jr. Aging of rodent VP systems. In: Gash DM, Boer GJ, eds. Vasopressin. Principles and properties. New York: Plenum, 1987:579-610.

Beck N, Yu BP. Effect of aging on urinary concentrating mechanism and vasopressin-dependent cAMP in rats. Am J Physiol 1982;243:F121-5.

Bell RH, Börjesson BA, Wolf PL, Fernández-Cruz L, Brimm JE, Lee S, Sayers HL, Orloff MJ. Quantitative morphological studies of aging in the kidney of the Lewis rat Renal Physiol 1984;7:176-84.

Bengele HH, Mathias RS, Perkins JH. Urinary concentrating defect in the aged rat. Am J Physiol 1981;240:F147-50.

Bohus B, Koolhaas JM, Nyakas C, Luiten PGM, Versteeg CAM, Kone SM, Jaarma D, Timmerman W, Eisenga W. Neuropeptides and behavioural and physiological stress response: the role of vasopressin and related peptides. In: Puglisi-Allegra S, Oliverio A, eds. Psychobiology of stress. Dordrecht: Kluwer, 1990:103-23.

Bolton WK, Benton FR, MacLay JG, Sturgill BC. Spontaneous glomerular sclerosis in aging Sprague-Dawley rats. Am J Pathol 1976;85:277-300.

Burek JD. Pathology of aging rats. A morphological and experimental study of age-asscciated lesions in aging $\mathrm{BN} / \mathrm{BiRij}$, WAG/Rij and (WAG $\times$ BN)F1 rats. Boca Raton: CRC Press, 1978.

Chambers KC, Phoenix $\mathrm{CH}$. Testosterone and the decline of sexual behavior in the rat brain. Behav Neural Biol 1984:40:87-97.

Chambers KC, Thomton JE, Roselli CE. Age-related deficits in brain androgen binding and metabolism, testosterone, and sexual behavior of male rats. Neurobiol Aging 1991;12:123-30.

Coleman GL, Barthold SW, Osbaldiston GW, Foster SJ, Jonas AM. Pathological changes during aging in barrier-reared Fischer 344 male rats. J Gerontol 1977;32:258-78.

Coleman P, Finch C, Joseph J. The need for multiple time points in aging studies. Neurobiol Aging 1990;11:1-2.

De Vries GJ, Buijs RM, Van Leeuwen FW, Caffe AR, Swaab DF. The vasopressinergic innervation of the brain in normal and castrated rats. J Comp Neurol 1985;233:236-54.

Dobie DJ, Miller MA, Urban JH, Raskind MA, Dorsa DM. Age-related decline of vasopressin mRNA in the bed nucleus of the stria terminalis. Neurobiol Aging 1991;12:419-23.

Elema JD, Arends A. Focal and segmental glomerular hyalinosis and sclerosis in the rat. Lab Invest 1975;33:491-501.

Everitt A, Meites J. Aging and anti-aging effects of hormones. J Gerontol 1989;44:B139-47.

Fliers E, Swaab DF. Activation of vasopressinergic and oxytocinergic neurons during aging in the Wistar rat. Peptides 1983;4:165-70.

Fliers E, De Vries GJ, Swaab DF. Changes with aging in the vasopressin and oxylocin innervation of the rat brain. Brain Res 1985;348:1-8.

Gilad GM, Gilad VH. Strain-dependent differences between the septo-hippocampal cholinergic system and hippocampal size. Brain Res 1981;222:423-7.

Goudsmit E, Fliers E, Swaab DF. Testosterone suppletion restores vasopressin innervation in the senescent rat brain. Brain Res 1988;473:306-13.

Goudsmit E, Luine VN, Swaab DF. Testosterone locally increases vasopressin content but fails to restore choline acetyltransferase activity in other regions in the senescent male rat brain. Neurosci Lelt 1990;112:290- 


\section{6.}

Gray JE, van Zwieten MJ, Hollander CF. Early light microscopic changes of chronic progressive nephrosis in several strains of aging laboratory rats. J Gerontol 1982;37:142-50.

Hess J, Lesser D, Landgraf R. Vasopressin and oxytocin in brain areas of rats selectively bred for differences in behavioral performance. Brain Res 1992;569:106-11.

Ingram D. Analysis of age-related impairments in learning and memory in rodent models. Ann NY Acad Sci 1985;44:312-31.

Kaler LW, Neaves WB. The androgen status of aging male rats. Endocrinology 1981;108:712-9.

Kroes R, Garbis-Berkvens JM, De Vries T, Van Nesselrooy JHJ. Histopathological profile of a Wistar rat stock including a survey of the literature. J Gerontol 1981;36:259-79.

Liu B, Burbach JPH. Detection and HPLC characterization of summer rises of vasopressin- and oxytocin immunoreactivity in the rat pineal gland. Endocrinology 1987;121:1716-20.

Liu B, Burbach JPH, Fernstrom JD, Antoni, FA. The hypothalamus is not the origin of vasopressin and oxytocin in the rat pineal gland. Neuroendocrinology 1991;53:523-7.

Marshall JF, Berrios N. Movement disorders of aged rats: reversal by dopamine receptor stimulation. Science 1982;206:477-9.

Meites J. Neuroendocrine basis of aging. In: Everitt AV, Walton JR, eds. Regulation of neuroendocrine aging. Basel: Karger, 1988:37-50.

Miller M. Influence of aging on vasopressin secretion and water regulation. In: Schrier RW, ed. Vasopressin. New York: Raven PTess, 1985:249-58.

Norton WT, Podulso SE. Myelination in rat brain: changes in myelin composition during brain maturation. J Neurochem 1973;21:759-73.

Phelps CJ, Carlson SW, Gallagher MJ, Sladek CD. Vasopressin in aged rats: longitudinal studies of vasopressin excretion in Sprague-Dawley and Fischer 344 strains. Neurobiol Aging 1989;10:233-9.

Prechel MM, Audhya TK, Schlesinger DH. A seasonal variation in arginine vasotocin immunoactivity in rat pineal glands. Endocrinology 1983;112:1474-8.

Ravid R, Fliers E, Swaab DF, Zurcher C. Changes in vasopressin and testosterone in the senescent BrownNorway (BN/BiRij) rat. Gerontology 1987;33:87-98.

Rogers J, Bloom FE. Neurotransmiuter metabolism and function in the aging central nervous system. In: Finch CE, Schneider EL, eds. Handbook of the biology of aging. 2nd edn. New York: Van Nostrand Reinhold, 1985:645-91. (Birren JE, ed. The Handbooks of aging; vol 1).

Sapolsky RM. Do glucoconicoid concentrations rise with age in the rat? Neurobiol Aging 1992;13:171-4.

Sladek CD, McNeill, Gregg CM, Blair ML, Baggs RB. Vasopressin and renin response to dehydration in aged rats. Neurobiol Aging 1981;2:293-302.

Smith CC, Hauser E, Renaud NK, Leff A, Aksentijevich S, Chrousos GP, Wilder RL, Gold PW, Sternberg EM. Increased hypothalamic $\left[{ }^{3} \mathrm{H}\right]$ flunitrazepam binding in hypothalamic-pituitary-adrenal axis hyporesponsive Lewis rats. Brain Res 1992;569:295-9.

Ten Haaf JA, Terwel D, Van de Heijning HJM, Van Wimersma Greidanus $\Upsilon \mathrm{jB}$. Radioimmunoassay: a goal or a tool? J Control Rel 1992 (in press).

Terwel D, Markerink M, Jolles J. Age-related changes in concentrations of vasopressin in the central nervous system and plasma of the male Wistar rat. Mech Ageing Dev 1992a (in press).

Terwel D, Ten Haaf JA, Markerink M, Jolles J. Changes in plasma vasopressin concentration and plasma osmolality in relation to age and time of day in the male Wistar rat. Acta Endocrinol (Coph) 1992b;126:357. 62.

Zbuzek VK, Wu W. Seasonal variations in vasopressin secretion in rats. Experientia 1979;35:123-4.

Zbuzek VK, Wu W. Age-related vasopressin changes in rat plasma and the hypothalamo-hypophyseal system. Exp Gerontol 1982;17:133-8.

Zbuzek VK, Zbuzek V, Wu W. The effect of aging in vasopressin system in Fischer 344 rats. Exp Gerontol 1983;18:305-11.

Zurcher C, Hollander CF. Multiple pathological changes in aging rat and man. Exp Biol Med 1982;7:55-62. 
Appendix I. Main effects of age and strain on testicular weight, brain tissue weight or protein content in rats.

\begin{tabular}{|c|c|c|c|c|c|c|c|}
\hline Struclure & Source & $\mathrm{F}$ & $P$ & Structure & Source & $\mathrm{F}$ & $P$ \\
\hline \multirow[t]{3}{*}{ Piuitary gland } & Str & 3.23 & $<0.05$ & \multirow[t]{3}{*}{ Hypothalamus } & Str & 44.7 & $<0.001$ \\
\hline & Age & 47.7 & $<0.001$ & & Age & 69.2 & $<0.001$ \\
\hline & Str $\times$ Age & 1.09 & 0.37 & & Str $\times$ Age & 2.86 & 0.05 \\
\hline \multirow[t]{3}{*}{ Hippocampus } & Str & 0.99 & 0.38 & \multirow[t]{3}{*}{ Septum } & Str & 21.6 & $<0.001$ \\
\hline & Age & 22.5 & $<0.001$ & & Age & 28.3 & $<0.001$ \\
\hline & Str $\times$ Age & 1.98 & 0.11 & & Str $\times$ Age & 1.44 & 0.25 \\
\hline \multirow{3}{*}{$\begin{array}{l}\text { Medulla } \\
\text { oblongata }\end{array}$} & Strain & 45.1 & $<0.001$ & \multirow{3}{*}{ Mesencephalon } & Str & 3.11 & 0.05 \\
\hline & Age & 131 & $<0.001$ & & Age & 22.9 & $<0.001$ \\
\hline & Str $\times$ Age & 0.68 & 0.61 & & Sur $\times$ Age & 1.29 & 0.29 \\
\hline \multirow[t]{3}{*}{ Amygdala } & Str & 11.2 & $<0.001$ & \multirow[t]{3}{*}{ Pineal gland } & Str & 17.5 & $<0.001$ \\
\hline & Age & 13.5 & $<0.001$ & & Age & 2.87 & 0.07 \\
\hline & Str $\times$ Age & 1.14 & 0.35 & & Str $\times$ Age & 0.18 & 0.95 \\
\hline
\end{tabular}

Appendix U. Main effects of age and strain on VP concentrations in rat brain and VP content in the rat pituitary gland.

\begin{tabular}{|c|c|c|c|c|c|c|c|}
\hline Structure & Source & F & $P$ & Structure & Source & $\mathrm{F}$ & $P$ \\
\hline $\begin{array}{l}\text { Pituitary gland } \\
\text { concentration }\end{array}$ & $\begin{array}{l}\text { Str } \\
\text { Age } \\
\text { Str } \times \text { Age }\end{array}$ & $\begin{array}{l}7.52 \\
16.7 \\
1.58\end{array}$ & $\begin{array}{l}<0.001 \\
<0.01 \\
0.20\end{array}$ & $\begin{array}{l}\text { Pituitary gland } \\
\text { content }\end{array}$ & $\begin{array}{l}\text { Str } \\
\text { Age } \\
\text { Str } \times \text { Age }\end{array}$ & $\begin{array}{l}21.2 \\
12.5 \\
0.78\end{array}$ & $\begin{array}{l}<0.001 \\
<0.001 \\
0.54\end{array}$ \\
\hline Hypothalamus & $\begin{array}{l}\text { Str } \\
\text { Age } \\
\text { Str } \times \text { Age }\end{array}$ & $\begin{array}{l}1.04 \\
16.9 \\
3.56\end{array}$ & $\begin{array}{l}0.36 \\
<0.001 \\
<0.05\end{array}$ & Hippocampus & $\begin{array}{l}\text { Str } \\
\text { Age } \\
\text { Str } \times \text { Age }\end{array}$ & $\begin{array}{l}13.6 \\
0.40 \\
0.22\end{array}$ & $\begin{array}{l}<0.001 \\
0.67 \\
0.92\end{array}$ \\
\hline Septum & $\begin{array}{l}\text { Str } \\
\text { Age } \\
\text { Str } \times \text { Age }\end{array}$ & $\begin{array}{l}42.7 \\
0.63 \\
0.53\end{array}$ & $\begin{array}{l}<0.001 \\
0.53 \\
0.72\end{array}$ & $\begin{array}{l}\text { Medulla } \\
\text { oblongata }\end{array}$ & $\begin{array}{l}\text { Str } \\
\text { Age } \\
\text { Sur } \times \text { Age }\end{array}$ & $\begin{array}{l}20.4 \\
18.9 \\
2.84\end{array}$ & $\begin{array}{l}<0.001 \\
<0.001 \\
<0.05\end{array}$ \\
\hline Mesencephalon & $\begin{array}{l}\text { Str } \\
\text { Age } \\
\text { Str } \times \text { Age }\end{array}$ & $\begin{array}{l}13.2 \\
7.67 \\
0.75\end{array}$ & $\begin{array}{l}<0.001 \\
<0.01 \\
0.57\end{array}$ & Amygdala & $\begin{array}{l}\text { Str } \\
\text { Age } \\
\text { Str } \times \text { Age }\end{array}$ & $\begin{array}{l}2.65 \\
1.84 \\
2.37\end{array}$ & $\begin{array}{l}0.08 \\
0.17 \\
0.06\end{array}$ \\
\hline Pineal gland & $\begin{array}{l}\text { Str } \\
\text { Age } \\
\text { Str } \times \text { Age }\end{array}$ & $\begin{array}{l}4.25 \\
1.42 \\
3.78\end{array}$ & $\begin{array}{l}<0.05 \\
0.25 \\
<0.01\end{array}$ & Testes & $\begin{array}{l}\text { Sur } \\
\text { Age } \\
\text { Sur } \times \text { Age }\end{array}$ & $\begin{array}{l}8.86 \\
15.8 \\
3.74\end{array}$ & $\begin{array}{l}<0.001 \\
<0.001 \\
<0.01\end{array}$ \\
\hline
\end{tabular}


Appendix III. Main effects of season and age on VP concentrations in the brain and VP content in the pituitary gland of Lewis rats.

\begin{tabular}{|c|c|c|c|c|c|c|c|}
\hline Structure & Source & $\mathrm{F}$ & $\mathbf{P}$ & Structure & Source & $\mathrm{F}$ & $\mathbf{P}$ \\
\hline $\begin{array}{l}\text { Pituitary gland } \\
\text { concentration }\end{array}$ & $\begin{array}{l}\text { Season } \\
\text { Age } \\
\text { Season*Age }\end{array}$ & $\begin{array}{l}3.82 \\
16.5 \\
0.52\end{array}$ & $\begin{array}{l}<0.05 \\
<0.001 \\
0.72\end{array}$ & $\begin{array}{l}\text { Pituitary gland } \\
\text { content }\end{array}$ & $\begin{array}{l}\text { Season } \\
\text { Age } \\
\text { Season*Age }\end{array}$ & $\begin{array}{l}6.76 \\
52.0 \\
1.92\end{array}$ & $\begin{array}{l}<0.01 \\
<0.001 \\
0.13\end{array}$ \\
\hline Hypothalamus & $\begin{array}{l}\text { Season } \\
\text { Age } \\
\text { Season*Age }\end{array}$ & $\begin{array}{l}2.71 \\
21.6 \\
1.40\end{array}$ & $\begin{array}{l}<0.08 \\
<0.001 \\
0.25\end{array}$ & Hippocampus & $\begin{array}{l}\text { Season } \\
\text { Age } \\
\text { Season*Age }\end{array}$ & $\begin{array}{l}0.87 \\
8.37 \\
0.57\end{array}$ & $\begin{array}{l}0.43 \\
<0.001 \\
0.69\end{array}$ \\
\hline $\begin{array}{l}\text { Medulla } \\
\text { oblongata }\end{array}$ & $\begin{array}{l}\text { Season } \\
\text { Age } \\
\text { Season*Age }\end{array}$ & $\begin{array}{l}1.44 \\
4.97 \\
1.63\end{array}$ & $\begin{array}{l}0.25 \\
<0.001 \\
0.19\end{array}$ & Septum & $\begin{array}{l}\text { Season } \\
\text { Age } \\
\text { Season*Age }\end{array}$ & $\begin{array}{l}0.84 \\
1.67 \\
0.98\end{array}$ & $\begin{array}{l}0.44 \\
0.20 \\
0.43\end{array}$ \\
\hline Mesencephalon & $\begin{array}{l}\text { Season } \\
\text { Age } \\
\text { Season*Age }\end{array}$ & $\begin{array}{l}1.89 \\
8.84 \\
1.12\end{array}$ & $\begin{array}{l}0.34 \\
<0.01 \\
0.34\end{array}$ & Amygdala & $\begin{array}{l}\text { Season } \\
\text { Age } \\
\text { Season*Age }\end{array}$ & $\begin{array}{l}1.57 \\
0.93 \\
1.04\end{array}$ & $\begin{array}{l}0.22 \\
0.40 \\
0.40\end{array}$ \\
\hline
\end{tabular}




\section{PART FOUR}

BRAIN VASOPRESSIN-CONVERTING ENZYMES IN AGING AND ALZHEIMER'S DISEASE 



\title{
VASOPRESSIN-CONVERTING ENZYMES IN RELATION TO AGING IN THE RAT BRAIN
}

\author{
Dirk Terwel, Manon H.F. Rudolph, Marjanne Markerink
}

\begin{abstract}
Changes in vasopressinergic systems with age have been reported. The question whether changes in peptidase activities are instrumental in this respect has not been addressed until now. Therefore in this study vasopressin (VP)-converting enzymes were measured in young and aged rats. Particulate aminopeptidase activities were studied in five different brain areas, and soluble peptidase activities (aminopeptidase and prolyl endopeptidase) were studied in the cortex and hippocampus. Particulate puromycin-sensitive aminopeptidase activity was reduced with age by about 10 and $30 \%$ in the hippocampus and septum, respectively. Prolyl endopeptidase activity was reduced by about $20 \%$ in the cortex, whereas aminopeptidase was increased by about $20 \%$. It is concluded that the changes in vasopressin-converting peptidase activities are too modest to account for the changes in vasopressinergic function with age.
\end{abstract}

\section{Introduction}

The influence of age on vasopressinergic systems has been thoroughly studied in rats. Research initially focused on the hypothalamo-neurohypophyseal system (HNS). In general, it appears that concentrations of VP in the HNS change in a straindependent manner. Neurosecretory activity is decreased in aged Sprague-Dawley and Fischer 344 rats (Zbuzek and Wu 1982, Zbuzek et al. 1983), but increased in LongEvans (Miller 1985), Wistar (Fliers and Swaab 1983, Terwel et al. 1992c) and BrownNorway rats (Goudsmit et al. 1988), probably due to reduced renal function. Reduced extrahypothalamic concentrations of VP with age have also been reported (Dorsa and Bottemiller 1982, Fliers et al. 1985, Terwel et al. 1992b). Since the levels of vasopressin in many extrahypothalamic sites are controlled by circulating testosterone (De Vries et al. 1985), the reduced vasopressin concentrations with age are probably related to testicular dysfunction (Fliers et al. 1985).

A number of peptidases that are able to convert VP in vitro have been identified, namely puromycin-insensitive aminopeptidase (Shimamura et al. 1988, Terwel et al., unpublished data), particulate and soluble puromycin-sensitive aminopeptidase (McLennan et al. 1988, Terwel et al., unpublished data) and prolyl endopeptidase (Burbach et al. 1987, Yoshimoto et al. 1981). After release from the nerve terminal, VP is probably metabolized by an aminopeptidase (Burbach and Lebouille 1983, Stark et al. 1988). Whether the other peptidases convert VP in vivo is not known at present, but their ubiquitous nature (McLellan et al. 1988, Yoshimoto et al. 1981) suggests that they serve general roles in the turnover of peptides and proteins, possibly also in the turnover of vasopressin.

Since vasopressin converting enzymes may contribute to changes in vasopressinergic functions with age we decided to determine these enzyme activities 
in young and aged Wistar rats. A study of peptidase activities with age is also of relevance to our knowledge of general protein catabolism with age, because of the presumed role of these enzymes in protein turnover.

\title{
Materials and methods
}

\begin{abstract}
Animals
In the present study male outbred Wistar rats (Bor:WISW(SPFCpb) were used. The rats were purchased from Winkelmann (Borchen, FRG) at 10 weeks of age and were kept under controlled environmental conditions (12/12 h light/dark cycle, free access to food and water). Eight 3-month-old and eight 32-month-old animals were used. The 50\% survival age of the strain of rats used is 28 months.
\end{abstract}

\section{Preparation of rough synaptosomal membranes and cytosolic fractions}

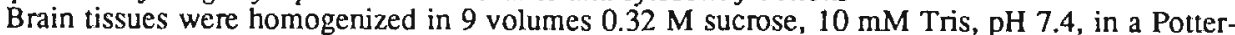
Elvehjem Teflon-glass homogenizer (12 up-and-down strokes, $700 \mathrm{mpm}, 0.25 \mathrm{~mm}$ clearance). The homogenates were centrifuged at $800 \mathrm{~g}$ for 5 minutes. The resulting supematant (S1) was centrifuged at $10,000 \mathrm{~g}$ for 20 minutes. The S2 fraction and the pellet (P2), resuspended in bidistilled water, were then centrifuged at $50,000 \mathrm{~g}$ for 20 minutes. The pellets were washed in $155 \mathrm{mM} \mathrm{NaCl}$, resuspended in $155 \mathrm{mM} \mathrm{NaCl}$, and stored at $-80^{\circ} \mathrm{C}$ together with the cytosolic fractions.

\section{Assays}

\section{Particulate puromycin-insensitive aminopeptidase}

This assay is a modification of the method of Davison et al. (1989) for the determination of plasma vasopressinase. lodinated VP was incubated with membrane fraction (containing $50 \mu \mathrm{g}$ protein) for 20 minutes in $100 \mu$ of a buffer consisting of $50 \mu \mathrm{M}$ Tris ( $\mathrm{pH} 7.4), 1 \mathrm{~g} / 1$ human serum albumin (HSA) and $32 \mu \mathrm{M}$ puromycin. The reaction was stopped by the addition of $0.4 \mathrm{ml} 1 \mathrm{M}$ acetic acid. The supernatants were evaporated under vacuum (Speed Vac Concentrator). The freeze dried residues were dissolved in $200 \mu \mathrm{l}$ of a Veronal/HSA buffer. Diluted anti-VP antiserum $(1: 1,000 ; 25 \mu \mathrm{l})$ was added to $50-\mu l$ aliquots of sample. After 72 hours of incubation, bound and free radioactivity were separated by the addition of $100 \mu \mathrm{l}$ of a suspension of dextran-Ficoll-coated charcoal (Ten Haaf et al. 1992). Charcoal was spun down and the supematant was removed by suction. Charcoal pellets were counted in a well-type $\gamma$-counter. The conversion of the peptide was corrected for nonspecific binding by the antibody.

\section{Particulate puromycin-sensitive aminopeptidase}

This assay proceded in the same manner as the determination of puromycin-insensitive aminopeptidase with the exception that a 60 -minute incubation was used. The difference between incubations in the presence or absence of puromycin was taken as a measure of puromycin-insensitive aminopeptidase.

\section{Soluble puromycin-sensitive aminopeptidase}

Aminopeptidase activity was measured with a modification of a previously reported assay. Vasopressin iodinated in the $\mathrm{Tyr}^{2}$ position was used as a substrate (Amersham, Buckinghamshire, UK). Two incubations were carried out, either in the presence of $32 \mu \mathrm{M}$ puromycin or in the absence of the inhibitor. The difference between the release of Tyr in these two incubations was used as an index of puromycin-sensitive aminopeptidase activity. Iodinated VP was incubated with $2.5 \mu \mathrm{g}$ cytosolic protein for 5 minutes in $100 \mu \mathrm{l}$ of a buffer consisting of $50 \mu \mathrm{M}$ Tris- $\mathrm{HCl}(\mathrm{pH} 7.4), 1 \mathrm{~g} / \mathrm{HSA}$ and $1 \mathrm{mM}$ dithiothreitol. The reaction was stopped by the addition of $0.9 \mathrm{ml} 0.1 \mathrm{M} \mathrm{NaOH}$. Iodinated Tyr was separated from the substrate by the addition of $50 \mathrm{mg}$ Amberlite XAD-2 (BDH, Pool, UK), prewetted with $50 \mu \mathrm{l}$ ethanol. The tubes were kept in a rotary tumbler (Luckham, Burgess Hill, UK) 
for 30 minutes to allow VP to bind to the beads. Beads were spun down at low speed and the Tyr containing supematants were pipetted off.

\section{Prolyl endopeptidase}

The prolyl endopeptidase assay was based on the method of Davison et al. (1989). Iodinated VP was used as a substrate. Davison et al. determined $\mathrm{N}$-terminal conversion of the peptide. In the present study, C-terminal conversion of the peptide was assessed as the reduced binding of radioactivity to excess C-terminus recognizing antibody. The antibody has been characterized previously (Burbach et al. 1984). Iodinated VP $(10 \mathrm{pM})$ was incubated with $25 \mu \mathrm{g}$ cytosolic protein for 10 minutes in $100 \mu \mathrm{I}$ of a buffer consisting of $50 \mathrm{mM}$ Tris- $\mathrm{HCl}(\mathrm{pH} \mathrm{7.4),1} \mathrm{g} / \mathrm{HSA}$ and $1 \mathrm{mM} \mathrm{1,10-phenanthroline.} \mathrm{1,10-}$ Phenanthroline was present during the incubation to inhibit aminopeptidase activity. The rcaction was stopped by addition of $0.4 \mathrm{ml} 1 \mathrm{M}$ acetic acid and boiling for 5 minutes. Flocculent matcrial was removed by centrifugation $\left(50 \times 10^{3} \mathrm{~g}, 30\right.$ minutes). The rest of the procedure was as described for puromycin-insensitive aminopeptidase.

\section{Statistics}

A statistics package was used for statistical analysis (StatView $512+^{\mathrm{TM}}$ ). Data were subjected to unpaired Student's t-tests.

\section{Results}

The activities of two membrane-bound aminopeptidases (puromycin-sensitive and puromycin-insensitive aminopeptidase) were determined in the cortex, cerebellum, striatum, hippocampus of young and aged rats (Fig. 1A,B). Puromycin-insensitive aminopeptidase was also measured in the septum (Fig. 1A). Two soluble peptidases (the soluble form of the puromycin-sensitive aminopeptidase and prolyl endopeptidase) were determined in the cortex and hippocampus of young and aged rats (Fig. 2A,B).

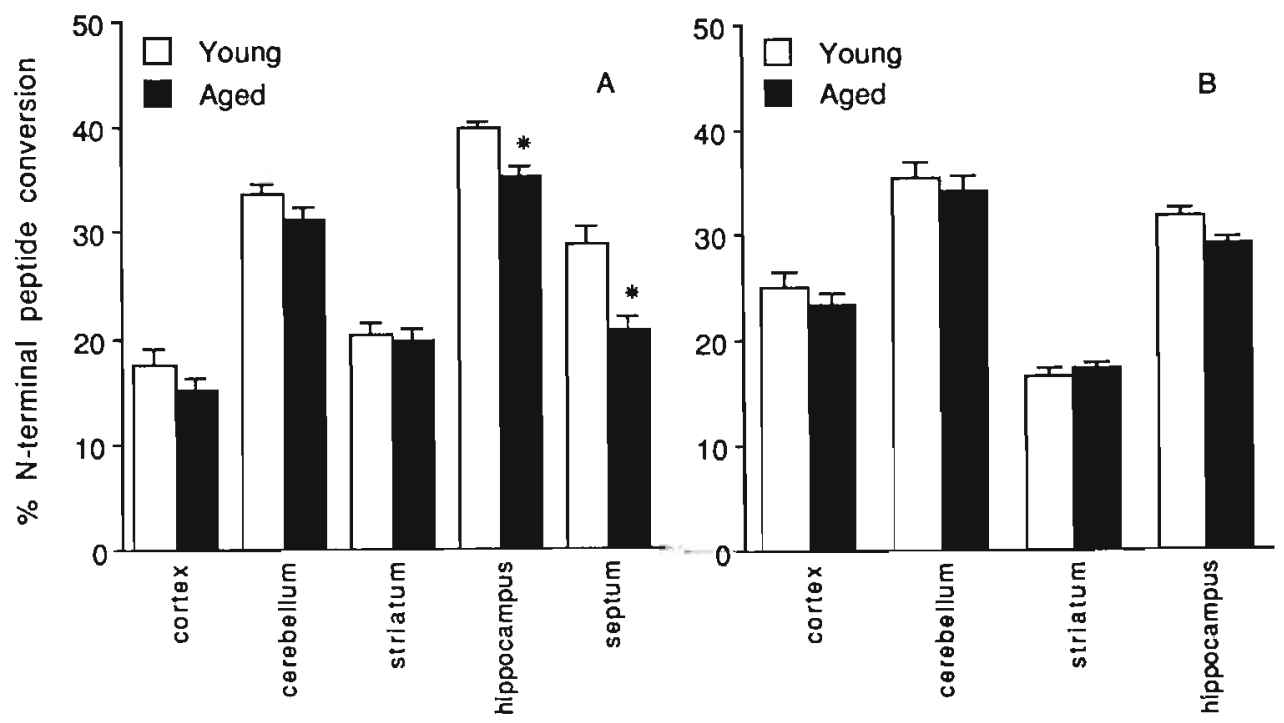

Fig. 1. Particulate puromycin-sensitive (A) and insensitive (B) aminopeptidase activities in 3- and 32month-old Wistar rats. 
Puromycin-insensitive aminopeptidase activity was not significantly different in the cortex, cerebellum and striatum of young animals as compared with aged animals ( $p>$ $0.05)$. This enzyme activity was reduced with age by $11 \%$ and $28 \%$ in the hippocampus and septum $(\mathrm{p}<0.05)$, respectively. Puromycin-insensitive aminopeptidase was unaffected by age in any of the brain structures examined $(p>0.05)$. Particulate puromycin-sensitive aminopeptidase was not determined in the septum because too little membrane material was obtained from the subcellular fractionation.

Soluble aminopeptidase activity appeared to be $19 \%$ higher in the cortex of aged animals than in the cortex of young animals $(\mathrm{p}<0.05$ ), but was unaltered in the hippocampus ( $p>0.05$ ). Prolyl endopeptidase activity was reduced by $22 \%$ in the cortex of aged as compared to young rats $(p<0.01)$.
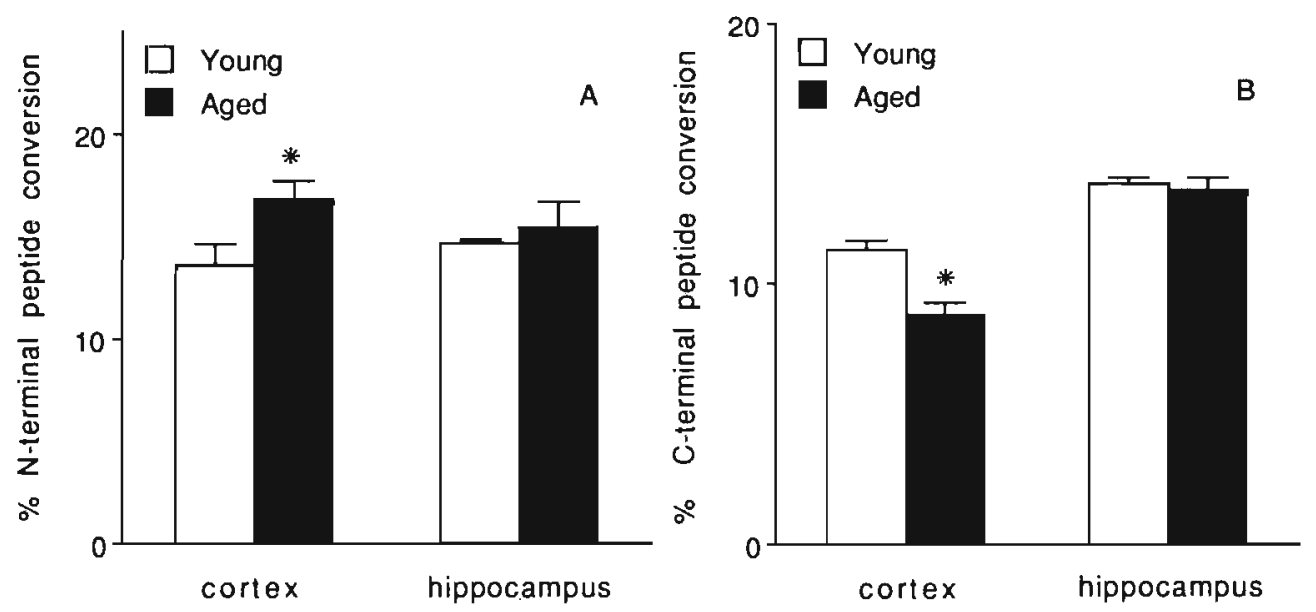

Fig. 2. Soluble puromycin-sensitive aminopeptidase (A) and prolyl endopeptidase (B) activities in 3and 32 -month-old Wistar rats.

\section{Discussion}

The present study is concerned with the influence of age on peptidases that have been shown to metabolize VP in vitro. The present study is not only of relevance to assess the contribution of peptidases to changes in vasopressinergic systems with age, but it is also one of the few studies on changes in the catabolism of peptides and proteins with age. Puromycin-sensitive aminopeptidase activity was reduced in the septum, soluble puromycin-insensitive aminopeptidase activity was increased in the cortex, and prolyl endopeptidase activity was reduced in the cortex with age.

Puromycin-insensitive aminopeptidase is probably directly involved in the termination of the action of VP after its release into the synaptic cleft. The reduced 
activity of puromycin-insensitive aminopeptidase, observed in the septum, probably enhances the action of VP. Whether this enzyme activity is reduced because vasopressinergic function in the septum is reduced is not clear as yet. It could also be that the reduced enzyme activity in the septum represents a general age-related decline. It is noteworthy, however, that puromycin-insensitive aminopeptidase activity was not reduced in the other structures, except for a small reduction in the hippocampus. Interestingly, the hippocampus also receives a vasopressinergic input, albeit a less extensive one than that to the septum. Since VP disappears from the septum after castration, it would be interesting to determine the effect of castration on puromycin-insensitive aminopeptidase activity.

Soluble aminopeptidase activity appeared to be increased in the cortex, whereas prolyl endopeptidase activity was reduced. These changes in enzyme activities with age may be directly related, since they showed a significant correlation $(p<0.05)$. The mechanism of the change in aminopeptidase activity is not known as yet.

Recently, we found a reduction in prolyl endopeptidase activity in Alzheimer's disease (AD) (Terwel et al. 1992a). The mechanism of the change in prolyl endopeptidase activity found in the present study may be identical to that in AD, despite the fact that the reduction in enzyme activity was far more pronounced in AD. Prolyl endopeptidase activity is reduced in HeLa cells after heat shock (Pratt et al. 1989), and the inactivation of the enzyme is thought to be caused by a change in the intracellular redox state (Tsukahara et al. 1990). These observations suggest that prolyl endopeptidase activity in the cortex of aged rats is reduced as a result of changes in intracellular redox state caused by neuronal stress. Stress to neurons in turn may be caused by, for instance, increased levels of hydroxyl radicals with age (de Haan et al. 1992).

The functional significance of the hydrolysis of VP by soluble enzymes in vitro is unclear, since their localization is incompatible with a role in neuropeptide inactivation at the synapse. However, neuropeptides are possibly also substrates for the enzymes involved in the intracellular turnover of secretory vesicles. The widespread occurrence of these enzymes in many cell types suggests that they have a fundamental role in the turnover of peptides and proteins (McLennan et al. 1988, Yoshimoto et al. 1981).

In conclusion, VP-converting enzymes appear to change with age. However, the changes in peptidase activities with age are probably too modest to cause major changes in vasopressinergic systems. The changes in peptidase activities, especially prolyl endopeptidase activity, seem to be more interesting from the point of view that they are possible models for the aging of enzymes. Since this is the first time that the influence of age on VP-converting enzymes was assessed and since the observed alterations in peptidase activities with age were rather small, we consider our findings preliminary. Further studies are necessary to substantiate our findings. 


\section{References}

Burbach JPH, Lebouille JLM. Proteolytic conversion of arginine-vasopressin and oxytocin by brain synaptic membranes. Characterization of formed peptides and mechanism of proteolysis. J Biol Chem 1983;258:148794.

Burbach JPH, Terwel D, Lebouille JLM. Measurement and distribution of vasopressin-convering aminopeptidase-activity in rat brain. Biochem Biophys Res Commun 1987;144:726-31.

Burbach JPH, Wang X-C, Ten Haaf JA, De Wied D. Substances resembling C-terminal vasopressin fragments are present in the brain but not in the pituitary gland. Brain Res 1984;306:384-7.

Davison JM, Sheills EA, Barron WM, Robinson AG, Lindheimer MD. Changes in the metabolic clearance of vasopressin and in plasma vasopressinase throughout human pregnancey. J Clin Invest 1989;83:1313-8.

de Haan JB, Newman JD, Kola I. Cu/Zn superoxide dismutase mRNA and enzyme activity, and susceptibility to lipid peroxidation, increases with aging in murine brains. Mol Brain Res 1992;13:179-87.

De Vries GJ, Buijs RM, Van Leeuwen FW, Caffe AR, Swaab DF. The vasopressinergic innervation of the brain in normal and castrated rats. J Comp Neurol 1985;233:236-54.

Dorsa DM, Bottemiller L. Age-related changes of vasopressin content of microdissected areas of the rat brain. Brain Res 1982;242:151-6.

Fliers E, Swaab DF. Activation of vasopressinergic and oxytocinergic neurons during aging in the Wistar rat. Peptides 1983;4:165-70.

Fliers E, De Vries GJ, Swaab DF. Changes with aging in the vasopressin and oxytocin innervation of the rat brain. Brain Res 1985;348:1-8.

Goudsmit E, Fliers E, Swaab DF. Vasopressin and oxytocin excretion in the Brown-Norway rat in relation to ageing, water metabolism and testosterone. Mech Ageing Dev 1988;44:241-52.

McLellan S, Dyer SH, Rodriguez G, Hersh LB. Studies on the tissue distribution of the puromycin-sensitive enkephalin-degrading aminopeptidases. J Neurochemistry 1988;51:1552-9.

Miller M. Influence of aging on vasopressin secretion and water regulation. In: Schrier RW, ed. Vasopressin. New York: Raven Press, 1985:249-58.

Pratt G, Hough R, Rechsteiner M. Proteolysis in heat-stressed HeLa Cells. Stabilization of ubiquitin correlates with the loss of proline endopeptidase. J Biol Chem 1989;264:12526-32.

Shimamura M, Hazato T, Iwaguchi T. A new aminopeptidase in monkey cerebral membrane fraction: hydrolysis of enkephalin. Brain Res 1988;445:350-3.

Stark H, Burbach JPH, Van der Kleij AAM, De Wied D. In vivo conversion of vasopressin after microinjections into limbic brain areas of rats. Peptides 1989;10:717-20.

Ten Haaf JA, Terwel D, Van de Heijning BJM, Van Wimersma Greidanus TjB. Radioimmunoassay: a goal or a tool? J Control Rel 1992 (in press).

Terwel D, Markerink M, Jolles J. Peptidases are affected differently in neocortical regions of brains from patients with Alzheimer's disease. Dementia 1992a;3:108-13.

Terwel D, Markerink M, Jolles J. Age-related changes in concentrations of vasopressin in the central nervous systcm and plasma of the male Wistar rat. Mech Ageing Dev 1992b (in press).

Terwel D, Ten Huaf JA, Markerink M, Jolles J. Changes in plasma vasopressin concentration and plasma osmolality in relation to age and time of day in the male Wistar rat. Acta Endocrinol 1992c;126:357-62.

Tsukahara $T$, Ishiura $S$, Sugita $H$. Regulation of prolyl endopeptidase activity by the intracellular redox state. J Biol Chem 1990;265:21448-53.

Yoshimoto T, Simmons WH, Kita T, Tsuru D. Post-proline cleaving enzyme from lamb brain. J Biochem 1981;90:323-34.

Zbuzek VK, Wu W. Age-related vasopressin changes in rat plasma and the hypothalamo-hypophyseal system. Exp Gerontol 1982;17:133-8.

Zbuzek VK, Zbuzek V, Wu W. The effect of aging on vasopressin system in Fischer 344 rats. Exp Gerontol 1983:18:305-11. 


\title{
PEPTIDASES ARE AFFECTED DIFFERENTLY IN NEOCORTICAL REGIONS OF BRAINS FROM PATIENTS WITH ALZHEIMER'S DISEASE
}

\author{
Dirk Terwel, Marjanne Markerink, Jellemer Jolles
}

\begin{abstract}
Although it is recognized that changes in protease activities may be involved in the etiology of pathological changes in the human brain, there have been few studies on normal and pathological protein catabolism. In the present study the activities of major cortical aminopeptidase and prolyl endopeptidase were determined in frontal and medial temporal cortical samples of brains from patients with Alzheimer's disease (AD) and control patients matched for age. Prolyl endopeptidase activity was reduced by $45-50 \%$ in the frontal and medial temporal cortex of AD patients as compared with controls, whereas major aminopeptidase activity was unaltered. The possibility that the changes in peptidase activities in AD are agedependent was studied in postmortem neocortical samples from 18 AD patients who had died between 55 and 90 years of age. Prolyl endopeptidase activity was lower in patients who died at a relatively early age than in patients who died at a relatively old age. This underscores the notion that, with respect to age, there may be heterogeneity in neurochemical changes in AD.
\end{abstract}

\section{Introduction}

Alzheimer's disease (AD) is the most prevalent neurodegenerative disorder, causing dementia, and affects $5 \%$ of the population over 65 years of age (Plum 1979). This disease is characterized by large numbers of neuritic plaques and neurofibrillary tangles and is associated with many biochemical alterations, such as reduced activities of choline acetyltransferase (Davies 1979, Perry and Perry 1980) and dopamine- $\beta$ hydroxylase (Adolfson et al. 1979, Cross et al. 1981), altered phosphorylation of cytoskeletal proteins (Grundke-Iqbal et al. 1986), and abnormal protein processing leading to deposition of $\beta$-amyloid peptide (Esch et al. 1990). How these biochemical alterations relate to each other and to the cause and pathogenesis of AD is not yet understood. The observation that the formation of neuritic plaques results from abnormal protein deposition prompted investigators to look for abnormalities in protein catabolism in AD. For instance, serine proteases (Abraham et al. 1988) (various complement factors), serine protease inhibitors (Eikelenboom et al. 1989), and calpain (Shimohama et al. 1991) have been identified as components of neuritic plaques. Ubiquitin, a small protein involved in energy-dependent proteolysis, is present in neurofibrillary tangles (Mori et al. 1987). Several studies on peptidase activities in AD have been carried out. Mantle et al. (1989) did not find changes in major aminopeptidase activity in neocortical samples from AD patients. Likewise, Kawashima et al. (1989) and Nilsson et al. (1990) failed to find changes in calpain activity in AD brains. Aoyagi et al. (1990) measured aminopeptidase, dipeptidylpeptidase, cathepsin $\mathrm{B}$ and serine protease activities in occipital cortex from $\mathrm{AD}$ patients and observed decreased kallikrein activity and increased prolyl 
endopeptidase activity. The fact that only these two proteases were affected in AD may be related to the age distribution of the patients examined, since it has been observed that neurochemical markers of AD are influenced by age (Rossor et al. 1984). It is thus important to consider age when studying neurochemical changes in AD. Major aminopeptidase is the most active aminopeptidase and prolyl endopeptidase is the most active serine protease of brain tissue (McDermott et al. 1985, Yoshimoto et al. 1981). Their ubiquitous nature suggests that they serve a fundamental role in protein turnover. So far these enzymes were studied in relatively old AD patients only (Aoyagi et al. 1990, Mantle et al. 1989). Therefore it was considered important to determine these enzyme activities in AD patients with respect to age. Firstly, major aminopeptidase and prolyl endopeptidase activities were determined in neocortical autopsy samples from relatively young $A D$ and control patients matched for age and postmortem delay. Secondly, these enzyme activities were determined in tissue from $\mathrm{AD}$ patients who died between 55 and 90 years of age.

\section{Materials and methods}

Brain tissues were obtained from the Netherlands Brain Bank. Eighteen patients ( 5 male, 13 female; age range 55-90 years) were selected that had been clinically diagnosed as probable Alzheimer cases according to the NINCDS-ADRDA criteria (McKhann et al. 1984) (for patient information see Table 1). They had a score of 6-7 on the Global Deterioration Scale of severity of dementia (Reisberg et al. 1982). The clinical diagnosis of AD was verified by postmortem neuropathological examination of formalin-fixed specimens. Five AD patients were selected for the first experiment [4 male, 1 female; mean age (SD) 68 (3); postmortem delay (SD) 294 (43) minutes; No. 2-6, Table 1]. Five patients with no evidence of dementia and no history of other neurological or psychiatric disorders were selected as normal controls [ 3 male, 2 female; mean age (SD) 67 (5); postmortem delay (SD) 322 (48) minutes; No. 1-5, Table 1].

Tissue blocks of about $1 \mathrm{~g}$ fresh weight were excised from the frontal superior gyrus and the medial temporal gyrus. The lcptomeninges were removed and the samples were rapidly frozen in liquid nitrogen. The frozen samples were stored at $-80^{\circ} \mathrm{C}$ until use. Brain tissue samples were homogenized in 9 volumes $0.32 \mathrm{M}$ sucrose, $1 \mathrm{mM}$ EGTA, $50 \mathrm{mM}$ Tris, pH 7.4, in a Potter-Elvehjem Teflon-glass homogenizer (12 up-and-down strokes, $700 \mathrm{rpm}, 0.25 \mathrm{~mm}$ clearance). The homogenates were centrifuged at $100,000 \mathrm{~g}$ for 60 minutes and the resulting membrane-free fraction was frozen in liquid nitrogen and stored at $-80^{\circ} \mathrm{C}$ until determination of peptidase activities.

\section{Assay for the determination of major aminopeptidase activity}

Aminopeptidase activity was measured with a modification of a previously reported assay (Burbach et al. 1987). Vasopressin iodinated in the $\mathrm{Tyr}^{2}$ position was used as peptide substrate (Amersham, Buckinghamshire, UK). Two incubations were carried out, either in the presence of 32 $\mu \mathrm{M}$ puromycine or in the absence of the inhibitor. The difference between the release of Tyr in these two incubations was used as an index of puromycin sensitive (major) aminopeptidase activity. lodinated VP was incubated with $2.5 \mu \mathrm{g}$ cytosolic protein for 2.5 minutes in $100 \mu \mathrm{l}$ of a buffer consisting of $50 \mathrm{mM}$ Tris- $\mathrm{HCl}(\mathrm{pH} 7.4), 1 \mathrm{~g} / 1$ human serum albumin (HSA) and $1 \mathrm{mM}$ dithiotreitol (DTT). Conditions were chosen such that less than $20 \%$ of the substrate was converted. The reaction was stopped by the addition of $0.9 \mathrm{ml} 0.1 \mathrm{M} \mathrm{NaOH}$. Iodinated Tyr was separated from the substrate by the addition of $50 \mathrm{mg}$ Amberlite XAD-2 (BDH, Poole, UK) prewetted with $50 \mu l$ ethanol. The tubes were kept in a rotary tumbler (Luckham, Burgess Hill, UK) for 30 minutes to allow VP to bind to the beads. Beads were spun down at low speed and the Tyr containing supematants were pipetted off. 


\section{Assay for the determination of prolyl endopeptidase activity}

The prolyl endopeptidase assay was based on the method of Davison et al. (1989). Iodinated VP was used as a substrate. Davison et al. determined N-terminal conversion of the peptide. In the present study, C-terminal conversion of the peptide was assessed as the reduced binding of radioactivity to excess C-terminus recognizing antibody. The antibody has been characterized previously (Burbach et al. 1984). Iodinated VP $(10 \mathrm{pM})$ was incubated with $12.5 \mu \mathrm{g}$ of cytosolic protein for 5 minutes in 100 $\mu \mathrm{l}$ of a buffer consisting of $50 \mathrm{mM}$ Tris- $\mathrm{HCl}(\mathrm{pH} 7.4), 1 \mathrm{mg} / \mathrm{ml} \mathrm{HSA}$ and $1 \mathrm{mM} \mathrm{1,10-phenanthroline.}$ 1,10-Phenanthroline was present during the incubation to inhibit aminopeptidase activity. Conditions were chosen such that less than $20 \%$ of the substrate was converted. The reaction was stopped by addition of $0.4 \mathrm{ml} 1 \mathrm{M}$ acetic acid and boiling for 5 minutes. Flocculent matcrial was removed by centrifugation $\left(50 \times 10^{3} \mathrm{~g}, 30\right.$ minutes). The supematants werc evaporated under vacuum (Speed Vac Concentrator). The freeze-dried residues were dissolved in $200 \mu \mathrm{l}$ of a Veronal/HSA buffer. Diluted anti-VP antiserum $(1: 1,000 ; 25 \mu \mathrm{l})$ was added to $50-\mu \mathrm{l}$ aliquots. After $72 \mathrm{~h}$ of incubation bound and free radioactivity were separated by the addition of $100 \mu \mathrm{l}$ of a suspension of dextran-Ficoll-coated charcoal (Ten Haaf et al. 1992). Charcoal was spun down and the supematant was removed by suction. Charcoal pellets were counted in a well-type $\gamma$-counter.

Table 1. Patient information

$\begin{array}{llll}\text { Cases } & \begin{array}{l}\text { Age } \\ \text { sex }\end{array} & \begin{array}{l}\text { Brain } \\ \text { weight, } g\end{array} & \begin{array}{l}\text { Postmortem } \\ \text { delay, minutes }\end{array}\end{array} \quad$ Cause of death

\section{Controls}

\begin{tabular}{llll}
1 & $60 \mathrm{M}$ & 1350 & 360 \\
2 & $65 \mathrm{M}$ & 1310 & 315 \\
3 & $66 \mathrm{~F}$ & 1100 & 375 \\
4 & $71 \mathrm{~F}$ & 1240 & 305 \\
5 & $73 \mathrm{M}$ & 1340 & 255 \\
\hline
\end{tabular}

septic shock following aorta valve implantation

heart failure

postoperative heart failure

sepsis and cardiogenic shock

cerebral infarct

$\begin{array}{clrl}\text { AD } & & & \\ 1 & 55 \mathrm{M} & 1020 & 180 \\ 2 & 64 \mathrm{M} & 1210 & 330 \\ 3 & 65 \mathrm{M} & 1360 & 240 \\ 4 & 68 \mathrm{~F} & 895 & 345 \\ 5 & 70 \mathrm{M} & 1075 & 270 \\ 6 & 72 \mathrm{M} & 1040 & 285 \\ 7 & 79 \mathrm{~F} & 1010 & 245 \\ 8 & 81 \mathrm{~F} & 910 & 225 \\ 9 & 84 \mathrm{~F} & 920 & 205 \\ 10 & 88 \mathrm{~F} & 1070 & 225 \\ 11 & 81 \mathrm{~F} & 1130 & 330 \\ 12 & 85 \mathrm{~F} & 1020 & 135 \\ 13 & 87 \mathrm{~F} & 950 & 235 \\ 14 & 89 \mathrm{~F} & 940 & 250 \\ 15 & 88 \mathrm{~F} & 960 & 225 \\ 16 & 89 \mathrm{~F} & 1050 & 200 \\ 17 & 90 \mathrm{~F} & 840 & 230 \\ 18 & 90 \mathrm{~F} & 1000 & 270\end{array}$

pneumonia, cachexia and dehydration

collum fracture (died after operation)

pulmonary embolism, dehydration

bronchopneumonia

cachexia

pneumonia and cachexia

bronchopneumonia and cachexia

pneumonia and heart disease

pneumonia

pneumonia

suffocation

intestinal bleeding

apnea after postoperative irreversiblehypotension

pneumonia

lung infection

unknown

cachexia and dehydration

acute myocard infarct, massive pulmonary embolism 

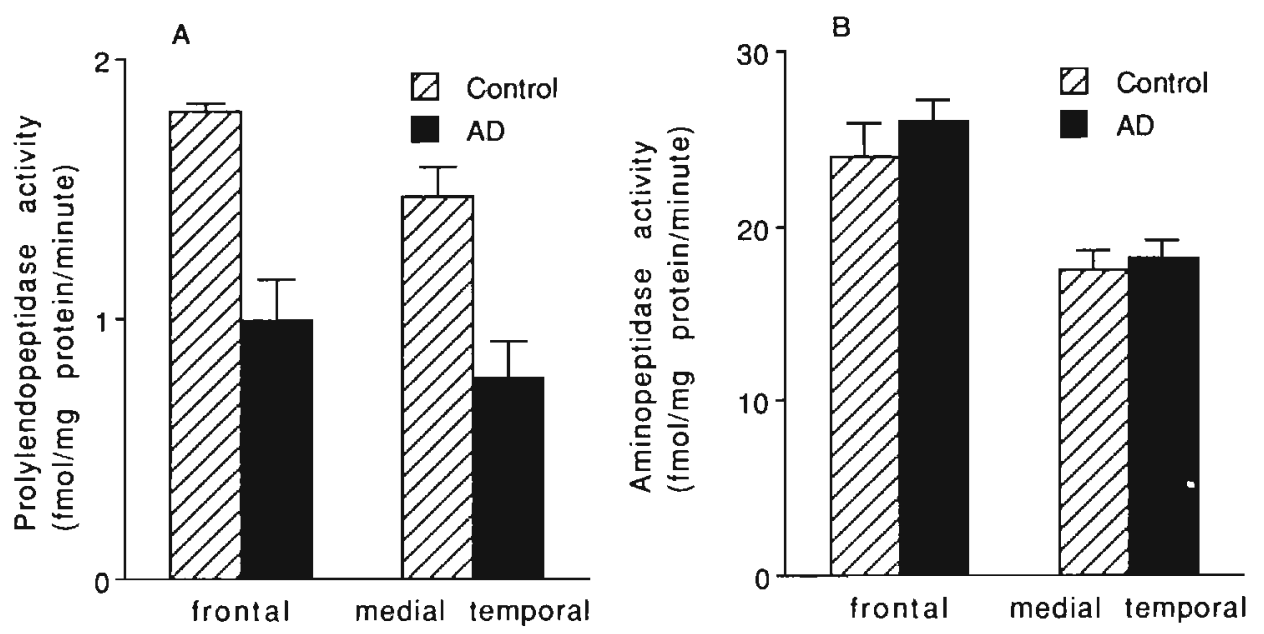

Fig. 1. Prolyl endopeptidase (A) and major aminopeptidase (B) activities in medial temporal and frontal cortex of $\mathrm{AD}$ and control patients matched for age. Each group consisted of five patients.

\section{Results}

Prolyl endopeptidase and major aminopeptidase activities were determined in autopsy samples of the frontal superior gyrus of $5 \mathrm{AD}$ patients and control subjects matched for age and postmortem delay. Total aminopeptidase activity consisted of puromycin-sensitive aminopeptidase activity only, that is puromycin-insensitive activity was not detected. Prolyl endopeptidase activity was reduced by 44 and $48 \%$ in the frontal and medial temporal cortex of the $5 \mathrm{AD}$ patients as compared with 5 control patients matched for age ( $p$ values $<0.01$, Fig. 1A). Aminopeptidase activity was not affected in the five AD patients ( $p$ values $>0.05$, Fig. 1B).

Peptidase activities were determined in medial temporal cortex samples of $18 \mathrm{AD}$ patients who had died between 55 and 90 years of age. Using a split half design, we tested whether there was an age-related difference in $\mathrm{AD}$ patients with respect to peptidase activities. The older AD patients ( $>84$ years) had a significantly higher prolyl endopeptidase activity than the younger ones $(<84$ years) $(p<0.05$, Fig. $2 A)$. The older AD patients did not differ from the 5 control patients $(p>0.05)$, but the younger AD patients did ( $p<0.01$, Fig. $2 \mathrm{~A})$. Comparisons with older control patients were not possible because material from older control patients was not available. Aminopeptidase activity was unrelated to age in AD patients ( $p>0.05$, Fig. 2B).

To investigate whether the lower prolyl endopeptidase activity was caused by either the presence of an endogenous inhibitor or the absence of a cofactor in cytosolic fractions of neocortical tissue from AD patients, cytosolic fractions prepared from AD 
A

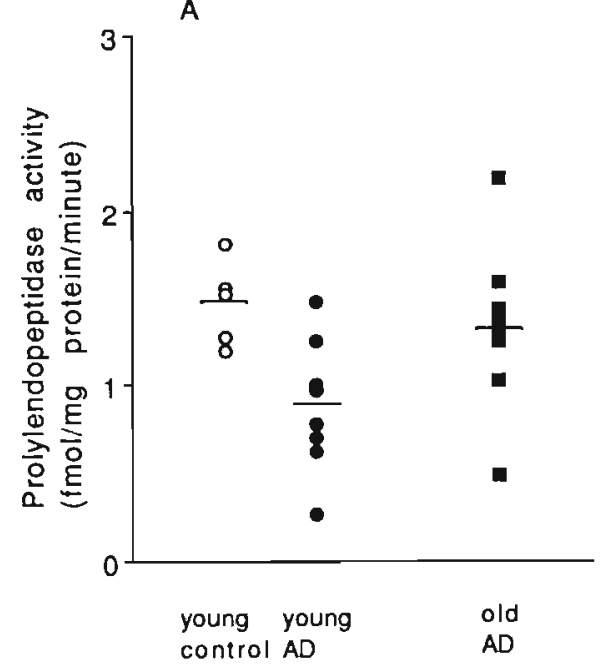

B

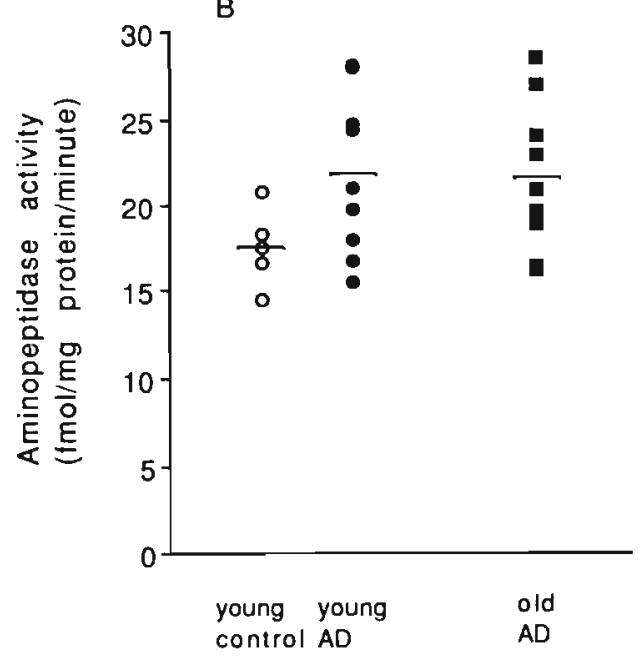

Fig. 2. Prolyl endopeptidase (A) and aminopeptidase activies (B) in medial temporal cortex of control $(\mathrm{O})$ and $\mathrm{AD}$ patients younger than 84 years $(\mathbf{)}$ ) and older than 84 years $(\boldsymbol{\square})$.

from AD material were combined with cytosolic fractions prepared from control material. Combination of cytosolic fractions did not result in a decrease in the sum of activities ( $p>0.05$, Fig. 3). Heat-denatured cytosolic fractions of AD patients did not affect the prolyl endopeptidase activity of cytosolic fractions of controls or vice versa (p values $>0.05$, Fig. 3).

\section{Discussion}

In the present study two peptidase activities were measured in postmortem brain samples of patients with $\mathrm{AD}$ and of control patients. Prolyl endopeptidase was determined radioimmunochemically and aminopeptidase radiometrically with vasopressin iodinated in the $\mathrm{Tyr}^{2}$ position. We used these methods on the basis of our experience with the measurement of the conversion of vasopressin by membrane and cytosolic fractions and with the radioimmunoassay of vasopressin (Burbach and Liu 1989, Burbach et al. 1987, Ten Haaf et al. 1992). Since vasopressin is not present in brain cortex, this study is not of relevance to the in vivo conversion of vasopressin. It has been shown previously that vasopressin is converted by purified major cytosolic aminopeptidase (McDermott et al. 1985) and prolyl endopeptidase (Yoshimoto et al.1981). In addition, vasopressin is converted by both $\mathrm{N}$ - and $\mathrm{C}$-terminal degrading enzymes when incubated with a cytosolic fraction (Burbach et al. 1987). When assessing prolyl endopeptidase activity, aminopeptidase activity was inhibited with 1 


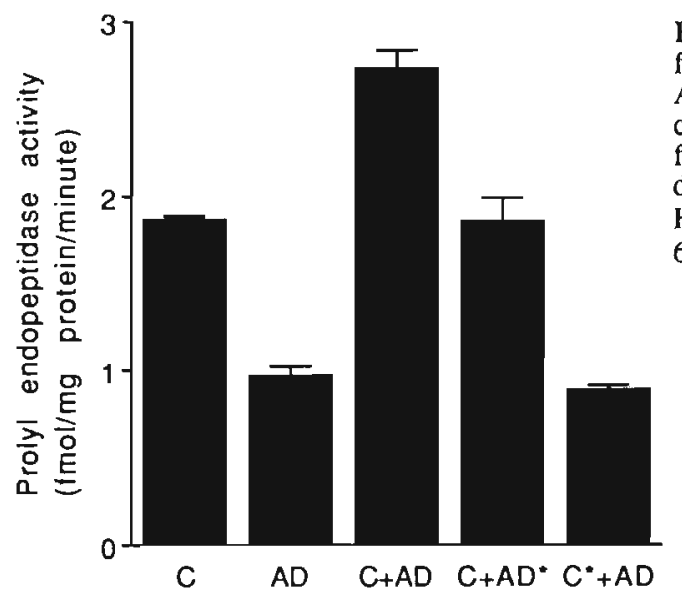

Fig. 3. Prolyl endopeptidase activity in cytosolic fractions of frontal cortex of control patients and AD patients, combined fractions ( $C+A D)$, combined control and heat-denatured $A D$ fractions $\left(\mathrm{C}+\mathrm{AD}^{*}\right)$, and combined heatdenatured control and $\mathrm{AD}$ fractions $\left(\mathrm{C}^{*}+\mathrm{AD}\right)$. Heat denaturation was achieved by heating at $65^{\circ} \mathrm{C}$ for 30 minutes.

$\mathrm{mM}$ 1,10-phenanthroline. The possibility that C-terminal conversion of vasopressin may have affected the determination of $\mathrm{N}$-terminal conversion can be excluded, because conditions were chosen such that only a few percent of vasopressin was converted $\mathrm{C}$-terminally, and $\mathrm{N}$-terminal fragments of vasopressin can still serve as a substrate for the aminopeptidase.

Prolyl endopeptidase activity was reduced by $45-50 \%$ in the frontal and medial temporal cortices of $\mathrm{AD}$ patients as compared with tissue from controls matched for age. In contrast, major aminopeptidase activity was not decreased in the frontal and medial temporal cortices of AD patients as compared with control patients. Since major aminopeptidase and prolyl endopeptidase are both cytosolic peptidases (McDermott et al. 1985, Yoshimoto et al. 1981) the decrease in the activity of the former enzyme is probably not related to neuronal death.

Prolyl endopeptidase also appeared to be affected by the age of the AD patients. This can be explained in two possible ways. Firstly, older patients may have died earlier in the disease. This possibility is not supported by the observation that the diagnosed duration of disease was not significantly different between the younger and older AD patients. Nor was there a correlation between the duration of disease and prolyl endopeptidase activity. Secondly, the age dependence of prolyl endopeptidase activity may reflect a nosological distinction between late and early onset $\mathrm{AD}$. Rossor et al. (1984) has reported on the age dependence of neurochemical markers of AD. The present findings corroborate these observations for prolyl endopeptidase activity. No effect of age was found on major aminopeptidase activity. The suggestion that an effect on major aminopeptidase activity may have been missed previously (Mantle et al. 1989) can now be excluded.

Prolyl endopeptidase activity in the brains of AD patients may be reduced by three possible mechanisms: (1) reduced synthesis of the enzyme; (2) damage to the enzyme; 
(3) inhibition of the enzyme by an endogenous component or the absence of a cofactor. The latter possibility was excluded by the observation that combination of cytosolic fractions of AD and control patients did not result in decreases or increases in the sum of activities which would have occurred if an inhibitor or the absence of a cofactor were the cause of the reduced enzyme activity. Nor did heat-denatured cytosolic fractions from $A D$ patients contain an inhibitor of prolyl endopeptidase activity.

In striking contrast to our findings Aoyagi et al. (1990) found an increase in prolyl endopeptidase activity in occipital cortex from AD patients. This cannot be readily explained. It may be related to the particular sample of patients selected by Aoyagi et al. (1990) and heterogeneity within AD cases; these investigators did not diagnose their patients according to the NINCDS-ARDRA criteria (McKhann et al. 1984) and used relatively old patients. In the present study no change was observed in prolyl endopeptidase in brain tissue from relatively old AD patients.

$\mathrm{AD}$ is characterized by a disturbance in protein catabolism (deposition of proteins and abnormal protein cleavage) and changes in protein degrading enzymes are probably involved. Whether the disturbance found in the present study is a causative factor in $A D$ and how peptidases participate in the etiology of $A D$ needs further investigation. Prolyl endopeptidase is a serine protease and the reduction in prolyl endopeptidase activity observed may be representative of other serine proteases.

Some of the enzymes affected in $A D$ are associated with well-defined transmitter systems (e.g., choline acetyltransferase (Perry and Perry 1980)), whereas other enzymes, such as the presently studied peptidases, are of a ubiquitous nature. It is likely that these reduced enzyme activities have a common cause. Some enzyme activities may be reduced by dephosphorylation, since tyrosine kinase activity is reduced in AD (Shapiro et al. 1991). This is not a likely explanation for the changes in the peptidase activities, since the activity of these enzymes is not regulated in such a way. It would be interesting to try to find a common denominator for the changes in enzyme activities observed. Factors that may reduce enzyme activities are changes in cellular metal concentrations (Wenstrup et al. 1990) and free radical formation (Subbarao et al. 1990). Whether one of these factors is the common denominator is far from certain, but tracing the cause of the changes in enzyme activities may be a fruitful approach to the elucidation of the etiolgy of $\mathrm{AD}$.

\section{References}

Abraham CR, Selkoe DJ, Potter H. Immunochemical identification of the serine protease inhibitor alpha-1antichymotrypsin in the brain amyloid deposits of Alzheimer's disease. Cell 1988;52:487-501.

Adolfsson R, Gottfries CG, Roos BE, Winblad B. Changes in brain cathecholamines in patients with dementia of Alzheimer type. Br J Psychiatry 1979;135:216-23.

Aoyagi T, Wada T, Nagai M, Kojima F, Harada S, Takeuchi T, Takahashi H, Hirokawa K, Tsumita T. Deficiency of kallikrein-like enzyme activities in cerebral tissue of patients with Alzheimer's disease. Experientia 1990;46:94-7.

Burbach JPH, Liu B. Measurement of vasopressin-converting aminopeptidase activity and vasopressin 
metabolites. Methods in Enzymology 1989;168:385-97.

Burbach JPH, Terwel D, Lebouille JLM. Measurement and distribution of vasopressin-converting aminopeptidase-activity in rat brain. Biochem Biophys Res Commun 1987;144:726-31.

Burbach JPH, Wang X-C, Ten Haaf JA, De Wied D. Substances resembling C-terminal vasopressin fragments are present in the brain but not in the pituitary gland. Brain Res 1984;306:384-7.

Cross AJ, Crow TJ, Perry EK, Perry RH, Blessed G, Tomlinson BE. Reduced dopamine- $\beta$-hydroxylase activity in Alzheimer's disease. Br Med J 1981;282:93-4.

Davies P. Neurotransmitter-related enzymes in senile dementia of the Alzheimer type. Brain Res 1979;171:319. 27.

Davison JM, Sheills EA, Barron WM, Robinson AG, Lindheimer MD. Changes in the metabolic clearance of vasopressin and in plasma vasopressinase throughout human pregnancy. J Clin Invest 1989;83:1313-8.

Eikelenboom P, Hack CE, Rozemuller JM, Stam FC. Complement activation in amyloid plaques in Alzheimer's dementia. Virchows Arch 1989;56:259-62.

Esch FS, Keim PS, Beattie EC, Blacher RW, Culwell AR, Oltersdorf T, McClure D, Ward PJ. Cleavage of amyloid B-peptide during constitutive processing of its precursor. Science 1990;248:1122-4.

Grundke-Iqbal I, Iqbal K, Tung Y-C, Quinlan M, Wisniewski HM, Binder LI. Abnormal phosphorylation in the microtubule-associated $\tau$ (tau) in Alzheimer cytoskeletal pathology. Proc Natl Acad Sci USA 1986;83:49137.

Kawashima S, Ihara $Y$, Inomata M. Transglutaminase and calcium-protease activities in Alzheimer's disease brain. Biomed Res 1989;10:17-23.

Mantle D, Lauffart B, Perry EK, Perry RH. Comparison of major cortical aminopeptidase activity in normal brain and brain from patients with Alzheimer's disease. J Neurol Sci 1989;89:227-34.

McDermott JR, Mantle D, Lauffart B, Kidd AM. Purification and characterization of a neuropeptide-degrading aminopeptidase from human brain. J Neurochem 1985;45:752-9.

McKhann G, Drachman D, Folstein M, Katzman P, Price D, Stadlan EM. Clinical diagnosis of Alzheimer's disease; report of the NINCDS-ADRDA work group. Neurology 1984;34:939-44.

Mori $\mathrm{H}$, Kondo J, Ihara Y. Ubiquitin is a component of paired helical filaments in Alzheimer's disease. Science 1987;235:1641-4.

Nilsson E, Alafuzoff I, Blennow K, Blomgren K, Hall CM, Janson I, Karlsson I, Wallin A, Gottfries CG, Karlsson J-O. Calpain and calpastatin in normal and Alzheimer-degenerated human brain tissue. Neurobiol Aging 1990;11:425-31.

Perty EK, Perry RH. The cholinergic system in Alzheimer's disease. In: Roberts PJ, ed. Biochemistry of dementia. Chichester: Wilcy, 1980:135-83.

Plum F. Dementia, an approaching epidemic. Nature 1979;279:372-3.

Reisberg B, Ferris SH, De Leon MJ, Crook T. Alzheimer's disease: a report of progress. Am J Psychol 1982;139:1136-9.

Rossor MN, lversen LL, Reynolds GP, Mountjoy CQ, Roth M. Neurochemical characteristics of early and late onset types of Alzheimer's disease. Br Med J 1984;288:961-4.

Shapiro IP, Masliah E, Saitoh T. Altered protein phosphorylation in Alzheimer's disease. J Neurochem 1991;56:1154-62.

Shimohama S, Suenaga T, Araki W, Yamaoaka Y, Shimizu K, Kimuza J. Presence of calpain II immunoreactivity in senile plaques in Alzheimer's disease. Brain Res 1991;558:105-8.

Subbarao KV, Richardson JS, Ang LC. Autopsy samples of Alzheimer's cortex show increased peroxidation in vitro. J Neurochem 1990;55:342-5.

Ten Haaf JA, Terwel D, Van de Heijning BJM, Van Wimersma Greidanus TjB. Radioimmunoassay, a goal or a tool? J Control Rel 1992 (in press).

Wenstrup D, Ehmann WD, Markesbery WR. Trace element imbalancies in isolated subcellular fractions of Alzheimer's disease brains. Brain Res 1990;553:125-31.

Yoshimoto T, Simmons WH, Kita T, Tsuru D. Post-proline cleaving enzyme from lamb brain. J Biochem $1981 ; 90: 323-34$. 


\section{GENERAL DISCUSSION}

This thesis deals with the radioimmunoassay (RIA) of vasopressin (VP) and vasopressinergic changes in the brain and plasma of the aging rat. Futhermore, some related studies on osmotic changes in man and peptidase activities in rat brain with age and human brain in Alzheimer's disease are described.

\section{RIA of VP}

If one wishes to quantitate peptidergic changes with age there are several possibilities. Immunocytochemistry, which is primarily a neuroanatomical tool, can be used to obtain semiquantitative information on peptidergic changes (Fliers et al. 1985). Other methods are determination of levels of messenger ribonucleic acid (liquid scintillation, dot blot, in situ hybridization) (Burbach et al. 1986, Van Tol et al. 1987, Miller et al. 1989a) and RIA (Brinton et al. 1983, Glick and Brownstein 1980, Hawthorn et al. 1980, Valiquette et al. 1985, this thesis: chapter 2). Immunocytochemistry is superior with respect to neuroanatomical resolution, but is probably less sensitive than in situ hybridization and RIA. For instance, colchicine pretreatment is required to detect VP in the bed nucleus of the stria terminalis by immunocytochemistry (De Vries et al. 1985), whereas VP can be detected by the other techniques without pretreatment (Miller et al. 1989a). Messenger ribonucleic acid determination and RIA do not provide equivalent information. Messenger ribonucleic acid levels are considered to reflect synthetic capacity. VP concentrations on the other hand are the sum of synthesis, transport and release. The information obtained by the latter two techniques therefore can be considered complementary. Messenger ribonucleic acid determination is difficult, especially in extrahypothalamic brain regions and, so far, has been carried out succesfully by one research group only (Miller et al, 1989a). We decided therefore to focus on the determination of vasopressinergic changes by RIA, but are aware of the fact that changes in VP concentrations with age have to be interpreted with caution. A change in peptide concentration in principle may indicate a change in any of the processes mentioned.

When studying the literature it came somewhat as a surprise that reports on RIAs for VP in general do not provide reliable protocols. Few who do rely on very sensitive antibodies which are not normally obtained after immunization of rabbits or are not sensitive enough (Robertson et al. 1973, Skowsky et al. 1974). RIAs for VP in brain do not appear to have been published with this purpose, but rather to demonstrate that VP is present at many different brain sites. We give reliable protocols for the RIA of VP in chapter 2 and elaborate on experimental justification of these protocols. Instead of trying out many alternative procedures we optimized those that we started out with. Our efforts were directed at (1) the optimization of the extraction of peptide from brain tissue, at (2) the separation of the free and bound ligand with coated charcoal, and at (3) standardization of the RIA. The acetic acid method generally used for the 
extraction of peptide from brain yielded a low recovery. A simple extension of the extraction procedure yielded almost quantitative recovery of the peptide material. It has been reported that the widely used coating of charcoal to improve selectivity in the separation of the free and bound ligand in RIA has no basis. Binoux and Odell (1973) found that coating of charcoal with dextran decreased binding of antibody and hCG to the same extent and concluded that dextran reduced the surface area available for binding indiscriminately. We found that charcoal coating changed the binding characteristics of charcoal selectively in the separation of VP and antibody. Dextran reduced the binding of antibody to charcoal eightfold, but did not affect the binding of VP. Other coating materials, Ficoll $400 \AA$ and serum albumin, increased the selectivity for the bound fraction even further. The sensitivity of the assay could be increased by volume reduction. This led inadvertedly to the concentration of impurities which interfered with the antibody-ligand binding characteristics. Methods were developed, therefore, to correct for this interference, that is it was made sure that standards contained the same amounts of impurities as unknown samples. By optimizing RIA procedures we roughly estimate a 5 -fold increase in sensitivity compared to other assays if these would have used the same antibody. The methods developed enabled us to determine VP concentrations in all relevant brain areas and in plasma under basal conditions. The sensitivity of the assay is illustrated by the fact that a circadian rhythm in VP concentration in rats could be demonstrated and that the effect of salt infusion on VP concentration in individual rats could be determined. The effect of salt infusion on VP concentration in individual rats has not been determined so far.

\section{Vasopressinergic changes in the hypothalamo-neurohypophyseal system and plasma with age}

There has been controversy with respect to question whether VP concentrations in the hypothalamo-neurohypophyseal system and plasma change with age. In humans, increases in basal plasma VP concentrations have been reported (Frolkis et al. 1982, Kirkland et al. 1984, Os et al. 1985, Rondeau et al. 1982), albeit that others did not observe any changes (Helderman et al. 1978, Rowe et al. 1982). Changes in plasma osmolality, a measure which is closely associated with plasma VP concentration under normal conditions, have not been found in man with aging (Helderman et al. 1978, Os et al. 1985). By contrast, we observed a significant increase in plasma osmolality in healthy volunteers with age after an overnight fast (chapter 5). We determined osmolality on freshly prepared plasma samples with a very small coefficient of variation in comparison to other studies, which may explain why we found an increase in plasma osmolality and others did not. The different findings on plasma VP concentration in man may be explained by differences in the protocols used. For instance, in some studies volunteers were hospitalized and kept in the recumbent position overnight, whereas in other studies subjects were kept in the supine position for only 30 minutes prior to blood sampling. Helderman et al. (1978) observed an increase in osmoreceptor sensitivity with age. These authors explained their findings 
by pressure changes in the elderly. This suggests that increased plasma VP concentrations in the elderly are caused by baroreflex changes rather than reduced kidney function. Although the half life time of circulating VP passes several times within 30 minutes, this period may have been too short for VP concentrations to have attained basal levels.

Findings on plasma VP concentration in rats with age are inconsistent and many confounders have been proposed to explain the differences. Seasonal fluctuations in VP concentrations in plasma and the pituitary gland have been reported for the Sprague-Dawley strain (Zbuzek and Wu 1979), but have not been convincingly demonstrated in other strains of rats. Zbuzek and Wu (1979) kept their rats under controlled conditions two weeks in advance of the experiments. Housing conditions prior to these two weeks were not reported. Therefore, it is not clear whether the observed seasonal changes are caused by environmental influences or not. Needless to say, however that housing conditions should be the same from birth onwards in these types of experiments. In the present studies we did not obtain any indication of seasonal fluctuations of plasma VP concentration in Lewis or Wistar rats. The age groups compared may comprise another important confounding variable. For instance, impaired VP release during dehydration has been found in 31-month-old Fischer 344 rats, but not in 25 -month-old Fischer 344 rats. The oldest age groups in our studies were mostly 28-month-old rats. Paradoxically, very old rats may not be suited for aging studies because they suffer from age-associated pathology, such as high tumor incidence, which may obscure the aging phenomena under investigation. Otherwise some age-associated lesions may only occur late in life. We used animals at approximately 50\% survival age, an arbitrary choice between aging and pathology. Other strains of rats showed increased VP release with age, Long-Evans (Miller 1985), Brown-Norway (Goudsmit et al. 1988a) and Wistar strains (chapter 3). In LongEvans rats, single plasma VP concentrations were determined, which may be unreliable because a circadian rhythm in VP concentration may be present (chapter 3). Ravid et al. (1987) determined 24-h urine VP excretion. This may also be unreliable, since VP excretion shows large excursions in rats kept in metabolic cages necessary for urine collection (Phelps et al. 1989). Moreover, renal handling of VP may change with age. We determined VP at several time points during the day and obtained evidence for increased VP release in aged Wistar rats (chapter 4). The physiological relevance of increased plasma VP concentration in aged Wistar rats was demonstrated by the fact that plasma VP concentration correlated with plasma osmolality. Increased plasma VP concentrations were also observed in aged Brown-Norway rats (chapter 7). However, it was not determined whether plasma VP concentration is increased in aged Brown-Norway rats throughout the day.

Studies on hypothalamic and pituitary VP concentration have also been at variance. Pituitary VP concentration per gland weight has been reported to be unaltered with age in the Fischer 344 strain (Zbuzek et al. 1983), but reduced in the Sprague-Dawley strain (Zbuzek and Wu 1982). Pituitary concentration per g protein was reduced with age in the Fischer 344 (Zbuzek et al. 1983), Long-Evans (Miller 1985), Lewis, Wistar and Brown-Norway (chapter 8) strains. Total VP content was unaltered in the Fischer 
344 strain with age (Zbuzek et al. 1983), increased in the Long-Evans and SpragueDawley strains (Miller 1985, Zbuzek and Wu 1982) and showed an initial rise and subsequent fall in the Lewis, Wistar and Brown-Norway strains (chapter 8). In conclusion, VP release appears to be impaired in Fischer 344 rats and SpragueDawley rats, but appears to be increased in other strains of rats. The cause of this dichotomy between strains of rats in not clear as yet. Fischer 344 rats and SpragueDawley show more profound renal lesions with age than Lewis, Wistar and BrownNorway rats (Bell et al. 1984, Gray et al. 1982, Kroes et al. 1981, Ravid et al. 1987) (morphological data on Long-Evans rats are not available). Renal lesions in Fischer 344 rats may be related to reduced renin secretion, since renin is secreted from kidney nephrons (Fisher 1971). Renin converts angiotensinogen into angiotensin I, which in turn is converted into angiotensin II by angiotensin converting enzyme (Fisher 1971). Angiotensin II inhibits VP release at the subfornical organ (Johnson and Loewy 1990, Lind and Ganten 1990). It has been shown that the noradrenergic innervation of the neuroendocrine nuclei is decreased in Fischer 344 rats (Aravich and Sladek 1987). This has not been determined for other strains of rats, but it is possible that the noradrenergic innervation is intact in other strains. Goudsmit et al. (1991) suggested that Fischer 344 and Sprague-Dawley rats may be less suited for aging studies, since the kidney lesions in these strains are pathological. This argument may not be valid, because kidney aging in Fischer 344 and Sprague-Dawley rats procedes at a different rate, but the nature of the lesions does not appear to be different from those seen in other strains of rats at a later age (López Novoa and Montañes 1989). Fischer 344 and Sprague-Dawley strains therefore are bad models of generalized aging, but might be valuable in the study of kidney aging per se. On the other hand, since neurosecretory activity in man appears to be increased, Lewis, Wistar and Brown-Norway rat probably provide a better model for the neuroendocrine system with aging.

Two hypotheses have been advanced to explain kidney dysfunction associated with aging: (1) excess VP secretion somehow causes kidney dysfunction (Miller 1985), (2) the primary cause of kidney dysfunction lies within the kidney itself (Ravid et al. 1987). The increased osmoreceptor sensitivity in man mentioned above is in favor of the latter possibility. In chapter 4 it was investigated whether osmoreceptor sensitivity is changed in aged Lewis rats. It was found that osmoreceptor sensitivity was reduced for relatively low osmolalities during infusion of salt solution instead of increased as in human subjects. However, the relationship between plasma osmolality and plasma VP concentration under basal conditions, as calculated from a series of measurements in individual animals, was much different from that under conditions of salt infusion. Such a relationship could not be established in aged Lewis rats. In Wistar rats, such a relationship could be established in both young and aged animals and appeared not to be different.

In conclusion, both in rats and in humans changes in water homeostasis occur with age. In humans both decreased kidney function and baroreflex changes may underlie changes in water homeostasis. The relative contribution and the onset of these changes, and the way they interact are not known at present. There is no indication that in rats altered baroreflex regulation is responsible for increased plasma VP 
concentration with age and thus the primary cause for altered water homeostasis probably resides within the kidney.

If renal dysfunction precedes increased neurosecretory activity what, then, is the cause of reduced renal function? Several lines of investigation support the idea that high concentrations of urine solutes decrease kidney function. Firstly, it was found recently that forced water intake in experimental renal mass reduction slowed down the increases in proteinuria and blood pressure normally found in this condition (Bankir et al. 1989). Secondly, high protein diet (the degradation products of which are concentrated in the urine) does not influence kidney function in Brattleboro rats, whereas such a diet increases glomerular filtration rate and leads to renal hypertrophy in its genetic counterpart (Bankir et al. 1989). These findings suggest that the decline in kidney function observed with aging may be caused by the long-term exposure of the kidneys to high concentrations of urine solutes. This suggestion is strengthened by the fact that the effects of renal mass reduction are very similar to the effects of aging, both on morphology and function of the kidneys (for reviews see Bankir et al.1989 and López Novoa and Montañes 1989). Since VP enables the kidney to concentrate urine, a role for VP in the development of reduced renal function still seems plausible.

\section{Changes in VP concentrations in the central nervous system of the rat in relation to testicular function}

Changes in gonadal function with age are relevant for a few neuropeptides including substance P (Frankfurt et al. 1985, Malsbury et al. 1987), cholecystokinine (Oro et al. 1988, Simerly and Swanson 1987) and VP (De Vries et al. 1986, Fliers et al. 1985). VP synthesis in the bed nucleus of the stria terminalis and the medial amygdala is under control of testosterone. Probably not testosterone itself stimulates VP systhesis but oestradiol (De Vries et al. 1986), which is formed from testosterone through conversion by an aromatase (Selmanoff et al. 1977). Circulating levels of testosterone decline with age in various strains of rats (Chambers and Phoenix 1984, Goudsmit et al. 1988b, Kaler and Neaves 1981), albeit not to the same extent in different strains. In Sprague-Dawley rats total secretory capacity is unaltered, but due to increased body size circulating levels of testosterone are reduced by $50 \%$. Testosterone levels in Brown-Norway rats appear to be differentially affected by age. Various studies report approximately $70 \%$ (Goudsmit et al. 1988b, Ravid et al. 1987) and 30\% (Goudsmit et al. 1990) reduced levels in $>30$-month-old Brown-Norway rats. In accordance with a testicular dysfunction Fliers et al. (1985) observed a pattern of decreased vasopressinergic innervation in the extrahypothalamic brain of aged Brown-Norway rats that resembled the pattern after castration. Moreover, Dobie et al. (1990) found reduced staining for mRNA coding for VP in aged Fischer 344 rats. However, concentrations of VP in testosterone-dependent brain regions have not been found to be consistently reduced in Brown-Norway rats (Goudsmit et al. 1990). In the present studies we did not find a general reduction in concentrations of VP in areas in which the presence of VP is testosterone-dependent. For instance, concentrations of VP 
remained unaltered in the septum of Wistar rats from 3 months until 28 months of age (chapter 5). When the effects of castration and aging were directly compared such a general decline of VP concentrations was noted in Brown-Norway rats with age, albeit that concentrations of VP were only moderately decreased (chapter 7). However, in a strain comparison including Lewis, Wistar and Brown-Norway strains the mesencephalon was the only extrahypothalamic area in which a consistent decline in VP concentration occurred with age (chapter 8 ). We observed testicular weight loss in Lewis and Brown-Norway rats, probably indicating testicular dysfunction, since it has been found that testosterone levels correlate with testicular weight (Goudsmit et al. 1988b, Kaler and Neaves 1981, Ravid et al. 1987).

One could argue that VP concentrations in testosterone-dependent brain areas do not reflect VP synthesis. We would take issue with such a point of view, since in conditions in which the steroid-dependent synthesis of VP changes (i.e. during the period after castration) peptide levels change too (De Vries et al. 1984, Miller et al. 1989a). Moreover, the different levels of VP synthesis in male and female rats are also reflected in different peptide concentrations (De Vries et al. 1981, Miller et al. 1989b, Van Leeuwen et al. 1985). Of course, the remote possibility exists that in senescence reduced synthesis would be exactly balanced by other processes (axonal transport, degradation, release), such that steady state VP concentrations would remain unaltered. The conclusion that VP synthesis was unchanged in our rats seems more likely. In fact there are other factors under steroid control that do not change with age. For instance, aromatase activity, which is under control of testosterone, is unaltered in the aged Fischer 344 rats (Chambers et al. 1991). Moreover, contrary to the number of preoptic area and hypothalamic nuclear androgen receptors, androgen receptor number in the amygdala is unaltered in aged Fischer 344 rats (Chambers et al. 1991). In conclusion, factors regulated by steroid hormones, including VP, do not necessarily change with age. How senescent neurons accomplish such a feat is an interesting topic for futher research.

There is evidence to suggest that VP in the hypothalamo-neurohypophyseal system is also influenced by the gonads, although this action may be indirect (Swaab and Jongkind 1970). The threshold for VP release is increased at the luteal phase of the menstrual cycle (Vokes et al. 1988) and during pregnancy (Davison et al. 1984, Durr et al. 1981). Gonadectomy has been reported to increase neurosecretory activity in the hypothalamo-neurohypophyseal system (Skowsky et al. 1979). Supplementation with testosterone did not affect neurosecretory activity in aged rats, which exhibited an increased neurosecretory activity (Goudsmit et al. 1988a). It was concluded therefore that testosterone probably is not involved in vasopressinergic changes with age. The possibility that water homeostasis does not respond to testosterone in senescence was not considered, however. From our experiments it could be concluded that long term (5 months) castration in male rats does not affect neurosecretory activity in male rats (chapter 7). Different findings made by others may be related to the fact that animals were sacrificed relatively shortly (2 weeks) after castration (Skowsky et al. 1979) or that immature animals were used (Crofton et al. 1985). 


\section{VP-converting enzymes in aging and in Alzheimer's disease}

The influence of age on VP-converting enzyme activities was investigated in Wistar rats (chapter 9). It was concluded that age-related changes in peptidase activities were too modest to account for changes in vasopressinergic function. Recently, it has been reported that changes in peptide-converting enzymes are responsible for reduced concentrations of somatostatin in cortical samples from Alzheimer's disease (AD) patients (Weber et al. 1992). Concentrations of VP have been reported to be reduced in several brain regions (Mazurek et al. 1986) and cerebrospinal fluid (Mazurek et al. 1986, Sørensen et al. 1985, Sundquist et al. 1983) in AD. These findings prompted us to investigate VP-converting enzymes in AD. It was found that prolyl endopeptidase activity was reduced and major aminopeptidase activity was unaltered in neocortical autopsies from AD patients (chapter 10). Whether reduced prolyl endopeptidase in AD brains is the cause of reduced VP concentrations is not clear as yet. VP is not localized in the cerebral cortex, but peptidase activities in VP containing brain structures are likely to be affected in AD. If VP were to be directly converted by prolyl endopeptidase increased instead of reduced VP concentrations in AD would be expected. Therefore, changes in prolyl endopeptidase activity in AD are responsible for reduced VP concentrations indirectly at best. So far only soluble VP-converting peptidases in cortical samples from AD patients were measured. Future studies therefore will aim at other cerebral locations and peptidase activities.

Several findings are in favor of a role of prolyl endopeptidase in the pathogenesis of AD. Firstly, it has been observed that an inhibitor of the enzyme causes neurodegenerative changes in cultured rat hippocampal neurons, including formation of phosphorylated neurofilaments. Secondly, prolyl endopeptidase is reduced in HeLa cells after heat shock (Pratt et al. 1989) and the inactivation of the enzyme is thought to be caused by a change in intracellular redox potential (Tsukahara et al. 1990). It is thus conceivable that the reduced enzyme activity in AD is part of a cellular stress response. The finding that reduced prolyl endopeptidase activity in cortial areas is already observed in normal aging, at least in rats, suggests that it may precede AD.

\section{Directions for future research}

The question whether changes in vasopressinergic systems may be a factor in aging in rats could not be answered confirmatively. Increases in plasma VP probably are caused by reduced renal function and changes in VP concentrations in the central nervous system vary from one study to another. This does not exclude that vasopressinergic systems are involved in aging in rats. For instance, VP receptor numbers may alter with age or the second messenger response following receptor occupation may be impaired. Unfortunately, no such information is available as yet. However, the observation that VP delays recovery of behavioral and cardiac responses to mild stress in young but not in aged rats points to the possibility that the neuronal 
response to VP may be impaired with age (Buwalda et al. 1992). It would be interesting thus to determine VP receptor numbers with age or more interesting still to determine the second messenger response elicited by VP. Another interesting option is to study the influence of age on the stimulating effect of VP on c-fos gene expression. C-fos gene expression has been reported to be increased in septal neurons after intracerebroventricular administration of VP (Giri et al. 1990). The c-fos protein is encoded by a so-called first order gene. $c$-fos protein together with c-jun protein induces gene expression after intracellular second messenger levels increase as a result of agonist binding to receptors.

An interesting paradigm to study the functional aspects of VP in aging is the social memory test (Dantzer et al. 1987). Social memory is VP-dependent in male rats (Dantzer et al. 1988); in female rats, social recognition is not dependent on VP (Bluthé et al. 1990). It is quite conceivable that in male rats social recognition switches to the female pattern with age, similar to the effects of castration on social recognition (Bluthé et al. 1990). Next, it could be studied whether testosterone supplementation could reverse the pattern of social recognition in aged male rats. Other vasopressinergic actions that could be studied in relation to the aging process are the effects of VP on the fibrile response (Kasting 1989) and on tolerance to drugs (Hoffman et al. 1987). Since it is not known whether other functions of VP are also sexually dimorphic it is important to study the functions of VP in female rats.

Recently, Swaab (1991) propagated the 'use it or lose it' principle of neuronal aging, which means that if a neurone is not properly stimulated it degenerates with age. The fact that VP synthesis is influenced by testosterone gives the opportunity to check this hypothesis for the stimulatory influence of testosterone on neurons. When rats are castrated at young age, will it still be possible to restore VP synthesis at old age by testosterone supplemention?

Renal aging on the other hand may be an example of 'wear and tear'. Evolution may have endowed us with kidneys that concentrate urine in such a way that it allows us to survive during draughts but at the same time forces the kidneys to yield such labour that cellular functions deteriorate. Surely, this may be an example of Late Acting Deleterious Genes (Williams 1957). To check the hypothesis of 'wear and tear' with respect to renal function forced increased water intake may be a means to an end. Otherwise, the results of chronic administration of VP on renal function may corroborate the hypothesis the other way around. If the hypothesis in true forced water intake would ameliorate renal dysfunction with aging, chronic VP administration would hasten age-associated renal dysfunction.

\section{References}

Aravich PF, Sladek JR Jr. Aging of rodent VP sysıems. In: Gash DM, Boer GJ, eds. Vasopressin. Principles and propertics. New York: Plenum, 1987:579-610.

Bankir L, Bouby N, Trinh-Trang-Tan M-M. Possible involvement of vasopressin and urine concentrating process in the progression of chronic renal failure. Kidney Int 1989;36 Suppl: S32-7.

Bell RH, Börjesson BA. Wolf PL, Femández-Cruz L, Brimm JE, Lee S, Sayers HL, Orloff MJ, Quantitative 
morphological studies of aging in the kidney of the Lewis rat. Renal Physiol 1984;7:176-84.

Binoux MA, Odell WD. Use of dextran-coated charcoal to separate antibody-bound from free homone: a critique. J Clin Endocrinol Metab 1973;36:303-10.

Bluthé R-M, Dantzer R. Social recognition does not involve vasopressinergic neurotransmission in female rats. Brain Res 1990;535:301-4.

Bluthé R-M, Schoenen J, Dantzer R. Androgen-dependent vasopressinergic neurons are involved in social recognition in rats. Brain Res 1990;519:150-7.

Brinton RE, Desmukh PP, Chen A, Davis TP, Hsiao S, Yamamura HI. A nonequilibrium 24-hour vasopressin radioimmunoassay: development and basal levels in the rat brain. Brain Res 1983;266:344-7.

Burbach JPH, van Tol HHM, Bakkus MHC, Schmale H, Ivell R. Quantitation of vasopressin mRNA and oxytocin mRNA in hypothalamic nuclei by solution hybridization assays. J Neurochem 1986;47:1814-21.

Buwalda B, Nyakas C, Koolhaas JM, Luiten PGM, Bohus B. Vasopressin delays recovery of behavioral and cardiac responses to mild stress in young but not in aged rats (Thesis). Groningen, The Netherlands: Groningen University, 1992.95 p.

Chambers KC, Phoenix $\mathrm{CH}$. Testosterone and the decline of sexual behavior in aging male rats. Behav Neural Biol 1984;40:87-97.

Chambers KC. Thomton JE, Roselli CE. Age-related deficits in brain androgen binding and metabolism, testosterone, and sexual behavior of male rats. Neurobiol Aging 1991;12:123-30.

Crofton JT, Baer PG, Share L, Brooks DP. Vasopressin release in male and female rats: effects of gonadectomy and treatment with gonadal steroid hormones. Endocrinology 1985;117:1195-200.

Dantzer R, Bluthé R-M, Koob GF, Le Moal M. Modulation of social memory in male rats by neurohypophyseal peptides. Psychopharmacology 1987;91:363-8.

Dantzer R, Koob GF, Bluthe R-M, Le Moal M. Septal vasopressin modulates social memory in male rats. Brain Res 1988;457:143-7.

Davison JM, Gilmore EA, Durr J, Robertson GL, Lindheimer MD. Altered osmotic thresholds for vasopressin secretion and thirst in human pregnancy. Am J Physiol 1984;246:F105-9.

De Vries GJ, Best W, Sluiter AA. Gonadal hormone actions on the morphology of the vasopressinergic innervation of the adult rat brain. Brain Res 1984;298:141-5.

De Vries GJ, Buijs RM, Van Leeuwen FW, Caffe AR, Swaab DF. The vasopressinergic innervation of the brain in normal and castrated rats. J Comp Neurol 1985;233:236-54.

De Vries GJ, Buijs RM, Swaab DF. Ontogeny of the vasopressinergic neurons of the suprachiasmatic nucleus and their extrahypothalamic projections in the brain-presence of a sex difference in the lateral septum. Brain Res 1981;218:67-8.

De Vries GJ, Duetz W, Buijs RM, Van Heerikhuizen J, Vreeburg JTM. Effects of androgens and estrogens on the vasopressin and oxytocin innervation of the adult rat brain. Brain Res 1986;399:296-302.

Dobie DJ, Miller MA, Urban JH, Raskind MA, Dorsa DM. Age-related decline of vasopressin mRNA in the bed nucleus of the stria terminalis. Neurobiol Aging 1990;12:419-3.

Durr JA, Stamoutsos B, Lindheimer MD. Osmoregulation during pregnancy in the rat. Evidence for resetting of the threshold for vasopressin secretion during gestation. J Clin Invest 1981;68:337-6.

Fisher JW. Kidney hormones. New York: Academic Press, 1971.

Fliers E, De Vries GJ, Swaab DF. Changes with aging in the vasopressin and oxytocin innervation of the rat brain. Brain Res 1985;348:1-8.

Frankfurt M, Siegel RA, Sim L, Wuttke W. Estrous cycle variations in cholecystokinin and substance P concentrations in discrete areas of the rat brain. Neuroendocrinology 1985;42:226-31.

Frolkis VV, Golovchenko SF, Medved VI, Frolkis RA. Vasopressin and cardiovascular system in aging. Gerontology 1982:28:290-302.

Giri PR, Dave JR, Tabakoff B, Hoffman PL. Arginine vasopressin induces the expression of c-fos in thr mouse seplum and hippocampus. Mol Brain Res 1990;7:131-7.

Glick S, Brownstein MJ. Vasopressin content of rat brain. Life Sci 1980;27:1 103-10.

Goudsmit E. Neural activation during aging and in Alzheimer's disease: the role of sex steroids and osmotic stimulation (Thesis). Amsterdam, The Netherlands: Amsterdam University, 1991. 175p.

Goudsmit E, Fliers E, Swaab DF. Vasopressin and oxytocin excretion in the Brown-Norway rat in relation to 
ageing, water metabolism and testosterone. Mech Ageing Dev 1988a;44:241-52.

Goudsmit E, Fliers E, Swaab DF. Testosterone supplementation restores vasopressin innervation in the senescent rat brain. Brain Res 1988b;473:306-13.

Goudsmit E, Luine VN, Swaab DF. Testosterone locally increases vasopressin content but fails to restore choline acetyltransferase activity. Neurosci Lett 1990;112:290-6.

Gray JE, van Zwieten MJ, Hollander CF. Early light microscopic changes of chronic progressive nephrosis in several strains of aging laboratory rats. J Gerontol 1982;37:142-50.

Hawthom J, Ang VTY, Jenkins JS. Localization of vasopressin in the rat brain. Brain Res 1980;197:75-81.

Helderman JH, Vestal RE, Rowe JW, Tobin JD, Andres R, Robertson GL. The response of arginine vasopressin to intravenous ethanol and hypertonic saline in man: the impact of aging. J Gerontol 1978;33:39-47.

Hoffman PL. Central nervous system effects of neurohypophyseal peptides. In: Smith CW, ed. Chemistry, biology, and medicine of neurohypophyseal hormones and their analogs. Orlando: Academic Press, 1987:23995. (In: Udenfriend S, Meienhofer J, eds. The peptides. Analysis, synthesis, biology; vol 8).

Johnson AK, Loewy AD. In: Loewy AD, Spyer K, eds. Central regulation of autonomic function. Oxford: University Press, 1990:247-67.

Kaler LW, Neaves WB. The androgen status of aging male rats. Endocrinology 1981;108:712-9.

Kasting NW. Criteria for establishing a physiological role for brain peptides. A case in point: the role of vasopressin in thermoregulation during fever and antipyresis. Brain Res Rev 1989;14:143-53.

Kirkland J, Lye M, Goddard C, Vargas E, Davies I. Plasma arginine vasopressin in dehydrated elderly patients. Clin Endocrinol 1984:20:451-6.

Kroes R, Garbis-Berkvens JM, De Vries T, Van Nessclrooy JHJ. Histopathological profile of a Wistar rat stock including a survey of the literature. J Gerontol 1981;36:259-79.

Lind RW, Ganten D. In: Bjorklund A, Hökfelt T, Kuhar M, eds. Neuropeptides in the CNS; part II. Amsterdam: Elsevier, 1990:165-286. (Handbook of chemical neuroanatomy; vol 9).

Lopez Novoa JM, Montañes I. In: Macias Nuñez JF, Cameron JS, eds. Renal function and disease in the elderly. Changes in renal function and morphology in aging laboratory animals. London: Butterworths, 1989:162-83.

Malsbury CW, McKay K, Hansen K. Testosterone regulates the substance P innervation of the medial nuc of the amygdala. Soc Neurosci Abstr 1987;13:1576.

Mazurek MF, Beal MF, Bird ED, Martin JB. Vasopressin in Alzheimer's disease: a study of postmortem brain concentrations. Ann Neurol 1986;20:665-70.

Mazurek MF, Growdon JH, Beal MF, Martin JB. Csf vasopressin concentration is reduced in Alzheimer's dise:ase. Neurology 1986:36:1133-7.

Miller M. Influence of aging on vasopressin secretion and waterregulation. In; Schrier RW, ed. Vasopressin. New York: Raven Prcss, 1985:249-58.

Miller MA, Urban JH, Dorsa DM. Steroid dependency of vasopressin neurons in the bed nucleus of the stria terminalis by in situ hybridization. Endocrinology 1989a;125:2335-40.

Miller MA, Vician L, Clifton DK, Dorsa DM. Sex differences in vasopressin neurons in the bed nucleus of the stria terminalis by in situ hybridization. Peptides 1989b;10:615-9.

Oro AE, Simerly RB, Swanson LW. Estrous cycle variation in levels cholescystokinin immunoreactivity with cells of three interconnected scxually dimorphic forcbrain nuclei. Neuroendocrinology 1988;47:225-35.

Os I, Kjelsen SE, Aakesson I, Skøıø J, Eide I, Hjermann I, Leren P. Evidence of age-related variation in plasma vasopressin of normotensive men. Scan J Clin Invest 1985;45:263-8.

Phelps CJ, Carlson SW, Gallagher MJ, Sladek CD. Vasopressin in aged rats: longitudinal studies of vasopressin excretion in Sprague-Dawley and Fischer 344 strains. Neurobiol Aging 1989; 10:233-9.

Pratt G, Hough R, Rechsteiner M. Proteolysis in heat-stressed HeLa cclls. J Biol Chem 1989;264:12526-32.

Ravid R, Fliers E, Swaib DF, Zurcher C. Changes in vasopressin and testosterone in the senescent BrownNorway (BN/BiRij) rat. Gerontology 1987;33:87-98.

Robertson GL, Mahr EA, Athar S, Sinha T. Development and clinical application of a new method for the radioimmunoassay of arginine vasopressin in human plasma. J Clin Invest 1973;52:2340-52.

Rondeau E, de Lima J, Caillens H, Ardaillou R, Vahanian A, Acar J. High plasma antidiuretic hormone in patients with cardiac failure: influence of age. Mineral Electrolyte Metab 1982;8:267-74.

Rowe JW, Minaker KL. Sparrow D, Robertson GL. Age-related failure of volume-pressure-mediated 
vasopressin release. J Clin Endocrinol Mctab 1982;54:661-4.

Selmanoff MK, Brodkin LD, Weiner RI, Siiteri PK. Aromatization and $5 \alpha$-reduction of androgens in dicrete hypothalamic and limbic regions of the male and female rats. Endocrinology 1977;101:841.

Simerly RB, Swanson LW. Castration reversibly alters levels of cholecystokinin immunoreactivity within cells of three interconnected sexually dimorphic forbrain nuclei in the raL Proc NaL Acad Sci USA 1987;84:208791.

Skowsky WR, Rosenbloom AA, Fisher DA. Radioimmunoassay measurement of arginine vasopressin in serum: development and application. J Clin Endocrinol Metab 1974;38:278-87.

Skowsky WR, Swan L, Smith P. Effects of sex steroid hormones on arginine vasopressin in intact and castrated male and female rats. Endocrinology 1979;104:105-8.

Sørensen PS, Gjerris A, Hammer M. Cerebrospinal fluid vasopressin in neurological and psychiatric disorders. J Neurol Neurosurg Psychiatry 1985;48:50-7.

Sundquist J, Forsling ML, Olsson JE, Akerlund M. Cerebrospinal fluid arginine vasopressin in degenerative disorders and other neurological diseases. J Neurol Neurosurg Psychiatry 1983;46:14-7.

Swaab DF. Brain aging and Alzheimer's disease, 'wear and tear' versus 'use it or lose it'. Neurobiol Aging $1991 ; 12: 317-24$.

Swaab DF, Jongkind JF. The hypothalamic neurosecretory activity during the oestrous cycle, pregnancy, parturition, lactation, and persistent oestrus, and after gonadectomy, in the rat. Neuroendocrinology 1970;6:133-45.

Tsukahara T, Ishiura S, Sugita $\mathrm{H}$. Regulation of prolyl endopeptidase activity by the intracellular redox state. J Biol Chem 1990;265:21448-53.

Valiquette G, Haldar J, Abrams GM, Nilaver G, Zimmerman EA. Extrahypothalamic neurohypophyseal peptides in the rat central nervous system. Brain Res 1985;331:176-9.

Van Leeuwen FW, Caffe AR, De Vries GJ. Vasopressin cells in the bed nucleus of the stria terminalis of the rat: sex differences and the influence of androgens. Brain Res 1985;325:391-4.

Van Tol HHM, Bolwerk ELM, Liu B, Burbach JPH. Oxytocin and vasopressin gene expression in the hypothalamo-neurohypophyseal system of the rat during the estrous cycle, pregnancy and lactation. Endocrinology 1987;120:71-6.

Vokes TJ, Weiss NM, Schreiber J, Gaskill MB, Robernson GL. Osmoregulation of thirst and vasopressin during normal menstrual cycle. Am J Physiol 1988;254:R641-7.

Weber SJ, Louis RB, Trombley L, Bissette G, Davies P, Davis TP. Metabolic half-life of somatostatin and pepudase activities are altered in Alzhcimer's disease. J Gerontol 1992;47:B18-25.

Williams GC. Pleiotropy, natural selection and the evolution of senescence. Evolution 1957;11:398-411.

Zbuzek VK, Wu W. Seasonal variations in vasopressin secretion in rats. Experientia 1979;35:1523-4.

Zbuzek VK, Wu W. Age-related vasopressin changes in rat plasma and the hypothalamo-hypophyseal system. Exp Gerontol 1982;17:133-8.

Zbuzek VK, Zbuzek V, Wu W. The effect of aging on vasopressin system in Fischer 344 rats. Exp Gerontol 1983;18:305-11. 



\section{SUMMARY}

Vasopressin (VP) is called after its pressor action on arterioles, but is alternatively called antidiuretic hormone after its predominant action on kidney tubular cells. The finding that the peptide affects cognitive performance in rats has prompted investigators to determine the distribution of VP in the brain. Elaborate vasopressinergic systems in the central nervous system have been described now. It has been proposed that in addition to learning and memory the peptide may be involved in central cardiovascular regulation, temperature regulation, and regulation of sexual behavior and aggression. All of these processes change with age and changes in vasopressinergic systems may be involved. Therefore, the present thesis deals with the question whether concentrations of VP change with age in plasma and in several areas of the brain. The influence of age on vasopressinergic systems has been studied before, but results have not been unequivocal probably due to straindifferences, seasonal and circadian influences, ages of the rats used and their health status. In the present studies we tried to control for these confounding factors as much as possible.

Since available radioimmunoassays of VP were not satisfactory, a highly sensitive radioimmunoassay (RIA) for VP was developed (chapter 2). VP was extracted from brain tissue in a two step procedure. The first extraction step was carried out with $1 \mathrm{M}$ boiling acetic acid. The second step involved re-extraction of the freeze-dried residues from the first step with 50\% ethanol. Immunoreactive material was extracted from plasma by adsorption to $V_{y c o r}{ }^{\circledR}$ glass powder. The effects of coating on the separation of free and bound fractions were tested for a dose range of charcoal concentrations. The data provide evidence that coating increases the selectivity of charcoal for the free ligand. The RIA was internally standardized to correct for methodological variability and nonspecific effects. One-ml portions of VP-free plasma or tissue homogenate to which known amounts of VP had been added served as internal standards. Displacement of tracer by extracted internal standards versus the amount of VP added to the portions of homogenate or plasma served an internal standard curve. The present assay was not dependent on the availability of a sensitive antiserum. The brain distribution of VP agreed well with that of immunocytochemical observations. VP largely disappeared from limbic brain structures after castration. An osmotic stimulus or a volume reduction in rats resulted in increases in plasma VPir concentration which were linearly related to osmolality and exponentially to volume change.

In chapter 3 the influence of age on several parameters related to water balance was studied in Wistar rats. Plasma VP concentration and plasma osmolality were increased at midday in 21-month-old rats as compared with 3-and 4-month-old rats. Daily water intake per $100 \mathrm{~g}$ body weight was reduced in 14- and 21 -month-old rats as compared with 3- and 4-month-old rats, but total water intake was unaltered. These results suggest that there is a change in water balance in Wistar rats with age. In order to obtain information about the influence of age on daily fluctuations in plasma VP 
concentration and osmolality these parameters were determined in 4-month-old Wistar rats sacrificed at $2 \mathrm{~h}$ intervals during the day and in 20- and 31-month-old rats sacrificed at $8 \mathrm{~h}$ intervals. The results suggested that there is a circadian rhythm of plasma VP concentration in Wistar rats which is age-related but which does not fully correlate with plasma osmolality. Average daily plasma VP concentration was increased in 31-month-old animals compared with 4- and 20-month-old ones. The relationship between plasma osmolality and plasma VP concentration did not change with age. Taken together these data lend support to the notion that the primary disturbance in water homeostasis with age is a kidney deficit as opposed to an increased release of VP into the blood.

However, in aged human subjects an increased release of VP in response to salt infusion has been observed, suggesting that VP concentrations are likely to increase in the absence of kidney dysfunction. Whether osmoreceptor sensitivity is altered in rats with age was not known. We therefore infused a salt solution in adult and aged Lewis rats and measured plasma VP concentration by RIA and osmolality by freezing-point depression (chapter 4). It turned out that osmoreceptor sensitivity was decreased instead of increased in aged rats for relatively low osmolalities and unaltered for relatively high osmolalities. However, the relationship between plasma VP and plasma osmolality under basal conditions was quite different from that obtained with salt infusion. Therefore, it is difficult to conclude whether the reduced osmoreceptor sensitivity with age affects water homeostasis. During salt infusion plasma osmolality increased more with time in aged than in adult animals, indicating a kidney dysfunction during salt infusion in aged animals.

Despite the fact that osmoreceptor sensitivity is increased in human volunteers it is not certain whether disturbances in water homeostasis occur with age during the day. We investigated whether plasma osmolality and plasma sodium are altered after an overnight fast in healthy human volunteers (chapter 5). Plasma osmolality appeared to increase about $0.2 \mathrm{mOsm} / \mathrm{kg}$ each year between 17 and 60 years of age, suggesting that mild kidney dysfunction in humans starts relatively early in life.

Since results of previous studies on the influence of age on VP concentrations in the central nervous system of the rat have not been unequivocal, and since studies on extrahypothalamic concentrations of VP in the aging rat mostly have used two age groups only and have provided limited quantitative data we determined, by RIA, the concentrations of VP in thirteen brain structures and in the plasma of 3-, 10-, 20- and 28-month-old male Wistar rats (chapter 6). Age-related decreases in VP concentrations were found in the pituitary gland, hypothalamus, thalamus, mesencephalon, medulla oblongata, amygdala and pineal gland, while an increase was noted in plasma. Decreases in the concentration of VP in the amygdala and pineal gland occurred between 3 and 10 months of age and probably represent developmental changes. In the pituitary, thalamus, mesencephalon, medulla oblongata and plasma, differences in the concentration of VP were also found between 10-month-old and older animals and are probably related to aging. The finding of increased plasma VP concentrations in aged animals agrees with the notion that neuronal function does not necessarily decline with age and suggests that neurons may even be activated. Age- 
related changes in VP concentrations were not observed in the anterior pituitary, septum, preoptic area, olfactory bulb, striatum and hippocampus. It has been reported that the vasopressinergic innervation of a number of brain structures depends on testosterone. Despite reports to the contrary VP concentrations do not generally decline in these structures with aging.

A reduction in immunocytochemical staining for VP has been observed in BrownNorway rats and these changes have been ascribed to changes in testicular function. In order to determine to what extent changes in VP concentrations with age can be explained by a decrease in testicular function we simultaneously determined the effects of aging and castration in male Brown-Norway rats (chapter 7). Castration resulted in a profound reduction ( $>80 \%$ ) in the concentration of VP in the septum, amygdala, mesencephalon, hippocampus and anterior part of the medulla oblongata. Lower concentrations (about 30\%) of VP were found in the same brain structures with aging. Castration did not affect the neurosecretory activity of the hypothalamoneurohypophyseal system (HNS), but aging did. Concentrations of VP in the hypothalamus and pituitary gland of aged rats were reduced by $40 \%$ to $50 \%$. Testicular weight was much reduced in aged animals, indicating a decreased testosterone status. The results of this study suggest that a reduction in the testosterone status of aged rats leads to a reduction in VP concentrations in areas in which the vasopressinergic innervation depends on testosterone. As testosterone does not appear to affect neurosecretory activity by a direct action on the brain, reduced testicular function cannot explain reduced neurosecretory activity with age.

In the two studies just described age seemed to affect vasopressinergic systems differently in Wistar and Brown-Norway rats. It is not known whether these disparate findings are due to real strain differences. Therefore we studied VP concentrations in relation to age in three different strains (ages 3,12 and 28 months; strains Lewis, Wistar and Brown-Norway) (chapter 8). Since the factor time of year was considered a possible confounder, seasonal effects on VP concentrations were studied in Lewis rats. Independent of strain, the VP concentration in the pituitary was reduced in aged rats as compared with young and middle-aged rats. Since pituitary weight increased with age, total content of VP first increased in the pituitary and thereafter decreased. Effects of age on VP concentrations in the hypothalamus were strain-dependent. VP concentrations in the hypothalamus did not change in Wistar rats with aging, but declined in the other strains examined. The mesencephalon was the only area in which a strain-independent effect of age on the concentration of VP was found. VP concentrations in the midbrain were lower in aged animals than in the other age groups. Strain-related differences in changes in concentrations of VP with age were observed in the medulla oblongata and hippocampus. The VP concentration in the hippocampus of Lewis rats was highest at middle age. It was also noticed that concentrations of VP differ in several brain regions among strains. Seasonal fluctuations in VP concentration were observed in the pineal gland only and occurred in all age groups. In the present study, reductions in testicular weight were found in aged Brown-Norway and Lewis rats, but not in aged Wistar rats, probably reflecting reduced testicular function in at least the former two strains. However, concentrations 
of VP did not generally decline with age in areas influenced by testosterone in any of the strains examined. The findings made in Brown-Norway rats in this study are not identical to those in the previous study. The former rats were obtained from TNO (Rijswijk), while the latter rats were of our own stock (CPB, Maastricht). It is not clear whether the difference in findings is coincidental or whether the two colonies of rats are not identical.

In vitro VP can be converted by a number of brain peptidases, namely particulate puromycin-sensitive aminopeptidase, puromycin-insensitive aminopeptidase, soluble puromycin-sensitive aminopeptidase and prolyl endopeptidase. After release into the synaptic cleft VP probably is degraded by particulate aminopeptidase activity. The soluble enzymes are possibly involved in the intracellular turnover of VP. Changes in peptidase activities with age may be instrumental in changes in vasopressinergic function with age. It was investigated therefore whether VP-converting enzyme activities change with age (chapter 9). Particulate aminopeptidase activities were studied in five different brain areas and soluble peptidase activities (aminopeptidase and prolyl endopeptidase) were studied in the cortex and hippocampus. Particulate puromycin-sensitive aminopeptidase activity was reduced with age by about 10 and $30 \%$ in the hippocampus and septum, respectively. Soluble prolyl endopeptidase was reduced by about $20 \%$ in the cortex, whereas aminopeptidase was reduced by about $20 \%$. In conclusion, the changes in VP-converting peptidase activities seem to be too modest to alter vasopressinergic function with age.

Proly] endopeptidase and soluble aminopeptidase activities were measured in neocortical autopsies from patiënts with Alzheimer's disease (AD) (chapter 10). The reason for this study has arisen from the notion that, although it is recognized that changes in peptidase activities may be involved in the etiology of pathological changes in the human brain, there have been few studies on normal and pathological protein/peptide catabolism. Prolyl endopeptidase activity was reduced by $45-50 \%$ in the frontal and medial temporal cortex of $\mathrm{AD}$ patients as compared with controls, whereas soluble puromycin-sensitive aminopeptidase activity was unaltered. The possibility that the changes in peptidase activities in AD are age-dependent was sludied in postmortem neocortical samples from $18 \mathrm{AD}$ patients who died between 55 and 90 years of age. Prolyl endopeptidase activity was lower in patients who died at a relatively early age than in patients who died at a relatively old age. This underscores the notion that, with respect to age, there may be heterogeneity in neurochemical changes in $\mathrm{AD}$. The question whether altered prolyl endopeptidase activity in AD is the cause of reduced VP concentrations in several brain areas cannot be answered yet.

To establish a possible role for VP in aging processes in rats, the main question of the present thesis was whether age-related changes in VP concentrations in brain and plasma occur. It can be concluded that the HNS is activated with age in the Wistar rat and probably also in Brown-Norway and Lewis rats. This appears to be a compensation for reduced renal function. Therefore, rather than to be the cause of agerelated disturbances in water homeostasis the HNS appears to counteract disturbances in water homeostasis. There are no indications that age-related testicular dysfunction affects neurosecretory activity. In man water homeostasis is also altered with age, 
although the causes may be somewhat different from those in rats. It was demonstrated for several strains of rats that the testosterone-dependent vasopressinergic innervation of the brain largely remains unaltered with age. Extrahypothalamic vasopressinergic changes do occur but these are strain-dependent or may even depent on the colony or cohort of rats used. In general, vasopressinergic neurons appear to adapt to age-related organ dysfunction and to try to maintain homeostasis. Nevertheless, vasopressinergic function may be impaired with age because other parts of the vasopressinergic system are out of order (reduced vasopressinergic responsiveness). This has already been demonstrated for the kidneys. Whether neuronal sensitivity for VP is changed with age remains to be investigated. 



\section{SAMENVATTING}

Vasopressine (VP) is genoemd naar zijn pressorwerking op arteriën, maar wordt ook aangeduid met de term antidiuretisch hormoon, die betrekking heeft op zijn belangrijkste werking, het bevorderen van de terugresorptie van water door de nieren. De bevinding dat het peptide cognitieve prestaties beïnvloedt, heeft onderzoekers ertoe aangezet de verdeling van VP in de hersenen te bepalen. Uitgebreide vasopressinerge systemen in het zenuwstelsel zijn inmiddels beschreven. Het wordt verondersteld dat het peptide, behalve bij leren en geheugen, betrokken is bij centrale cardiovasculaire regulatie, temperatuursregulatie, en regulatie van aggressief en sexueel gedrag. Al deze processen veranderen bij veroudering en veranderingen in vasopressinerge systemen kunnen daarbij een rol spelen. Derhalve beoogt dit proefschrift antwoord te geven op de vraag of concentraties van VP veranderen in verschillende hersengebieden bij veroudering. De invloed van leeftijd op vasopressinerge systemen is al eerder onderzocht, maar de resultaten waren niet eenduidig, waarschijnlijk als gevolg van stamverschillen, seizoens- en circadiane invloeden, verschil in leeftijden van de ratten die werden gebruikt en hun gezondheidstoestand. In de huidige studies werd zoveel mogelijk getracht deze verstorende invloeden uit te schakelen.

Aangezien beschikbare radioimmunoassays voor VP niet in voldoende mate voldeden, werd een zeer gevoelige RIA voor VP ontwikkeld (hoofdstuk 2). VP werd geëxtraheerd uit hersenweefsel in een tweestaps procedure. De eerste stap is extractie met $1 \mathrm{M}$ kokende azijnzuur. De tweede stap betreft herextractie van gevriesdroogde residuen verkregen uit de eerste stap met $50 \%$ ethanol. Immunoreactief materiaal werd uit plasma geëxtraheerd door adsorptie aan Vycor ${ }^{\circledR}$ glaspoeder. De effecten van 'coating' op de gebonden en vrije fractie werden uitgetest in een reeks doseringen van charcoal. De gegevens tonen aan dat 'coating' de selectiviteit van charcoal voor het vrije antigen vergroot. De RIA werd intem gestandaardiseerd om te corrigeren voor methodologische variabiliteit en nonspecifieke effecten. Porties plasma of weefselhomogenaat van $1 \mathrm{ml}$ die geen endogeen VP bevatten, waaraan bekende hoeveelheden exogeen VP werden toegevoegd, werden gebruikt als interne standaarden. Verdringing van tracer door geëxtraheerde interne standaarden versus de hoeveelheden VP die werden toegevoegd aan de porties plasma of homogenaat, diende als interne standaardcurve. De gevoeligheid van de ontwikkelde assay was slechts in relatief geringe mate afhankelijk van de affiniteit van het antilichaam voor VP. De verdeling van VP die in de hersenen werd gevonden met de huidige assay was in goede overeenstemming met immuuncytochemische waarnemingen. Castratie had als gevolg dat VP immunnreactiviteit grotendeels verdween uit de limbische hersenstructuren. Een osmotische stimulus of volumevermindering resulteerde in een stijging van plasma VP concentratie welke lineair gerelateerd was aan osmolaliteit en exponentieel aan volumeverandering.

In het onderzoek beschreven in hoofdstuk 3 werd de invloed van leeftijd onderzocht op een aantal parameters die gerelateerd zijn aan de waterhuishouding. Plasma VP concentratie en plasma osmolaliteit waren toegenomen om 12.00 bij 21-maanden- 
oude ratten vergeleken met 3- en 4-maanden-oude dieren. Dagelijkse waterinname per $100 \mathrm{~g}$ lichaamsgewicht was afgenomen bij 14- en 21 -maanden-oude ratten vergeleken met 3- en 4-maanden oude ratten, maar totale waterinname bleef onveranderd. Deze resultaten suggereren dat er een verandering in waterhuishouding optreedt bij Wistar ratten met leeftijd. Om informatie te krijgen over de invloed van leeftijd op fluctuaties in plasma VP concentratie en osmolaliteit gedurende de dag, werden deze parameters met 2 uurs intervallen bij groepen van 4-maanden-oude ratten en met 8 uurs intervallen bij groepen van 20- en 31-maanden-oude ratten bepaald. De resultaten suggereren dat er een circadiane fluctuatie in plasma VP concentratie plaatsvindt bij Wistar ratten die veranderd met leeftijd, maar niet helemaal correleert met plasmaosmolaliteit. De gemiddelde dagelijkse plasma VP concentratie was toegenomen bij 31-maanden-oude ratten vergeleken met die bij 4- en 20-maandenoude. De relatie tussen plasma osmolaliteit en plasma VP concentratie bleef onveranderd met leeftijd. Tesamen ondersteunen deze gegevens de opvatting dat de primaire verstoring in waterhuishouding met leeftijd in de nieren gezocht moet worden in tegenstelling tot het hypothalamo-neurohypofysaire systeem (HNS).

Bij oude mensen is de stijging in de plasma VP concentratie echter groter tijdens zoutinfusie dan bij jonge mensen, wat suggereert dat VP concentratie kan toenemen met leeftijd zonder dat er sprake is van een nierdysfunctie. Aangezien het onbekend was of osmoreceptorgevoeligheid verandert met leeftijd bij ratten, infuseerden wij een zoutoplossing bij volwassen en oude ratten en bepaalden plasma VP concentratie en osmolaliteit (hoofdstuk 4). Het bleek dat de osmoreceptorgevoeligheid is afgenomen bij oude ratten in plaats van toegenomen, zoals bij oude mensen, voor relatief lage osmolaliteiten en onveranderd is voor relatief hoge osmotische waarden. De relatie tussen plasmaosmolaliteit en plasma VP concentratie onder basale omstandigheden was echter tamelijk afwijkend van die tijdens snelle osmotische veranderingen. Derhalve kunnen ten aanzien van verstoringen in waterhuishouding met leeftijd geen conclusies worden getrokken uit het feit dat de osmoreceptorgevoeligheid is veranderd. Gedurende zoutinfusie stegen plasmaosmolaliteiten meer bij oude dan bij volwassen ratten, wat duidt op een nierfunctiestoornis bij oude dieren tijdens zoutinfusie.

Ondanks het feit dat de osmoreceptorgevoeligheid is toegenomen bij humane vrijwilligers is het niet zeker of verstoringen in waterhomeostasis plaatsvinden gedurende de dag. Wij onderzochten of plasma osmolaliteit en plasma natrium veranderd zijn bij humane vrijwilligers na een nachtrust (hoofdstuk 5). Plasma osmolaliteit bleek ongeveer $0.2 \mathrm{mOsm} / \mathrm{kg}$ per jaar toe te nemen tussen 17 en 60 jarige leeftijd, hetgeen suggereert dat milde nierdysfunctie al op relatief jonge leeftijd begint.

Vervolgens richtten wij onze aandacht op de invloed van leeftijd op VP concentraties in het centrale zenuwstelsel van de rat. Aangezien de resultaten van vorige studies terzake niet eenduidig waren en aangezien studies aan extrahypothalamische VP concentraties bij de verouderende rat veelal gebruik maakten van twee leeftijdsgroepen en een beperkte hoeveelheid kwantitatieve resultaten hebben opgeleverd bepaalden wij, met RIA, de concentraties van VP in dertien hersenstructuren en plasma van 3-, 10-, 20- en 28-maanden-oude ratten 
(hoofdstuk 6). Leeftijdsafhankelijke afnames in VP concentraties werden gevonden in de hypofyse, hypothalamus, thalamus, mesencephalon, medulla oblongata, amygdala en epifyse, terwijl een toename werd opgemerkt in plasma. Afnames in de concentratie van VP in de amygdala en epifyse vonden plaats tussen een leeftijd van 3 en 10 maanden en stellen waarschijnlijk veranderingen als gevolg van ontwikkeling voor. In de hypofyse, thalamus, mesencephalon, medulla oblongata en plasma werden verschillen in concentraties van VP ook gevonden tussen 10-maanden-oude en oudere dieren en zijn waarschijnlijk gerelateerd aan veroudering. De bevinding dat plasma VP concentraties zijn toegenomen bij oude dieren komt overeen met de opvatting dat de neuronale functie niet noodzakelijkerwijs achteruit gaat met leeftijd en zelfs geactiveerd kan worden. Leeftijdsafhankelijke veranderingen werden niet gevonden in de adenohypofyse, het septum, het preoptisch gebied, de bulbus olfactorius, het striatum en de hippocampus. Het is gerapporteerd dat de vasopressinerge innervatie van een aantal hersenstructuren afhankelijk is van testosteron. Ondanks rapporten die het tegendeel beweren, lijken VP concentraties in deze structuren in het algemeen niet te verminderen bij veroudering.

Een afname in immuuncytochemische kleuring van vasopressinerge vezels is waargenomen bij de Brown-Norway rat en deze afname is toegeschreven aan veranderingen in testisfunctie. Om te bepalen in welke mate veranderingen in VP concentraties met leeftijd toegeschreven kunnen worden aan een vermindering in testisfunctie bepaalden wij tegelijkertijd de effecten van veroudering en castratie bij mannelijke Brown-Norway ratten (hoofdstuk 7). Castratie resulteerde in sterke afnames $(>80 \%)$ in concentraties van VP in het septum, de amygdala, het mesencephalon, de hippocampus en het voorste gedeelte van de medulla oblongata. Lagere concentraties (ongeveer 30\%) van VP werden gevonden in dezelfde hersenstructuren bij veroudering. Castratie had geen invloed op de neurosecretoire activiteit van het HNS, maar veroudering had er wel invloed op. Concentraties van VP in de hypothalamus en hypofyse waren verminderd met 40 tot $50 \%$. Testisgewicht was sterk afgenomen bij oude dieren, wat op een verminderde testisfunctie duidt. De resultaten van deze studie suggereren dat een afgenomen testisfunctie van oude ratten leidt tot een reductie in VP concentraties in gebieden waarvan de vasopressinerge innervatie gevoelig is voor testosteron. Aangezien castratie geen effect had op neurosecretoire activiteit kan de afgenomen testisfunctie met leeftijd niet de afgenomen neurosecretoire activiteit verklaren.

In de zojuist beschreven studies leek leeftijd de vasopressinerge systemen verschillend te beïnvloeden bij Wistar en Brown-Norway ratten. Het is onduidelijk of deze ongelijke resultaten te wijten zijn aan echte stamverschillen. Derhalve werden VP concentraties in relatie tot leeftijd bepaald bij drie verschillende stammen (leeftijden 3,12 and 28 maanden; stammen Lewis, Wistar, Brown-Norway) (hoofdstuk 8). Aangezien seizoenseffecten van verstorende invloed kunnen zijn in een studie naar de effecten van veroudering, werd de seizoensinvloed op VP concentraties in het centrale zenuwstelsel bestudeerd bij Lewis ratten. De VP concentratie in de hypofyse was lager bij oude ratten dan bij jonge ratten en ratten van middelbare leeftijd. Aangezien het gewicht van de hypofyse groter werd met leeftijd, nam de 
totale hoeveelheid van VP eerst toe en nam daarna pas af. Leeftijdsgerelateerde veranderingen in de hypothalamus waren stamafhankelijk. VP concentraties in de hypothalamus veranderden niet met leeftijd bij Wistar ratten, maar daalden bij de andere stammen. Het mesencephalon was het enige hersengebied waarin een verouderingseffect werd gevonden dat niet stamafhankelijk was. Stamafhankelijke verschillen in veranderingen in VP concentraties met leeftijd werden waargenomen in de medulla oblongata en hippocampus. VP concentraties in de medulla oblongata lieten een continue daling zien met leeftijd bij Wistar en Brown-Norway ratten, maar daalden niet verder na middelbare leeftijd bij Lewis ratten. Bij Lewis ratten werden in de hippocampus de hoogste concentraties van VP gemeten op middelbare leeftijd. Seizoensafhankelijke veranderingen in de concentratie van VP werden alleen waargenomen in de epifyse en traden op bij alle leeftijdsgroepen. In de huidige studie werden verminderingen in testisgewicht gevonden bij oude Lewis en Brown-Norway ratten, maar niet bij Wistar ratten, hetgeen waarschijnlijk op een afgenomen testisfunctie is duidt bij tenminste de eerste twee stammen. Concentraties van VP waren niet afgenomen in alle gebieden die worden beïnloed door testosteron, wat sommige bevindingen van anderen tegenspreekt. De bevindingen gedaan bij Lewis ratten in deze studie zijn niet hetzelfde als in de vorige studie. De ratten uit de vorige studie waren afkomstig van TNO (Rijswijk), terwijl de ratten die werden gebruikt in de laatste studie afkomstig waren uit eigen fok (CPB, Maastricht). Het is niet duidelijk of de verschillende bevindingen toevallig zijn of dat beide kolonies ratten niet identiek zijn.

VP kan in vitro door een aantal peptidases worden omgezet, te weten membraangebonden puromycine-gevoelig aminopeptidase, puromycine-ongevoelig aminopeptidase, oplosbaar puromycine-gevoelig aminopeptidase en prolylendopeptidase. $\mathrm{Na}$ afgifte in de synaptische spleet wordt VP waarschijnlijk afgebroken door membraangebonden aminopeptidase activiteit. De oplosbare enzymen vervullen mogelijk een rol bij de intracellulaire turnover van VP. Mogelijke veranderingen met leeftijd in peptidase activiteit zouden betrokken kunnen zijn bij veranderingen in vasopressinerge functie bij veroudering. Derhalve werd onderzocht of activiteiten van VP-omzettende enzymen veranderen met leeftijd (hoofdstuk 9). Membraangebonden aminopeptidaseactiviteiten werden gemeten in vijf verschillende hersengebieden van jonge en oude ratten en oplosbare peptidaseactiviteiten werden gemeten in de cortex en hippocampus. De membraangebonden puromycine-gevoelige activiteit was lager in de hippocampus en het septum (respectievelijk 10 en 30\%) van oude ratten dan in die van jonge ratten. Prolylendopeptidaseactiviteit was verminderd met $20 \%$ in de cortex, terwijl oplosbare aminopeptidaseactiviteit was toegenomen met 20\%. De veranderingen in peptidase activiteiten lijken te gering om een wezenlijke bijdrage te kunnen leveren aan verminderde vasopressinerge functie met leeftijd.

Prolylendopeptidase en oplosbare aminopeptidaseactiviteiten werden vervolgens gemeten in neocorticale biopten afkomstig van patiënten met de ziekte van Alzheimer (hoofdstuk 10). De reden voor deze studie komt voort uit het feit dat, hoewel het onderkend wordt dat veranderingen in peptidaseactiviteiten betrokken kunnen zijn bij pathologische veranderingen in het humane brein, er slechts een beperkt aantal studies 
zijn uitgevoerd naar normaal en pathologisch eiwitcatabolisme. Prolylendopeptidaseactiviteit was afgenomen met $45-50 \%$ in de frontale en mediaal temporale cortex uit patiënten met de ziekte van Alzheimer vergeleken met controles, terwijl aminopeptidaseactiviteit onveranderd was. De mogelijkheid dat de veranderingen in peptidase activiteiten bij patiënten met de ziekte van Alzheimer leeftijdsafhankelijk zijn werd bestudeerd aan postmortem neocorticale monsters afkomstig van 18 patiënten met de ziekte van Alzheimer die waren gestorven tussen de leeftijd van 55 en 90 jaar. Prolylendopeptidaseactiviteit was lager bij patiënten die op relatief jonge leeftijd waren gestorven dan bij patiënten die op relatief hoge leeftijd waren gestorven. Dit onderstreept de opvatting dat met betrekking tot leeftijd er een heterogeniteit bestaat in neurochemische veranderingen bij de ziekte van Alzheimer. De vraag of veranderingen in prolylendopeptidaseactiviteit bij de ziekte van Alzheimer de oorzaak kunnen zijn van de lage VP concentraties in verschillende hersenregio's kan nog niet beantwoord worden.

De belangrijkste vraag van dit proefschrift was of leeftijdsgerelateerde veranderingen in VP concentraties in de hersenen en plasma optreden bij de rat, omdat beantwoording van deze vraag belangrijk is om aannemelijk te maken dat VP betrokken is bij verouderingsprocessen. Het kan worden geconcludeerd dat het HNS geactiveerd wordt tijdens veroudering bij Wistar ratten, en waarschijnlijk ook bij Brown-Norway ratten en Lewis ratten. Dit is hoogst waarschijnlijk een compensatie voor verminderde nierfunctie. Derhalve, in plaats van de oorzaak te zijn van leeftijdsgerelateerde verstoringen in de waterhuishouding, lijkt het HNS zulke verstoringen juist tegen te gaan. De veronderstelde leeftijdsgerelateerde vermindering in testisfunctie is waarschijnlijk geen factor van betekenis in veranderde neurosecretorische activiteit in het HNS. Bij mensen verandert de waterhuishouding ook met leeftijd, hoewel de oorzaken enigszins verschillend kunnen zijn van die bij ratten. Het werd voor verschillende rattestammen aangetoond dat de testosteronafhankelijke vasopressinerge innervatie grotendeels intact blijft met veroudering. Extrahypothalamische vasopressinerge veranderingen treden op, maar deze zijn stamafhankelijk of kunnen zelfs afhankelijk zijn van de kolonie of het cohort waar de ratten uit afkomstig zijn. In het algemeen kan gesteld worden dat vasopressinerge neuronen zich aanpassen aan leeftijdsgerelateerde veranderingen in orgaanfuncties en homeostasis blijven nastreven. Desondanks kunnen vasopressinerge functies toch verminderd zijn, doordat de gevoeligheid van de nieren en neuronen is afgenomen. Voor de nieren is dit al aangetoond. Veranderingen in neuronale gevoeligheid voor VP met leeftijd moeten nog onderzocht worden. 



\section{LIST OF PUBLICATIONS}

\section{Full papers and chapters}

Burbach JPH, Terwel D, Lebouille JLM. Measurement and distribution of vasopressin-converting enzyme activity in rat brain. Biochem Biophys Res Commun 1987;144:726-731.

Bohnen N, Twijnstra A, Terwel D. Csf arginine-vasopressin decreases during dehydration in a patient with post-traumatic diabetes insipidus. Horm Metab Res 1990;22:508-509.

Terwel D, Markerink M. Age-related changes in vasopressin in the rat brain. In: Van Bezooijen, Ravid R, Verhofstad AAJ, eds. From gene to man - gerontological research in The Netherlands. Rijswijk: Stichting Gerontologie en Geriatrie, 1990:178-181.

Deen PMT, Terwel D, Bussemakers MJM, Roubos EW, Martens GJM. Structural analysis of the entire proopiomelanocortin gene of Xenopus laevis. Eur J Biochem 1991;201:129-137.

Bohnen N, Twijnstra A, Terwel D, Jolles J. Inverse relationship between plasma vasopressin and intracranial pressure. Horm Metab Res 1992;24:141-142.

Terwel D, Ten Haaf JA, Markerink M, Jolles J. Changes in plasma vasopressin concentration and plasma osmolality in relation to age and time of day in the male Wistar rat. Acta Endocrinol $1992 ; 126: 357-362$.

Deen PMT, Bussemakers MJG, Terwel D, Roubos EW, Martens GJM. Comparative structural analysis of the transcriptionally active proopiomelanocortin genes A and B of Xenopus Laevis. Mol Biol Evol 1992;9:483-494.

Terwel D, Markerink M, Jolles J. Peptidases are affected differently in neocortical regions of brain from patients with Alzheimer's disease. Dementia 1992;3:108-113.

Terwel D, Markerink M, Jolles J. Age-related changes in concentrations of vasopressin in the central nervous system and plasma of the male Wistar rat. Mech Ageing Dev 1992 (in press).

Ten Haaf JA, Terwel D, Van de Heijning HJM, Van Wimersma Greidanus TjB. Radioimmunoassay: a goal or a tool? J Control Rel 1992 (in press).

Bohnen N, Terwel D, Twijnstra A, Markerink M, Jolles J. Effects of apprehension of lumbar puncture procedure on salivary contisol, plasma vasopressin and osmolality in man. Stress Medicine 1992 (in press).

Bohnen N, Terwel D, Markerink M, Ten Haaf JA, Jolles J. Pitfalls in the measurement of plasma osmolality pertinent to research in vasopressin and water metabolism. Clin Chem 1992 (in press).

Terwel D, Markerink M, Jolles J. Effects of aging and castration on vasopressin concentration in the brain of male Brown-Norway rats. Submitted.

Terwel D, Markerink M, Jolles J. Radioimmunoassay for vasopressin in brain and plasma. Submitted.

Terwel D, Markerink M, Jolles J. Alterations in vasopressinergic systems in the rat brain in relation to age, strain and season. Submitted.

Terwel D, Jolles J. Osmoreceptor sensitivity is reduced in old male Lewis rats. Submitted. 


\section{Abstracts}

Terwel D, Markerink M. Age-related changes in vasopressin content in the central nervous system of the Wistar rat. Vih Meet Dutch Found Gerontol Geriatrics, Egmond aan Zee, 1989.

Terwel D, Jolles J. Strain differences, correlations and age-related decline in levels of vasopressin in the amygdala and pineal of the rat. XIth Intemational Congress of Pharmacology. Amsterdam, 1990. Abstract 20.

Twijnstra A, Bohnen N, Terwel D, Jolles J. Plasma vasopressin and fluctuating intracranial pressure. J Neurol 1990; vol 237 (Suppl):35-25.

Terwel D, Markerink M, Jolles J. Decreased protease activity in Alzheimer's disease. VIth Meet Dutch Found Gerontol Geriatrics, Egmond aan Zee, 1991. Abstract 32.

Terwel D, Markerink M, Jolles $J$. The influence of age and time of day on plasma vasopressin concentration in the male Wistar rat. Proc 33 rd Dutch Fed Meet, Rotterdam, 1992:105.

Terwel D, Markerink M. A reduced testicular function in aged rats only partly explains changes in vasopressinergic systems in the brain. Proc 33 rd Dutch Fed Meet, Rotterdam, 1992:106.

Terwel D. Osmoreceptor sensitivity is reduced in the old male Lewis rat. 13th Meet Assoc Exp Clin Neurochem, Utrecht: Arch Int Pharmcodyn, 1992 (in press).

Terwel D, Markerink M, Jolles J. Peptidases are affected differently in neocortical brain regions from patients with Alzheimer's disease. Third Intemational Conference on Alzheimer's Disease and Related Disorders, Padova. Neurobiol Aging, 1992 (in press). 


\section{Dankwoord}

Maastricht dat is een mooie stad, maar net iets te ver weg. Toch wil ik Jelle Jolles bedanken dat hij mij de kans heeft gegeven hier promotieonderzoek te doen. Ik ben hem ook dank verschuldigd voor zijn inhoudelijke en wetenschappelijke bijdrage aan dit proefschrift en voor zijn leerzame lessen ten aanzien van het wetenschappelijk bedrijf. Marjanne Markerink kan ik niet genoeg bedanken voor het vele werk dat zij heeft verricht en de belangrijke morele ondersteuning. Nico Bohnen ben ik buitengewoon erkentelijk voor zijn enthousiasme, aanstekelijke werklust en collegialiteit en de niet onbelangrijke bijdrage aan mijn wetenschappelijke output. Manon Rudolph wil ik danken voor de bijdrage die zij als doctoraalstudent heeft geleverd aan gedane experimenten. Verder wil bedanken: Arjan Blokland, voor zijn levendige discussies en het demonstreren dat snel werken ook wetenschappelijk resultaat kan opleveren; John Bothmer, voor het delen van de kamer en de vakinhoudelijke diepgang; Wijnand Raaijmakers, voor de erudiete gesprekken over het doet er niet toe welk onderwerp; Peter Houx, voor zijn betrokkenheid en interesse; en Wiel Honig, voor de vriendschappelijke samenwerking. Jeroen ten Haaf ben ik erkentelijk voor het in mij gestelde vertrouwen aan het begin van de rit. Helaas hebben wij hem niet samen kunnen uitzitten. Bijzondere waardering gaat uit naar Jane Sykes voor haar kritische bijdrage aan een zo correct mogelijk Engels en omdat ze soms beter wist wat ik bedoelde dan ikzelf.

Wieke ben ik zeer dankbaar voor haar niet aflatende steun en geduld, en fysieke bijdrage aan het proefschrift. 



\section{Curriculum vitae}

Dirk Terwel werd geboren te Zutphen op 4 december 1958. Hij doorliep de MAVO te Borculo van 1972 tot 1976 en behaalde het Atheneum diploma aan de Rijksscholengemeenschap te Lochem in 1979. In september van dat jaar werd met de studie biologie (oude stijl) begonnen aan de Rijksuniversiteit van Utrecht. Het doctoraal werd behaald in april 1987 en omvatte de hoofdvakken scheikundige dierfysiologie en moleculaire neurobiologie, en het bijvak moleculaire biologie. Aansluitend startte hij zijn promotieonderzoek aan de Rijksuniversiteit Limburg bij de vakgroep Neuropsychologie en Psychobiologie (hoofd Prof. Dr. J. Jolles), waarvan dit proefschrift de weerslag is. In de toekomst zal de hij zich bezig gaan houden met neurochemisch onderzoek bij patiënten met de ziekte van Alzheimer. 
DATAWYSE | Universitaire Pers Maastricht ISBN 9052780447

NUGI 743 